\title{
Late Holocene Hurricane Activity and Climate Variability in the Northeastern Gulf of Mexico
}

\author{
by \\ Daniel Philip Lane \\ B.S. Atmospheric Science, Cornell University, 2005 \\ Submitted in partial fulfillment of the requirements for the degree of \\ Doctor of Philosophy in Geology and Geophysics \\ at the \\ MASSACHUSETTS INSTITUTE OF TECHNOLOGY \\ and the \\ WOODS HOLE OCEANOGRAPHIC INSTITUTION
}

SEPTEMBER 2011

(C) 2011 Daniel P. Lane. All rights reserved.

The author hereby grants MIT and WHOI permission to reproduce and to distribute publicly paper and electronic copies of this thesis document in whole or in part in any medium now or known hereafter created.

Signature of Author:

Daniel P. Lane

Joint Program in Oceanography / Marine Geology and Geophysics Massachusetts Institute of Technology and Woods Hole Oceanographic Institution

Certified by:

Jeffrey P. Donnelly Associate Scientist, Department of Marine Geology and Geophysics Woods Hole Oceanographic Institution Thesis Co-Supervisor

Certified by:

Kerry A. Emanuel Professor/Director, Program in Atmospheres, Oceans, and Climate Massachusetts Institute of Technology Thesis Co-Supervisor

Accepted by:

Robert L. Evans

Chairman, Joint Committee for Marine Geology and Geophysics

Massachusetts Institute of Technology Woods Hole Oceanographic Institution 


\title{
Late Holocene Hurricane Activity and Climate Variability in the Northeastern Gulf of Mexico
}

by

Daniel Philip Lane

Submitted to the Massachusetts Institute of Technology / Woods Hole Oceanographic Institution Joint Program in Oceanography on 26 May 2011 in Partial Fulfillment of the Requirements for the Degree of Doctor of Philosophy in Geology and Geophysics

\begin{abstract}
Hurricane activity in the Northeastern Gulf of Mexico and its relationship to regional and large-scale climate variability during the Late Holocene is explored. A 4500 -year record of hurricane-induced storm surges is developed from sediment cores collected from a coastal sinkhole near Apalachee Bay, Florida. Reconstructed hurricane frequency is shown to exhibit statistically significant variability with the greatest activity occurring between 2700 and 2400 years ago and the least activity between 1900 to 1600 years ago and after 600 years ago. Proxy records of stormrelevant climate variables contain similar timescales of variability and suggest both regional and large-scale mechanisms have influenced hurricane activity on centennial to millennial timescales. In particular, low-frequency migrations of the Loop Current may exercise control over regional hurricane activity by changing the thermal structure of the upper ocean and influencing the role of storm-induced upwelling on hurricane intensification. A new method for estimating the frequency of hurricanegenerated storm surges is presented and applied to Apalachee Bay, Florida. Multisite paleohurricane reconstructions from this region are developed, and the effects of geographic boundary conditions and temporal resolution on estimates of paleohurricane frequency are explored.
\end{abstract}

\footnotetext{
Thesis Co-Supervisor: Jeffrey P. Donnelly

Title: $\quad$ Associate Scientist, Department of Marine Geology and Geophysics Woods Hole Oceanographic Institution

Thesis Co-Supervisor: Kerry A. Emanuel

Title: $\quad$ Professor/Director, Program in Atmospheres, Oceans, and Climate Massachusetts Institute of Technology
} 


\section{ACKNOWLEDGEMENTS}

I would like to thank my academic advisors Jeff Donnelly and Kerry Emanuel for their expertise and encouragement throughout my time in the Joint Program. I am also grateful to the other committee members, Delia Oppo and Michael Mann, for their time and constructive comments. I also thank Kris Karnauskas for his willingness to act as the chair of my defense.

I would also like to thank Andrew Ashton, Katie Boldt, Christine Brandon, Ilya Buynevich, Emily Carruthers, Bill Curry, Andrew Desnoyers, Pat Donnelly, Jeff Dusenberry, Rob Evans, Liviu Giosan, Maya Gomes, Andrea Hawkes, Ning Lin, Dana McDonald, Skye Moret, Richard Poore, Sai Ravela, Rebecca Sorrell, Richard Sullivan, Jess Tierney, Michael Toomey, and Jon Woodruff for their efforts in the field, the lab and for insightful discussions of ideas and useful feedback on manuscripts.

I am also grateful for the financial support provided by the American Meteorological Society, the National Science Foundation, the Bermuda Risk Prediction Initiative, the National Center for Airborne Laser Mapping, and the Coastal Ocean Institute. 


\section{Table of Contents}

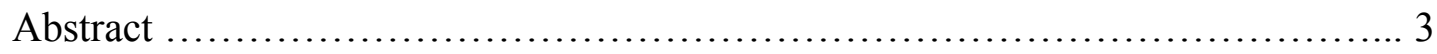

Acknowledgements .................................................. 4

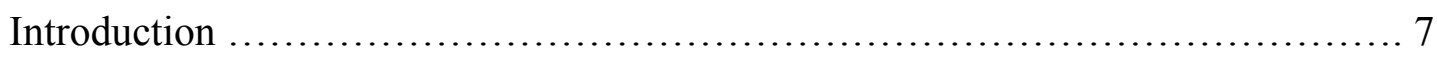

Chapter 1. A decadally-resolved paleohurricane record archived in the late Holocene sediments of a Florida sinkhole ...................... 18

Chapter 2. Gulf Coast hurricane activity and climate variability during the last half of the Holocene $\ldots \ldots \ldots \ldots \ldots \ldots \ldots \ldots \ldots \ldots \ldots \ldots \ldots \ldots . . . \ldots 3$

Chapter 3. Modeling the storm surge climate of Apalachee Bay, Florida using synthetic hurricane records

Chapter 4. Assessing the role of geographic boundary conditions on two paleohurricane records from Bald Point, Florida 163

\section{Appendices}

Appendix A1. Supplementary Information for Chapter 1 193

Appendix A2. Supplementary Information for Chapter 3 


\section{Introduction}

The life history of a hurricane is dictated by the environmental conditions it encounters (Bergeron 1954, Emanuel et al. 2004). Likewise, climate, which encompasses the full range of conditions experienced by all storms, constrains the attributes of hurricane populations (Gray 1968, Emanuel 1987, Emanuel 1988). Tropical cyclones are also important, active components of Earth's climate system (Hart 2010, Sriver et al. 2008). The relative climatic stability of the tropics is a theme that stretches from the warm, equable climates of Earth's distant past (Korty et al. 2008), through the variable climates of the Quaternary (Crowley 2000) and on into present day and possibly future climates. The tropics may behave as the fulcrum of the earth's climate system where small forcings are applied and leveraged into large responses elsewhere (Meehl et al. 2009, Marchitto et al. 2010). As facilitators of significant heat transport within and between the atmosphere and ocean, tropical cyclones may play a crucial role in this process by dampening variability in the tropical regions where they form and develop while amplifying changes in higher latitudes (Emanuel 2001, Emanuel 2002, Scott and Maritzke 2002, Sriver and Huber 2007).

Given the destructive role that tropical cyclones have played through history, a great deal of effort has been directed at understanding the processes that control their frequency, intensity, and track. Making these efforts all the more urgent, humans, like hurricanes, may also be influencing the very climate by which we are affected. In a 1957 paper about the accumulation of $\mathrm{CO}_{2}$ in the atmosphere, Roger Revelle famously wrote "human beings are now carrying out a large-scale geophysical experiment [that], if adequately documented, may yield a far-reaching insight into the processes determining weather and climate" (Revelle and Suess 1957). Indeed, we may learn a great deal over the next several decades; however, given the stakes, we should very much like to know the outcome of this experiment in advance. 
One strategy aimed at predicting the outcome has been to employ numerical climate models to simulate the response of hurricane activity to projected $21^{\text {st }}$ century warming, but most global-scale models have had difficulty simulating intense tropical cyclones (Gualdi et al. 2008, Knutson et al. 2008, Zhao et al. 2009). While advances have been made toward more realistic hurricane intensity distributions in storm climate modeling (Emanuel et al. 2008, Bender et al. 2010), such models still do not incorporate the feedbacks that tropical cyclones exert on the climate system.

Examining historic records of hurricane activity for trends and patterns has been another approach toward understanding the effects of climate variability and change on tropical cyclones. However, our ability to monitor the environment has grown along with our capacity to alter it, which has led to debate over whether trends in historic storm observations reflect changes in the underlying population of Atlantic hurricanes or if they result merely from advances in storm detection and observation (Goldenberg et al. 2001, Emanuel 2005a, Webster et al. 2005, Anthes et al. 2006, Hoyos et al. 2006, Mann and Emanuel 2006, Trenberth and Shea 2006, Chang and Guo 2007, Holland and Webster 2007, Kossin et al. 2007, Landsea 2007, Mann et al. 2007, Elsner et al. 2008b, Chen et al. 2009). Further complicating the problem, official records of the number, track and intensity of hurricanes in the Atlantic extend back only to the mid- $19^{\text {th }}$ century, around the time of the Industrial Revolution, which implies that the entire available storm archive may bear the influence of both secular anthropogenic changes and natural, inherent climate variability. Even if the historic hurricane record is consistent and complete, its brevity might allow low-frequency, natural variability to either mask or be mistaken for secular, anthropogenic changes. Natural variability, on the other hand, may also provide the key to understanding how tropical cyclone populations respond to changes in climate.

Oscillating components of the climate system like the Madden-Julian Oscillation (MJO) (Klotzbach 2010), the Quasi-Biennial Oscillation (QBO), the El Niño Southern Oscillation (ENSO) (Gray 1984), the Atlantic Multidecadal Oscillation (AMO), and the Atlantic Meridional Mode (AMM) (Vimont and Kossin 
2007) influence hurricane activity on timescales ranging from the intraseasonal to the multidecadal. Lower-frequency and possibly higher amplitude variations in storm activity may also exist. The idea that tropical cyclone activity can and has varied well beyond the bounds set by modern observations is not new. In 1954, meteorologist Tor Bergeron posited that "during certain geological epochs, hurricanes may have been just as frequent as the cyclones of our latitudes, or they may have occurred all over the oceans and within all coastal regions, and they may have been even more violent than nowadays. During other periods they may have been lacking altogether" (Bergeron 1954, Emanuel 2005b). Addressing such thought provoking possibilities requires longer records than the instrumental record can provide. To this end, geologic archives are being developed to identify and characterize climate modes that may influence storm activity on centennial and longer timescales.

A number of paleohurricane proxies are being developed in an effort to extend the hurricane record further into the past. At the same time, marine and terrestrial paleoclimate records reveal that several environmental factors known to affect hurricane activity have varied significantly over the last five millennia. This most recent sliver of geologic time, still more than thirty times longer than the era of meteorological observations, can be thought of as a natural experiment in which climate variations on many time and space scales have elicited changes in hurricane activity. Paleohurricane data from this experiment have been archived in corals, tree rings, cave speleothems and the sediments of coastal lakes and marshes. Other types of hurricane proxy records likely await discovery.

Paleohurricane records can be categorized into two main kinds: isotope-based proxies that rely on the detection of tropical cyclone rainfall signatures preserved in corals (Cohen 2001, Hetzinger et al. 2008), tree rings (Miller et al. 2006), and speleothems (Frappier et al. 2007, Nott et al. 2007), and sediment-based proxies such as cyclone surge-constructed beach ridges (Nott and Hayne 2001, Nott et al. 2009) and overwash deposits preserved in back barrier lagoons (Donnelly 2005, Donnelly and Woodruff 2007, Woodruff et al. 2008a, Woodruff et al. 2008b, Wallace and 
Anderson 2010), coastal lakes (Liu and Fearn 1993, Liu and Fearn 2000, Liu and Fearn 2002, Lambert et al. 2003, Lambert et al. 2008), and marshes (Donnelly et al. 2001a, Donnelly et al. 2001b, Donnelly et al. 2004, Scileppi and Donnelly 2007, Boldt et al. 2010). Isotope-based proxies have in some cases provided exceptional, sub-annual resolution; however, such records often span only a relatively short interval of time. The longest paleohurricane records span the last few millennia and are based on coastal lake and pond sediments that contain signatures of repeated marine inundation by hurricane storm surges.

Sedimentary storm archives from the Caribbean, the Gulf of Mexico, and the Northeastern U.S. have documented centennial to millennial-scale variability in the local frequency of intense hurricanes. However, low sediment accumulation rates and high flooding thresholds at most sites studied have provided low-resolution records of high magnitude events. For these reasons, paleohurricane frequency in existing sediment records has usually averaged less than one storm per century. Such low probabilities of occurrence make it difficult to differentiate significant changes in storm climate affecting a site from the random, temporal clustering of events that could result merely from the stochastic nature of hurricane landfalls at any particular location. Connecting shifts in hurricane activity with climate variability requires a more thorough census of storms through time, though synthetic storm records have been successfully used to identify intervals of abnormally infrequent hurricanes in a paleohurricane record from Vieques (Woodruff et al. 2008a).

In Chapter 1, a 4500-year, sub-decadal resolution paleohurricane record is developed from the sediments of coastal sinkhole near Apalachee Bay on Florida's Gulf Coast. Storm deposits were identified by sand and microfossil content, and the record was calibrated by correlating recent deposits with modeled surges from historic hurricanes affecting the site. Statistically significant low-frequency, highamplitude variability in the frequency of large storm deposits indicates that the region experienced intervals of both anomalously low and high hurricane activity during the 
late Holocene. The most active interval was between 2.7 and $2.4 \mathrm{ka}$ and the least active intervals were between 1.9 and $1.6 \mathrm{ka}$ and after $0.4 \mathrm{ka}$.

In Chapter 2, significant timescales of variability near 200 and 1000 years are identified in this paleohurricane record. Other regional and larger scale climate records exhibit variability on these timescales during the late Holocene. In particular, comparisons with marine records of mixed layer thickness in the Gulf of Mexico suggest that local variations in storm activity may have resulted from low-frequency migrations of the Loop Current, which would exercise regional control over the intensity distribution of hurricanes by dictating the effectiveness with which storms mix up cooler, sub-surface waters. Other climate factors like the El Niño Southern Oscillation, SST of the Atlantic relative to other ocean basins, and the residence of the Inter-Tropical Convergence Zone may have influenced regional storm activity and coordinated activity across the Atlantic basin.

In Chapter 3, a new method for estimating the return time of storm surges is developed and applied to the Apalachee Bay region. In this method, large numbers $\left(10^{4}\right)$ of hypothetical but plausible storms are generated using a statisticaldeterministic hurricane wind risk model, and the surge generated by each event is simulated using the Sea, Lake, and Overland Surges from Hurricanes (SLOSH) model. These modeled values are then used to calculate return times even for the most extreme and rare events, which cannot be ascertained from analyses of tide gauge records. When taken with existing records of sea level from the region, the 100-year surge of approximately $4 \mathrm{~m}$ at the paleohurricane site implies that, in the absence of a significant change in the local storm climate, this location would be expected to be routinely inundated by coastal floods for at least the last few thousand years. The relationship between storm intensity and resulting surge is explored and, while the most extreme surges (500-year events) are almost always the result of Saffir-Simpson category 4 or 5 storms, most large surges (100-year events) are produced by a broad range of storm intensities. 
In Chapter 4, the influence of geographic boundary conditions and temporal resolution on paleohurricane reconstructions is explored. LIDAR data is used to develop a high-resolution elevation and inundation model for the Bald Point peninsula in the Big Bend region of Florida's Gulf Coast. Two sinkhole ponds with quite different geographic boundary conditions are shown to have nearly identical flooding thresholds. Though one site is located approximately $350 \mathrm{~m}$ from the Gulf and the other is more than $2 \mathrm{~km}$ inland, both reconstructions suggested similar paleohurricane frequencies during intervals when sediment accumulation rates in both ponds were similar. Estimates of storm frequency increased significantly with sedimentation rate suggesting that variable temporal resolution can complicate storm reconstructions. 


\section{References}

Anthes, R.A., Corell, R.W., Holland, G., Hurrell, J.W., MacCracken, M.C., Trenberth, K.E., 2006. Hurricanes and Global Warming: Potential Linkages and Consequences. Bulletin of the American Meteorological Society. 87, 623-628.

Bender, M.A., Knutson, T.R., Tuleya, R.E., Sirutis, J.J., Vecchi, G.A., Gerner, S.T., Held, I.M., 2010. Modeled impact of anthropogenic warming on the frequency of intense Atlantic hurricanes. Science. 327(5964), 454-458.

Bergeron, T. 1954. "The problem of tropical cyclones." Quarterly Journal of the Royal Meteorological Society. 80 pp. 131-164.

Boldt, K.V., Lane, P., Woodruff, J.D., Donnelly, J.P., 2010. Calibrating a sedimentary record of overwash from Southeastern New England using modeled historic hurricane surges. Marine Geology. 275. pp. 127-139.

Chang, E. K. M., Guo Y., 2007. Is the number of North Atlantic tropical cyclones significantly underestimated prior to the availability of satellite observations? Geophysical Research Letters. 34, L14801,doi:10.1029/2007GL030169.

Chen, K., McAneney, J., Cheung, K., 2009. Quantifying changes of wind speed distributions in the historical record of Atlantic tropical cyclones. Natural Hazards and Earth System Sciences. 9, 1749-1757.

Cohen, A., 2001. Hurricane tracking with chemistry: Exploring the coral archive. Workshop on Atlantic Basin paleohurricane reconstructions from high resolution records, March 25-27, 2001. Columbia, South Carolina, University of South Carolina.

Crowley, T.J., 2000. CLIMAP SSTs re-revisited. Climate Dynamics. 16. pp.241-255.

Donnelly, J.P., S.S. Bryant, J. Butler, J. Dowling, L. Fan, N. Hausmann, P. Newby, B. Shuman, J. Stern, K. Westover, Webb III., T., 2001. A 700-year sedimentary record of intense hurricane landfalls in southern New England. Geological Society of America Bulletin. 113, 714-727.

Donnelly, J.P., S. Roll, M. Wengren, J. Butler, R. Lederer, Webb III, T., 2001. Sedimentary evidence of intense hurricane strikes from New Jersey. Geology. 29, 615-618.

Donnelly, J.P., J. Butler, S. Roll, Micah Wengren, Webb III, T., 2004. A backbarrier overwash record of intense storms from Brigantine, New Jersey. Marine Geology. 210, 107-121. 
Donnelly, J.P., 2005. Evidence of Past Intense Tropical Cyclones from Backbarrier Salt Pond Sediments: A Case Study from Isla de Culebrita, Puerto Rico, USA. Journal of Coastal Research. SI42, 201-210.

Donnelly, J.P., Woodruff, J.D., 2007. Intense hurricane activity over the past 5,000 years controlled by El Niño and the West African monsoon. Nature. 447, 465-468. Elsner, J.B., Kossin, J.P., Jagger T.H., 2008. The increasing intensity of the strongest tropical cyclones. Nature. 455, 92-95.

Emanuel, K.A., 1987. The dependence of hurricane intensity on climate. Nature. 326(6112), 483-485.

Emanuel, K.A., 1988. The maximum intensity of hurricanes. Journal of the Atmospheric Sciences. 45(7). 1143-1155.

Emanuel, K.A., 2001. The contribution of tropical cyclones to the oceans' meridional heat transport. Journal of Geophysical Research. 106, 14771-14782.

Emanuel, K.A., 2002. A simple model of multiple climate regimes. Journal of Geophysical Research. 107(D9). 4077. doi: 10.1029/2001JD001002.

Emanuel, K.A., DesAutels, C., Holloway, C., Korty, R. 2004. "Environmental Control of Tropical Cyclone Intensity." Journal of the Atmospheric Sciences. 61. pp. 843-858.

Emanuel, K.A., 2005. Increasing destructiveness of tropical cyclones over the past 30 years. Nature. 436, 686-688.

Emanuel, K.A., 2005. Divine Wind: The history and science of hurricanes. Oxford University Press, New York. 304 pp.

Emanuel, K.A., Sundararajan, R., William, J., 2008. Hurricanes and global warming: results from downscaling IPCC AR4 simulations. Bulletin of the American Meteorological Society. 89, 347-367.

Frappier, A.B., Sahagian, D., Carpenter, S.J., Gonzalez, L.A., Frappier, B.R., 2007. Stalagmite stable isotope record of recent tropical cyclone events. Geology. 35(2). pp. 111-114.

Goldenberg, S.B., Landsea, C.W., Mestas-Nuñez, A.M., Gray, W.M., 2001. The recent increase in Atlantic hurricane activity: causes and implications. Science. 293, 474-479.

Gray, W. M., 1968. Global view of the origin of tropical disturbances and storms. 
Monthly Weather Review. 96, 669-700.

Gray, W.M., 1984. Atlantic seasonal hurricane frequency. Part I: El Niño and $30 \mathrm{mb}$ Quasi-Biennial Oscillation influences. Monthly Weather Review. 112. pp. 1649-1668.

Gualdi, S., Scoccimarro, E., Navarra, A., 2008. Changes in tropical cyclone activity due to global warming: results from a high-resolution coupled general circulation model. Journal of Climate. 21, 5204-5228.

Hart, R.E., 2010. An inverse relationship between aggregate tropical cyclone activity and subsequent winter climate. Geophysical Research Letters, doi:10.1029/2010GL045612.

Hetzinger, S., Pfeiffer, M., Dullo, W.-C., Keenlyside, N., Latif, M., Zinke, J., 2008. Caribbean coral tracks Atlantic multidecadal oscillation and past hurricane activity. Geology. 36(1), 11-14.

Holland, G. J., Webster, P.J., 2007. Heightened tropical cyclone activity in the North Atlantic: Natural variability or climate trend? Philosophical Transactions of the Royal Society of London. Ser. A. doi:10.1098/rsta.2007.2083.

Hoyos, C. D., P. A. Agudelo, P. J. Webster, Curry, J.A., 2006. De-convolution of the factors contributing to the increase in global hurricane intensity. Science. 312, 94-97.

Klotzbach, P.J., 2010. On the Madden-Julian-Atlantic hurricane relationship. Journal of Climate. 23. pp. 282-293.

Knutson, T.R., Sirutis, J.J., Garner, S.T., Vecchi, G.A., Held, I.M., 2008. Simulated reduction in Atlantic hurricane frequency under twenty-first-century warming conditions. Nature Geoscience. doi:10.1038/ngeo202.

Korty, R.L., Emanuel, K.A., Scott, J.R., 2008. Tropical cyclone-induced upper-ocean mixing and climate: application to equable climates. Journal of Climate. 21, 638-654.

Kossin, J. P., K. R. Knapp, D. J. Vimont, R. J. Murnane, Harper, B.A., 2007. A globally consistent reanalysis of hurricane variability and trends. Geophysical Research Letters. 34, L04815, doi:10.1029/2006GL028836.

Lambert, W. J., Aharon, P., Rodriguez, A.B., 2003. An Assessment of the Late Holocene Record of Severe Storm Impacts from Lake Shelby, Alabama. TransactionsGulf Coast Association of Geological Societies. 53. pp. 443. 
Lambert, W.J., Aharon, P., Rodriguez, A.B., 2008. Catastrophic hurricane history revealed by organic geochemical proxies in coastal lake sediments: a case study of Lake Shelby, AL (USA). Journal of Paleolimnology. 39, 117-131.

Landsea, C. W., 2007. Counting Atlantic tropical cyclones back to 1900. Eos Transactions. 88(18), 197-202.

Liu, K.B., Fearn, M.L., 1993. Lake-sediment record of late Holocene hurricane activities from coastal Alabama. Geology 21, 793-796.

Liu, K.B., Fearn, M.L., 2000. Reconstruction of prehistoric landfall frequencies of catastrophic hurricanes in northwestern Florida from lake sediment records. Quaternary Research 54, 238-245.

Liu, K. B., Fearn, M.L., 2002. Lake sediment evidence of coastal geologic evolution and hurricane history from Western Lake, Florida: Reply to Otvos. Quaternary Research. 57, 429-431.

Mann, M. E., Emanuel, K.A., 2006. Atlantic hurricane trends linked to climate change. Eos Transactions. 87(24), 233-235.

Mann, M.E., Emanuel, K.A., Holland, G.J., Webster, P.J., 2007. Atlantic tropical cyclones revisited. Eos Transactions. 88(36), 350-352.

Marchitto, T.M., Muscheler, R., Ortiz, J.D., Carriquiry, J.D., van Geen, A., 2010. Dynamical response of the tropical Pacific Ocean to solar forcing during the early Holocene. Science. 330. pp. 1378-1381.

Meehl, G.A., Arblaster, J.M., Matthes, K., Sassi, F., Loon, H. van, 2009. Amplifying the Pacific climate system response to a small 11-year solar cycle forcing. Science. $325,1114-1118$.

Miller, D.L., Mora, C.I., Grissino-Mayer, H.D., Mock, C.J., Uhle, M.E., Sharp, Z., 2006. Tree-ring isotope records of tropical cyclone activity. Proceedings of the National Academy of Sciences. 103(39), 14294-14297.

Nott, J., Hayne, M., 2001. High frequency of 'super-cyclones' along the Great Barrier Reef over the last 5000 years. Nature. 413, 508-512.

Nott, J., Smithers, S., Walsh, K., Rhodes, E., 2009. Sand beach ridges record 6000 year history of extreme tropical cyclone activity in northeastern Australia. Quaternary Science Reviews. 28, 1511-1520. 
Revelle, R., Suess, H., 1957. "Carbon dioxide exchange between atmosphere and ocean and the question of an increase of atmospheric $\mathrm{CO} 2$ during the past decades." Tellus. 9. pp. 18-27.

Scileppi, E.M., Donnelly, J.P., 2007. Sedimentary evidence of hurricane strikes in western Long Island, New York. Geochemistry, Geophysics, Geosystems. 8(6), Q06011.

Scott, J.R., Marotzke, J., 2002. The location of diapycnal mixing and the meridional overturning circulation. Journal of Physical Oceanography. 32, 3578-3595.

Sriver, R.L., Huber, M., 2007. Observational evidence for an ocean heat pump induced by tropical cyclones. Nature. 447, 577-580.

Sriver, R.L., Huber, M., Nusbaumer, J., 2008. Investigating tropical cyclone-climate feedbacks using the TRMM microwave imager and the Quick Scatterometer. Geochemistry, Geophysics, and Geosystems. 9(9), Q09V11, doi: 10/1029/2007.GC001842.

Trenberth, K. E., Shea, D.J., 2006. Atlantic hurricanes and natural variability in 2005. Geophysical Research Letters. 33, L12704, doi:10.1029/2006GL026894.

Vimont, D.J., Kossin, J.P., 2007. The Atlantic Meridional Mode and hurricane activity. Geophysical Research Letters. 34, L07709, doi:10.1029/2007GL029683.

Wallace, D.J., Anderson, J.B., 2010. Evidence of similar probability of intense hurricane strikes for the Gulf of Mexico over the late Holocene. Geology. 38(6). pp. 511-514.

Webster, P.J., Holland, G.J, Curry, J.A., Chang, H.R., 2005. Changes in tropical cyclone number, duration, and intensity, in warming environment. Science. 309, 1844-1846.

Woodruff, J.D., Donnelly, J.P., Emanuel, K.A., Lane, P., 2008. Assessing sedimentary records of paleohurricane activity using modeled hurricane climatology. Geochemistry, Geophysics, Geosystems. 9(9). Q09V10.

Woodruff, J.D., Donnelly, J.P., Mohrig, D., Geyer, W.R., 2008. Reconstructing relative flooding intensities responsible for hurricane-induced deposits from Laguna Playa Grande, Vieques, Puerto Rico. Geology. 36(5), 391-394.

Zhao M., Held, I.M., Lin, S.J., Vecchi, G.A., 2009. Simulations of global hurricane climatology, interannual variability, and response to global warming using a $50 \mathrm{~km}$ resolution GCM. Journal of Climate: In Press. doi: 10.1175/2009JCLI3049.1 


\title{
CHAPTER 1
}

\section{A decadally-resolved paleohurricane record archived in the late Holocene sediments of a Florida sinkhole *}

\begin{abstract}
A 4500-year record of hurricane-induced storm surges is developed from sediment cores collected from a coastal sinkhole near Apalachee Bay, Florida. Recent deposition of sand layers in the upper sediments of the pond was found to be contemporaneous with significant, historic storm surges at the site modeled using SLOSH and the Best Track post-1851 A.D. dataset. Using the historic portion of the record for calibration, paleohurricane deposits were identified by sand content and dated using radiocarbon-based age models. Marine-indicative foraminifera, some originating at least $5 \mathrm{~km}$ offshore, were present in several modern and ancient storm deposits. The presence and long-term preservation of offshore foraminifera suggest that this site and others like it may yield promising microfossil-based paleohurricane reconstructions in the future. Due to the sub-decadal ( $\sim 7$ year) resolution of the record and the site's high susceptibility to hurricane-generated storm surges, the average, local frequency of recorded events, approximately 3.9 storms per century, is greater than that of previously published paleohurricane records from the region. The high incidence of recorded events permitted a time series of local hurricane frequency during the last five millennia to be constructed and compared against what would be expected from a random, Poisson process. Variability in the frequency of the largest storm layers was found to be greater than what would likely occur by chance alone, with intervals of both anomalously high and low storm frequency identified.

However, the rate at which smaller layers were deposited was relatively constant over the last five millennia. This may suggest that significant variability in hurricane frequency has occurred only in the highest magnitude events. The frequency of high magnitude events peaked near 6 storms/century between 2700 and 2400 years ago. High magnitude events were anomalously infrequent with about 0-3 storms/century occurring between 1900 to 1600 years ago and between 400 to 150 years ago. A marked decline in the number of large storm deposits, which began around 600 years ago, has persisted through present with below average frequency over the last 150 years when compared to the preceding five millennia.

* This manuscript has been submitted to Marine Geology
\end{abstract}




\section{Introduction}

\subsection{Review and Motivation}

The manner in which tropical cyclone activity and climate interact has critical implications for society and is not well understood. Meteorological records of the number, track and intensity of hurricanes in the Atlantic extend back to the mid-19 ${ }^{\text {th }}$ century, although debate exists over whether trends in these storm observations reflect secular changes in the underlying population of Atlantic hurricanes or, alternatively, if they result from advances in storm detection and observation (Goldenberg et al. 2001, Emanuel 2005, Webster et al. 2005, Anthes et al. 2006, Hoyos et al. 2006, Mann and Emanuel 2006, Trenberth and Shea 2006, Chang and Guo 2007, Holland and Webster 2007, Kossin et al. 2007, Landsea 2007, Mann et al. 2007, Elsner et al. 2008, Chen et al. 2009). Moreover, the brief observational record is inadequate for characterizing natural variability in hurricane activity occurring on longer than multi-decadal timescales.

In an effort to extend the hurricane record further into the past, a number of paleohurricane proxies are being developed. These proxies can be categorized into two main types: isotope-based proxies that rely on the detection of tropical cyclone rainfall signatures preserved in corals (Cohen 2001, Hetzinger et al. 2008), tree rings (Miller et al. 2006), and speleothems (Frappier et al. 2007, Nott et al. 2007), and sediment-based proxies such as cyclone surge-constructed beach ridges (Nott and Hayne 2001, Nott et al. 2009) and overwash deposits preserved in back barrier lagoons (Donnelly 2005, Donnelly and Woodruff 2007, Woodruff et al. 2008a, Woodruff et al. 2008b, Wallace and Anderson 2010), coastal lakes (Liu and Fearn 1993, Liu and Fearn 2000, Liu and Fearn 2002, Lambert et al. 2003, Lambert et al. 2008), and marshes (Donnelly et al. 2001a, Donnelly et al. 2001b, Donnelly et al. 2004, Scileppi and Donnelly 2007, Boldt et al. 2010). Isotope-based proxies have in some cases provided exceptional, sub-annual resolution; however, such records often 
span only a relatively short interval of time. While sediment-based proxies have yielded much longer records reaching back several millennia, low sediment accumulation rates and high flooding thresholds at most sites studied have resulted in low resolution records of high magnitude events. For these reasons, paleohurricane frequency in existing sediment records has usually averaged less than one storm per century. Such low probabilities of occurrence make it difficult to differentiate significant changes in storm climate affecting a site from the random, temporal clustering of events that could result merely from the stochastic nature of hurricane landfalls at any particular location.

In this study, we develop a 4500-year record of hurricane storm surges impacting Bald Point, Florida. The record, developed from the sedimentary archive preserved in a coastal sinkhole, provides sub-decadal resolution and is the first produced from this type of depositional environment. The average event frequency of 3.9 storms per century, greater than that of any published paleohurricane record, permitted the objective identification of intervals with significantly elevated storm frequency as well as abnormally inactive periods in the Northeastern Gulf of Mexico during the last half of the Holocene.

\subsection{Study Area}

Apalachee Bay, situated in the Big Bend region of Florida's Gulf Coast, encompasses $400 \mathrm{~km}^{2}$ of the coastal shelf submerged to an average depth of 3 meters (USEPA 1999) (Figure 1a,b). This shallow, concave bay is highly susceptible to extreme storm surges generated by hurricanes that frequent the Gulf of Mexico. Storm tide frequency analysis by a joint probability method suggests that the expected 100 -yr still water level surge in the bay is about 4.5 meters above mean sea level (Ho and Tracey 1975). Storm surges in excess of 4 meters have been observed in the area (Ludlum 1963, Case 1986), and inundation modeling indicates that surges exceeding 
8 meters, which would penetrate tens of kilometers inland, can occur under plausible storm conditions (Jelesnianski et al. 1992).

Bald Point, a roughly $40 \mathrm{~km}^{2}$ peninsula adjoining Ochlokonee Bay to the north and Apalachee Bay to the east and south (Figure 1b), is perforated by dozens of sinkholes. The local landscape rests on hundreds of meters of underlying limestone and dolomite, which is overlain by a veneer of clastic sand and clays that, in turn, is covered by a layer of fine quartz sand ten to sixty meters thick (Puri and Vernon 1964, Sinclair and Stewart 1985). The $\mathrm{pH}$ of meteoric water is lowered by its contact with the atmosphere and organics in the soil, and the acidity of the resulting groundwater erodes the underlying limestone (Lane 1986). The resulting subterranean dissolution causes sinkhole formation either through the gradual, local subsidence of the ground, thereby forming a cover-subsidence sinkhole, or by the sudden, catastrophic failure of an underground cavity, resulting in a cover-collapse sinkhole. The character of the overlying sediments determines the type of sinkhole that forms. On Bald Point, where the overlying clays and sands are thick and cohesive enough to temporarily support the ground surface above a cavity, most sinkholes are of the cover-collapse variety (Sinclair and Stewart 1985). Once formed, the sinkholes begin to fill with sediments that preserve valuable paleoenvironmental and climatic records (Watts et al. 1992, Watts and Hansen 1994, Kindinger et al. 1999, Hodell et al. 2005, Zarikian et al. 2005).

Sediment cores used to develop this study's paleohurricane record were collected from Mullet Pond $\left(29^{\circ} 55.520^{\prime} \mathrm{N}, 84^{\circ} 20.275^{\prime} \mathrm{W}\right)$, a nearly circular, $200 \mathrm{~m}$ diameter cover-collapse sinkhole located on Bald Point. The pond is $350 \mathrm{~m}$ from Apalachee Bay and is separated from the bay by a 3-4 m high (NAVD88) dune ridge $200 \mathrm{~m}$ to the east (Figure 1c). The local landscape west of the dune ridge has a relatively flat 2 to $3 \mathrm{~m}$ (NAVD88) elevation and, owing to the sandy soils that limit runoff during rain events (Puri and Vernon 1964), freshwater stream and river systems are absent (Figure 1c). A tidal creek running through a small salt marsh to the north intermittently connects Mullet Pond to the open coast (Figure 1c) where the 
local mean tidal range is about $0.70 \mathrm{~m}$ (NOAA 2010a). When field work was conducted in January of 2008, the pond had a maximum water depth of $2.3 \mathrm{~m}$ and an average surface salinity of $10 \mathrm{psu}$.

\section{Methods}

\subsection{Field work}

A portable Edgetech $31004-24 \mathrm{kHz}$ sonar was used to map the bathymetry and image the sub-bottom stratigraphy of Mullet Pond, and the resulting data guided the selection of coring locations. Four sediment cores were collected along a transect, with two long $(\sim 6 \mathrm{~m})$ cores (hereafter MLT1 and MLT2) retrieved from the deep, central portion of the pond and two short $(\sim 2 \mathrm{~m})$ cores collected nearer to the pond's eastern shore (Figure 1c). A piston corer was used to capture surface drives in 3" polycarbonate barrels, while deeper drives were collected in 3" aluminum vibracores. Laboratory analyses focused on the two $\sim 6 \mathrm{~m}$ cores (MLT1 and MLT2) retrieved from the central portion of the pond in water depths of 2.3 and $2.2 \mathrm{~m}$, respectively. These cores were taken in regions where the sub-bottom stratigraphy indicated the deepest reservoirs of lacustrine sediments (Figure 2a,b). Twenty-seven surface sediment samples (top $1 \mathrm{~cm}$ ) were collected near the pond, dune ridge, beach, nearshore and offshore environments down to water depths of $14 \mathrm{~m}$ up to $20 \mathrm{~km}$ offshore. Marine samples were collected along three shore-normal depth transects: one in Ochlokonee Bay and two in the Gulf beginning 12 and $16 \mathrm{~km}$ west of Mullet Pond (Table 1). A handheld GPS unit provided the coordinates of coring and surface sample locations, and salinities were measured with an optical diffraction salinity meter. 


\subsection{Age control}

To develop age models for MLT1 and MLT2, plant and wood fragments were collected, cleaned, dried and sent to the National Ocean Sciences AMS facility at Woods Hole Oceanographic Institution for radiocarbon dating. Calendar ages (in years before present, where present is 1950 A.D. by convention) and corresponding uncertainties were calculated from ${ }^{14} \mathrm{C}$ ages and associated analytical errors using the IntCa109 calibration curves in the Calib6 program (Reimer et al. 2009).

A more detailed, modern age model was needed to date and attribute recent event deposits in Mullet Pond to historic hurricanes that impacted the area. A Canberra GL2020RS low-energy Germanium gamma well detector measured the activity of ${ }^{210} \mathrm{~Pb}$ and ${ }^{137} \mathrm{Cs}$ at intervals ranging from $1-5 \mathrm{~cm}$ in the uppermost $40 \mathrm{~cm}$ of MLT1. Supported levels of ${ }^{210} \mathrm{~Pb}$ activity from the in situ decay of ${ }^{226} \mathrm{Ra}$ were estimated by plotting ${ }^{210} \mathrm{~Pb}$ activity with depth and identifying the nearly constant, baseline activity in the deeper samples. Supported activity was subtracted from the total activity of each sample to find the atmosphere-sourced, or unsupported, ${ }^{210} \mathrm{~Pb}$ activity. A constant flux of ${ }^{210} \mathrm{~Pb}$ from the atmosphere was assumed, and the time elapsed since each sample was at the top of the sediment column was estimated from these activity measurements (Koide et al. 1973, Robbins and Edgington 1975, Faure 1986). The initial rise and subsequent peak in ${ }^{137} \mathrm{Cs}$ activity were used to identify the sedimentary horizons associated with the advent of ( 1954 A.D.) and moratorium on ( 1963 A.D.) atmospheric nuclear weapons testing (Pennington et al. 1973).

\subsection{Sedimentary analysis}

Loss on ignition analysis was performed on the entire length of MLT1 and MLT2 at continuous, $1-\mathrm{cm}$ resolution. Samples were dried at $105^{\circ} \mathrm{C}$ for 24 hours and then combusted at $550^{\circ} \mathrm{C}$ for 2 hours. Before and after each process, samples were weighed to determine the relative contributions of water, organics and inorganics to 
the mass of the sediment (Dean 1974). The remaining inorganic ash was sieved and the sand size particles $(>63 \mu \mathrm{m})$ were retained, dried and weighed to determine the percent coarse by dry weight in each sample.

The presence of offshore foraminifera in coastal pond sediments is a valuable indicator of marine flooding; however, analyzing the microfossil assemblages along the entire lengths of MLT1 and MLT2 (> $12 \mathrm{~m}$ of sediment) would be prohibitively time consuming. We adopted a limited sampling strategy that would enable us to learn about the deposition and preservation potential of foraminifera in Mullet Pond without expending an unreasonable amount of resources. The uppermost $40 \mathrm{~cm}$ of MLT1 was sampled at 1-cm intervals to determine the modern microfossil assemblage at the site and to identify taxa possibly associated with storm deposition during historic hurricanes. The most visually obvious sand layer in each core $(\sim 292$ $\mathrm{cm}$ in MLT1 and $431 \mathrm{~cm}$ in MLT2) was also sampled for microfossil content to determine if these apparently "large" events were associated with distinctly offshore foraminifera assemblages. Coarse layers deposited in the earliest lacustrine sediments of the pond (between 500 and $540 \mathrm{~cm}$ in MLT2) were also sampled to assess the long-term preservation potential of foraminifera at the site and to determine if these oldest events could still be definitively attributed to marine flooding in spite of lower sea-levels and greater site-to-sea distances at the time of their deposition. To understand the evolution of the local environment from a fresh to a brackish pond, foraminifera content away from coarse layers was also assessed at approximately $1 \mathrm{~m}$ intervals in MLT1 until their first appearance in the stratigraphy was identified. Further subsampling refined the absence-presence (fresh-brackish) transition interval. The basal peat and sand sequences in MLT2 were also sampled for microfossil content. Beach, near-shore, and offshore surface sediment samples were also analyzed to understand the contemporary distribution of foraminiferal assemblages and constrain the likely source of microfossils deposited in Mullet Pond.

Standard methods for foraminiferal sample preparation and analysis were employed (Scott and Medioli 1980, de Rijk 1995, de Rijk and Troelstra 1997, Scott et 
al. 2001, Horton and Edwards 2006). Foraminifera were concentrated from $3-\mathrm{cm}^{3}$ bulk sediment samples by washing the material over $500 \mu \mathrm{m}$ and $32 \mu \mathrm{m}$ sieves and retaining the particles in this size range. When foraminiferal abundance was sufficient, up to 300 specimens were tallied from the remaining $32 \mu \mathrm{m}$ to $500 \mu \mathrm{m}$ fraction, and benthic species were identified using criteria provided by Phleger (1965), Scott et al. (1991), Javaux and Scott (2003), and Sen Gupta (1999).

\subsection{Spectral analysis}

Thompson's Multi-Taper Method (MTM) was used to find the power spectra of the inorganic and coarse fraction time series from MLT1 and MLT2 (Huybers 2010). For MLT2, this analysis was confined to the most recent 3500 years of the time series, which was the portion of the core with the highest and steadiest sedimentation rate similar to that of MLT1 (Supplementary Figure 1). Appropriate linear fits to the calibrated radiocarbon dates were used to construct the necessary uniform time vectors, and the data were detrended before the MTM was applied. The 95 percent confidence limits for the power estimations were based on a chi-squared distribution calculated from the equivalent degrees of freedom (Percival and Walden 1993). A time-bandwidth product of 3 was used, and 5 discrete prolate spheroidal sequence (dpss) tapers were applied. Peaks significant at the 95 and 99 percent confidence levels were identified by comparing the computed power spectra to that of a red noise process (Mann and Lees 1996; Ghil et al. 2002).

\subsection{Event detection}

In order to remove the significant, low-frequency variability identified by the spectral analysis, each coarse fraction time series was high-pass filtered so that it contained only variability on frequencies greater than $30^{-1} \mathrm{yrs}^{-1}$. This filtering isolated the coarse fraction anomalies associated with short-lived, storm deposition 
events from the background sediment composition variations driven by environmental changes occurring on longer timescales. A threshold value for event detection was needed to determine what magnitude of coarse fraction anomalies might be attributable to storm-induced surge events. The post-1851 A.D. portion of the record was used to calibrate the storm record by relating recent coarse fraction anomalies to the storm surge events that may have produced them. Due to a lack of a local instrumental surge record, however, it was first necessary to determine which historic hurricanes may have produced significant coastal flooding at the site.

The Sea, Lake and Overland Surges from Hurricanes (SLOSH) model was used to identify which historic hurricanes produced the largest still water level storm surges near Mullet Pond. The Atlantic Best-Track Dataset provided storm positions and maximum wind speed estimates at 6-hour intervals going back to 1851 A.D. (Jarvinen et al. 1984, Landsea et al. 2004, Landsea et al. 2008, NOAA 2010b). Rather than maximum wind speed, SLOSH uses the barometric pressure difference between the storm center and the ambient environment $(\Delta \mathrm{P})$ as the intensity parameter (Jelesnianski et al. 1992). This quantity was estimated from the Best-Track maximum wind using an empirical wind-pressure parameterization specific to the Gulf of Mexico (Landsea et al. 2004). Similarly, each storm's radius of maximum wind (RMW) was estimated using an empirical expression that relates the climatological RMW of Atlantic hurricanes to storm latitude and $\Delta \mathrm{P}$ (Vickery et al. 2000).

Bald Point is included in the model domains of three different SLOSH basins. To better assess model uncertainties, flooding events caused by Best Track storms impacting the area were modeled using three different grid domains: the Apalachicola Basin, the Cedar Key Basin, and the Gulf-Wide Extratropical Basin. The Apalachicola basin provides the highest model resolution at Bald Point but neglects the effects of remotely-produced, coastally-trapped Kelvin waves, which are sometimes generated beyond the model domain and can travel into the area of interest. Such waves can contribute significantly to the overall surge along this 
coastline. Hurricane Dennis in 2005 generated a coastally-trapped wave, and the operational use of the spatially-limited Apalachicola Basin to forecast the anticipated surge led to a dramatic under-prediction of the coastal flooding in Apalachee Bay (Morey et al. 2006). The Cedar Key basin includes more of the coastal shelf and, thus, can better simulate trapped coastal waves when they occur; however, this basin has lower spatial resolution at Bald Point. The Gulf-Wide basin includes the whole northern Gulf of Mexico and does the best job of simulating trapped waves, but this basin also has the coarsest resolution and does not permit surges to penetrate inland.

Surges were modeled in all three basins for all Best-Track storms having maximum sustained winds of at least 100 knots (SS-Category 3) while within a 500 $\mathrm{km}$ radius of a point in the northeastern Gulf $\left(27.3^{\circ} \mathrm{N}, 85.6^{\circ} \mathrm{W}\right)$ or 34 knots (tropical storm) while within a $200 \mathrm{~km}$ radius of Mullet Pond. The uncertainty in each modeled surge was calculated from the spread among the three basins. For cases where the input parameters are perfectly known, SLOSH is estimated to have a 20 percent analytical error (Jelesnianski et al. 1992), which was also included in the uncertainty estimates for storm surge at Bald Point. Model topography and surge levels are both referenced to the North American Vertical Datum of 1988 (NAVD88).

Once the modern coarse fraction anomalies that corresponded in time to significant historic surges were identified, two calibration strategies using different critical values for event detection were applied. First, a low threshold (hereafter, LT) that classified most historic, positive coarse fraction anomalies as events was used. Then, a more conservative high threshold (hereafter, HT) was applied to the coarse fraction anomalies. The HT identified only values equal to or larger than the largest coarse fraction anomaly in the modern record as an event. In this way, two event chronologies, one for each detection threshold, were constructed from the coarse fraction anomaly time series. 


\subsection{Constructing the event frequency time series}

A sliding 157-yr window was used to facilitate comparisons between storm frequency in the instrumental record (1851 - 2007 A.D.) and event frequency in the paleorecord. Moving averages of event frequency were obtained using the average occurrence rate of significant coarse fraction anomalies per year within the sliding 157-yr window. A time series of event frequency was produced for both the LT and HT event chronologies. Owing to the stochastic nature of hurricane landfalls, the number of storms impacting a specific site would likely vary from one sampled period to the next even if the statistics of Atlantic hurricanes were stationary through time. Thus, some portion of the variability in local flooding frequency was due to chance only, while the remainder may have resulted from actual changes in storm climate. To construct confidence intervals for the random portion of the variability, ten thousand 157-year-long artificial bootstrap records were generated. In each bootstrap record, the occurrence of an event was modeled as a Poisson process with a constant, average frequency equal to that of the whole sedimentary record. This method is similar to the one employed in Woodruff et al. (2008a), but the average event frequency was prescribed by the sediment record itself rather than by an external model. A modeled event frequency was calculated for each bootstrap sample, and the process was repeated ten thousand times. The $10^{\text {th }}$ and $90^{\text {th }}$ percentiles were then found for each set of modeled frequencies. Sets of confidence intervals were found for both the LT and HT records by using their respective average event frequencies. 


\section{Results}

\subsection{Description of the sediments in Mullet Pond}

Visual inspection of the cores together with a CHIRP profile revealed three main sedimentary units in Mullet Pond: basal sand, peat, and an overlying unit of dark, fine-grained sediment (Figure 2a). Loss on ignition and microfossil analysis located the marine transition in the stratigraphy, which divided the fine-grained sediments into a lower fresh lacustrine unit and an upper brackish lacustrine unit. Much of the detailed stratigraphy was obscured by gas in the brackish lacustrine unit; however, a prominent reflector in the upper portion of the sediments could be traced continuously across the basin (Figure $2 b$ ). This spatially-uniform reflector corresponded to a sand layer and a peak in inorganic content near $72 \mathrm{~cm}$ depth in MLT1 and $64 \mathrm{~cm}$ depth in MLT2 (Figure 2b,c). Though MLT2 was slightly longer and captured the basal sand and peat sequences, MLT1 was extracted closest to the pond's sediment depot center and captured a longer segment of the fine-grained, lacustrine sediments only (Figure 2c).

\subsection{Description of the sediment cores}

All of MLT1 and most of MLT2, with total lengths of 601 and $619 \mathrm{~cm}$ respectively, were comprised of dark, fine-grained sediment containing occasional gray clay-rich layers approximately $1-2 \mathrm{~cm}$ thick. Visually, the composition of MLT1 appeared fairly uniform throughout, whereas MLT2 contained coarse sand below $600 \mathrm{~cm}$ and peat between 550 and $600 \mathrm{~cm}$ depth. Loss on ignition analysis revealed that the bulk water content of the dark sediment was near 80 percent with the highest water content ( $~ 90$ percent) in the uppermost 15 to $20 \mathrm{~cm}$ of MLT1 (Figure 2c). The average dry weight composition of the sediment was about 70 percent inorganic with about 20 percent of this being sand and the rest finer silts and clays. 
Abrupt, transient peaks in coarse fraction suggested that centimeter or smaller scale sand layers were numerous in both cores. These sand fraction peaks were present in the whole of MLT1 and in the upper $530 \mathrm{~cm}$ of MLT2.

\subsection{Foraminifera content}

Foraminifera were absent from terrestrial, dune ridge, beach and near-shore samples taken at elevations above -1 m MSL (Table 1). For samples taken below -1 $\mathrm{m}$ MSL, depth (at $5 \mathrm{~m}$ intervals) and location-specific assemblages for Ochlokonee Bay and the Gulf are summarized in Table 1. Taxa typical of subtidal marsh and brackish pond environments (Tiphotrocha comprimata, Jadammina macrescens, Ammobaculites sp., and Arenoparella mexicana) were present in the core top and in every sample taken above $\sim 330 \mathrm{~cm}$ in MLT1, which is presumably the horizon associated with sea-level intercepting the pond. Seven intervals in the upper $40 \mathrm{~cm}$ of MLT1, all associated with coarse layers, contained marine assemblages typical of water depths of at least -1 to $-5 \mathrm{~m}$ MSL (currently found 3 to $5 \mathrm{~km}$ offshore), and four of these had taxa which currently reside only at depths exceeding $-5 \mathrm{~m}$ MSL. The very prominent coarse layers near $292 \mathrm{~cm}$ in MLT1 and $431 \mathrm{~cm}$ in MLT2 contained taxa typical of offshore environments now found at depths and distances of -5 to -10 $\mathrm{m}$ MSL and 12 to $16 \mathrm{~km}$, respectively. The oldest coarse deposits in the stratigraphy ( $\sim 504 \mathrm{~cm}, 510 \mathrm{~cm}$, and $531 \mathrm{~cm}$ in MLT2) contained marine assemblages typical of modern depths between -1 to $-5 \mathrm{~m}$ (Figure 2c). Foraminifera were absent from the basal peat and sand units in MLT2 (Table 2).

\subsection{Age control}

Eleven radiocarbon dates provided age control for MLT1 (Table 3). All but one of the calibrated ages were chronostratigraphically consistent, and the errant sample at $268-269 \mathrm{~cm}$ was discarded because its age was approximately 200 years 
younger than what would be expected based on the sequence of other calibrated ages. Based on the ten remaining dates, MLT1 had a remarkably constant sedimentation rate of $1.35 \mathrm{~mm} \mathrm{yr}^{-1}$, and a linear fit to the medians of the highest probability $1 \sigma$ calibrated ranges had an $\mathrm{R}^{2}$ of 0.998 (Figure 3a, Supplementary Figure 1). The deepest radiocarbon sample from $569 \mathrm{~cm}$ yielded an age of about $4200 \mathrm{cal}$. yrs. B.P. (Table 3), and linear extrapolation of the sedimentation rate to the bottom of the core suggested that the MLT1 record spans approximately the last 4500 years.

The five radiocarbon dates sampled from MLT2 were all chronostratigraphically consistent (Table 4). The linear fit to the three uppermost ages had an $\mathrm{R}^{2}$ of 0.998 and suggested a sedimentation rate of $1.2 \mathrm{~mm} \mathrm{yr}^{-1}$ above 415 $\mathrm{cm}$ depth, with much lower sedimentation rates of $0.55 \mathrm{~mm} \mathrm{yr}^{-1}$ between $542 \mathrm{~cm}$ and $415 \mathrm{~cm}$ and $0.33 \mathrm{~mm} \mathrm{yr}^{-1}$ below $542 \mathrm{~cm}$ (Supplementary Figure 1). However, given the absence of a date between 415 and $542 \mathrm{~cm}$ depth and a significant change in lithology from peat to fine-grained organic sediment around $550 \mathrm{~cm}$, some uncertainty exists for the $0.55 \mathrm{~mm} \mathrm{yr}^{-1}$ rate between 415 and $542 \mathrm{~cm}$. The sedimentation rate of $1.2 \mathrm{~mm} \mathrm{yr}^{-1}$ may actually continue down to the lacustrine/peat transition. The deepest sample was taken from $616 \mathrm{~cm}$, near the bottom of the core, and returned a calibrated age of about $7950 \mathrm{cal}$. yrs. B.P.

The background, sediment-supported ${ }^{210} \mathrm{~Pb}$ activity in MLT1, measured at depths below $19 \mathrm{~cm}$, was approximately $0.035 \mathrm{~Bq} / \mathrm{g}$ (Supplementary Figure 2a). Seventeen distinct ${ }^{210} \mathrm{~Pb}$ ages were calculated above this depth and ranged from 1904 A.D. to 2006 A.D (Figure 3b). The ${ }^{137}$ Cs horizons corresponding to 1954 A.D. and 1963 A.D. were identified at approximately 9.5 and $6.5 \mathrm{~cm}$ respectively (Supplementary Figure 2b). Though the long-term, radiocarbon-based sedimentation rate of $1.35 \mathrm{~mm} \mathrm{yr}^{-1}$ in MLT1 was very stable, the ${ }^{137} \mathrm{Cs}$ and ${ }^{210} \mathrm{~Pb}$ data indicated a somewhat higher sedimentation rate of $1.8 \mathrm{~mm} \mathrm{yr}^{-1}$ during the $20^{\text {th }}$ Century. The loss on ignition data showed that a significant increase in organic content accompanied the recently increased sedimentation rate. Also, sediment porosity in MLT1 peaked in the uppermost $20 \mathrm{~cm}$ with water content just under 90 percent by bulk weight. The 
very recent increase in sedimentation rate indicated by the modern age model of MLT1 may have been due to the uncompacted nature of the uppermost sediments or might have resulted from landscape or water quality changes caused by local human activity during the $20^{\text {th }}$ Century. To account for the recent, apparent acceleration of the sedimentation rate, a polynomial age model (Figure 3b) was fit to the ${ }^{137} \mathrm{Cs}$ horizons, ${ }^{210} \mathrm{~Pb}$ ages and uppermost, calibrated radiocarbon date of MLT1 (Table 3). This model was used to date historic sand deposits in MLT1. For MLT2, recent sand deposits were approximately dated using the uppermost linear age model based on radiocarbon dating.

\subsection{Natural history of Mullet Pond}

Based on the lowermost radiocarbon date in MLT2, the sinkhole that would eventually become Mullet Pond probably formed when a cavity in the underground limestone collapsed at least 7,000 to 8,000 yrs. B.P. The sand unit at the base of MLT2 (Figure 2a) is likely the surficial sediment that fell into the original depression during and immediately after the collapse. Based on the depth of the overlying sediments in Mullet Pond, the original depression was up to $8 \mathrm{~m}$ deep, assuming no post-collapse subsidence of the bottom. According to the radiocarbon-based age model, the $0.5 \mathrm{~m}$ of freshwater peat between 600 and $550 \mathrm{~cm}$ depth in MLT2 was deposited from about 7,000 through 5,800 cal. yrs. B.P. No foraminifera were present in the basal peat, but a peak in sand and inorganic content just above the peat interval at $531 \mathrm{~cm}$ depth, dated by the age model to around 5,500 yrs. B.P., was found to contain shallow marine foraminifera Ammobaculites dilatus and Ammobaculites exiguus (Table 1, Table 2). The presence of these taxa suggested that this earliest coarse fraction layer in Mullet Pond had a marine origin and was likely deposited during a coastal flood. A subsequent increase in baseline sand and inorganic content around the time of this coarse deposit suggested that the site was intercepted by a rising water table and transitioned into a freshwater pond. 
Numerous ephemeral peaks in coarse and inorganic fraction occasionally accompanied by marine-indicative foraminifera (A. dilatus and A. exiguus) were detected in sediments deposited after the site became a freshwater pond (Table 1, Table 2, Figure 2c). Rising sea levels (Donnelly and Giosan, 2008) eventually intercepted the pond resulting in a transition to a brackish environment and the development of a salt marsh around the pond perimeter between 2450 and $2320 \mathrm{yrs}$. B.P. Brackish foraminifera were continuously present in all sediments sampled for microfossil content after this transition (Table 2). The fresh-to-brackish transition was also accompanied by subtle increases in baseline sand and inorganic content in both MLT1 (near $330 \mathrm{~cm}$ depth) and MLT2 (near $300 \mathrm{~cm}$ depth) (Figure 2c).

Given the spatial uniformity of the sedimentary units and deposits in Mullet Pond, MLT1 and MLT2 should both have recorded the same environmental changes and short-lived depositional events through time. However, MLT1 yielded a greater temporal resolution owing to its higher and remarkably steady sedimentation rate, thus providing the opportunity to develop an event record with uniform, sub-decadal resolution ( 7 years with $1-\mathrm{cm}$ sampling). Only the most recent $\sim 3500$ years of MLT2 had a similarly high ( $~ 8$ years with $1-\mathrm{cm}$ sampling) and uniform temporal resolution, so the storm record from MLT2 was derived from that interval only.

\subsection{Spectral properties of MLT1 and MLT2}

The power spectra of the MLT1 inorganic (Figure 4a) and coarse fraction (Figure 4b) time series both exhibited significant peaks at frequencies of $\sim 1100^{-1} \mathrm{yrs}^{-}$

${ }^{1}, \sim 230^{-1}$ yrs. $^{-1}, \sim 70^{-1}$ yrs. $^{-1}, \sim 50^{-1}$ yrs. $^{-1}$ and $\sim 30^{-1}$ yrs. $^{-1}$. In both time series, about a tenth of the frequencies evaluated had spectral power significant on the 95 percent level; therefore, the prevalence of significant power was about twice what would be expected by chance. Peaks significant at the 99 percent level were present near $1100^{-}$ ${ }^{1} \mathrm{yrs}^{-1}, 246^{-1} \mathrm{yrs}^{-1}, 52^{-1} \mathrm{yrs}^{-1}$, and $34^{-1} \mathrm{yrs}^{-1}$ in the power spectrum of MLT1 inorganics (Figure 4a). The coarse fraction power spectrum had peaks significant at 
the 99 percent level centered at $20^{-1}$ and $15^{-1} \mathrm{yrs}^{-1}$ (Figure $4 \mathrm{~b}$ ). These higher frequency peaks, close to the Nyquist frequency of $14.8^{-1} \mathrm{yrs}^{-1}$, were significant only in the coarse fraction power spectrum, which suggested that short-lived deposition events occurring on timescales near the temporal resolution of the record $(\sim 7.4$ yrs. $)$ controlled much of the variability in the coarse fraction. High-pass filtering of the

coarse fraction raw data to include only variability on frequencies higher than $30 \mathrm{yrs}^{-1}$ isolated this event signal from the original time series (Figure 5a,b; Figure 6a,b). The resulting time series of MLT1 coarse fraction anomalies (Figure 5b, Figure 6b) displayed a distribution of peaks similar to the raw coarse fraction time series (Figure 5a, Figure 6a), but with the background variability removed. Based on the power spectra of the most recent 3500 years of MLT2 (Supplementary Figure 3a,b), coarse fraction anomalies for MLT2 were also found by filtering out frequencies lower than $30 \mathrm{yrs}^{-1}$.

\subsection{Historic hurricanes and calibration of the paleorecord}

SLOSH modeling of the 66 Best Track storms that met the intensity and proximity criteria revealed that fifteen hurricane-induced surges of at least $1 \mathrm{~m}$ likely occurred at Bald Point between 1851 and 2007 A.D. A total of eight surges exceeding $2 \mathrm{~m}$, within the provided uncertainty, were modeled in the years 1985, 1966, 1941, 1929, 1926, 1894, 1886 and 1852 (Figure 5c). The largest modeled surge was associated with Hurricane Elena in 1985, and the median modeled value of $3.2 \mathrm{~m}$ is consistent with observations of an approximately $3 \mathrm{~m}$ surge in the area during the event (Case 1986). The modeled 0.8 - $1.6 \mathrm{~m}$ surge from Hurricane Eloise in 1975 is also consistent with eyewitness observations of a small surge locally (Hebert 1976). However, the simulated surge from Hurricane Dennis (2005) differed significantly from observations. The surge from Hurricane Dennis was modeled to be between 0.9 and 1.6 meters at Bald Point. However, the model underestimated the actual storm tide from Hurricane Dennis, which was observed to be $2-3 \mathrm{~m}$ in western Apalachee 
Bay (Morey et al. 2006) (Figure 5c). The discrepancy between modeled and observed flooding magnitudes likely arose from uncertainties in the SLOSH model input. Simplifying assumptions including the use of parameterizations for the RMW, wind field, and wind-pressure relationships as well as the omission of astronomical tides, wind waves, and wave setup may account for some of the differences between the modeled still water level surges and observed storm tides. Errors in the Best Track storm intensity or position data would also add uncertainty particularly in the earlier years of the dataset. However, the intent was not to precisely hindcast historical storm tides, but rather to objectively sieve through the hundreds of Gulf storms in the Best-Track data for the few historic storms likely represented in the sediment record.

When plotted against the polynomial age model, the largest modern coarse fraction anomalies in MLT1 tended to coincide with significant modeled surges (Figure $5 \mathrm{~b}, \mathrm{c}$ ). Five of the six largest coarse fraction anomalies dated to surge events that were modeled or otherwise known to exceed $2 \mathrm{~m}$, within the provided uncertainty. The smallest of these is likely associated with the 1941 A.D. Hurricane, and this value was taken as the low threshold (LT) for storm detection. All coarse fraction anomalies above the LT in the modern record were coincident with modeled surges caused by historic hurricanes impacting the area. When applied to the older portions of the MLT1 record, the LT attributes all values meeting or exceeding the 1941 A.D. coarse fraction anomaly to paleohurricane events. However, not every modern surge-producing event was present in the modern sedimentary record, so the paleohurricane record likely also only documented a fraction of all storms impacting the site. The coarse fraction anomaly associated with Hurricane Elena in $1985(\sim 3.3)$ was selected as the more conservative high threshold (HT) for storm detection. The HT would qualify only the largest, modern coarse fraction anomaly, and coincidentally the largest modeled surge, as a significant event. Obviously this less sensitive detection method resulted in a greater underestimation of event occurrence; however, using the HT provided a higher degree of certainty that values exceeding 
the threshold correspond to significant coastal floods in the past and served as a sensitivity analyses of the result to the threshold value used.

The MLT2 time series of modern coarse fraction anomalies was very similar to MLT1 (Supplementary Figure 4a,b). Hurricane Dennis was not detected in MLT2; however, and this may be due to inadequate preservation of or failure to capture the sediment-water interface. The sand deposit likely associated with Hurricane Alma was more prominent in the MLT2 sequence, and the Hurricane Elena deposit is the largest modern coarse fraction anomaly in both cores. The congruence of the upper portions of MLT1 and MLT2 suggests that the modern record is reproducible across the pond basin.

\subsection{Event frequency in the modern and paleorecord}

Since 4500 cal. yrs. B.P., 177 events exceeded the LT and 107 events exceeded the HT in MLT1 (Figure 6b,c). The resulting average event frequencies were 3.9 events/century and 2.4 events/century for the LT and HT cases, respectively. The corresponding event frequencies in the post-1851 A.D. portion of the sediment record were 3.8 events/century when the LT was applied and 0.6 events/century when the HT was applied. Thus, modern event frequency was similar to the long-term average when events were identified using the LT; however, modern event frequency was four times lower than the long-term average when the HT was applied.

According to the event frequency time series constructed with the HT, the occurrence of events at Mullet Pond must have been significantly more common during part of the paleorecord than they were in the $19^{\text {th }}$ and $20^{\text {th }}$ centuries.

The LT-based time series showed relatively little variability with event frequency only briefly exceeding the $90^{\text {th }}$ percentile of the bootstrap records $(5.7$ events/century) around 2600 and 2800 cal. yrs. B.P. (Figure 7a). Of the ten thousand 157-year-long bootstrap records modeled with the record mean HT frequency of 2.4 events/century, only the most active 10 percent had more than 3.8 events/century and 
the least active 10 percent had fewer than 0.6 events/century (Figure $7 b$ ). Seven periods in the HT-based time series exhibited event frequencies at or above the $90^{\text {th }}$ percentile of the bootstrap records: three 50 - 100-year intervals centered at 3950, 3750 and 3550 cal. yrs. B.P. with about 3.8 events/century, a $50-100$-year period around 3300 cal. yrs. B.P. with about 4.5 events/century, 2800 to 2400 cal. yrs. B.P. with a peak of 5.5 events/century near 2500 cal. yrs. B.P., an approximately 50-year interval around 1200 cal. yrs. B.P. with 3.8 events/century, and an approximately 100-year period with about 4.5 events/century around 700 cal. yrs. B.P. Three periods in the record had event frequencies in the bottom $10^{\text {th }}$ percentile of the bootstrap records. These periods, each averaging no more than one event every 200 years, were around 2100 cal. yrs. B.P., between 1800 and 1600 cal. yrs. B.P. and 500 cal. yrs. B.P. through present (Figure 7b). A cumulative plot of HT events with time showed pronounced variability in its slope (event frequency), while the cumulative plot of the LT events was more linear and suggested modest changes in event frequency through time (Figure 6c).

Though age models and temporal resolutions differ between the two cores, the time series of hurricane frequency constructed using the last 3500 years of MLT2 reveals many of the same features present in the MLT1 time series (Supplementary Figure 5a,b). The biggest differences are present between 3000 and 3500 yrs. B.P., when the MLT2-based time series suggests hurricane frequency was most elevated. Also, the overall frequency of storms in the MLT2 record is lower, and this can likely be attributed to the core's lower temporal resolution, which would increase the classification of multiple, sequential events as single events. These similar time series were achieved by applying identical procedures to materials taken from two separate coring locations, and these results suggest that the storm record is reasonably reproducible across the Mullet Pond basin. 


\section{Discussion}

\subsection{Coarse fraction anomalies as hurricane deposits}

As the power spectrum of the coarse fraction time series suggests, the most significant variability in sand content occurred on relatively short timescales near the sampling resolution ( $\sim 7$ yrs.). Transient increases in the abundance of larger $(>63$ um) particles in the pond sediments could be caused by short-lived transitions to a higher-energy environment, which would occur during flooding events. The sandy soils, low relief of the carbonate platform, and absence of stream and river networks on the local landscape suggest that terrestrial runoff during rain events is minimal (Puri and Vernon 1964); moreover, Mullet Pond has shallow banks and a small watershed (Figure 1c). Furthermore, the water level of the pond is essentially the same as the groundwater level, so freshwater flooding would simply cause the pond to "fill up" thereby limiting the lateral transport of terrestrial sediment into the basin. If terrestrial, freshwater flooding events have played a role in depositing sand into Mullet Pond, then this process would likely be most prominent when the collapse feature was young and the relief surrounding its sediment depot center was greatest. The absence of coarse grain deposits in the 1200-year basal peat sequence in MLT2 strongly suggests that terrestrial runoff did not play a role in transporting sand into the pond at the time when the basin would have been configured to be most susceptible to this process. It is therefore unlikely that freshwater flooding would have played a role in any subsequent coarse layer deposition. Moreover, the oldest sand deposit overlying the peat, dated to around 5,500 yrs. B.P., contained marine foraminifera (Table 2, Figure 2c). Given subsequent rising sea levels and decreasing site-to-sea distances, this oldest deposit serves as a precedent and indicates that Mullet Pond would have been susceptible to inundation from marine flooding events since that time. While the presence of offshore taxa has been considered a sufficient basis for identifying paleohurricane deposits (Hippensteel and Martin 1999, Collins et al. 1999, 
Hippensteel and Martin 2000, Hippensteel et al. 2005, Hippensteel 2008, Scott et al. 2003), the absence of foraminifera in other sand layers does not rule out a marine origin for deposits (Williams 2010). Dune, beach and nearshore surface samples above $-1 \mathrm{~m}$ elevation (MSL) were absent of foraminifera, which suggests that coarse deposits containing offshore taxa were likely produced only by relatively more dynamic coastal flooding events (Table 1). The CHIRP profile of Mullet Pond (Figure 2a), though mostly obscured by gas, suggested that the upper sediment stratigraphy is spatially uniform across the basin. The reproducibility of both modern and paleohurricane records from the MLT1 and MLT2 cores supports this (Supplementary Figure 5). Horizontal continuity of the coarse deposits would indicate they originated when sand suspended by surge and wave action was advected over the dune ridge or through the marsh and then subsequently settled out after the flooding had subsided. Given the relative seismic stability of the region, tsunamis in the Gulf of Mexico seem to be an unlikely cause of the coastal floods. Storm-induced coastal flooding remains the most likely mechanism for the production of the thin, coarse-grained deposits in Mullet Pond. While coastal flooding can occur during non-tropical storms, every significant coarse fraction anomaly in the modern portion of the record was contemporaneous with a historic hurricane either documented or deemed capable via modeling of generating coastal flooding at the site. We therefore conclude that coarse fraction anomalies in the Mullet Pond record provide a reasonable proxy for local tropical cyclone-induced storm surges.

\subsection{Surges and sedimentary signatures of historic hurricanes}

The post-1851 A.D. period covered by the Best Track Dataset was represented by the upper 20 or $25 \mathrm{~cm}$ of MLT1, depending on whether the linear or polynomial age model was applied. The polynomial age model, which took into account the recent increase in the sedimentation rate, suggested that nearly every significant coarse fraction anomaly coincided with a significant (at least 2 meters), historic surge. 
Not every historic hurricane with a modeled surge exceeding 2 meters was detected in the recent sediment record, but the actual storm tides may have been smaller than the modeled surges in some cases. Moreover, the age model for the last half of the $19^{\text {th }}$ Century was based on an interpolation between the upper ${ }^{137} \mathrm{Cs}$ and ${ }^{210} \mathrm{~Pb}$ constraints and a radiocarbon date at $80 \mathrm{~cm}(\sim 545 \mathrm{cal}$. yrs. B.P. $)$. The more tenuous age controls for the $19^{\text {th }}$ Century chronology may have prevented the proper attribution of significant coarse fraction anomalies to large, modeled surge events such as the one associated with the 1852 A.D. Hurricane (Figure 5c). While the sediment record may not document every hurricane that affected the area since 1851 A.D., the correspondence of the largest, recent coarse fraction anomalies with the most significant documented hurricane events in the area is encouraging.

Although the largest historic hurricane events were represented in the record, some smaller events likely went undetected resulting in an underestimate of the number of storms impacting the site through time. While 66 historic storms met the intensity and proximity criteria for SLOSH modeling and 15 of these were modeled to have surges of at least $1 \mathrm{~m}$ at the site, only six modern storm deposits were detected in the modern portion of the sediment record. This translates into a detection rate of approximately 9 percent of all modeled storms and 40 percent of storms with $1+\mathrm{m}$ of modeled surge, respectively. Undercounting may also have occurred as a result of limited sampling resolution. For example, the hurricanes of 1894 and 1896 A.D. occurred in such quick succession that they could not be distinguished as two separate events in MLT1 given the approximately 7-year resolution of the sediment record (Figure 5b,c). Multiple storms occurred in the years 1985 and 1886 A.D., and these storms would also be lumped together as single events. Undercounting of paleohurricanes likely occurred throughout the record, and more storms were probably missed during periods of greater storm frequency (Woodruff et al. 2008a). Therefore the actual amplitude and statistical significance of the storm frequency variations through time were likely greater than what was derived from the sediment record. 
Shallow, benthic (-1 to $-5 \mathrm{~m} \mathrm{MSL}, 3$ to $5 \mathrm{~km}$ ) foraminifera were present in deposits associated with the 1941 A.D. Hurricane and possibly Dennis in 2005 A.D. (Table 2, Figure 5b). Benthic taxa that currently reside in marine sediments between -5 and $-10 \mathrm{~m}$ MSL depth (5 to $16 \mathrm{~km}$ offshore) were identified in the storm deposits of Elena (1985 A.D.), 1926/29 A.D., and 1894/96 A.D. The shallow marine assemblage was also present in an interval spanning 1797 - 1823 A.D., while the deeper and more offshore species were found at 1780 A.D. (Table 2, Figure 2c). While we have not identified written records of historic hurricane strikes near Apalachee Bay between 1797 and 1823 A.D. (Ludlum 1963), it is possible that storms impacting this sparsely populated region in the late $18^{\text {th }}$ and early $19^{\text {th }}$ centuries may have gone undocumented. The foraminifera-rich deposit dating to $\sim 1780$ A.D. is associated with the largest coarse fraction anomaly of the last 500 years in MLT1 (Figure 6b). This deposit dates to Solano's Hurricane of 1780 A.D.one of three devastating hurricanes that occurred during the deadliest Atlantic hurricane season on record. This well documented storm killed thousands at sea in the eastern Gulf of Mexico when it intercepted a fleet of Spanish ships en route to capture the Florida Panhandle from the British (Ludlum 1963). Solano's Hurricane appears to also be documented in an independent, tree ring isotope-based paleohurricane record from southern Georgia (Miller et al. 2006). As previously noted, the presence of distinctly offshore taxa in a coastal pond serves as a compelling indicator of marine inundation, but foraminifera may not always be present in storm deposits.

\subsection{Site sensitivity to storm surge through time}

Much of the criticism against using the historic Atlantic hurricane record to detect secular trends in tropical cyclone activity is related to the improvement of storm detection and observation through time (Landsea 2007, Chen et al. 2009). A similar criticism could be leveled against the paleohurricane record contained in 
Mullet Pond, which should have experienced increasing susceptibility to storm surges as sea-level rose and, therefore, should have become a more complete record of storm activity toward present. Debate exists over the evolution of sea-level in the Gulf of Mexico during the Holocene. Some investigators have proposed that Gulf sea-level has risen in a generally smooth and continuous fashion through the mid-late Holocene (Otvos 2001, Törnqvist et al. 2004, Wright et al. 2005, Donnelly and Giosan 2008, Milliken et al. 2008, Simms et al. 2009), while more complex sea-level curves for the region have also been suggested (Stapor et al. 1991, Tanner 1992, Morton et al. 2000). Dating of relic beach ridges along the northern Gulf of Mexico has been offered as evidence for periods of higher than modern sea level $(\sim+2 \mathrm{~m})$ during the mid-Holocene (Morton et al. 2000, Blum et al. 2003). However, if sea level had been significantly higher than modern at any time in the last 7,000 years, then a near-shore or open marine sequence should be evident from the lithology and microfossil profile of MLT2, which spans the last 8000 years. No such evidence for a significant late Holocene sea-level highstand exists in the sedimentary archive of Mullet Pond (Figure 2c, Table 2).

The combined effects of continuous sea-level rise and shoreline retreat should have colluded to increase the frequency of hurricane inundations through time. However, the record does not provide evidence for such a trend and possesses variability that cannot be explained by steady sea-level rise. In fact, sea level along the Gulf Coast of Florida has been placed at 1.2 to $1.5 \mathrm{~m}$ below modern levels around 2500 yrs. B.P. (Wright et al. 2005), when storm frequency peaked in the Mullet Pond record. Moreover, the decline in storm events since $600 \mathrm{cal}$. yrs. B.P. is inconsistent with subsequently rising sea levels and associated increasing susceptibility to inundation. With the 100-year coastal still water flood level near Bald Point purported to be $4.5 \mathrm{~m}$ (Ho and Tracey 1975), the surge potential in Apalachee Bay is larger than the proposed $\sim 3 \mathrm{~m}$ sea-level rise that occurred during the entire period spanned by the MLT1 record (Wright et al. 2005, Donnelly and Giosan 2008). Today, a $4.5 \mathrm{~m}$ surge would submerge most of Bald Point, including the eastern half 
of the peninsula where Mullet Pond is located. Given the modern bathymetry of Apalachee Bay, the maximum site-to-sea distance 4500 years ago would have been about $3.8 \mathrm{~km}$. A recent examination of the surge deposit from Hurricane Ike in Texas found that suspended littoral and offshore sediments containing foraminifera were transported almost $3 \mathrm{~km}$ inland and were then preserved in subaerial environments (Williams 2010). These findings suggest that appropriate depositional settings can preserve microfossil-based paleohurricane records stretching back thousands of years. Foram dissolution and bioturbation complicate microfossil-based paleohurricane reconstructions in many settings (Hippensteel and Martin 1999, Collins et al. 1999, Hippensteel and Martin 2000, Hippensteel et al. 2005, Hippensteel 2008, Scott et al. 2003); however, lateral continuity of distinct storm layers and prolonged microfossil preservation indicate that these processes play a limited role in Mullet Pond. The presence of calcareous marine foraminifera in a sand layer dating to 5500 cal. yrs. B.P. suggests that the site has been recording surge events for almost six millennia (Table 2, Figure 2c). At modern coastal sites along Apalachee Bay, where the topography is very low-lying and the surge potential is extreme, it is likely that overwash frequency is dominated by the frequency and magnitude of marine flooding events rather than changes in geographic boundary conditions through time. We deduce that the changes in flooding frequency suggested by the sedimentary record in Mullet Pond primarily reflect variability in storm climate rather than changes in site sensitivity.

\subsection{Comparisons with other paleohurricane records}

Given the stochastic nature of hurricane landfalls, changes in the frequency of storms at one particular site may not necessarily reflect larger-scale changes in storm frequency. The discrepancy between site-specific and basin-wide activity may be largest when short time periods are considered. For this reason, any very recent trend in Atlantic-wide hurricane frequency caused by anthropogenic climate change would 
be nearly impossible to detect in a single sedimentary record. When longer time periods are considered, changes in local hurricane frequency are more likely to reflect larger-scale changes in storm climate (Woodruff et al. 2008a). Other sediment-based paleohurricane records from the Caribbean, Northeastern U.S., and the northern Gulf of Mexico have documented significant multi-centennial to millennial-scale variability in hurricane frequency similar to the centennial to multi-centennial variability identified in the Mullet Pond reconstruction, though the timing and extent of the variability differs somewhat among the records (Liu and Fearn 1993, Liu and Fearn 2000, Scileppi and Donnelly 2007, Donnelly and Woodruff 2007).

Liu and Fearn $(1993,2000)$ identified low-frequency variability in the number of visible sand layers deposited by hurricanes impacting Western Lake, Florida. They suggested that long-term shifts in atmospheric circulation directed the majority of hurricanes toward either the Gulf or U.S. East Coast resulting in alternating hyperactive (from 3400 to 1000 cal. yrs. B.P.) and quiescent storm phases (between 5000 to 3400 cal. yrs. B.P. and after 1000 cal. yrs. B.P.) in the Gulf of Mexico. This Bermuda High Hypothesis has found support from studies of the instrumental record that have identified high-frequency variability in the dominant tracks of modern Atlantic hurricanes (Elsner et al. 2000, Elsner 2003, Holland 2007, Kossin and Camargo, 2009). However, a paleohurricane record based on salt marsh cores from Alder Island, NY exhibited a period and phase of variability similar to that of the Gulf Coast record (Scileppi and Donnelly 2007). Hurricane inundation layers were most abundant in the Alder Island marsh between 3200 and 700 cal. yrs. B.P. but were rare between 700 and $300 \mathrm{cal}$. yrs. B.P. Another record documenting intense hurricane strikes in the Caribbean indicated a similar pattern of activity over the last 5000 years in Vieques, Puerto Rico (Donnelly and Woodruff 2007). The stormiest intervals at Vieques were from 5500 to 3700 cal. yrs. B.P., 2500 to 1000 cal. yrs. B.P. and after 250 cal. yrs. B.P., while the calmest periods occurred from 3700 to 2500 cal. yrs. B.P. and 1000 to 500 cal. yrs. B.P. The authors argued that the local frequency of storms at Vieques was influenced by the low-frequency behaviors of the ENSO and the West 
African Monsoon - a hypothesis inspired by the instrumental record (Goldenberg and Shapiro 1996) and supported by paleorecords of these climatic phenomena (Moy et al. 2002, Nguetsop et al. 2004). In contrast to storm track-driven changes, this variability could drive large-scale, basin-wide variations in storm frequency and possibly intensity. One recent paleohurricane record developed from the sediments of Laguna Madre in South Texas produced no evidence for significant variability in intense, landfalling hurricane frequency during the last five millennia (Wallace and Anderson 2010). However, similar to the previously discussed paleohurricane records from the Caribbean and Gulf, overall storm detection rates at the site are lower than one event every two hundred years. Such low annual probabilities of occurrence make it difficult to objectively identify or detect meaningful changes in local storm climate through time. Another recent study based on marsh sediments from Mattapoisett, Massachusetts also did not detect large variations in storm frequency over the last two millennia (Boldt et al. 2010). However, with a probability of occurrence exceeding one storm per century, the marsh had a high sensitivity to overwash relative to many other paleohurricane sites, which suggested that significant variability in the late Holocene tropical cyclone frequency may have been confined to intense hurricanes only. The significant variability in the frequency of HT events compared with the relative constant frequency of LT events in Mullet Pond is consistent with this hypothesis.

The Mullet Pond reconstruction shares many features with a 1500-year reconstruction of basin-wide landfalling Atlantic hurricanes, which was based on a compilation of several paleohurricane records including most of those already discussed (Mann et al. 2009) (Figure 8a,b). Both the paleorecord compilation and the Mullet Pond record show increasing storm frequency between 1500 and 1000 cal. yrs. B.P. and a prolonged decline in hurricane landfalls beginning after $600 \mathrm{cal}$. yrs. B.P. The spike in hurricane landfalls that occurs just prior to 600 cal. yrs. B.P. in the Mann et al. (2009) reconstruction is present in the Mullet Pond record but was dated approximately 100 years earlier. This discrepancy may be authentic or merely result 
from the differences between the Mullet Pond age model and the merged age models and associated uncertainties of the other paleohurricane reconstructions.

While the available Atlantic paleohurricane reconstructions share some similar characteristics, significant differences also exist. Many factors contribute to these differences. The local sedimentary expression of a basin-wide change in overall Atlantic hurricane frequency and/or intensity could be quite different depending on a host of site-specific and regional factors. Discrepancies in hurricane reconstructions may reflect differences in local storm frequency and intensity distributions, age models, temporal resolutions of the records, flooding thresholds, local sea-level rise and associated geomorphological changes. Owing to more frequent inundations and more complete detection of events, the record we present here provides a more detailed history of Holocene hurricane climate than have other records. Mean storm frequencies over the last 2500 years were 0.32 storms/century at Western Lake, 0.52 storms/century at Alder Island, 0.68 storms/century at Vieques, 1.2 storms/century at Mattapoisett, and between 1.8 and 4 storms/century at Mullet Pond depending on whether the HT or LT time series was considered (Figure 9). This wide range of local landfall rates likely results both from geographic differences in the number and intensity distribution of hurricanes affecting each region and from the local susceptibility of each site to inundation by storm surge. Region-specific variability in hurricane frequency and intensity through time may have also contributed to differences among late Holocene paleohurricane records.

The Western Lake, Vieques and Alder Island records were developed from sites that are relatively difficult to inundate; therefore, these records likely documented only the largest hurricane-induced surges (Liu and Fearn 2000, Scileppi and Donnelly 2007, Woodruff et al. 2008a, Woodruff et al. 2008b). As suggested by their much higher paleohurricane frequencies, Mullet Pond and Mattapoisett Marsh are more susceptible to smaller storm surges and can be inundated by a broader range of surge events. Changes in the intensity distribution of hurricanes occurring in concert with changes in storm frequency could cause the frequency of storm deposits 
in sites with different flooding susceptibilities to diverge. Numerical modeling of late $21^{\text {st }}$ century hurricane climatology has suggested that declines in overall Atlantic hurricane frequency could occur simultaneously with a broadening of the intensity distribution of hurricanes leading to fewer but more intense storms (Emanuel et al. 2008, Gualdi et al. 2008, Knutson et al. 2008, Zhao et al. 2009, Bender et al. 2010). However, recent warming and increased hurricane frequency in the Atlantic has purportedly been accompanied by a disproportionate increase in the occurrence of intense hurricanes (Emanuel 2005, Webster et al. 2005, Hoyos et al. 2006, Elsner et al. 2008, Jagger and Elsner 2008). When considering the climate system feedbacks likely associated with the atmospheric and upper ocean anomalies generated by tropical cyclones (Hart et al. 2007, Hart 2010), it seems likely that significant changes in the frequency of storms would also change their intensity statistics.

Although the magnitude of the coarse fraction anomaly associated with a hurricane is not necessarily an indication of storm intensity, some of the coarsest deposits do contain evidence of extremely energetic events. A few of the most prominent coarse deposits were sampled for microfossils and found to contain marine taxa common to deeper, offshore environments. These taxa, not typical of a coastal pond or salt marsh, included Brizalina spathulata, Ammonia beccarii and radiolarians. For example, deposits dating to 2100 and 3670 cal. yrs. B.P., when sea level was at least a meter lower than modern (Wright et al. 2005), contained taxa found at modern water depths of at least $-5 \mathrm{~m}$ in the region (Table 1, Table 2). Given the shallow bathymetry of Apalachee Bay, the foraminifera were transported at least $12 \mathrm{~km}$ before being deposited into Mullet Pond (Table 3). The presence of these taxa suggests large deposits like these were produced by violent events capable of transporting offshore sediment a considerable distance.

Understanding the relationship between storm frequency and intensity distribution during the last few thousand years will require a multi-site approach. A suite of records from closely-spaced sites with different flooding thresholds but the same history of storm strikes is needed to quantify the relative contributions of storm 
frequency and intensity to variability in hurricane activity. More thorough and detailed microfossil analysis, though very time consuming, could also aid in constraining flooding event intensity for the most intense paleohurricane events by identifying the provenance of the marine sediment in the resulting overwash deposit.

\section{Conclusions}

The Mullet Pond record indicates that the most active interval for tropical cyclones in the Northeastern Gulf of Mexico during the late Holocene was 2700 to 2400 cal. yrs. B.P. Storms were rarely detected between 1900 and 1600 cal. yrs. B.P. and after 400 cal. yrs. B.P. A decline in the number of large storm deposits, which began around 600 years ago, has persisted through present with below average frequency over the last 150 years when compared to the preceding five millennia. However, given the stochastic nature of hurricane landfalls, any trend in basin-wide hurricane frequency during the late $20^{\text {th }}$ century would not be detectable in a single sedimentary record. With an approximately 7 year temporal resolution and a record mean storm frequency of 3.9 events per century, Mullet Pond provides a richer and more detailed archive of storm activity than other existing paleohurricane records. The record presented here provides further evidence for significant variability in the frequency of high magnitude storm events in the Gulf of Mexico during the late Holocene. When all events were considered, however, variations in local storm frequency could be explained entirely by the random clustering of events in time. This finding suggests that variability in flooding frequency at this and other Atlantic and Gulf paleohurricane study sites might have been controlled by changes in the intensity distribution of hurricanes rather than changes in overall storm frequency.

The successful development of a high-resolution paleohurricane record from Mullet Pond indicates that coastal sinkholes can serve as valuable archives of past hurricane activity. These depositional basins can have high sedimentation rates that make sub-decadal resolution records possible. As valuable indicators of marine 
provenance, foraminifera have served as definitive indicators of coastal flooding in back-barrier depositional settings. Good foraminifera preservation together with low bioturbation make Mullet Pond and similar sinkhole environments good targets for future microfossil-based paleohurricane research. The presence of calcareous, marine microfossils as early as 5500 cal. yrs. B.P. serves as evidence that the site has been periodically inundated for over five millennia and proves that prolonged preservation of foraminifera is possible in these environments. On carbonate platforms where sinkholes are often abundant, topography is low and surge penetration is extensive, a very large number of long, high-resolution paleohurricane records likely exist and await discovery. Ongoing efforts to identify and develop paleohurricane records from the geologic register will further clarify how tropical cyclones have interacted with late Holocene climate variability and change. 


\section{Acknowledgments}

Funding for this research was supported by the National Science Foundation and the Coastal Ocean Institute. P. Donnelly provided assistance with fieldwork and M. Gomes, S. Moret and S. Zipper assisted with laboratory analysis. Source code for the SLOSH model was provided by the National Hurricane Center (NOAA), and J. Dusenberry assisted with setting up the model. The Florida State University Marine Laboratory provided lodging during fieldwork. This research was completed during an American Meteorological Society Graduate Fellowship, National Science Foundation Graduate Fellowship and Coastal Ocean Institute Fellowship. This work was further supported by National Science Foundation award \#OCE-0903020. This is a contribution of IGCP 495 - 'Holocene land-ocean interactions: driving mechanisms and coastal responses'.

\section{References}

Anthes, R.A., Corell, R.W., Holland, G., Hurrell, J.W., MacCracken, M.C., Trenberth, K.E., 2006. Hurricanes and Global Warming: Potential Linkages and Consequences. Bulletin of the American Meteorological Society. 87, 623-628.

Bender, M.A., Knutson, T.R., Tuleya, R.E., Sirutis, J.J., Vecchi, G.A., Gerner, S.T., Held, I.M., 2010. Modeled impact of anthropogenic warming on the frequency of intense Atlantic hurricanes. Science. 327(5964), 454-458.

Blum, M.D., Sivers, A.E., Zayac, T., Goble, R.J., 2003. Middle Holocene sea level and evolution of the Gulf of Mexico coast. Transactions-Gulf Coast Association of Geological Societies. 53, 64-77.

Boldt, K.V., Lane, P., Woodruff, J.D., Donnelly, J.P., 2010. Calibrating a sedimentary record of overwash from Southeastern New England using modeled historic hurricane surges. Marine Geology. 275. pp. 127-139.

Case, R. A., 1986. Atlantic Hurricane Season of 1985. Monthly Weather Review. 114, 1390-1405.

Chang, E. K. M., Guo Y., 2007. Is the number of North Atlantic tropical cyclones significantly underestimated prior to the availability of satellite observations? Geophysical Research Letters. 34, L14801,doi:10.1029/2007GL030169.

Chen, K., McAneney, J., Cheung, K., 2009. Quantifying changes of wind speed distributions in the historical record of Atlantic tropical cyclones. Natural Hazards and Earth System Sciences. 9, 1749-1757.

Cohen, A., 2001. Hurricane tracking with chemistry: Exploring the coral archive. 
Workshop on Atlantic Basin paleohurricane reconstructions from high resolution records, March 25-27, 2001. Columbia, South Carolina, University of South Carolina.

Collins, E.S., Scott, D.B., Gayes, P.J., 1999. Hurricane records on the South Carolina coast: can they be detected in the sediment record? Quaternary International. 56. pp. $15-26$.

Cooper, C.K., 1992. A preliminary case for the existence of hurricane alleys in the Gulf of Mexico. Proceedings of the $24^{\text {th }}$ annual offshore technology conference. OTC6831. OTC: Houston, TX. pp. 213-222.

Dean, W.E., 1974. Determination of carbonate and organic matter in calcareous sediments and sedimentary rocks by loss on ignition: comparison with other methods. Journal of Sedimentary Petrology. 44, 242-248.

de Rijk, S., 1995. Salinity control on the distribution of salt-marsh foraminifera (Great-Marshes, Massachusetts). Journal of Foraminiferal Research. 25, 156-166.

de Rijk, S., Troelstra, S.R., 1997. Salt marsh foraminifera from the Great Marshes, Massachusetts: environmental controls. Palaeogeography, Palaeoclimatology, Palaeoecology. 130, 81-112.

Donnelly, J.P., S.S. Bryant, J. Butler, J. Dowling, L. Fan, N. Hausmann, P. Newby, B. Shuman, J. Stern, K. Westover, Webb III., T., 2001. A 700-year sedimentary record of intense hurricane landfalls in southern New England. Geological Society of America Bulletin. 113, 714-727.

Donnelly, J.P., S. Roll, M. Wengren, J. Butler, R. Lederer, Webb III, T., 2001. Sedimentary evidence of intense hurricane strikes from New Jersey. Geology. 29, 615-618.

Donnelly, J.P., J. Butler, S. Roll, Micah Wengren, Webb III, T., 2004. A backbarrier overwash record of intense storms from Brigantine, New Jersey. Marine Geology. 210, 107-121.

Donnelly, J.P., 2005. Evidence of Past Intense Tropical Cyclones from Backbarrier Salt Pond Sediments: A Case Study from Isla de Culebrita, Puerto Rico, USA. Journal of Coastal Research. SI42, 201-210.

Donnelly, J.P., Woodruff, J.D., 2007. Intense hurricane activity over the past 5,000 years controlled by El Niño and the West African monsoon. Nature. 447, 465-468.

Donnelly, J.P., Giosan, L., 2008. Tempestuous highs and lows in the Gulf of Mexico. Geology. 36(9), 751-752. 
Elsner, J.B., Liu, K.B., Kocher, B.L., 2000. Spatial variations in major United States hurricane activity: Statistics and a physical mechanism. Journal of Climate 13, 2293 2305.

Elsner, J. B., 2003. Tracking hurricanes. Bulletin of the American Meteorological Society. 84, 353-356.

Elsner, J.B., Kossin, J.P., Jagger T.H., 2008. The increasing intensity of the strongest tropical cyclones. Nature. 455, 92-95.

Emanuel, K.A., 2005. Increasing destructiveness of tropical cyclones over the past 30 years. Nature. 436, 686-688.

Emanuel, K.A., Sundararajan, R., William, J., 2008. Hurricanes and global warming: results from downscaling IPCC AR4 simulations. Bulletin of the American Meteorological Society. 89, 347-367.

Faure, G., 1986. Principles of Isotope Geology: Second Edition. John Wiley and Sons, U.S.A., pp. 374-377.

Frappier, A.B., Sahagian, D., Carpenter, S.J., Gonzalez, L.A., Frappier, B.R., 2007. Stalagmite stable isotope record of recent tropical cyclone events. Geology. 35(2). pp. 111-114.

Ghil, M., Allen, M.R., Dettinger, M.D., Ide, K., Kondrashov, D., Mann, M.E., Robertson, A.W., Saunders, A., Tian, Y., Varadi, F., Yiou, P., 2002. Advanced Spectral Methods for Climatic Time Series. Review of Geophysics. 40(1), 1-1 - 1-4.

Goldenberg, S.B., Shapiro, L.J., 1996. Physical mechanisms for the association of El Niño and West African rainfall with Atlantic major hurricane activity. Journal of Climate. 9, 1169-1187.

Goldenberg, S.B., Landsea, C.W., Mestas-Nuñez, A.M., Gray, W.M., 2001. The recent increase in Atlantic hurricane activity: causes and implications. Science. 293, 474-479.

Gualdi, S., Scoccimarro, E., Navarra, A., 2008. Changes in tropical cyclone activity due to global warming: results from a high-resolution coupled general circulation model. Journal of Climate. 21, 5204-5228.

Hart, R., Maue, R., Watson, M., 2007. Estimating the atmospheric and SST memory of tropical cyclones through MPI anomaly evolution. Monthly Weather Review. 135, 3990-4005. 
Hart, R.E., 2010. An inverse relationship between aggregate tropical cyclone activity and subsequent winter climate. Geophysical Research Letters, doi:10.1029/2010GL045612.

Hebert, P.J., 1976. Atlantic Hurricane Season of 1975. Monthly Weather Review. 104, 458-462.

Hetzinger, S., Pfeiffer, M., Dullo, W.-C., Keenlyside, N., Latif, M., Zinke, J., 2008. Caribbean coral tracks Atlantic multidecadal oscillation and past hurricane activity. Geology. 36(1), 11-14.

Hippensteel, S.P., Martin, R.E., 1999. Foraminifera as an indicator of overwash deposits, barrier island sediment supply, and barrier island evolution, Folly Island, South Carolina. Palaeogeography, Palaeoclimatology, Palaeoecology. 149, 115-125.

Hippensteel, S.P., Martin, R.E., 2000. Foraminifera as indicators of storm deposition: Implications for barrier island sediment supply and evolution, in Martin, R.E., ed., Environmental Micropaleontology: Dordrecht, Kluwer Press, p. 351-369.

Hippensteel, S.P., Martin, R.E., Harris, M.S., 2005. Discussion: Records of prehistoric hurricanes on the South Carolina Coast based on micropaleontological and sedimentological evidence, with comparison to other Atlantic Coast records. Geological Society of America Bulletin. 117, 250-256.

Hippensteel, S.P., 2008. Preservation potential of storm deposits in South Carolina back-barrier marshes. Journal of Coastal Research. 24(3), 594-601.

Ho, F.P., Tracey, R.J., 1975. Storm tide frequency analysis for the Gulf Coast of Florida from Cape San Blas to St. Petersburg Beach. NOAA Technical Memorandum NWS HYDRO-20. Office of Hydrology, Silver Spring, MD.

Hodell, D. A., Brenner, M., Curtis, J. H., Medina-González, R., Ildefonso-Chan Can, E., Albornaz-Pat, A., Guilderson, T. P., 2005. Climate change on the Yucatan Peninsula during the Little Ice Age. Quaternary Research. 63, 109-121.

Holland, G. J., Webster, P.J., 2007. Heightened tropical cyclone activity in the North Atlantic: Natural variability or climate trend? Philosophical Transactions of the Royal Society of London. Ser. A. doi:10.1098/rsta.2007.2083.

Holland, G.J., 2007. Misuse of landfall as a proxy for Atlantic tropical cyclone activity. Eos Transactions. 88(36), 349-350. 
Horton, B.P., Edwards, R.J., 2006. Quantifying Holocene sea-level change using intertidal foraminifera: lessons for the British Isles. Cushman Foundation for Foraminiferal Research, Special Publication, 40, 97 pp.

Hoyos, C. D., P. A. Agudelo, P. J. Webster, Curry, J.A., 2006. De-convolution of the factors contributing to the increase in global hurricane intensity. Science. 312, 94-97.

Huybers, P., 2010. "Multi-taper Spectral Analysis." < http://www.people.fas.harvard.edu/ phuybers/Mfiles/pmtmPH.m>.

Jagger, T.H., Elsner, J.B., 2008. Modeling tropical cyclone intensity with quantile regression. International Journal of Climatology. doi: 10.1002/joc.1804.

Jarvinen, B.R., Neumann, C.J., Davis, M.A.S., 1984. A tropical cyclone data tape for the North Atlantic Basin, 1886-1983: Contents, limitations, and uses. NOAA Technical Memorandum NWS NHC 22, Coral Gables, Florida, 21 pp.

Javaux, E., Scott, D.B., 2003. Illustration of recent benthic foraminifera in Bermuda and remarks on species distribution. Palaeontologica electronica. 6 (1). Sept. 2003.

Jelesnianski, C.P., Chen, J., Shaffer W.A., 1992. SLOSH: Sea, Lake, and Overland Surges from Hurricanes. NOAA Technical Report NWS 48, April 1992, Silver Spring, Maryland.

Kindinger, J. L., Davis, J. B., Flocks, J. G., 1999. Geology and evolution of lakes in north-central Florida. Environmental Geology. 38, 301-321.

Knutson, T.R., Sirutis, J.J., Garner, S.T., Vecchi, G.A., Held, I.M., 2008. Simulated reduction in Atlantic hurricane frequency under twenty-first-century warming conditions. Nature Geoscience. doi:10.1038/ngeo202.

Koide, M., Bruland, K.W., Goldberg, E.D., 1973. $\mathrm{Th}^{228} / \mathrm{Th}^{232}$ and $\mathrm{Pb}^{210}$ geochronologies in marine and lake sediments. Geochimica et Cosmochimica Acta. 37, 1171-1188.

Kossin, J. P., K. R. Knapp, D. J. Vimont, R. J. Murnane, Harper, B.A., 2007. A globally consistent reanalysis of hurricane variability and trends. Geophysical Research Letters. 34, L04815, doi:10.1029/2006GL028836.

Kossin, J.P., Camargo, S.J., 2009. Hurricane track variability and secular potential intensity trends. Climatic Change Letters. 97, 329-337. 
Lambert, W. J., Aharon, P., Rodriguez, A.B., 2003. An Assessment of the Late Holocene Record of Severe Storm Impacts from Lake Shelby, Alabama. TransactionsGulf Coast Association of Geological Societies. 53. pp. 443.

Lambert, W.J., Aharon, P., Rodriguez, A.B., 2008. Catastrophic hurricane history revealed by organic geochemical proxies in coastal lake sediments: a case study of Lake Shelby, AL (USA). Journal of Paleolimnology. 39, 117-131.

Landsea, C.W., C. Anderson, N. Charles, G. Clark, J. Dunion, J. Fernández-Partagás, P. Hungerford, C. Neuman, Zimmer, M., 2004. The Atlantic hurricane database reanalysis project: documentation for 1851-1910 alterations and additions to the HURDAT database. In: Murnane, R. and Liu, K. (eds.), Hurricanes and Typhoons: Past Present and Future, New York: Columbia Press, pp. 177-221.

Landsea, C. W., 2007. Counting Atlantic tropical cyclones back to 1900. Eos Transactions. 88(18), 197-202.

Landsea, C.W., Glenn, D.A., Bredemeyer, W., Chenoweth, M., Ellis, R., Gamache, J., Hufstetler, L., Mock, C., Perez, R., Prieto, R., 2008. A Re-Analysis of the 19111920 Atlantic Hurricane Database. Journal of Climate. 21(10), 2138-2168.

Lane, E., 1986. Karst in Florida. Special Publication No. 29. Florida Geological Survey. $100 \mathrm{pp}$.

Liu, K.B., Fearn, M.L., 1993. Lake-sediment record of late Holocene hurricane activities from coastal Alabama. Geology 21, 793-796.

Liu, K.B., Fearn, M.L., 2000. Reconstruction of prehistoric landfall frequencies of catastrophic hurricanes in northwestern Florida from lake sediment records. Quaternary Research. 54, 238-245.

Liu, K. B., Fearn, M.L., 2002. Lake sediment evidence of coastal geologic evolution and hurricane history from Western Lake, Florida: Reply to Otvos. Quaternary Research. 57, 429-431.

Ludlum, D. M., 1963. Early American Hurricanes. American Meteorological Society, Boston

Mann, M.E., Lees, J., 1996. Robust estimation of background noise and signal detection in climatic time series. Climatic Change. 33, 409-445.

Mann, M. E., Emanuel, K.A., 2006. Atlantic hurricane trends linked to climate change. Eos Transactions. 87(24), 233-235.

Mann, M.E., Emanuel, K.A., Holland, G.J., Webster, P.J., 2007. Atlantic tropical 
cyclones revisited. Eos Transactions. 88(36), 350-352.

Mann, M.E., Woodruff, J.D., Donnelly, J.P., Zhang Z., 2009. Atlantic hurricanes and climate over the past 1500 years. Nature. $460,880-885$.

Miller, D.L., Mora, C.I., Grissino-Mayer, H.D., Mock, C.J., Uhle, M.E., Sharp, Z., 2006. Tree-ring isotope records of tropical cyclone activity. Proceedings of the National Academy of Sciences. 103(39), 14294-14297.

Milliken, K.T., Anderson, J.B., Rodriguez, A.B., 2008. A new composite Holocene sea-level curve for the northern Gulf of Mexico." In Anderson, J.B. and A.B.

Rodriguez, eds. "Response of upper Gulf Coast estuaries to Holocene climate change and sea level change. The Geological Society of America Special Paper 443, 1-11.

Morey, S.L., Baig, S., Bourassa, M.A., Duklovskoy, D.S., O’Brien, J.J., 2006. Remote forcing contribution to storm-induced sea level rise during Hurricane Dennis. Geophysical Research Letters. 33, L19603, doi:10.1029/2006GL027021.

Morton, R.A., Paine, J.G., Blum, M.D., 2000. Responses of stable bay-margin and barrier-island systems to Holocene sea-level highstands, western Gulf of Mexico. Journal of Sedimentary Research. 70, 478-490.

Moy, C.M., Seltzer, G.O., Rodbell, D., Anderson, D.M., 2002. Variability of El Nino/Southern Oscillation activity at millennial time scales during the Holocene epoch. Nature. 420(6912), 162-165.

Nguetsop, V.F., Servant-Vildary, S., Servant M., 2004. Late Holocene climatic changes in West Africa, a high resolution diatom record from equatorial Cameroon. Quaternary Science Review. 23, 591-609.

NOAA., 2010. Tides and Currents. <http://tidesandcurrents.noaa.gov $>$.

NOAA,. 2010. Hurricane Research Division Re-Analysis Project. < http://www.aoml.noaa.gov/hrd/hurdat/Data_Storm.html>.

Nott, J., Hayne, M., 2001. High frequency of 'super-cyclones' along the Great Barrier Reef over the last 5000 years. Nature. 413, 508-512.

Nott, J., Haig, J., Neil, H., Gillieson, D., 2007. Greater frequency variability of landfalling tropical cyclones at centennial compared to seasonal and decadal scales. Earth and Planetary Science Letters. 255. pp. 367-372.

Nott, J., Smithers, S., Walsh, K., Rhodes, E., 2009. Sand beach ridges record 6000 year history of extreme tropical cyclone activity in northeastern Australia. 
Quaternary Science Reviews. 28, 1511-1520.

Otvos, E.G., 2001. Assumed Holocene highstands, Gulf of Mexico: basin issues of sedimentary and landform criteria: discussion. Journal of Sedimentary Research. 71(4), 645-647.

Pennington, W., Cambray, R.S., Fisher, E.M., 1973. Observations on Lake Sediments Using Fallout Cs-137 as a Tracer. Nature. 242, 324-326.

Percival, D.B., Walden, A.T., 1993. Spectral analysis for physical applications: multitaper and conventional univariate techniques. Cambridge University Press. pp. $256 \& 370$.

Phleger, F.B., 1965. Living foraminifera from coastal marsh, southwestern Florida. Bol. Soc. Geology Mexicana. 28, 45-60.

Puri, H.S., Vernon, R.O., 1964. Summary of the geology of Florida and a guidebook to the classic exposures. Special Publication No. 5. Florida Geological Survey. 311 pp.

Reimer, P.J., Baillie, M.G.L., Bard, E., Bayliss, A., Beck, J.W., Blackwell, P.G., Bronk-Ramsey, C., Buck, C.E., Burr, G.S., Edwards, R.L., Friedrich, M., Grootes, P.M., Guilderson, T.P., Hajdas, I., Heaton, T.J., Hogg, A.G., Hughen, K.A., Kaiser, K.F., Kromer, B., McCormac, F.G., Manning, S.W., Reimer, R.W., Richards, D.A., Southon, J.R., Talamo, S., Turney, C.S.M., van der Plicht, J., Weyhenmeyer, C.E., 2009. IntCal09 and Marine09 radiocarbon age calibration curves, $0-50,000$ years cal BP. Radiocarbon. 51(4), 1111-1150.

Robbins, J.A., Edgington, D.N., 1975. Determination of recent sedimentation rates in Lake Michigan using Pb-210 and Cs-137. Geochimica et Cosmochimica Acta. 39, 285-304.

Scileppi, E.M., Donnelly, J.P., 2007. Sedimentary evidence of hurricane strikes in western Long Island, New York. Geochemistry, Geophysics, Geosystems. 8(6), Q06011.

Scott, D.B., Medioli, F.S., 1980. Quantitative studies of marsh foraminiferal distributions in Nova Scotia: Implications for sea level studies. Cushman Foundation for Foraminiferal Research Special Publication 17, 58 p.

Scott, D.B., Suter, J., Kosters, E.C., 1991. Marsh foraminifera and arcellaceans of the lower Mississippi Delta: controls on spatial distributions. Micropaleontology. 37, 373-392. 
Scott, D.B., Medioli, F.S., Schafer, C.T., 2001. Monitoring in coastal environments using foraminifera and thecamoebian indicators. Cambridge University Press, London. $175 \mathrm{p}$.

Scott, D.B., Collins, E.S., Gayes, P.T., Wright, E., 2003. Records of prehistoric hurricanes on the South Carolina coast based on micropaleontological and sedimentological evidence, with comparison to other Atlantic Coast records. Geological Society of America Bulletin. 115, 1027-1039.

Sen Gupta, B.K., 1999. Foraminifera in marginal marine environments. In: B.K. Sen Gupta, Editor, Modern Foraminifera, Kluwer Academic Publishers, London. pp. $141-160$.

Simms, A.R. Aryal, N., Yokoyama, Y., Matsuzuki, H, Dewitt, R., 2009. Insights on proposed mid-Holocene highstand along the northwestern Gulf of Mexico from the evolution of small coastal ponds. Journal of Sedimentary Research. 79(10), 757-772.

Sinclair, W.C., Stewart, J.W., 1985. Sinkhole type, development, and distribution in Florida. USGS. Map Series No. 110. Tallahassee, Florida.

Stapor, F.W., Mathews, T.D., Lindfors-Kearns, F.E., 1991. Barrier-island progradation and Holocene sea-level history in southwest Florida. Journal of Coastal Research. 7, 815-838.

Tanner, W.F., 1992. 3000 years of sea level change. Bulletin of the American Meteorological Society. 73, 297-304.

Trenberth, K. E., Shea, D.J., 2006. Atlantic hurricanes and natural variability in 2005. Geophysical Research Letters. 33, L12704, doi:10.1029/2006GL026894.

Törnqvist, T. E., Gonzalez, J. L., Newsom, L. A., van der Borg, K., de Jong, A. F. M., Kurnik, C.W., 2004. Deciphering Holocene sea-level history on the US Gulf Coast: A high-resolution record from the Mississippi Delta. Geological Society of America Bulletin. 116(7-8), 1026-1039.

USEPA., 1999. Ecological condition of estuaries in the Gulf of Mexico. EPA 620-R98-004. U.S. Environmental Protection Agency, Office of Research and Development, National Health and Environmental Effects Research Laboratory, Gulf Ecology Division, Gulf Breeze, Florida. 80 pp.

Vickery, P. J., Skerlj, P.F., Twisdale, L.A., 2000. Simulation of hurricane risk in the U. S. using empirical track model. Journal of Structural Engineering. 126, 12221237. 
Wallace, D.J., Anderson, J.B., 2010. Evidence of similar probability of intense hurricane strikes for the Gulf of Mexico over the late Holocene. Geology. 38(6). pp. 511-514.

Watts, W. A., Hansen, B. C. S., Grimm, E. C., 1992. Camel Lake: A 40,000-yr record of vegetational and forest history from northwest Florida. Ecology. 73, 1056-1066.

Watts, W.A., Hansen, B.C.S., 1994. Pre-Holocene and Holocene pollen records of vegetation history from the Florida peninsula and their climatic implications. Palaeogeography, Palaeoclimatology, Palaeoecology. 109, 163-176.

Webster, P.J., Holland, G.J, Curry, J.A., Chang, H.R., 2005. Changes in tropical cyclone number, duration, and intensity, in warming environment. Science. 309, 1844-1846.

Williams, H.F.L., 2010. Storm surge deposition by Hurricane Ike on the McFaddin National Wildlife Refuge, Texas: Implications for paleotempestology studies. Journal of Foraminiferal Research. 40(3). pp. 210-219.

Woodruff, J.D., Donnelly, J.P., Emanuel, K.A., Lane, P., 2008. Assessing sedimentary records of paleohurricane activity using modeled hurricane climatology. Geochemistry, Geophysics, Geosystems. 9(9). Q09V10.

Woodruff, J.D., Donnelly, J.P., Mohrig, D., Geyer, W.R., 2008. Reconstructing relative flooding intensities responsible for hurricane-induced deposits from Laguna Playa Grande, Vieques, Puerto Rico. Geology. 36(5), 391-394.

Wright, E.E., Hine, A.C., Goodbred, S.L., Locker, S.D., 2005. The Effect of Sea-Level and Climate Change on the Development of a Mixed Siliciclastic-Carbonate, Deltaic Coastline: Suwannee River, Florida, USA. Journal of Sedimentary Research. 75(4), 621-635.

Zarikian, C.A., Swart, P.K., Gifford, J.A., Blackwelder, P.L., 2005. Holocene paleohydrology of Little Salt Spring, Florida, based on ostracod assemblages and stable isotopes. Palaeogeography, Palaeoclimatology, Palaeoecology. 225, 134-156.

Zhao M., Held, I.M., Lin, S.J., Vecchi, G.A., 2009. Simulations of global hurricane climatology, interannual variability, and response to global warming using a $50 \mathrm{~km}$ resolution GCM. Journal of Climate: In Press. doi: 10.1175/2009JCLI3049.1 
Figure 1 - Regional and local site maps. Panel (a) shows the Gulf of Mexico with the location of Apalachee Bay indicated by the black rectangle. Panel (b) is a regional map of Apalachee Bay showing the Bald Point peninsula near $29.9^{\circ} \mathrm{N}$ and $84.4^{\circ} \mathrm{W}$, and the location of Mullet Pond is indicated by the black star. Panel (c) is a local site map showing that Mullet Pond is situated approximately $350 \mathrm{~m}$ to the west of the Bay at the southernmost extent of a salt marsh. Numbered core locations are shown as white circles. Mullet Pond is connected to the Bay by the tidal creek to the north but is otherwise separated from the ocean by a $3-4 \mathrm{~m}$ beach dune ridge $200 \mathrm{~m}$ to the east. Topography between 2 and $4 \mathrm{~m}$ (NAVD88) is contoured at $1 \mathrm{~m}$ intervals. The marsh surface and seaward portions of the beach have elevations of less than 2 $\mathrm{m}$. The highest elevations ( 3 to $4 \mathrm{~m}$ ) exist along the dune ridge axis on the western portion of the beach, though the ridge is slightly lower in front of the pond and along southern portion of the marsh. Most of the landscape is nearly flat with an elevation between 2 and $3 \mathrm{~m}$. 

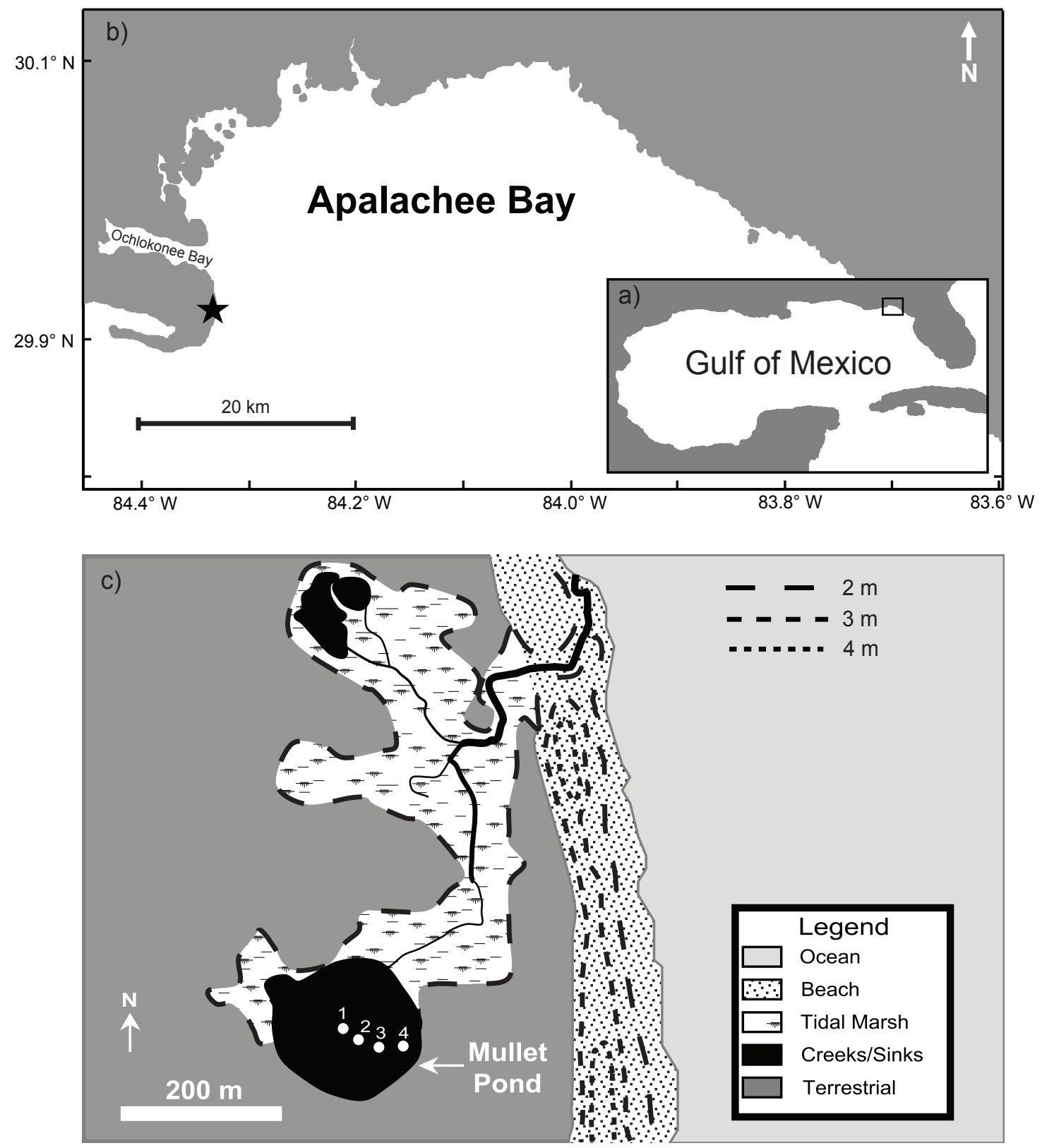
Figure 2 - Mullet Pond stratigraphy. Panel (a) is a cross-sectional drawing of the major stratigraphic units of the sediments in Mullet Pond: basal sand overlain by peat, then fresh lacustrine mud, followed by brackish mud. Panel (b) is a CHIRP profile of the sediments taken from the northwest (left) to the southeast (right) and approximately transecting all four coring locations. The inset in the lower right corner of panel (b) is a planar map of Mullet Pond showing the coring locations and the path of the transect. The dark, laminar reflector that stretches continuously across the basin near the sediment surface corresponds to a sand layer and a peak in inorganic content near $72 \mathrm{~cm}$ depth in MLT1 and $64 \mathrm{~cm}$ depth in MLT2. Much of the signal was attenuated by gas in the brackish lacustrine portion of the sediments, and the resulting image of the underlying sediments was obscured. Coring locations are shown as dashed lines, and the coarse fraction by dry weight data for MLT1 and MLT2 are shown to the right of the coring locations. Panel (c) shows both the percent inorganic (black) and percent coarse (gray) content by depth in MLT1 and MLT2 in greater detail. Sand, peat and fine-grained (fresh and brackish) units are denoted. The corresponding depths of the prominent reflector in the CHIRP profile are marked by black arrows in both the MLT1 and MLT2 loss on ignition data. The approximate location of the fresh-to-brackish transition in both cores $(\sim 330 \mathrm{~cm}$ in MLT1 and $\sim 300 \mathrm{~cm}$ in MLT2) is indicated by a black dashed line. Intervals containing shallow ( -1 to $-5 \mathrm{~m}$ MSL) marine foraminifera are indicated by open rectangles, and intervals where offshore ( -5 to $-10 \mathrm{~m}$ MSL) taxa were detected are indicated by closed (black) rectangles. 

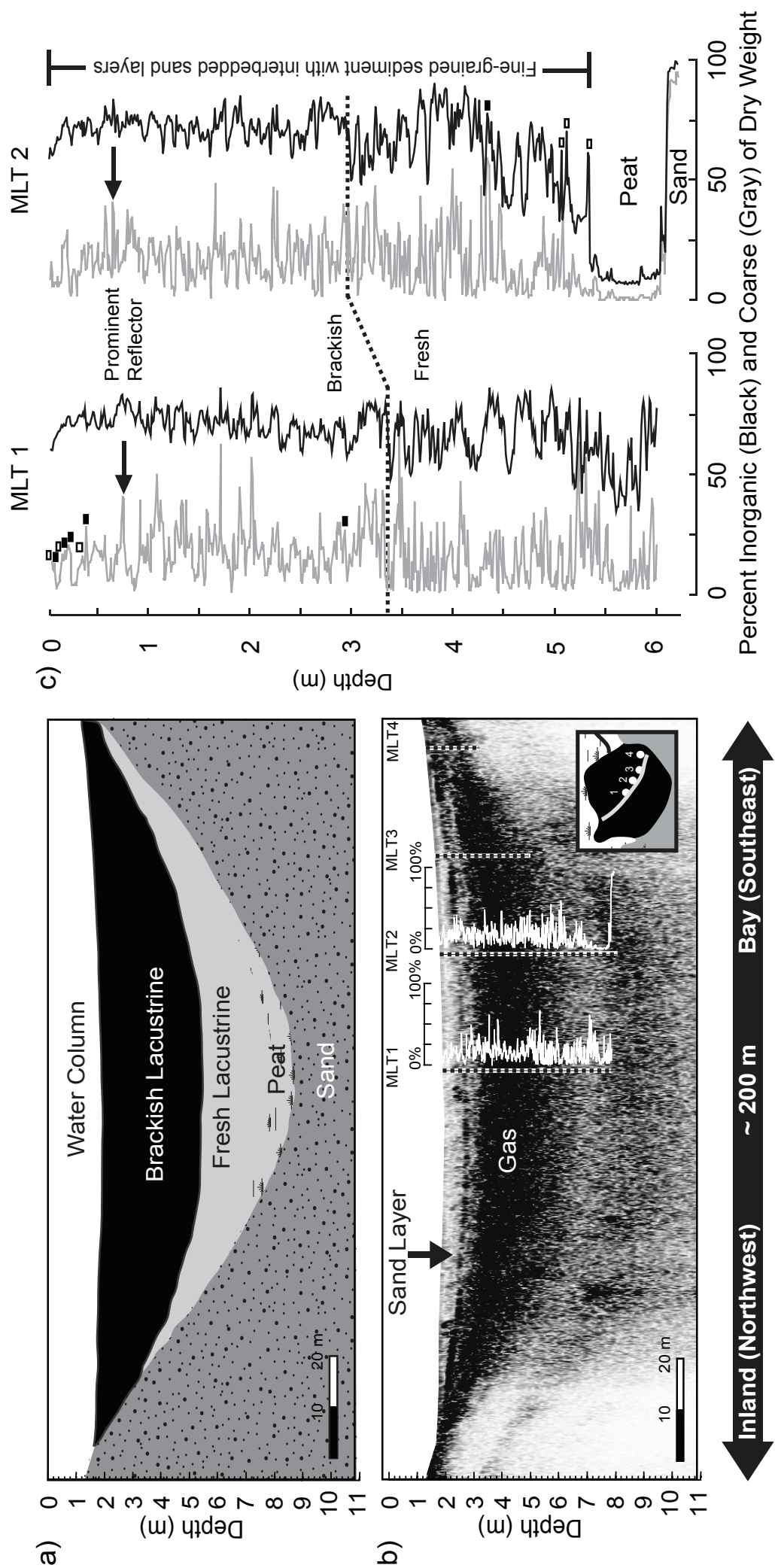
Figure 3 - MLT1 age model. Panel (a) shows eleven radiocarbon-based calendar age ranges for terrestrial plant fragments taken from MLT1 versus the depths from which they were collected in the core. Calendar ages and ranges in years before 1950 A.D. were found from ${ }^{14} \mathrm{C}$ ages and uncertainties using the IntCal09 calibration dataset in the Calib6 program (Reimer et al. 2009). See Table 1 for details. Onesigma (black) and two-sigma (gray) age ranges are shown for each date, and a linear fit (black line) to the median of the highest probability one-sigma age ranges reveals a roughly constant sedimentation rate of $1.35 \mathrm{~mm} \mathrm{yr}^{-1}$ throughout the $601 \mathrm{~cm}$ (or 4450 -year) record. One-sigma and two-sigma age ranges for the anomalous date at 268-269 cm, which was not included in the development of the linear age model, are shown as a black open rectangle and a gray dashed line, respectively. Panel (b) shows an alternate age model with A.D. dates for the uppermost $27 \mathrm{~cm}$ of MLT1. This age model is based on ${ }^{210} \mathrm{~Pb}$ ages, ${ }^{137} \mathrm{Cs}$ horizons and the uppermost radiocarbon date at $80 \mathrm{~cm}$ depth. The seventeen ${ }^{210} \mathrm{~Pb}$ ages and associated uncertainties are shown as black squares and gray bars respectively. The ${ }^{137} \mathrm{Cs}$ horizons associated with the advent of ( 1954 A.D.) and moratorium on ( 1963 A.D.) atmospheric nuclear weapons testing are shown as an open and a closed (black) triangle respectively. A second-order, polynomial fit (black curve) to these data is shown, and this age model accounts for the apparent increase in sedimentation rate during the $20^{\text {th }}$ Century. 


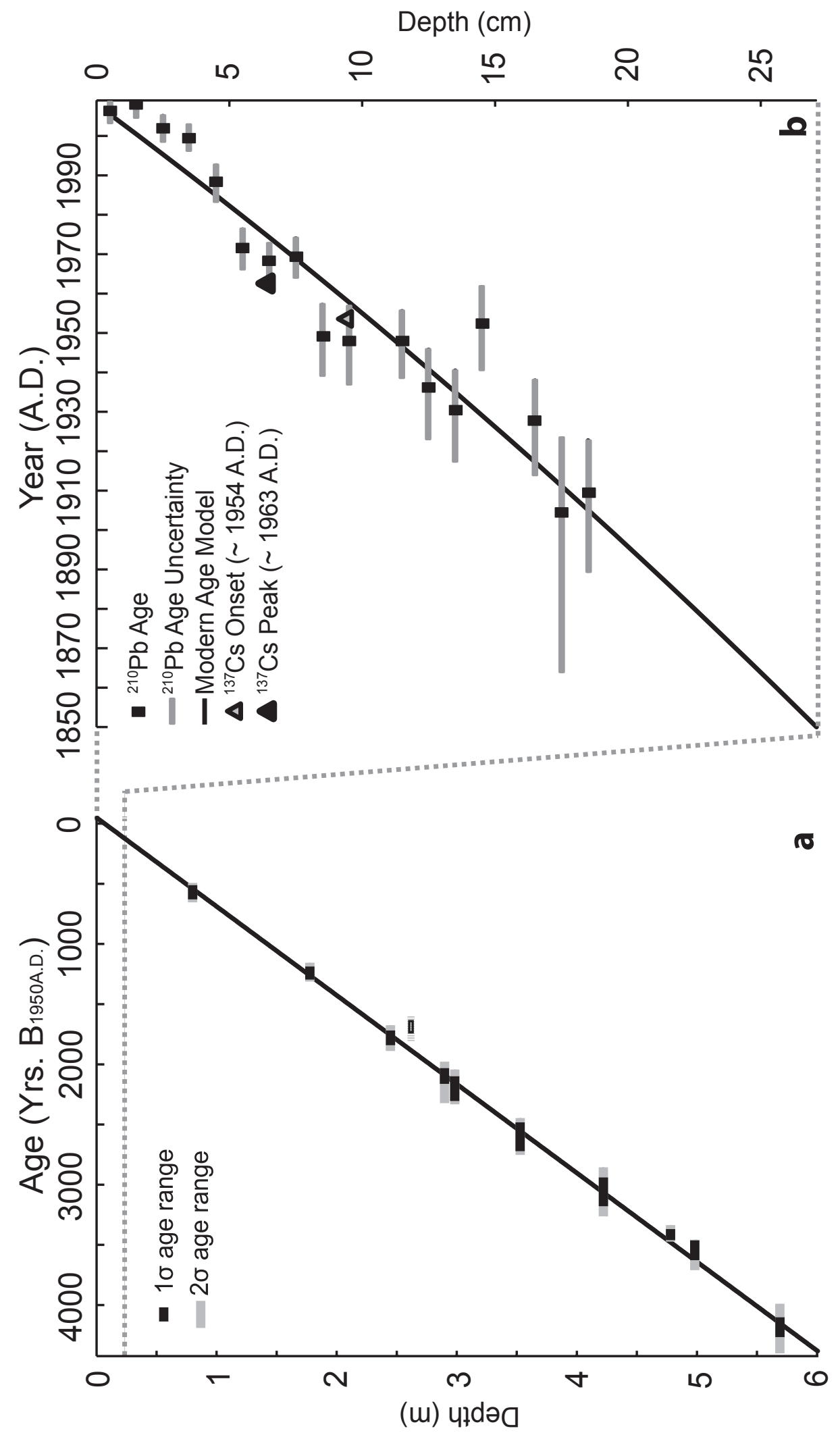


Figure 4 - Power spectra of MLT1 inorganics and coarse fraction time series. Panel (a) shows the power spectrum of the MLT1 time series of percent inorganics. The solid, black curve is the power calculated for each frequency bin and the gray shading is the 95 percent confidence interval of that power calculation. The dashed and dotted curves are the 95 and 99 percent confidence intervals for a comparable red noise power spectrum. Periods (in years) corresponding to frequencies with calculated power exceeding the 95 and 99 percent red noise confidence intervals are labeled in regular and bold fonts respectively. Panel (b) shows the same analysis for the MLT1 time series of percent coarse $(>63 \mu \mathrm{m})$. 

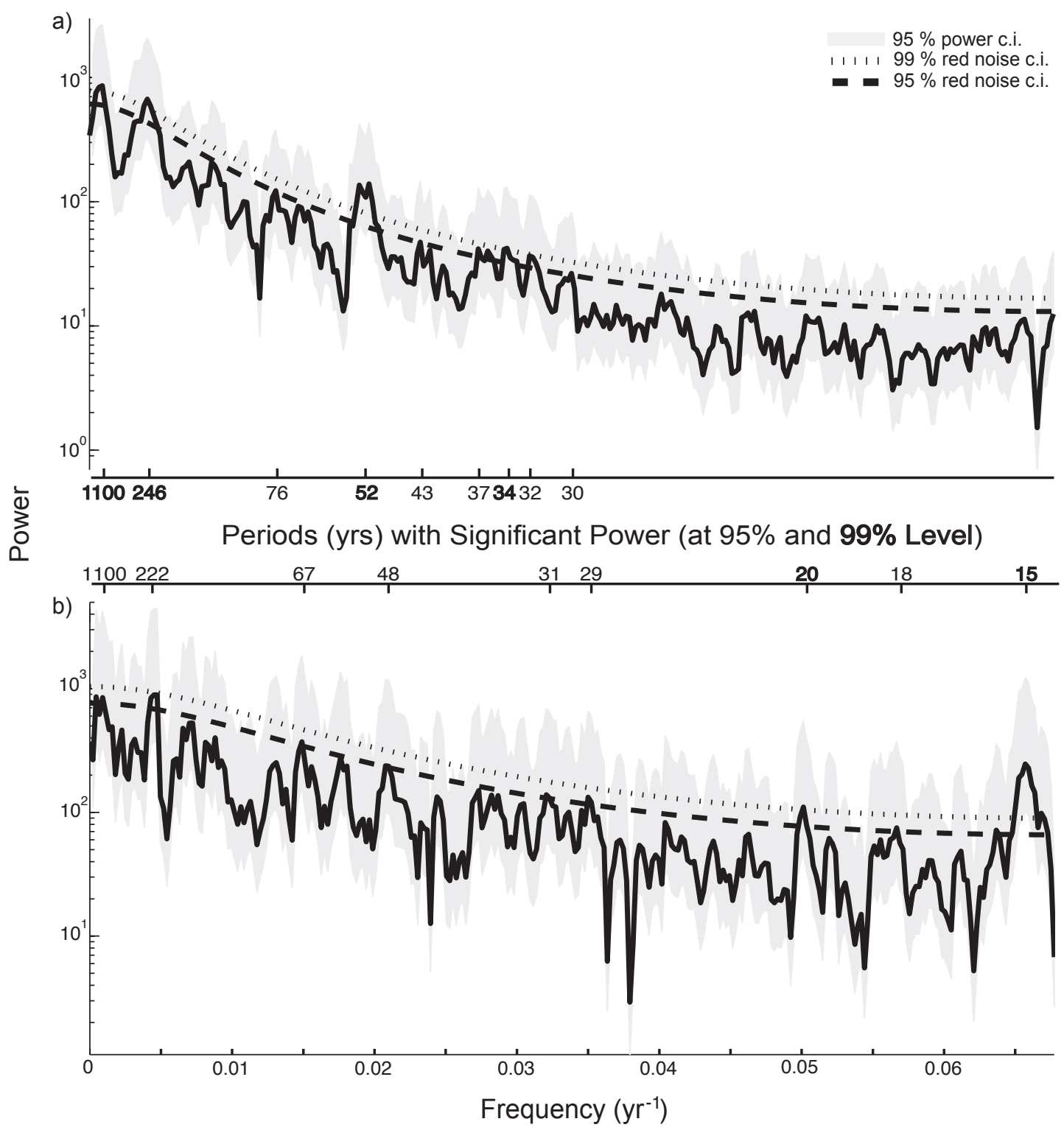
Figure 5 - Modern event deposits and historic surge events. Panel (a) shows the raw percent coarse data (black) for the uppermost (modern) sediments of MLT1 along with the superimposed low-frequency background (gray curve) produced by applying a low-pass filter to the raw data that removes variability on timescales shorter than 30 years. Panel (b) shows the positive coarse fraction anomalies that result from the subtraction of the low-frequency background from the raw data. These coarse fraction anomalies represent the high-frequency $(<30$ years) variability in the modern coarse fraction time series. The coarse fraction anomalies that form the basis for the low (LT, gray dashed line) and high thresholds (HT, black dashed line) used for storm detection were related to hurricanes in 1941 A.D. (gray arrow) and 1985 A.D. (Elena, $1985)$ respectively. Intervals where shallow marine (-1 to $-5 \mathrm{~m} \mathrm{MSL})$ and offshore (5 to $-10 \mathrm{~m} \mathrm{MSL}$ ) foraminifera were detected are indicated by open and closed rectangles, respectively. The magnitude of historic (1851 - 2008 A.D.) storm surges at Mullet Pond, which were estimated using the Best Track dataset and the SLOSH model, are shown in panel (c). The estimated maximum surge heights (in meters above NAVD88) for the fifteen events with modeled surges of at least $1 \mathrm{~m}$ are shown (black dots) along with the uncertainty (gray bars) in each surge estimate. The shown uncertainty in the surge estimates resulted from the combination of domain-specific factors and the analytical error of the SLOSH model. The A.D. year of occurrence of each significant $(>1 \mathrm{~m})$ surge is labeled to the far right along with either the name of the storm or its number of occurrence within that year. For example, 1941 A.D. Hurricane \# 5 was the fifth North Atlantic storm to achieve tropical storm strength in that year. Multiple significant surges occurred in the years 1886 and 1985 A.D. Hurricane \# 3 produced the larger of the two surges in 1886 A.D. and Hurricane Elena produced the larger of the two surges occurring in 1985 A.D. The observed surge from Hurricane Dennis near Bald Point is indicated by the asterisk (Morey et al. 2006). 


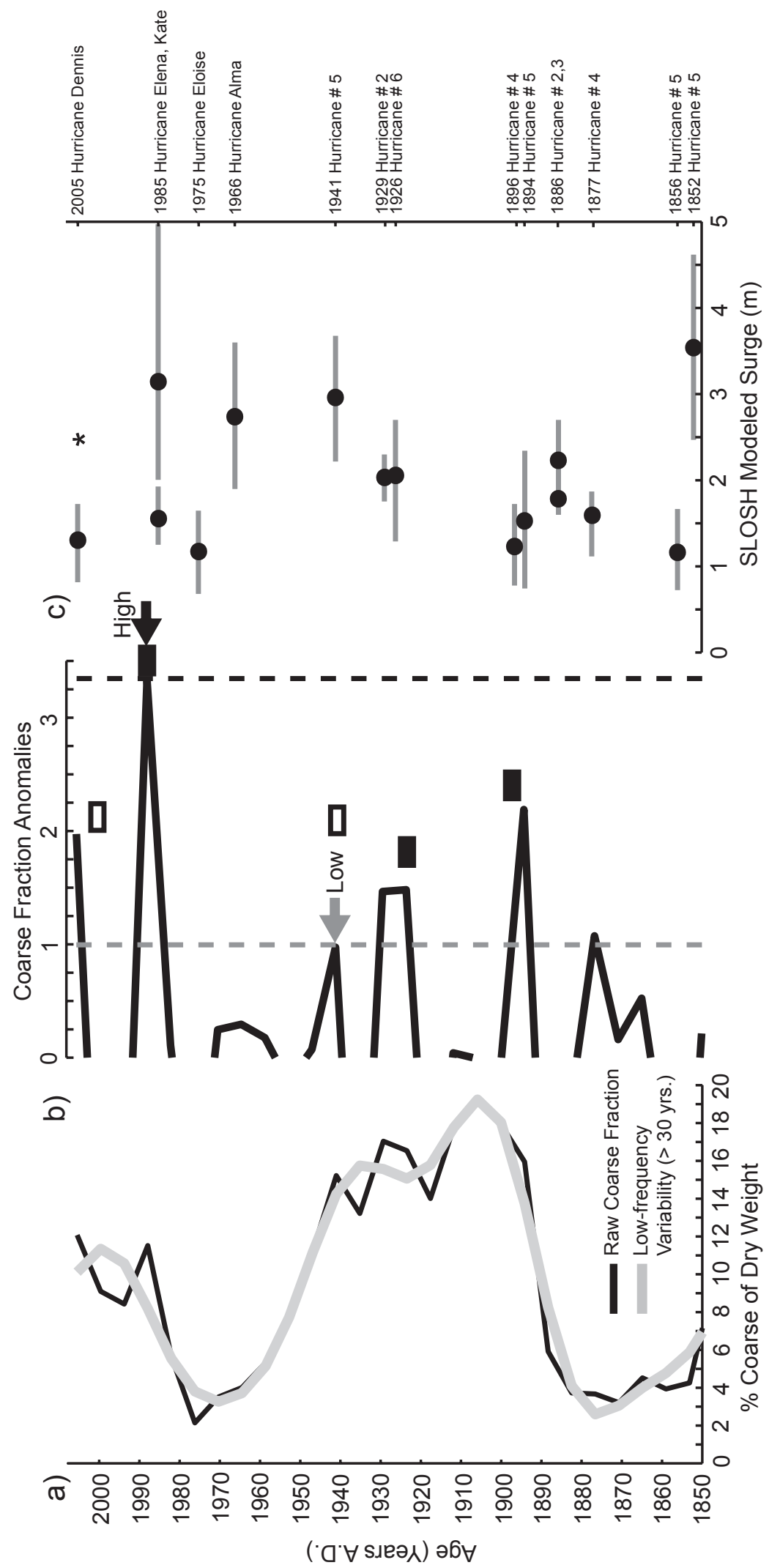


Figure 6 - Identification of paleohurricanes in MLT1. Panel (a) shows the raw coarse fraction time series from MLT1 (solid black) with the gray portion outlining the low-frequency, (>30 year) background variability of the time series. The approximate location of the fresh to brackish transition, as suggested by a shift in the coarse fraction, inorganic content and microfossil assemblages, is indicated by a black arrow. Panel (b) displays the corresponding coarse fraction anomalies, which represent the high-frequency $(<30$ year) variability of the raw time series. 177 anomaly values (gray circles) exceeded the low threshold (LT, gray line) and 107 anomaly values (black circles) exceeded the high threshold (HT, black line). The coarse fraction anomaly that may be associated with Solano's Hurricane of 1780 A.D. is identified. Panel (c) shows the cumulative number of LT (gray) and HT (black) events with time. The slope of the cumulative function is equal to the frequency of storm events. 

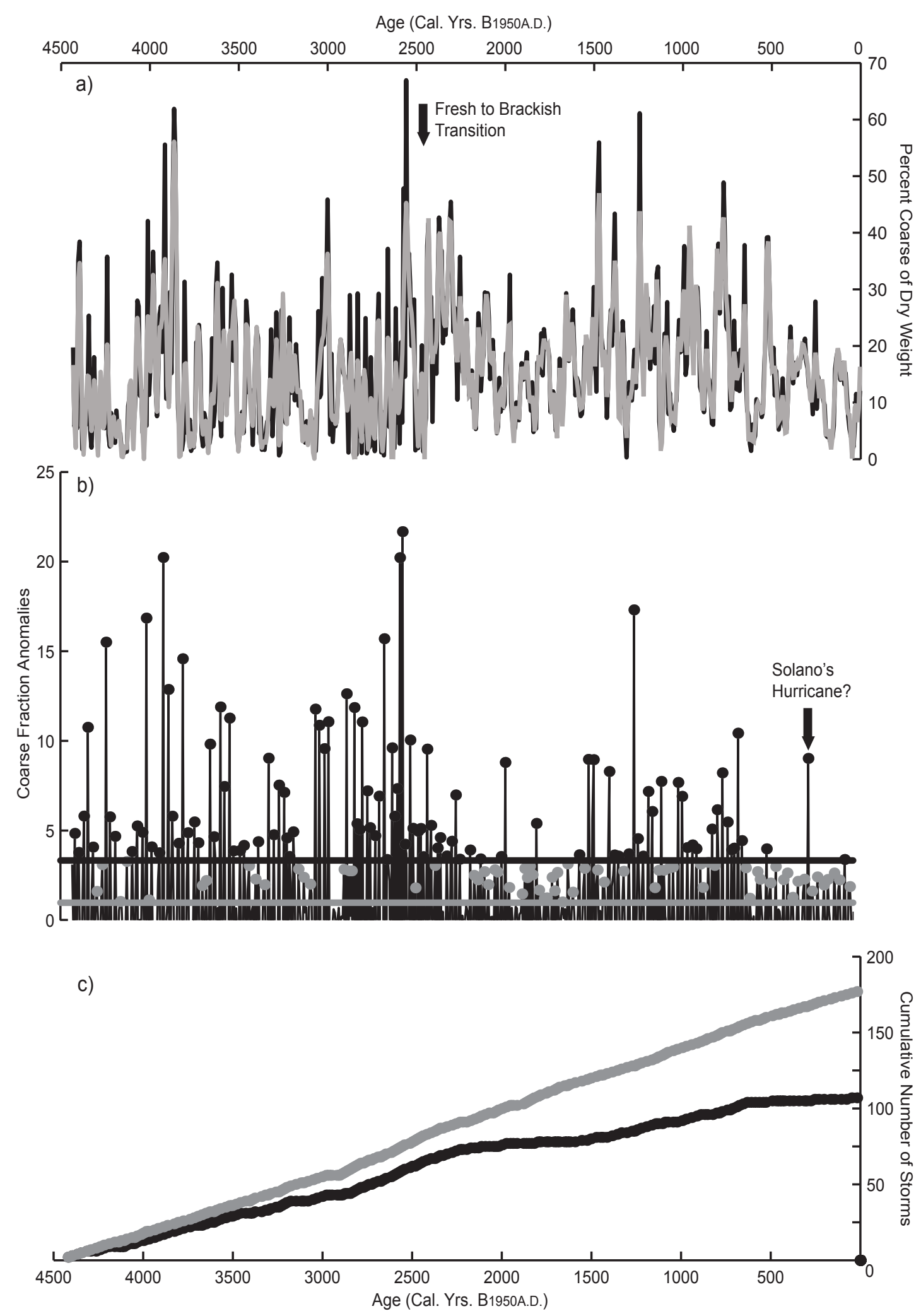
Figure 7 - Local storm frequency through time. Panel (a) is the MLT1 time series of hurricane frequency normalized to events per century (gray curve) when all coarse fraction anomalies exceeding the $\mathrm{LH}$ were attributed to storms. Due to truncation required by the 157-year sliding window, the time series spans the period from 4294 to 21 cal. yrs. B 1950 A.D. The solid gray line is the mean storm frequency ( 4.1 storms per century) over the entire length of the record, while the dashed gray lines represent the $90^{\text {th }}$ (upper line, $\sim 5.7$ storms per century) and $10^{\text {th }}$ (lower line, $\sim 1.9$ storms per century) percentiles of storm frequency based on ten thousand 157-year-long bootstrap records. In the bootstrap records, storm occurrence was modeled as a Poisson process with an average frequency equal to that of the mean storm frequency for the entire sediment record (again, $\sim 4.1$ storms per century). Panel (b) is the same analysis, but only coarse fraction anomalies exceeding the HT were attributed to storms. In this case, the record mean storm frequency over the entire 4450-year period (solid black line) was approximately 2.5 storms per century. The dashed black lines represent the $90^{\text {th }}$ (upper line, $\sim 3.8$ storms per century) and $10^{\text {th }}$ (lower line, $\sim$ 0.6 storms per century) percentiles based on the bootstrap method. Darker gray shaded portions of panel (b) highlight periods with storm frequency that exceeded the $90^{\text {th }}$ percentile of what would be expected by chance. The lighter gray periods were less active times in the record when storm frequency was in the bottom $10^{\text {th }}$ percentile of what would be expected by chance. 


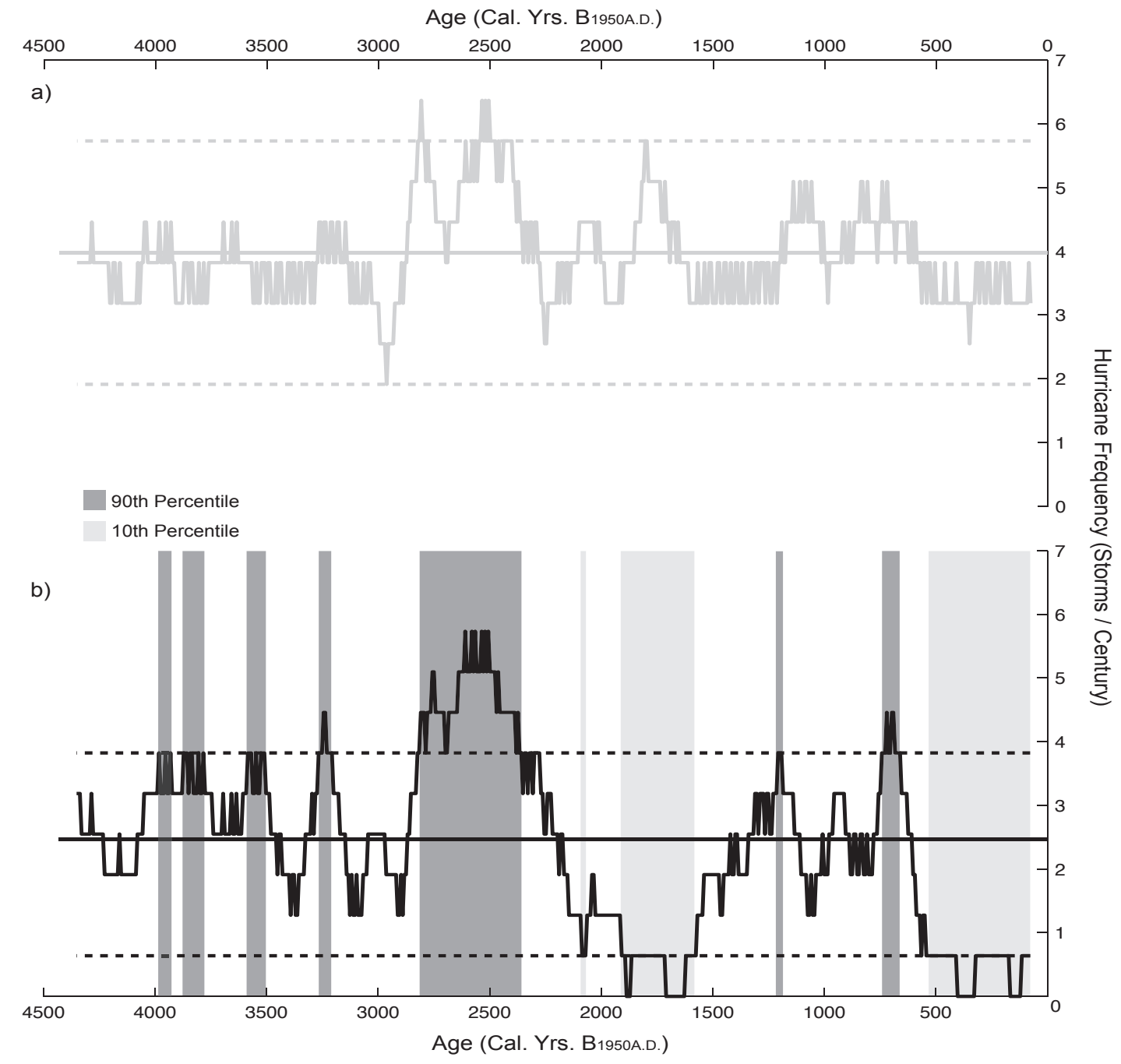


Figure 8 - Comparison of MLT1 record with Mann et al. 2009 Atlantic Basin paleohurricane record compilation. Panel (a) is the time series of hurricane frequency at Mullet Pond from 1500 to 21 cal. yrs. B 1950 A.D. The gray curve is the LT time series and the black curve is the HT time series. The darker gray shaded portion highlights a period with storm frequency that exceeded the $90^{\text {th }}$ percentile of what would be expected by chance. The period shaded in light gray saw fewer hurricanes with storm frequency in the bottom $10^{\text {th }}$ percentile of what would be expected by chance. Panel (b) is a reconstruction of annual basin-wide Atlantic hurricane landfalls based on a composite of various paleohurricane reconstructions from the Caribbean, U.S. East Coast and the northern Gulf of Mexico for the period $1450-100$ yrs. B 1950 A.D. (Mann et al. 2009). 


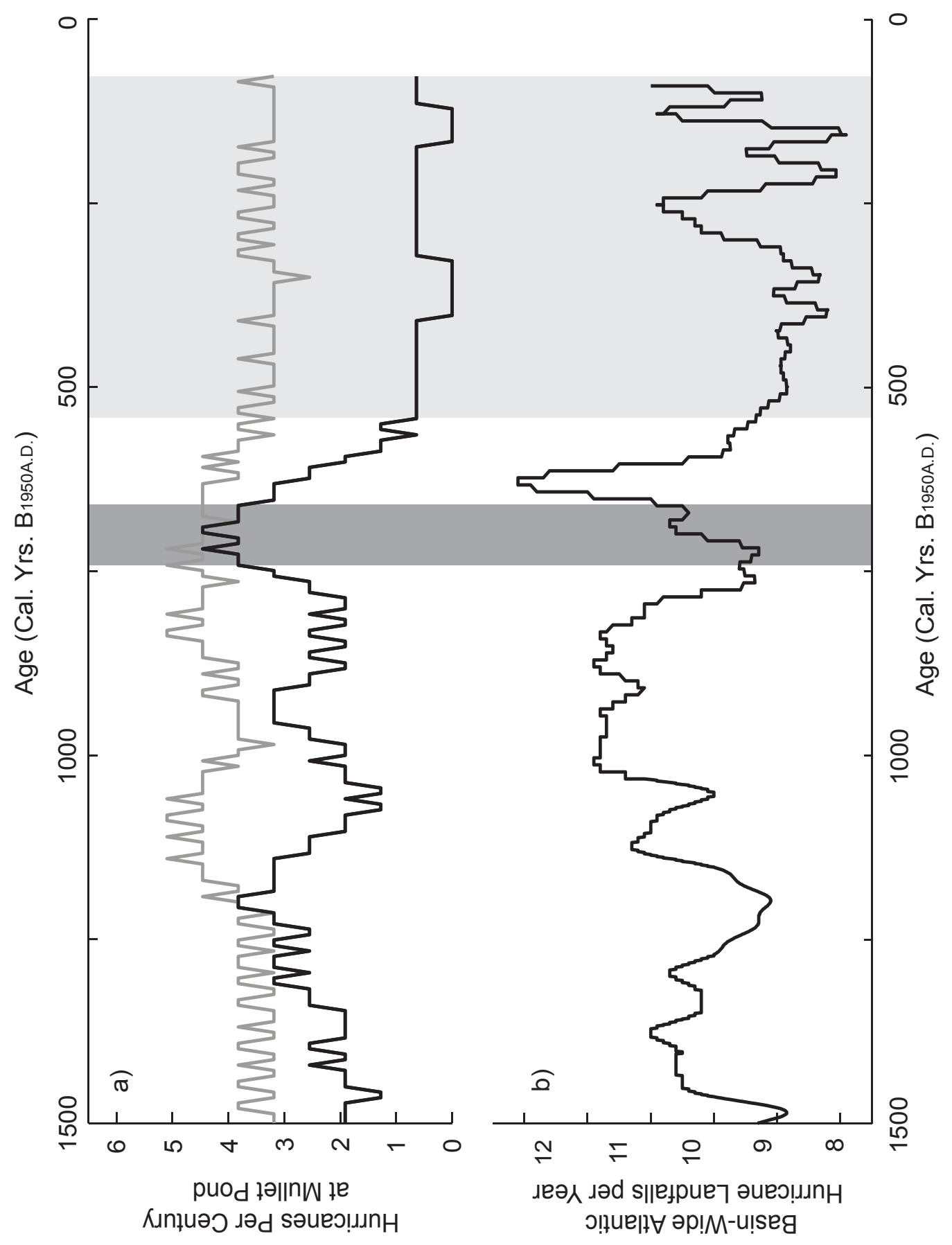


Figure 9 - Comparison of MLT1 record with other paleohurricane records. Plot of the cumulative number of storms since 2500 cal. yrs. B.P. detected in paleohurricane records from the Caribbean, the Northeastern United States, and the northern Gulf of Mexico. Records from Laguna Playa Grande in Vieques, Puerto Rico (x) (Donnelly and Woodruff 2007), Alder Island in New York ( $\square$ ) (Scileppi and Donnelly 2007), Western Lake in Florida (०) (Liu and Fearn 2000), and Mattapoisett Marsh in Massachusetts $(\bullet)$ (Boldt et al. 2010) are shown alongside the LT $(\diamond)$ and HT (+) versions of the MLT1 record. 
Cumulative Number of Storms Since 2500 yrs. B1950A.D.

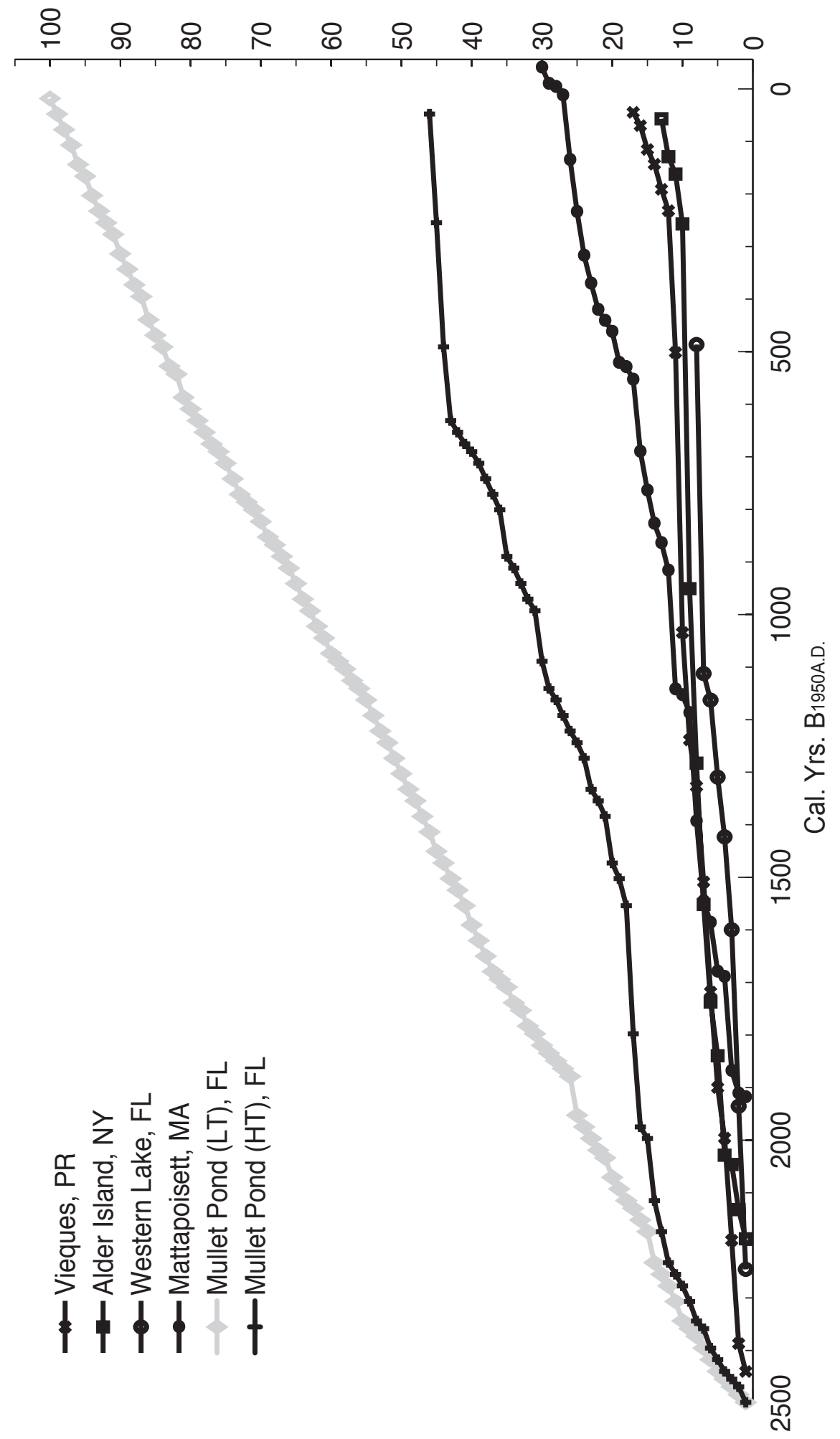


Table 1 - Dominant foraminifera in surface samples along depth transect

\begin{tabular}{|c|c|c|c|c|}
\hline Elevation $(\mathbf{m}) *$ & Distance $(\mathbf{k m})^{* *}$ & $\begin{array}{cl}\text { Ochlokonee Bay } \\
\\
\text { Start: } 29.9612^{\circ} \mathrm{N} \\
& 84.3852^{\circ} \mathrm{W} \\
& 0 \mathrm{~m} \mathrm{MSL} \\
\text { End: } & 29.9623^{\circ} \mathrm{N} \\
& 84.3806^{\circ} \mathrm{W} \\
& -2.3 \mathrm{~m} \mathrm{MSL}\end{array}$ & $\begin{array}{c}\text { Gulf of Mexico } \\
\text { Transect } \mathbf{1}^{\mathbf{a}} \\
\\
\text { Start: } 29.9281^{\circ} \mathrm{N} \\
84.4565^{\circ} \mathrm{W} \\
-0.8 \mathrm{~m} \mathrm{MSL} \\
\text { End: } 29.7554^{\circ} \mathrm{N} \\
\\
84.5108^{\circ} \mathrm{W} \\
-12.0 \mathrm{~m} \mathrm{MSL}\end{array}$ & 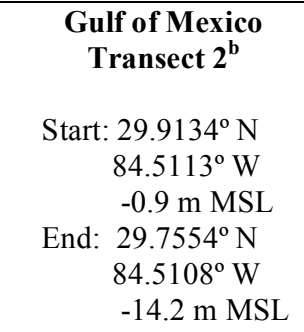 \\
\hline 3 to $-1 \mathrm{~m}$ & $+0.1^{\dagger}$ to $0.4 \mathrm{~km}$ & barren & barren & barren \\
\hline-1 to $-5 \mathrm{~m}$ & 0.4 to $5 \mathrm{~km}$ & $\begin{array}{l}\text { Ammobaculites dilatus } \\
\text { Ammobaculites exiguus } \\
\text { Ammobaculites salsum } \\
\text { Ammonia beccarri } \\
\text { Elphidium spp. } \\
\text { Milliammina fusca }\end{array}$ & $\begin{array}{l}\text { Ammonia beccari } \\
\text { Amphistegina spp. } \\
\text { Quinqueloculina spp. }\end{array}$ & $\begin{array}{l}\text { Ammonia beccarri } \\
\text { Amphistegina spp. } \\
\text { Rosalina spp. }\end{array}$ \\
\hline-5 to $-10 \mathrm{~m}$ & 5 to $16 \mathrm{~km}$ & & $\begin{array}{l}\text { Ammonia beccari } \\
\text { Amphistegina spp. } \\
\text { Astacolus crepidulus } \\
\text { Brizalina spathulata } \\
\text { Elphidium spp. } \\
\text { Fursenkoina fusiformis } \\
\text { planktonics } \\
\text { Quinqueloculina spp. } \\
\text { Rosalina spp. }\end{array}$ & $\begin{array}{l}\text { Ammobaculites exiguus } \\
\text { Ammonia beccari } \\
\text { Amphistegina spp. } \\
\text { Astacolus crepidulus } \\
\text { Brizalina spathulata } \\
\text { Buccella frigida } \\
\text { Elphidium spp. } \\
\text { Fursenkoina fusiformis } \\
\text { planktonics } \\
\text { Quinqueloculina spp. } \\
\text { Rosalina spp. }\end{array}$ \\
\hline-10 to $-15 \mathrm{~m}$ & 16 to $21 \mathrm{~km}$ & & $\begin{array}{l}\text { Ammonia spp. } \\
\text { Astacolus crepidulus } \\
\text { Cibicides lobatulus } \\
\text { Elphidium spp. } \\
\text { planktonics } \\
\text { Quinqueloculina spp. } \\
\text { Rosalina spp. }\end{array}$ & $\begin{array}{l}\text { Ammonia spp. } \\
\text { Astacolus crepidulus } \\
\text { Cibicides lobatulus } \\
\text { Elphidium spp. } \\
\text { planktonics } \\
\text { Quinqueloculina spp. } \\
\text { Rosalina spp. } \\
\text { Textularia agglutinans }\end{array}$ \\
\hline
\end{tabular}

* represents approximate elevation relative to MSL in meters

** represents approximate distance from MSL in kilometers

$\dagger$ inland dune ridge samples

${ }^{\text {a }}$ Transect 1 lies $12 \mathrm{~km}$ west of Bald Point

${ }^{\mathrm{b}}$ Transect 2 lies $16 \mathrm{~km}$ west of Bald Point 
Table 2 - Provenance of foraminiferal assemblages in core samples

\begin{tabular}{|c|c|c|c|c|}
\hline Core & Depth (cm) & $\begin{array}{l}\text { Approximate Cal. } \\
\text { Age (Yrs. B } 1950 \text { A.D.) }\end{array}$ & $\begin{array}{c}\text { Foraminifera } \\
\text { Assemblage } \\
\text { Source Depth (m } \\
\text { MSL) } \\
\end{array}$ & $\begin{array}{c}\text { Modern Shore-to- } \\
\text { Source Distance } \\
(\mathrm{km})\end{array}$ \\
\hline $\operatorname{MLT} 1^{a}$ & $0.5 \mathrm{~cm} \pm 0.5 \mathrm{~cm}$ & - 55 yrs. (2005 A.D.)* & Endemic** & $0.0 \mathrm{~km}$ \\
\hline $\operatorname{MLT} 1{ }^{b}$ & $2 \mathrm{~cm} \pm 1 \mathrm{~cm}$ & - 48 yrs. (1998 A.D.)* & -1 to $-5 \mathrm{~m}$ & 0.4 to $5 \mathrm{~km}$ \\
\hline $\operatorname{MLT} 1{ }^{b}$ & $4 \mathrm{~cm} \pm 0.5 \mathrm{~cm}$ & - 37 yrs. (1987 A.D.)* & $>-5 m$ & $>5 \mathrm{~km}$ \\
\hline $\mathrm{MLT}^{\mathrm{b}}$ & $12 \mathrm{~cm} \pm 0.5 \mathrm{~cm}$ & 6 yrs. (1944 A.D.)* & -1 to $-5 \mathrm{~m}$ & 0.4 to $5 \mathrm{~km}$ \\
\hline $\operatorname{MLT} 1^{b}$ & $16 \mathrm{~cm} \pm 1.0 \mathrm{~cm}$ & 29 yrs. (1921 A.D.)* & -5 to $-10 \mathrm{~m}$ & 5 to $16 \mathrm{~km}$ \\
\hline $\operatorname{MLT} 1^{b}$ & $20 \mathrm{~cm} \pm 1.0 \mathrm{~cm}$ & 53 yrs. (1897 A.D.)* & -5 to $-10 \mathrm{~m}$ & 5 to $16 \mathrm{~km}$ \\
\hline $\operatorname{MLT} 1^{b}$ & $34 \mathrm{~cm} \pm 2.0 \mathrm{~cm}$ & 140 yrs. (1810 A.D.)* & -1 to $-5 \mathrm{~m}$ & 0.4 to $5 \mathrm{~km}$ \\
\hline $\operatorname{MLT} 1^{b}$ & $39 \mathrm{~cm} \pm 0.5 \mathrm{~cm}$ & 172 yrs. (1778 A.D.)* & $>-5 \mathrm{~m}$ & $>5 \mathrm{~km}$ \\
\hline $\operatorname{MLT} 1^{a}$ & $52 \mathrm{~cm} \pm 0.5 \mathrm{~cm}$ & 326 yrs. & Endemic** & $0.0 \mathrm{~km}$ \\
\hline $\operatorname{MLT} 1^{\mathrm{a}}$ & $130 \mathrm{~cm} \pm 0.5 \mathrm{~cm}$ & 902 yrs. & Endemic** & $0.0 \mathrm{~km}$ \\
\hline $\operatorname{MLT} 1^{\mathrm{a}}$ & $234 \mathrm{~cm} \pm 0.5 \mathrm{~cm}$ & $1670 \mathrm{yrs}$. & Endemic $* *$ & $0.0 \mathrm{~km}$ \\
\hline $\operatorname{MLT} 1^{b}$ & $292 \mathrm{~cm} \pm 0.5 \mathrm{~cm}$ & 2098 yrs. & -5 to $-10 \mathrm{~m}$ & 5 to $16 \mathrm{~km}$ \\
\hline $\operatorname{MLT} 1^{a}$ & $340 \mathrm{~cm} \pm 0.5 \mathrm{~cm}$ & 2452 yrs. & Barren & NA \\
\hline $\operatorname{MLT} 1^{\mathrm{a}}$ & $427 \mathrm{~cm} \pm 0.5 \mathrm{~cm}$ & 3094 yrs. & Barren & NA \\
\hline $\operatorname{MLT} 1^{a}$ & $542 \mathrm{~cm} \pm 0.5 \mathrm{~cm}$ & 3943 yrs. & Barren & NA \\
\hline $\operatorname{MLT} 1^{a}$ & $601 \mathrm{~cm} \pm 0.5 \mathrm{~cm}$ & 4379 yrs. & Barren & NA \\
\hline $\operatorname{MLT} 2^{b}$ & $431 \mathrm{~cm} \pm 0.5 \mathrm{~cm}$ & 3667 yrs. & -5 to $-10 \mathrm{~m}$ & 5 to $16 \mathrm{~km}$ \\
\hline $\operatorname{MLT} 2^{b}$ & $504 \mathrm{~cm} \pm 0.5 \mathrm{~cm}$ & 4996 yrs. & -1 to $-5 \mathrm{~m}$ & 0.4 to $5 \mathrm{~km}$ \\
\hline $\operatorname{MLT} 2^{b}$ & $510 \mathrm{~cm} \pm 0.5 \mathrm{~cm}$ & 5105 yrs. & -1 to $-5 \mathrm{~m}$ & 0.4 to $5 \mathrm{~km}$ \\
\hline $\operatorname{MLT} 2^{b}$ & $531 \mathrm{~cm} \pm 0.5 \mathrm{~cm}$ & 5487 yrs. & -1 to $-5 \mathrm{~m}$ & 0.4 to $5 \mathrm{~km}$ \\
\hline $\operatorname{MLT} 2^{c}$ & $604 \mathrm{~cm} \pm 0.5 \mathrm{~cm}$ & 7740 yrs. & Barren & NA \\
\hline $\operatorname{MLT} 2^{d}$ & $617 \mathrm{~cm} \pm 0.5 \mathrm{~cm}$ & 8180 yrs. & Barren & NA \\
\hline
\end{tabular}

\footnotetext{
${ }^{\text {a }}$ Sampled away from coarse layers, ${ }^{\mathrm{b}}$ Sampled at coarse layer, ${ }^{\mathrm{c}}$ Sampled from peat, ${ }^{\mathrm{d}}$ Sampled from coarse basal sand unit

* Approximate age calculated from mean sample depth and polynomial, historic age model for upper MLT1

** Endemic, core top assemblage (-2.3 m MSL): Ammobaculites sp., Arenoparella mexicana, Jadammina macrescens, and Tiphotrocha comprimata.
} 


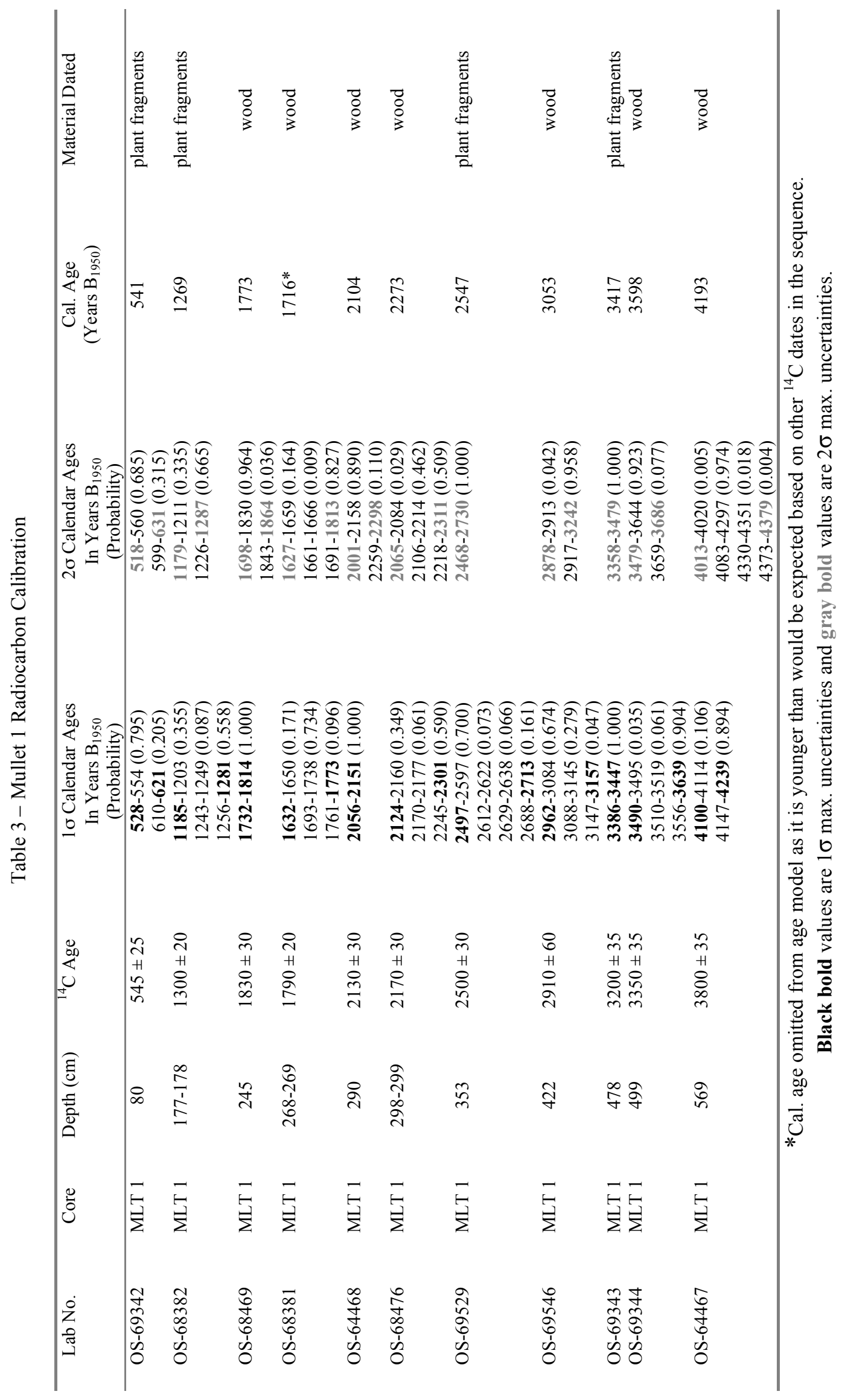




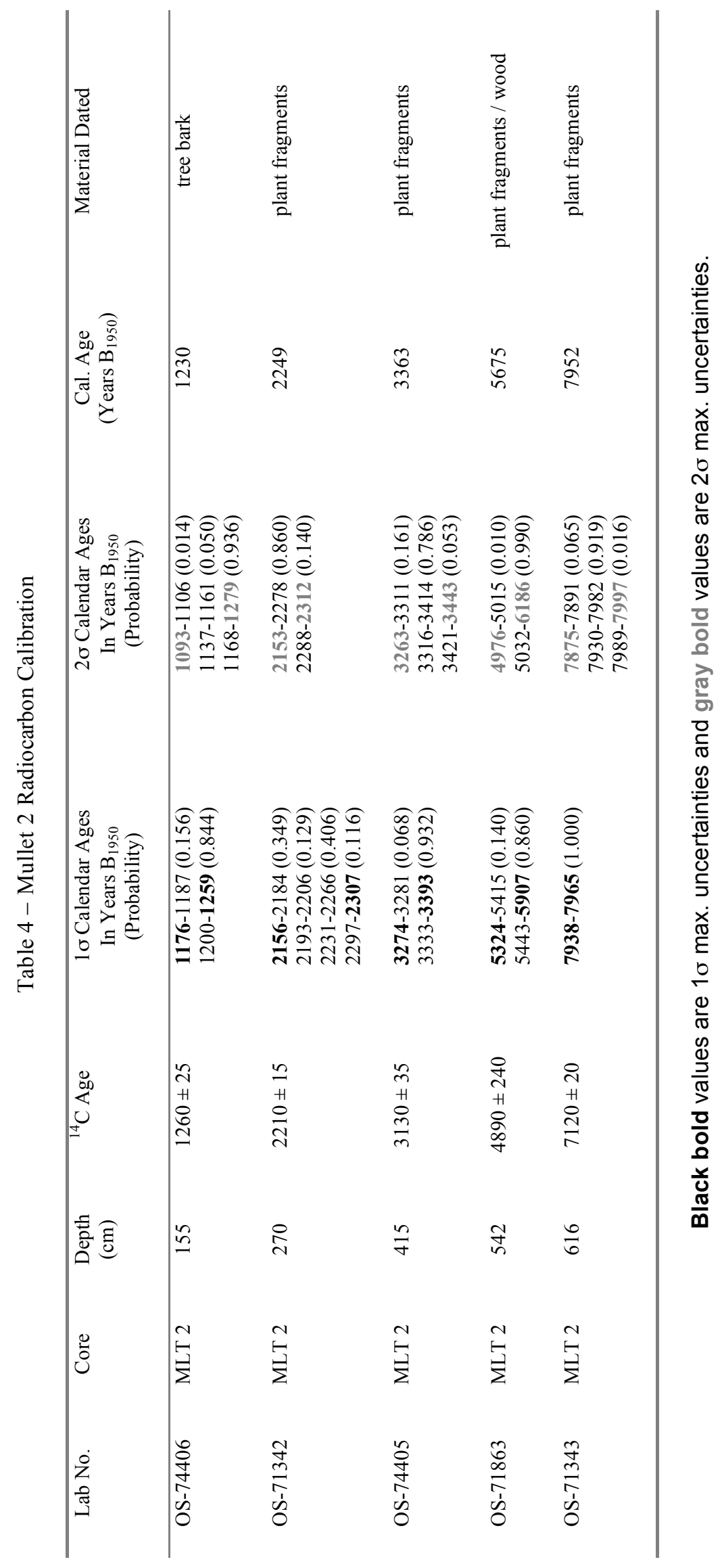




\title{
CHAPTER 2
}

\section{Gulf Coast hurricane activity and climate variability during the last half of the Holocene}

\begin{abstract}
The dominant timescales of variability in a 4500-year sediment-based storm chronology from the northeastern Gulf of Mexico are identified, and relationships between storm frequency and climate are explored. Changes in the frequency of large storm surge deposits in the record likely represent variability in the intensity distribution of hurricanes impacting the site during the late Holocene. The significant (99\% c.i.) variability at approximately 200 and 1000-year timescales that was detected in the storm record is shared by numerous Holocene climate records including reconstructions of Loop Current penetration into the Gulf of Mexico. Intense storm landfalls were most frequent around $3.7 \mathrm{ka}$, between 2.7 and $2.4 \mathrm{ka}$, and around $0.7 \mathrm{ka}$ when foraminiferal proxies of mixed layer depth indicate a more permanent residence of the Loop Current within the northeastern Gulf. Migrations of the Loop Current would exercise control over regional hurricane activity by changing the thermal structure of the upper ocean and influencing the role of storm-induced upwelling on hurricane intensification. Other factors that influenced regional and Atlantic-basin hurricane activity include the El Niño/Southern Oscillation and the position of the Inter-Tropical Convergence Zone. Many authors have suggested that bicentennial and millennial-scale climate variability may have been driven ultimately by changes in solar irradiance. Thus, low-frequency variability in Atlantic hurricane activity may be an expression of the climate system's response to exogenous forcing.
\end{abstract}




\section{Introduction}

Climate constrains the attributes of hurricane populations by dictating the range of environmental conditions that control the formation and life histories of tropical cyclones (Gray 1968, Emanuel 1987, Emanuel 1988, Emanuel et al. 2004). As facilitators of significant heat transport within and between the atmosphere and ocean, tropical cyclones (TCs) are also important, active components of Earth's climate system (Emanuel 2001, Emanuel 2002, Scott and Marotzke 2002, Sriver and Huber 2007, Hart et al. 2007, Korty et al. 2008, Sriver et al. 2008, Hart 2010). The manner in which TC activity and climate co-evolve has critical implications for society and is not well understood. Oscillating components of the climate system like the Madden-Julian Oscillation (MJO) (Klotzbach 2010), the Quasi-Biennial Oscillation (QBO), the El Niño Southern Oscillation (ENSO) (Gray 1984), the Atlantic Multidecadal Oscillation (AMO), and the Atlantic Meridional Mode (AMM) (Vimont and Kossin 2007) influence Atlantic hurricane activity on timescales ranging from the intraseasonal to the multidecadal. However, the brief observational record does not permit the identification and characterization of climate modes that may influence storm activity on centennial and longer timescales.

Sediment-based records of marine flooding caused by intense hurricane strikes at sites in the Western Atlantic, Caribbean and the Gulf of Mexico have extended local storm chronologies back as far as 5000 years, and many of these paleohurricane records contain centennial to millennial-scale clusters of storm surge deposits left by intense TCs (Liu and Fearn 1993, Liu and Fearn 2000, Donnelly et al. 2001a, Donnelly et al. 2001b, Liu and Fearn 2002, Lambert et al. 2003, Donnelly et al. 2004, Donnelly 2005, Donnelly and Woodruff 2007, Scileppi and Donnelly 2007, Liu and Fearn 2008, Lambert et al. 2008, Woodruff et al. 2008a, Boldt et al. 2010, Lane et al., In Review). Investigators have proposed that changes in prevailing storm tracks (Liu and Fearn 2000) or basin-wide variations in storm frequency and intensity (Donnelly and Woodruff 2007, Scileppi and Donnelly 2007, Boldt et al. 2010) may 
be responsible for alternating phases of high and low storm activity at the sites studied. A recent, decadally-resolved proxy record of hurricanes in the northeastern Gulf of Mexico exhibited statistically significant, low-frequency variability in the number of large storm surges impacting the northern Gulf Coast over the last five millennia (Lane et al. In Review). Here, we identify the dominant timescales of variability present in this paleohurricane record and, through comparison with paleoclimate records, examine the possible climatic controls on regional and Atlantic basin-wide hurricane activity during the last half of the Holocene.

\section{Study site and methods}

Mullet Pond, a brackish coastal pond that originated as a cover-collapse sinkhole, is located 350 meters from Apalachee Bay in the northeastern Gulf of Mexico (Figure 1). With wave action subdued by the shallow and gradually sloping bathymetry of Apalachee Bay and a tidal range of $70 \mathrm{~cm}$ (USEPA 1999, NOAA 2010), the site adjoins a low-energy coastline; however, these calm conditions are occasionally interrupted by extreme coastal flooding during hurricanes. Surges exceeding 4 meters MSL have been observed, and numerical modeling indicates surges in excess of 8 meters MSL, capable of penetrating tens of kilometers inland, are possible during plausible storm conditions (Ludlum 1963, Case 1986, Ho and Tracey 1975, Jelesnianski et al. 1992). Several meters of organic-rich, fine-grained sediments, which have steadily accumulated in the pond over the last five millennia, are punctuated by numerous sand layers deposited by the energetic surge and wave action of hurricanes. Two long cores ( $\sim 6 \mathrm{~m}$ each) were collected from the basin, and sand content ( $>63 \mu \mathrm{m}$ fraction) together with ${ }^{137} \mathrm{Cs},{ }^{210} \mathrm{~Pb}$, and AMS radiocarbon dating were used to identify and date historic hurricane and paleohurricane deposits. Using the sedimentary signatures of historic hurricanes to calibrate the record, Lane et al. (In Review) constructed a local storm chronology spanning the last 4500 years. While variations in the rate of total hurricane occurrence in the record were 
indistinguishable from what could be observed by random chance, the rate at which the largest storm layers were deposited exhibited statistically significant variability with time. This finding suggests that variations in hurricane activity along the Gulf Coast were driven by changes in intensity distribution rather than the overall frequency of storms.

Here, we develop a technique for identifying significant timescales of variability in a time series of discrete events and apply it to the chronology of large storm deposits in Mullet Pond. In Lane et al. (In Review), a sliding 157-year window was applied to the Mullet Pond storm chronology to construct a time series of local hurricane frequency. Periods of statistically significant deviations in hurricane frequency were identified by comparing the rate of storm occurrence calculated from the sediment record to the distribution of event frequencies in a large number $\left(10^{4}\right)$ of synthetic bootstrap records. In each bootstrap record, the occurrence of an event was modeled as a Poisson process with a constant, average frequency equal to that of the whole sedimentary record. In this paper, we repeat this process using window sizes and bootstrap record lengths ranging from 14.8 yrs. (twice the 7.4-year resolution of the record) up to 2250 yrs. (half the length of the record) at 7.4-year intervals. The resulting maximum and minimum values of hurricane frequency (normalized to storms per century) calculated from the sediment record were then plotted as functions of timescale (twice the window size used) together with the bootstrapgenerated $95^{\text {th }}$ and $99^{\text {th }}$ percentile confidence intervals (Figure 2).

\section{Results}

Significant deviations (at the $99^{\text {th }}$ percent confidence interval) from the mean storm rate of 2.4 hurricanes per century were detected using window sizes of 85 and 125 years as well as any window size larger than 200 years (Figure 2). These window sizes correspond to timescales (twice the window size, or the period of a complete cycle) of 170, 250 and $>400$ years, respectively. The lower-frequency 
variability was most significant, however, in the 800 to 1200 -year band with peak significance $(\mathrm{p}<0.001)$ near the millennial timescale. Statistically significant $(99 \%$ c.i.) lulls in storm activity were found to occur on $\sim 250$ to 1800 -year timescales, with significance also peaking in the 800 to 1200 -year band.

These results indicate the clustering of hurricane layers in the sediments of Mullet Pond is very unlikely to have resulted from a random process. Therefore, the null hypothesis that storm climate was stationary over the last five millennia is inadequate, and patterns in the sediment record likely did not result merely from stochastic encounters of storms with this particular location. Moreover, our analysis identifies millennial-scale intervals with significantly elevated storm frequency $(\sim 5$ hurricanes per century, more than twice the record average) as well as millennialscale intervals with significantly depressed storm frequency $(<1$ hurricane per century, approximately one third the record average). The analysis also identified 200 -year intervals with significantly elevated storm frequency ( $\sim .5$ hurricanes per century, or three times the record average); however, this method is not able to identify significant lulls in hurricane activity on this timescale because gaps of up to 210 years between successive storms are possible in the least active five percent of the Poisson bootstrap samples. The site experienced the highest frequency of large storms around $3.7 \mathrm{ka}, 2.7$ to $2.4 \mathrm{ka}$, and around $0.7 \mathrm{ka}$. Large storm deposits were rare between 1.9 and $1.6 \mathrm{ka}$ and after $0.6 \mathrm{ka}$.

Though the $\sim 200$-year active intervals exhibited higher storm frequency than the active millennial periods, the active 1000-year intervals are considered more significant by our method because the variance among the modeled bootstrap storm rates decreases as the period of time considered increases. Under a stationary storm climate, hurricane frequency is expected to vary less from one millennium to the next than from one century to the next. The result implies that storm frequency in the northeastern Gulf of Mexico is dominated by millennial-scale variability but also exhibits significant bicentennial variability. 


\section{Discussion}

\subsection{Climatic controls on Gulf of Mexico hurricane frequency during the Late Holocene}

\subsubsection{Sea surface temperature}

TCs quickly strengthen or weaken in response to changes in their environment (Emanuel et al. 2004), so the variability in storm frequency at Mullet Pond results most directly from variations in regional TC activity, which in turn may reflect largerscale or basin-wide activity. The most significant variability in storm activity occurred on long $\left(>10^{2}\right.$ yrs.) timescales, so the climatic forcings responsible for the variability are likely not confined to the northern Gulf of Mexico. A 1500-year compilation of sediment-based records from the Caribbean, Gulf, and Eastern U.S. (Figure 1, Figure 3c) is generally congruent with the Mullet Pond record, which indicates hurricane frequency increased after $1.5 \mathrm{ka}$, peaked between $0.7-0.6 \mathrm{ka}$, and then declined abruptly thereafter (Figure 3d). Similarities among North Atlantic paleohurricane records have been previously noted by other authors and have been

offered as evidence for temporally coherent, basin-wide variability in hurricane activity (Scileppi and Donnelly 2007). Changes in ocean temperature during the late Holocene may provide one possible mechanism capable of coordinating the variability identified in Atlantic basin paleohurricane records.

Tropical cyclones require sufficiently warm sea surface temperatures (SSTs) for their formation and intensification, and SST has been used to forecast seasonal and longer-term TC activity. SST has also been used to reconstruct past storm climate. For example, a statistical model developed by Mann et al. (2009) to reconstruct basin-wide Atlantic hurricane landfalls during the last 1.5 ka relied, in part, on tropical Atlantic SST as a predictor (Figure 1, Figure 3a). Modern Gulf of Mexico SSTs have been shown to be highly correlated with those in the Main 
Development Region (MDR) of the tropical North Atlantic (Enfield et al. 2001, Poore et al. 2009), and paleo-SST records suggest that this correspondence may have held over the past $1.5 \mathrm{ka}$. A 1400-year foraminiferal $\mathrm{Mg} / \mathrm{Ca}$-based SST reconstruction from the Pigmy Basin in the northern Gulf of Mexico (Figure 1, Figure 3b) indicates an abrupt, sustained cooling of $\sim 2^{\circ} \mathrm{C}$ occurred around $1 \mathrm{ka}$ (Richey et al. 2007), while other proxy records of SSTs in the western Atlantic and Caribbean also suggest cooling occurred near $1 \mathrm{ka}$ (Keigwin 1996, Nyberg et al. 2002). Similarly, the statistical model partially based on MDR SSTs suggests that Atlantic hurricane activity peaked with SST around 1 ka before declining markedly around $0.85 \mathrm{ka}$.

Variability in Gulf (Figure 3d) and basin-wide hurricane landfalls (Figure 3c) does not seem to reflect changes in SST during the last 1500 years (Figure 3b), which is consistent with the finding that SSTs as warm as modern were not required to support intervals of frequent, intense hurricanes in the Caribbean over the last $5 \mathrm{ka}$ (Donnelly and Woodruff 2007). Other factors must have influenced regional and basin-wide hurricane activity during the late Holocene. The temperature of the ocean's surface is only a rough measure of the heat content available to developing tropical cyclones, and changes in the thermal structure of the upper ocean, which might not be accompanied by changes in SST, may influence the intensity distribution of TCs. The northeastern Gulf of Mexico experiences pronounced variability in ocean thermal structure due to the influence of the Loop Current.

\subsubsection{Loop Current variability}

The Loop Current (LC) is the portion of the North Atlantic Western Boundary Current that flows from the Caribbean, through the Yucatan Channel, into the Gulf of Mexico and exits through the Florida Strait to join the Gulf Stream (Lund and Curry 2004). The deep, warm waters of the LC occasionally meander northward into the eastern Gulf of Mexico and make a clockwise loop before exiting (Figure 1). These meanders occasionally break off from the flow to form anti-cyclonic Warm Core 
Eddies that propagate westward as they dissipate. The frequency of eddy formation and the extent to which the LC penetrates into the Gulf is thought to be aperiodic on sub-decadal timescales; however, lower-frequency variations in wind stress may drive periodicities on longer timescales (Sturges and Leben 2000).

The relative abundance of the foraminifer Globigerinoides sacculifer in marine cores taken from the Pigmy Basin in the northern Gulf has been offered as a proxy for the extent and/or frequency of LC incursions into the Gulf (Poore et al. 2004, Poore, In Press). Though not contemporaneous with SST cooling, the significant decline in hurricane frequency that occurred around 600 cal. yrs. B.P. was accompanied by a decrease in the relative abundance of G. sacculifer (Figure 1, Figure 3e) (Richey et al. 2007). This implies reduced advection of Caribbean surface waters into the Gulf of Mexico and a shoaling of the thermocline caused by a more southerly residence of the LC (Poore et al. 2004). This change in regional hydrography would lower the ocean heat content available to tropical cyclones in the northeastern Gulf without necessarily lowering the SSTs.

Although SSTs in the Gulf are warm enough $\left(\geq 26^{\circ} \mathrm{C}\right)$ to support tropical cyclone development in the summer months, the mixed layer of warm surface waters is quite shallow with the $26^{\circ} \mathrm{C}$ isotherm typically only $30-40 \mathrm{~m}$ below the surface (Chouinard et al. 1997). As storms intensify, they quickly mix up cooler waters from below, and this process limits further storm development (Emanuel et al. 2004). In the LC and its associated eddies, however, the $26^{\circ} \mathrm{C}$ isotherm can be as deep as $200 \mathrm{~m}$ below the surface providing several times more available energy to developing cyclones by limiting the role of storm-induced upwelling (Goni and Trinanes 2003).

While summertime SSTs are nearly homogenous in the Gulf, the spatial distribution of historic Gulf hurricane intensities is not (Cooper et al. 1992). Some of the most severe, historic Gulf hurricanes achieved their exceptional intensities while interacting with the LC or its associated Warm Core Eddies (Shay et al. 2000, Hong et al. 2000). Longer records of G. sacculifer relative abundance support the connection between LC penetration and storm frequency in the Mullet Pond record 
over the last five millennia. G. sacculifer abundance in a large box core taken from the Pigmy Basin suggests the LC resided further north until about 2.7 ka when it abruptly shifted south. While the general features of the two records are congruent, differences in timing between this G. sacculifer record and the Mullet Pond hurricane record likely result from mechanical stretching or compression of the box core during retrieval, but here we have resisted the urge to tune the record (Figure 4a,b) (Poore, In Press). Such modifications of the core may explain why the longer, but lower resolution ( 30-year) G. sacculifer abundance record presented in Poore (In Press) differs somewhat in the overlapping, 1400-year record period spanned by the higher resolution ( 10-year) G. sacculifer abundance record of Richey et al. (2007). These records were constructed from two different cores and, while taken from neighboring locations in the Pigmy Basin, apparent differences may have resulted from the different resolutions and independent age models of the records (Figure 3e, 4b).

Reconstructions of LC penetration into the eastern Gulf of Mexico during the Holocene have been found to exhibit significant centennial ( 200 yrs.) and millennial-scale variability (Poore et al. 2003, Poore, In Press). Records of ocean surface density based on foraminiferal $\partial^{18} \mathrm{O}$ from the Pigmy Basin (Richey et al. 2007) and near the Dry Tortugas (Lund and Curry 2004) indicate that the structure of the upper ocean has also varied on these timescales, with relatively high (less negative) values of foraminiferal $\partial^{18} \mathrm{O}$ (implying higher density, cooler and/or more saline surface waters) corresponding to periods of decreased LC influence and fewer storms at Mullet Pond. Regional changes in surface hydrography may, in part, drive changes in the intensity distribution of hurricanes affecting Mullet Pond. Given the association of the LC with the most extreme historic hurricanes, long-term changes in the extent of the LC could also provide support for and explain previously postulated, millennial-scale catastrophic hurricane regimes along the Gulf coast (Liu and Fearn 2000). Though the timing of the active and inactive intervals in the Mullet reconstruction differs from that originally proposed by Liu and Fearn, age model adjustments that account for marine radiocarbon deficits have brought the record 
more in line with the Mullet hurricane record and reconstructions of LC position (Aharon and Lambert 2009). With these age corrections, recent but shorter ( last 0.6 ka) paleohurricane records from the Gulf Coast display a brief period of frequent, intense hurricanes followed by a prolonged decline in catastrophic storm frequency associated with the beginning of the Little Ice Age - the same pattern observed in the Mullet Pond record (Liu et al. 2008, Lambert et al. 2008).

The low-frequency migrations of the $\mathrm{LC}$ are thought to be driven by variations in the position of the Inter-Tropical Convergence Zone (ITCZ) and associated changes in wind stress and wind-driven ocean circulation (Poore et al. 2003, Poore et al. 2004, Richey et al. 2007, Poore, In Press), which, in turn, may also impact basinwide Atlantic hurricane activity. The recent decline in both the Loop Current's influence and storm frequency in the Gulf may have both been related to a southward shift in the ITCZ that occurred around 600 cal. yrs. B.P. (Peterson et al. 1991, Haug et al. 2001, Richey et al. 2007). In this way, the low-frequency migrations of the LC not only provide a regional mechanism for variability in the intensity distribution of TCs on centennial and millennial timescales but may also reflect the favorability of the North Atlantic as a whole for hurricane formation and development.

\subsubsection{ENSO variability}

The El Niño Southern Oscillation (ENSO) has been shown to strongly impact Atlantic tropical cyclone activity on the interannual timescale by affecting the vertical wind profile and atmospheric stability over the basin. During warm phases of the ENSO (El Niño), wind shear increases over the tropical Atlantic thereby making conditions less favorable for the development of tropical cyclones. Conversely, wind shear is lessened during La Niña events, thus providing more favorable conditions in the Atlantic (Goldenberg and Shapiro 1996). El Niño events also warm the troposphere over the tropical Atlantic thereby reducing the sea-to-atmosphere disequilibrium, increasing column stability, and creating less favorable conditions for 
hurricane development (Tang and Neelin 2004). Centennial-to-millennial scale variability in the ENSO has been found to correspond with paleohurricane regimes in the Caribbean (Donnelly and Woodruff 2007), with intervals of more frequent El Niño events inferred from the Laguna Pallcacocha record (Moy et al. 2002) coinciding with periods of fewer intense hurricanes at Vieques.

Recently published proxy records have revised our knowledge of ENSO variability during the Holocene (Conroy et al. 2008, Makou et al. 2010, Conroy et al. 2010, Marchitto et al. 2010). A lake level record from the Galapágos suggests El Niño frequency increased during the late Holocene and peaked between 2.0 and 1.5 ka (Figure 4c) (Conroy et al. 2008), which is coincident with very low hurricane frequency at Mullet Pond. Similarly, the beginning of the Medieval Warm Period (about 1.2 to $0.8 \mathrm{ka}$ ) was characterized by high hurricane activity and low El Niño frequency. However, El Niño frequency and Gulf hurricane frequency seem to covary after about $0.8 \mathrm{ka}$, with both reaching relatively high levels around $0.6 \mathrm{ka}$ and both declining precipitously by $0.5 \mathrm{ka}$ (Figure $4 \mathrm{a}, \mathrm{c}$ ). Sterol-based records from the Peru Margin, which are capable of differentiating the cool and warm phases of the ENSO, suggest that intervals of high El Niño frequency were accompanied by increased La Niña occurrence as well (Makou et al. 2010). These records imply that overall ENSO variability increased after $2.0 \mathrm{ka}$ and peaked around $0.6 \mathrm{ka}$ before declining abruptly.

Using interannual variability as an analogy, one might expect a simultaneous increase in both El Niño and La Niña to drive greater year-to-year variance in Atlantic storm activity without necessarily affecting hurricane frequency in the long term. However, long-term Gulf hurricane frequency apparently was affected. While the frequency of cool and warm phases co-varied during the last five millennia, the mean state of the equatorial Pacific also varied. A reconstruction of the Pacific equatorial zonal gradient suggests a more La Nina-like mean state persisted between 1.2 and $0.7 \mathrm{ka}$ and then the gradient relaxed after about $0.4 \mathrm{ka}$ (Conroy et al. 2010). Changes in the mean state of the Pacific may, in part, explain the relatively high 
levels of Atlantic hurricane activity during the Medieval Warm Period and less frequent storms during the Little Ice Age.

On longer than interannual timescales, basin-wide hurricane frequency likely reflects the warmth of the tropical North Atlantic basin relative to neighboring ocean basins. Differential warming of the tropical North Atlantic relative to other ocean basins may have contributed to observed increases in Atlantic hurricane activity during the $20^{\text {th }}$ Century (Latif et al. 2007, Knutson et al. 2008, Zhao et al. 2009). Active intervals in the hurricane record tend to correspond to warm periods in the Atlantic (Keigwin 1996, Nyberg et al. 2002) coupled with relatively cool periods (typically La Nina-like conditions) in the tropical Eastern Pacific (Figure 4a,c,d). ENSO state may simply be a good approximation for the warmth of the tropical North Atlantic relative to the tropical East Pacific. However, El Niño events and Atlantic hurricanes can both increase in frequency if the tropical Atlantic is warmer than the tropical East Pacific in the long term (for example, 0.8 to $0.6 \mathrm{ka}$ ) and, conversely, intervals with fewer El Niño events can also exhibit lower Atlantic storm frequency if the tropical Atlantic has cooled relative to the tropical East Pacific (for example, post$0.6 \mathrm{ka}$ ). An ocean basin that is warm relative to its surroundings is the most likely region for atmospheric ascent and sufficient potential intensity, the two basic requirements for TC development, to coincide.

\subsubsection{Relative SST - The ITCZ, AMO and AMM}

In the same way that the ENSO is a measure of the warmth of the tropical North Atlantic relative to the tropical East Pacific, the Atlantic Multi-decadal Oscillation (AMO) reflects the warmth of the tropical North Atlantic relative to the tropical South Atlantic. Multi-decadal variability in north Atlantic climate has been documented in the historic record (Schlesinger and Ramankutty 1994, Zhang et al. 2007), climate models (Delworth and Mann 2000), and in paleoclimate reconstructions (Gray et al. 2004, Grosfeld et al. 2007, Hetzinger et al. 2008). The 
AMO, which is thought to have a quasi-periodic cyclicity ranging from 40 to 90 years, may be responsible for some of the variability in basin-wide Atlantic hurricane activity during the $20^{\text {th }}$ century (Goldenberg et al. 2001). However, the persistence and even existence of the AMO as a durable mode of internal climate variability in the tropical Atlantic has been called into question (Mann and Emanuel 2006, Saenger et al. 2009).

That said, significant (at the $99 \%$ c.i.) variability near $50^{-1} \mathrm{yrs}^{-1}$ was detected in the time series of inorganic content in Mullet Pond (Lane et al. In Review). Strong multi-decadal variability in sediment composition has also been identified in lake cores from the Yucatan, and this is thought to reflect lake level changes driven by variations in the evaporation to precipitation ratio (E/P) (Figure 1) (Hodell et al. 2001). The AMO is known to affect rainfall and lake levels in Florida, with the positive (negative), warm (cold) phase of the AMO accompanied by increased (decreased) precipitation (Enfield et al. 2001, Curtis 2008). These records suggest that multi-decadal variability has been a persistent feature of late Holocene climate in the Gulf region.

Historic records indicate that hurricane landfall frequency along the Gulf Coast is influenced by the phase of the AMO, with more storms striking during the positive, warmer state (Poore et al. 2009). However, significant, multi-decadal variability in the frequency of storm layer deposition was not detected in the Mullet Pond record. The lack of a detectable, multi-decadal signal in storm deposition at Mullet Pond does not necessarily imply that the AMO has not influenced landfall frequency at the site or in the basin during the last few millennia. Rather, it suggests that any changes in single-site landfall probability driven by the AMO were too small and too short-lived to be detected in the record. Similarly, any very recent, secular trend in hurricane landfall frequency would likely not be detectable in a single site sedimentary record.

De-convolving the relative contributions of SST, the LC, the ENSO, and the AMO to the variability in the paleohurricane record is, at best, challenging and, at 
worst, counterproductive. All of these components are dynamically linked, and no single factor influences storm activity in isolation. The ENSO, for example, may have driven some of the variability in Atlantic hurricane activity over the last 5000 years, but a modeling study found that even a permanent El Niño-like state could not on its own account for the extent and duration of late Holocene hurricane "droughts" in the Caribbean (Woodruff et al. 2008).

The position of the ITCZ, which is dynamically linked to all previously discussed factors, may supply the best combined measure of TC favorability in the North Atlantic basin. When the northward displacement of the ITCZ is larger (smaller), North Atlantic SSTs tend to be warmer (cooler), penetration of the LC is greater (smaller), the eastern tropical Pacific tends to be cooler (more La Niña-like), and the AMO tends to be in its positive/warm (negative/cool) phase (Curtis and Hastenrath 1995, Saravanan and Chang 2000, Haug et al. 2001, Chiang et al. 2002, Poore et al. 2003). The Atlantic Meridional Mode (AMM), which has been useful in explaining higher-frequency variability in the instrumental record of Atlantic hurricanes (Vimont and Kossin 2007), supplies a useful analogy for how ITCZ position may drive a suite of thermodynamic and circulation changes that cooperate in their influence over TC formation and development. For example, northward (southward) drift of the ITCZ, which essentially implies a relative warming (cooling) of the North Atlantic, would tend to increase (decrease) SSTs, latent heat flux, lowlevel convergence and vorticity while decreasing (increasing) sea level pressure, static stability and vertical wind shear over the tropical North Atlantic. Such collusion of storm-relevant variables on bicentennial and millennial timescales may drive the high amplitude variations in storm activity evidenced in the paleohurricane record. 


\subsection{Possible solar forcing of late Holocene tropical climate variability and Atlantic hurricane activity}

Many Holocene paleoclimate records share the significant bicentennial and millennial-scale variability present in the Mullet Pond hurricane record. Significant variability on $\sim 200$-year and $\sim 1000$-year timescales has been detected in Gulf region proxy records of SST (Richey et al. 2007, Poore 2008), Loop Current residence (Poore et al. 2003, Richey et al. 2007, Poore In Press), ocean surface density $\left(\partial^{18} \mathrm{O}\right.$ ) (Lund and Curry 2004), and lake levels in the Yucatan (Hodell et al. 2001). Similar periodicities have been found in more distant records including upwelling in the Cariaco Basin north of Venezuela (Peterson et al. 1991), ice-rafted debris transported by North Atlantic sea ice (Bond et al. 2001), and wind-blown sea salt preserved in Greenland ice indicative of Icelandic Low strength and high-latitude storminess (O'Brien et al. 1995, Meeker and Mayewski 2002). Centennial-to-millennial scale variability is common in paleoclimate records from the tropical Pacific as well (Makou et al. 2010, Conroy et al. 2010, Marchitto et al. 2010).

Variability on these timescales is also a feature common to records of the cosmogenic nuclides ${ }^{14} \mathrm{C}$ and ${ }^{10} \mathrm{Be}$, which have been used to infer changes in solar insolation through time, and this has led some authors to suggest that variability in many Holocene climate records was partially driven by cyclic changes in solar irradiance (Peterson et al. 1991, Bond et al. 2001, Hodell et al. 2001, Lund and Curry 2004, Richey et al. 2007, Makou et al. 2010). However, proposed sun-driven climate variability has been controversial because the magnitude of changes in solar insolation —only a fraction of one percent—is thought to be much smaller than what would be required to produce the observed variability in the climate system (Marchitto et al. 2010).

Minute changes in solar irradiance associated with the sun's 11-year sunspot cycle have purportedly driven decadal variability in instrumental (Jagger and Elsner 2008, Elsner and Jagger 2008) and reconstructed (Nyberg et al 2007) Atlantic 
hurricane activity. The proposed mechanism for this variability involves changes in the potential intensity of hurricanes through modulation of the thermodynamic efficiency of tropical cyclones. This is thought to be achieved primarily through changes in lower stratospheric, or "output," temperature. Variability in the ultraviolet portion of the sun's irradiance, which is primarily absorbed by ozone and re-radiated as heat in the lower stratosphere, is estimated to be an order of magnitude larger than changes in total solar irradiance (Lean 2000, Meehl et al. 2009). In this model, periods of lower solar irradiance correspond to decreased ultraviolet absorption by ozone, cooler stratospheric temperatures, higher thermodynamic efficiencies for TCs and a shift toward higher intensity storms overall.

As with multi-decadal variability in the Mullet Pond storm record, any change in landfall probability on a decadal timescale cannot be detected in this single-site sediment record, but the dominance of bicentennial and millennial timescales in the storm record suggests that solar forcing may ultimately be responsible for lowfrequency variability. On these longer timescales, however, increased solar irradiance appears to be associated with greater storm frequency and the factors that favor it - warmer SSTs (Richey et al. 2007, Nyberg et al. 2002), greater penetration of the LC (Poore et al. 2003), more La Niña-like conditions in the Pacific (Marchitto et al. 2010), and a more northward position of the ITCZ (Peterson et al. 1991, Poore et al. 2004). This implies that, at least on centennial and longer timescales, a positive relationship exists between solar irradiance and North Atlantic hurricane activity. Low-frequency solar influence over TC activity may be exercised through large-scale changes in atmospheric and wind-driven ocean circulation rather than through the modulation of TC thermodynamic efficiency.

Periods of greater solar irradiance would be expected to initially drive differential warming of the lower stratosphere relative to the surface. The thermodynamic efficiency of the Hadley circulation itself, analogous to the hurricane Carnot engine, would be decreased thereby weakening the strength of the trade winds and causing the ITCZ (and, hence, the LC) to migrate. As with the AMM, this 
process could drive changes in a suite of variables collaborating to create more favorable conditions for Atlantic hurricane formation and development. By enhancing the meridional overturning circulation through vigorous mixing of the tropical ocean (Emanuel 2001, Emanuel 2002, Scott and Marotzke 2002, Sriver and Huber 2007, Korty et al. 2008, Sriver et al. 2008), hurricanes may help broadcast the initial, exogenous forcing to the rest of the climate system.

\section{Conclusions}

The frequency of severe hurricanes along the northern Gulf coast exhibited significant bicentennial and millennial-scale variability during the late Holocene, and low-frequency migrations of the LC likely served as the regional mechanism for changes in the intensity distribution of TCs affecting Mullet Pond. As part of the ocean's larger, wind-driven circulation, the LC's residence is likely governed by atmospheric circulation, and records of G.sacculifer abundance in the northern Gulf suggest that LC penetration is higher (lower) when the ITCZ is situated in a more northerly (southerly) position. In this way, the position of the ITCZ, which is correlated with a number of factors influencing $\mathrm{TC}$ formation and development, may synchronize severe hurricane activity in the Gulf with hurricane activity in the rest of the Atlantic. On longer than interannual timescales, ENSO variability or Pacific mean thermal state may serve as a measure of the SST difference between the tropical Atlantic and neighboring ocean basins. Changes in this differential warmth would affect Atlantic hurricane activity by modulating wind shear and atmospheric ascent over the basin. Low-frequency variability in hurricane activity may ultimately be driven by changes in solar irradiance that exercise control over TCs through modifications to atmospheric and ocean circulation. 


\section{Acknowledgments}

Funding for this research was supported by the Paleo Perspectives on Climate Change (P2C2) program at the National Science Foundation (OCE-0903020) and the Coastal Ocean Institute at Woods Hole Oceanographic Institution. J. Woodruff and P. Donnelly provided assistance with fieldwork and M. Gomes, S. Moret and S. Zipper assisted with laboratory analysis. The Florida State University Marine Laboratory provided lodging during fieldwork. This research was completed during an American Meteorological Society Graduate Fellowship, National Science Foundation Graduate Fellowship and Coastal Ocean Institute Fellowship.

\section{References}

Aharon, P., Lambert, W.J., 2009. Radiocarbon deficiencies of US Gulf Coast lakes compromise paleo-hurricane records. Quaternary Research. 71. pp. 266-270.

Boldt, K.V., Lane, P., Woodruff, J.D., Donnelly, J.P., 2010. Calibrating a sedimentary record of overwash from Southeastern New England using modeled historic hurricane surges. Marine Geology. 275. pp. 127-139.

Bond, G.G., Kromer, B., Beer, J., Muscheler, R., Evans, M., Showers, W., Hoffmann, S., Lotti Bond, R., Hajdas, I., Bonani, G., 2001. Persistent Solar Influence on North Atlantic Climate During the Holocene. Science. 294, 2130-2136.

Case, R. A., 1986. Atlantic Hurricane Season of 1985. Monthly Weather Review. 114, $1390-1405$.

Chiang, J.C.H., Kushnir, Y., Giannini, A., 2002. Deconstructing Atlantic Intertropical Convergence Zone variability: influence of the local cross-equatorial sea surface temperature gradient and remote forcing from the eastern equatorial Pacific. Journal of Geophysical Research. 107(D1,4004), 10.1029/2000JD000307.

Chouinard, L.E., Liu, C., Cooper, C.K., 1997. Model for severity of hurricanes in the Gulf of Mexico. Journal of Waterways, Harbour, and Coastal Engineering of the American Society of Civil Engineering. May/June 1997, 120-129.

Conroy, J.L., Overpeck, J.T., Cole, J.E., Shanahan, T.M., Steinitz-Kannan, M., 2008. Holocene changes in eastern tropical Pacific climate inferred from a Galapágos lake sediment record. Quaternary Science Reviews. 27. pp. 1166-1180.

Conroy, J.L., Overpeck, J.T., Cole, J.E., 2010. El Niño/Southern Oscillation and changes in the zonal gradient of tropical Pacific sea surface temperature over the last 1.2ka. Science Pages. 18(1). pp. 32-34. 
Cooper, C.K., 1992. A preliminary case for the existence of hurricane alleys in the Gulf of Mexico. Proceedings of the $24^{\text {th }}$ annual offshore technology conference. OTC6831. OTC: Houston, TX. pp. 213-222.

Curtis, S., Hastenrath, S., 1995. Forcing of anomalous sea-surface temperature evolution in the tropical Atlantic during Pacific warm events. Journal of Geophysical Research-Oceans. 100, 15835-15847.

Curtis, S., 2008. The Atlantic multidecadal oscillation and extreme daily precipitation over the United States and Mexico during the hurricane season. Climate Dynamics. $30,343-351$.

Delworth, T.L, Mann, M.E., 2000. Observed and simulated multidecadal variability in the Northern Hemisphere. Climate Dynamics. 16, 661-676.

Donnelly, J.P., S.S. Bryant, J. Butler, J. Dowling, L. Fan, N. Hausmann, P. Newby, B. Shuman, J. Stern, K. Westover, Webb III., T., 2001. A 700-year sedimentary record of intense hurricane landfalls in southern New England. Geological Society of America Bulletin. 113, 714-727.

Donnelly, J.P., S. Roll, M. Wengren, J. Butler, R. Lederer, Webb III, T., 2001. Sedimentary evidence of intense hurricane strikes from New Jersey. Geology. 29, 615-618.

Donnelly, J.P., J. Butler, S. Roll, Micah Wengren, Webb III, T., 2004. A backbarrier overwash record of intense storms from Brigantine, New Jersey. Marine Geology. 210, 107-121.

Donnelly, J.P., 2005. Evidence of Past Intense Tropical Cyclones from Backbarrier Salt Pond Sediments: A Case Study from Isla de Culebrita, Puerto Rico, USA. Journal of Coastal Research. SI42, 201-210.

Donnelly, J.P., Woodruff, J.D., 2007. Intense hurricane activity over the past 5,000 years controlled by El Niño and the West African monsoon. Nature. 447, 465-468.

Elsner, J.B., Jagger, T.H., 2008. United States and Caribbean tropical cyclone activity related to the solar cycle. Geophysical Research Letters. 35.

doi:10.1029/2008GL034431.

Emanuel, K.A., 1987. The dependence of hurricane intensity on climate. Nature. 326(6112), 483-485.

Emanuel, K.A., 1988. The maximum intensity of hurricanes. Journal of the Atmospheric Sciences. 45(7). 1143-1155. 
Emanuel, K.A., 2001. The contribution of tropical cyclones to the oceans' meridional heat transport. Journal of Geophysical Research. 106, 14771-14782.

Emanuel, K.A., 2002. A simple model of multiple climate regimes. Journal of Geophysical Research. 107(D9). 4077. doi: 10.1029/2001JD001002.

Emanuel, K.A., DesAutels, C., Holloway, C., Korty, R., 2004. Environmental Control of Tropical Cyclone Intensity. Journal of the Atmospheric Sciences. 61, 843-858.

Enfield, D.B., Mestas-Nuñez, A.M., Trimble, P.J., 2001. The Atlantic multidecadal oscillation and its relation to rainfall and river flows in the continental United States. Geophysical Research Letters. 28(10), 2077-2080.

Goldenberg, S.B., Shapiro, L.J., 1996. Physical mechanisms for the association of El Niño and West African rainfall with Atlantic major hurricane activity. Journal of Climate. 9, 1169-1187.

Goni, G.J., Trinanes, J.A., 2003. Ocean thermal structure monitoring could aid in the intensity forecast of tropical cyclones. Eos. 84(51), 573-576.

Gray, W. M., 1968. Global view of the origin of tropical disturbances and storms. Monthly Weather Review. 96, 669-700.

Gray, W.M., 1984. Atlantic seasonal hurricane frequency. Part I: El Niño and $30 \mathrm{mb}$ Quasi-Biennial Oscillation influences. Monthly Weather Review. 112. pp. 1649-1668.

Gray, S.T., Graumlich, L.J., Betancourt, J.L., Pederson, G.T., 2004. A tree-ring based reconstruction of the Atlantic Multidecadal Oscillation since 1567 A.D. Geophysical Research Letters. 31(L12205), doi: 10.1029/2004GL019932.

Grosfeld, K., Lohmann, G., Rimbu, N., Fraedrich, K., Lunkeit, F., 2007. Atmospheric multidecadal variations in the North Atlantic realm: proxy data, observations and atmospheric circulation model studies. Climate of the Past. 3, 39-50.

Hart, R., Maue, R., Watson, M., 2007. Estimating the atmospheric and SST memory of tropical cyclones through MPI anomaly evolution. Monthly Weather Review. 135, 3990-4005.

Hart, R.E., 2010. An inverse relationship between aggregate tropical cyclone activity and subsequent winter climate. Geophysical Research Letters, doi:10.1029/2010GL045612.

Haug, G.H., Hughen, K.A., Sigman, D.M., Peterson, L.C., Röhl, U., 2001. Southward migration of the Intertropical Convergence Zone through the Holocene. Science. 
293(5533), 1304-1308.

Hetzinger, S., Pfeiffer, M., Dullo, W.-C., Keenlyside, N., Latif, M., Zinke, J., 2008. Caribbean coral tracks Atlantic multidecadal oscillation and past hurricane activity. Geology. 36(1), 11-14.

Ho, F.P., Tracey, R.J., 1975. Storm tide frequency analysis for the Gulf Coast of Florida from Cape San Blas to St. Petersburg Beach. NOAA Technical Memorandum NWS HYDRO-20. Office of Hydrology, Silver Spring, MD.

Hodell, D.A., Brenner, M., Curtis, J.H., Guilderson, T., 2001. Solar-forcing of drought frequency in the Maya Lowlands. Science. 292, 1367-1370.

Hodell, D. A., Brenner, M., Curtis, J. H., Medina-González, R., Ildefonso-Chan Can, E., Albornaz-Pat, A., Guilderson, T. P., 2005. Climate change on the Yucatan Peninsula during the Little Ice Age. Quaternary Research. 63, 109-121.

Hong, X., Chang, S.W., Raman, S., Shay, L.K., Hodur, R., 2000. The interaction between Hurricane Opal (1995) and a warm core ring in the Gulf of Mexico. Monthly Weather Review. 128(5), 1347-1365.

Jagger, T.H., Elsner, J.B., 2008. Modeling tropical cyclone intensity with quantile regression. International Journal of Climatology. doi: 10.1002/joc.1804.

Jelesnianski, C.P., Chen, J., Shaffer W.A., 1992. SLOSH: Sea, Lake, and Overland Surges from Hurricanes. NOAA Technical Report NWS 48, April 1992, Silver Spring, Maryland.

Keigwin, L.D., 1996. The Little Ice Age and Medieval Warm Period in the Sargasso Sea. Science. 274(5292), 1504-1508.

Klotzbach, P.J., 2010. On the Madden-Julian-Atlantic hurricane relationship. Journal of Climate. 23. pp. 282-293.

Knutson, T.R., Sirutis, J.J., Garner, S.T., Vecchi, G.A., Held, I.M., 2008. Simulated reduction in Atlantic hurricane frequency under twenty-first-century warming conditions. Nature Geoscience. doi:10.1038/ngeo202.

Korty, R.L., Emanuel, K.A., Scott, J.R., 2008. Tropical cyclone-induced upper-ocean mixing and climate: application to equable climates. Journal of Climate. 21, 638-654.

Lambert, W. J., Aharon, P., Rodriguez, A.B., 2003. An Assessment of the Late Holocene Record of Severe Storm Impacts from Lake Shelby, Alabama. TransactionsGulf Coast Association of Geological Societies. 53. pp. 443. 
Lambert, W.J., Aharon, P., Rodriguez, A.B., 2008. Catastrophic hurricane history revealed by organic geochemical proxies in coastal lake sediments: a case study of Lake Shelby, AL (USA). Journal of Paleolimnology. 39, 117-131.

Lane, P., Donnelly, J.P., Woodruff, J.D., Hawkes, A.D., In Review. A decadallyresolved paleohurricane record archived in the late Holocene sediments of a Florida sinkhole.

Latif, M., Keenlyside, N., Bader, J., 2007. Tropical sea surface temperature, vertical wind shear, and hurricane development. Geophysical Research Letters. 34. L01710.

Lean, J.L., 2000. Evolution of the Sun's spectral irradiance since the Maunder Minimum. Geophysical Research Letters. 27(16), 2425-2428.

Liu, K.-B., Fearn, M.L., 1993. Lake-sediment record of late Holocene hurricane activities from coastal Alabama. Geology 21, 793-796.

Liu, K-B., Fearn, M.L., 2000. Reconstruction of prehistoric landfall frequencies of catastrophic hurricanes in northwestern Florida from lake sediment records. Quaternary Research 54, 238-245.

Liu, K.-B., Fearn, M.L., 2002. Lake sediment evidence of coastal geologic evolution and hurricane history from Western Lake, Florida: Reply to Otvos. Quaternary Research. 57, 429-431.

Liu, K.-B., Lu, H., Shen, C., 2008. A 1200-year proxy record of hurricanes and fires from the Gulf of Mexico coast: Testing the hypothesis of hurricane-fire interactions. Quaternary Research. 69. pp. 29-41.

Ludlum, D. M., 1963. Early American Hurricanes. American Meteorological Society, Boston

Lund, D.C., Curry, W.B., 2004. Late Holocene variability in the Florida Current surface density: patterns and possible causes. Paleoceanography. 19, PA4001, doi:10.1029/2004PA001008.

Makou, M.C., Eglinton, T.I., Oppo, D.W., Hughen, K.A., 2010. Postglacial changes in El Niño and La Niña behavior. Geology. 38(1). pp. 43-46.

Mann, M. E., Emanuel, K.A., 2006. Atlantic hurricane trends linked to climate change. Eos Transactions. 87(24), 233-235.

Mann, M.E., Woodruff, J.D., Donnelly, J.P., Zhang Z., 2009. Atlantic hurricanes and climate over the past 1500 years. Nature. 460, 880-885. 
Marchitto, T.M., Muscheler, R., Ortiz, J.D., Carriquiry, J.D., van Geen, A., 2010. Dynamical response of the tropical Pacific Ocean to solar forcing during the early Holocene. Science. 330. pp. 1378-1381.

Meehl, G.A., Arblaster, J.M., Matthes, K., Sassi, F., Loon, H. van, 2009. Amplifying the Pacific climate system response to a small 11-year solar cycle forcing. Science. $325,1114-1118$.

Meeker, L.D., Mayewski, P.A., 2002. A 1400-year high-resolution record of atmospheric circulation over the North Atlantic and Asia. Holocene. 12, 257-266.

Moy, C.M., Seltzer, G.O., Rodbell, D., Anderson, D.M., 2002. Variability of El Nino/Southern Oscillation activity at millennial time scales during the Holocene epoch. Nature. 420(6912), 162-165.

NOAA., 2010. Tides and Currents. <http://tidesandcurrents.noaa.gov >.

Nyberg, J., Malmgren, B.A., Kuijpers, A., Winter, A., 2002. A centennial-scale variability of tropical North Atlantic surface hydrography during the late Holocene. Palaeogeography, Palaeoclimatology, Palaeoecology. 183, 25-41.

Nyberg, J., Malmgren, B.A., Winter, A., Jury, M.R., Kilbourne, K.H., Quinn, T.M., 2007. Low Atlantic hurricane activity in the 1970s and 1980s compared to the past 270 years. Nature. 447, 698-701.

O’Brien, S., Mayewski, P. A., Meeker, L. D., Meese, D. A., Twickler, M. S., Whitlow, S. I.,1995. Holocene Climate as Reconstructed from a Greenland Ice Core. Science. 270, 1962-1964.

Peterson, L.C., Overpeck, J.T., Kipp, N.G., Imbrie J., 1991. A high-resolution Late Quaternary upwelling record from the anoxic Cariaco Basin, Venezuela. Paleoceanography. 6, 99-119.

Poore, R.Z., Dowsett, H.J., Verardo, S., Quinn, T.M., 2003. Millennial-to-centuryscale variability in Gulf of Mexico Holocene climate records. Paleoceanography. 18(2), 1048. doi:10.1029/2002PA000868.

Poore, R.Z., Quinn, T.M., Verardo, S., 2004. Century-scale movement of the Atlantic Intertropical Convergence Zone linked to solar variability. Geophysical Research Letters. 31, L12214, doi: 10.1029/2004GL019940.

Poore, R.Z., DeLong, K.L., Richey, J.N., Quinn, T.M., 2009. Evidence of multidecadal climate variability and the Atlantic Multidecadal Oscillation from a Gulf 
of Mexico sea-surface temperature-proxy record. Geo-Marine Letters. 29. pp. 477484.

Poore, R.Z., Verardo, S., Caplan, J., Pavich, K., and Quinn, T., in press, Planktic foraminiferal relative abundance and trends in Gulf of Mexico Holocene sediments: records of climate variability, in Holmes, C., ed., Gulf of Mexico: its origins, waters, biota, and human impact: College Station, Texas A\&M University Press.

Richey, J.N., Poore, R.Z., Flower, B.P., Quinn, T.M., 2007. 1400-yr multiproxy record of climate variability from the Northern Gulf of Mexico. Geology. 35(5), 423426.

Saenger, C., Cohen, A.L., Oppo, D.W., Halley, R.B., Carilli, J.E., 2009. Surfacetemperature trends and variability in the low-latitude North Atlantic since 1552. Nature Geoscience. doi: 10.1038/NGEO552.

Saravanan, R., Chang, P., 2000. Interactions between tropical Atlantic variability and El Niño-Southern Oscillation. Journal of Climate. 13, 2177-2194.

Schlesinger, M.E., Ramankutty, N., 1994. An oscillation in the global climate system of period 65-70 years. Nature. 367, 723-726.

Scileppi, E.M., Donnelly, J.P., 2007. Sedimentary evidence of hurricane strikes in western Long Island, New York. Geochemistry, Geophysics, Geosystems. 8(6), Q06011.

Scott, J.R., Marotzke, J., 2002. The location of diapycnal mixing and the meridional overturning circulation. Journal of Physical Oceanography. 32, 3578-3595.

Shay, L.K., Goni, G.J., Black, P.G., 2000. Effects of a warm oceanic feature on Hurricane Opal. Monthly Weather Review. 128(5), 1366-1383.

Sriver, R.L., Huber, M., 2007. Observational evidence for an ocean heat pump induced by tropical cyclones. Nature. 447, 577-580.

Sriver, R.L., Huber, M., Nusbaumer, J., 2008. Investigating tropical cyclone-climate feedbacks using the TRMM microwave imager and the Quick Scatterometer.

Geochemistry, Geophysics, and Geosystems. 9(9), Q09V11, doi:

10/1029/2007.GC001842.

Sturges, W., Leben, R., 2000. Frequency of ring separations from the Loop Current in the Gulf of Mexico: A revised estimate. Journal of Physical Oceanography. 30. pp. 1814-1819. 
Tang, B.H., Neelin, J.D., 2004. ENSO Influence on Atlantic hurricanes via tropospheric warming. Geophysical Research Letters. 31. L24204.

USEPA., 1999. Ecological condition of estuaries in the Gulf of Mexico. EPA 620-R98-004. U.S. Environmental Protection Agency, Office of Research and Development, National Health and Environmental Effects Research Laboratory, Gulf Ecology Division, Gulf Breeze, Florida. 80 pp.

Vimont, D.J., Kossin, J.P., 2007. The Atlantic Meridional Mode and hurricane activity. Geophysical Research Letters. 34, L07709, doi:10.1029/2007GL029683.

Woodruff, J.D., Donnelly, J.P., Emanuel, K.A., Lane, P., 2008. Assessing sedimentary records of paleohurricane activity using modeled hurricane climatology. Geochemistry, Geophysics, Geosystems. 9(9). Q09V10.

Zhao M., Held, I.M., Lin, S.J., Vecchi, G.A., 2009. Simulations of global hurricane climatology, interannual variability, and response to global warming using a $50 \mathrm{~km}$ resolution GCM. Journal of Climate: In Press. doi: 10.1175/2009JCLI3049.1 
Figure 1 - Map of paleohurricane and paleoclimate record sites. A map showing the site locations of Mullet Pond, the eight paleohurricane records used in the Mann et al. (2009) sediment-based reconstruction of basin-wide Atlantic hurricane landfalls since $1.5 \mathrm{ka}$, and relevant paleoclimate records. The paleoclimate records are numbered according to the order in which they are discussed in the text. (1) Pigmy Basin $\left(27^{\circ} 11.61^{\prime} \mathrm{N}, 91^{\circ} 24.54^{\prime} \mathrm{W}\right)$ records of annual mean SST based on foraminiferal $\mathrm{Mg} / \mathrm{Ca}$, ocean surface density based on foraminiferal $\partial^{18} \mathrm{O}$ (Richey et al. 2007), and Loop Current influence in the northeastern Gulf based on G. sacculifer relative abundance (Poore 2003, Poore 2004, Richey et al. 2007, Poore 2009, Poore, In Press). (2) Bermuda Rise $\left(33^{\circ} 41.6^{\prime} \mathrm{N}, 57^{\circ} 36.7^{\prime} \mathrm{W}\right)$ annual mean SST estimated from $\partial^{18} \mathrm{O}$ values of the foraminifer G. ruber (Keigwin 1996). (3) Neural network and foraminiferal $\partial^{18} \mathrm{O}$-based estimates of summertime SST near Puerto Rico $\left(17^{\circ} 53.27^{\prime} \mathrm{N}, 66^{\circ} 36.02^{\prime} \mathrm{W}\right)\left(\right.$ Nyberg et al. 2002). (4) Dry Tortugas $\left(24^{\circ} 21.5^{\prime} \mathrm{N}\right.$, $\left.83^{\circ} 20.9^{\prime} \mathrm{W}\right)$ record of Florida Current surface density based on foraminiferal $\partial^{18} \mathrm{O}$

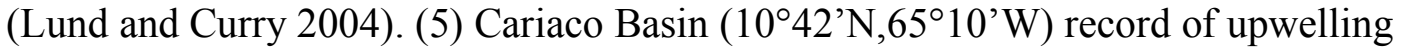
intensity and trade wind strength based on relative abundance of $\mathrm{G}$. bulloides (Peterson et al. 1991) and a record of the mean position of the ITCZ based on terrestrially-sourced titanium concentrations in the marine record suggestive of rainfall and runoff (Haug et al. 2001). (6) Galapágos ( $0^{\circ} 54^{\prime} \mathrm{S}, 8^{\circ} 30^{\circ} \mathrm{W}$ ) proxy record of El Niño frequency based on lake levels inferred from sand content in El Junco crater lake (Conroy et al. 2008, Conroy et al. 2010). (7) Lake Chichancanab, Yucatan $\left(19^{\circ} 51^{\prime} \mathrm{N}, 88^{\circ} 46^{\prime} \mathrm{W}\right)$ lake level record inferred from sediment density (Hodell et al. 2001). Typical configurations of the Loop Current are shown with the solid black line indicating the low penetration case and the dashed black line indicating the high penetration case. 


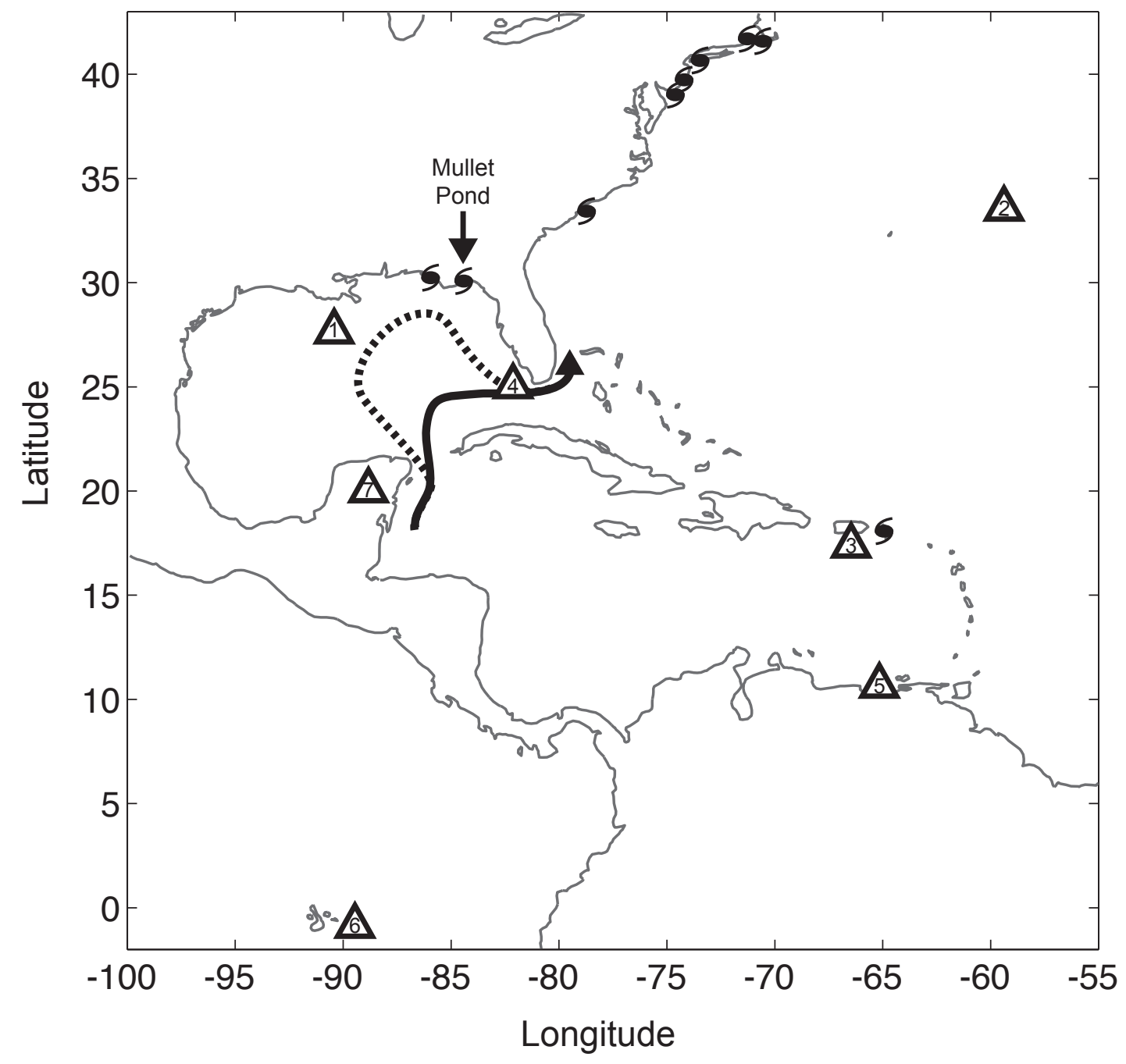


Figure 2 - Significant timescales of variability in the Mullet Pond hurricane record. Storm frequency, normalized to events per century, is plotted (solid black line) as a function of the timescale considered (twice the window size used). The record mean event frequency (2.4 hurricanes/century) is shown (solid horizontal gray line) alongside the 95 and $99 \%$ confidence intervals estimated from Poisson bootstrap samples. Peaks in significance above the $99 \% \mathrm{c}$.i. are indicated with black arrows, and the broad peak in variability (in both high and low storm activity) in the 800 to 1200 year band is shaded in gray. 


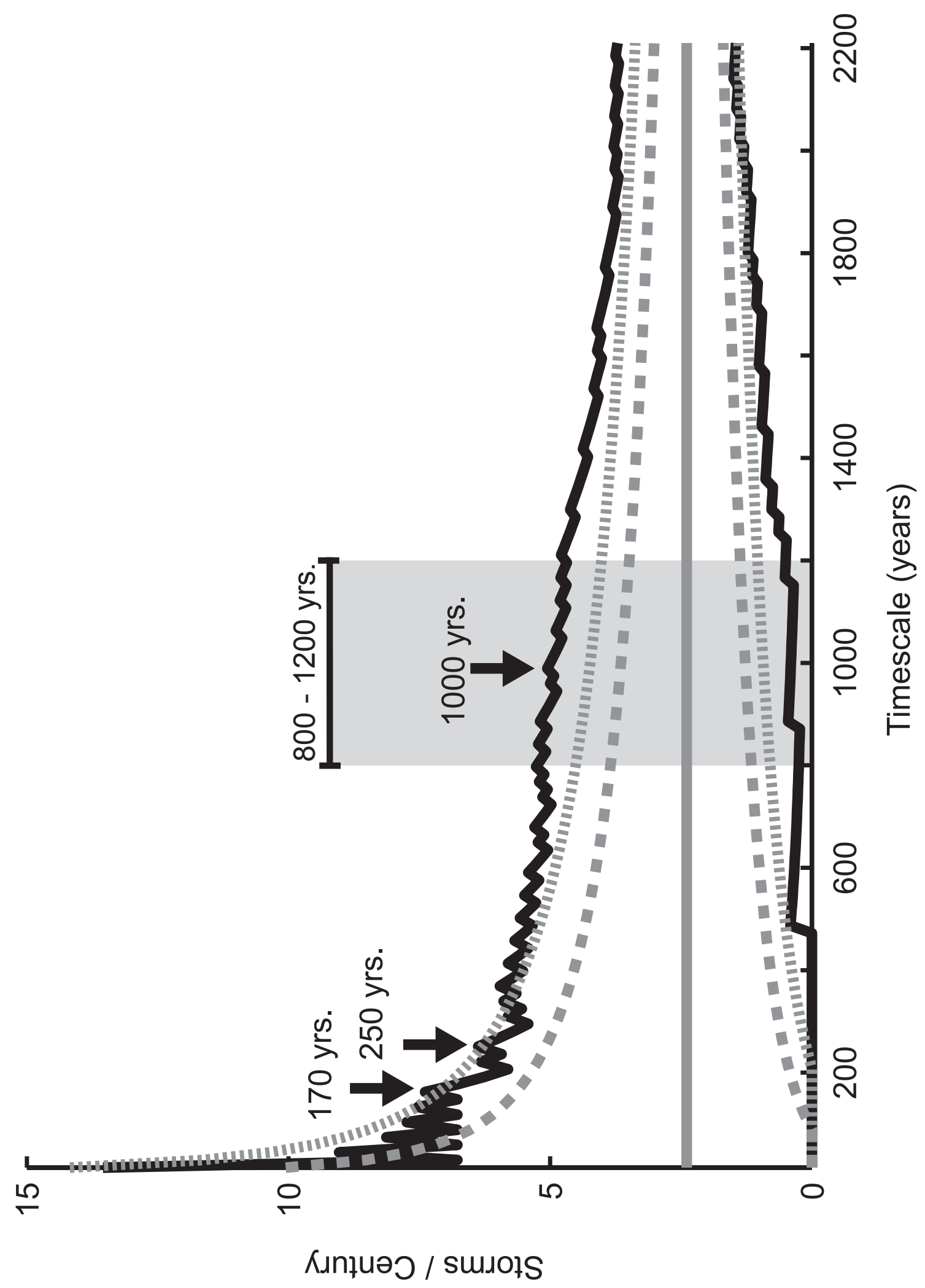


Figure 3 - Comparison of Mullet Pond storm record with other paleohurricane and regional paleoclimate records. Panel (a) is a reconstruction of annual basinwide Atlantic hurricane landfalls for the last $1.5 \mathrm{ka}$ based on a statistical model that uses MDR SST, Niño3 and the North Atlantic Oscillation (NAO) index as predictors (Mann et al. 2009). Panel (b) is a foraminiferal $\mathrm{Mg} / \mathrm{Ca}$ record of annual mean seasurface temperature in the northern Gulf of Mexico based on an ocean sediment core taken from the Pigmy Basin (Richey et al. 2007). Panel (c) is a reconstruction of annual basin-wide Atlantic hurricane landfalls based on a composite of various paleohurricane reconstructions from the Caribbean, U.S. East Coast and the northern Gulf of Mexico, not including the Mullet Pond record (Mann et al. 2009). Panel (d) is the time series of hurricane frequency at Mullet Pond truncated to the last $1.5 \mathrm{ka}$. The darker gray shaded portion highlights a period with storm frequency that exceeded the $90^{\text {th }}$ percentile of what would be expected by chance. The period shaded in light gray saw fewer hurricanes with storm frequency in the bottom $10^{\text {th }}$ percentile of what would be expected by chance. Panel (e) is the time series of $G$. sacculifer abundance in the same core used to develop the SST record shown in panel (b). Greater (lesser) abundance of G. sacculifer is indicative of increased (decreased) Caribbean surface water input into the Gulf of Mexico and is interpreted as increased (decreased) Loop Current penetration into the Gulf (Richey et al. 2007). 


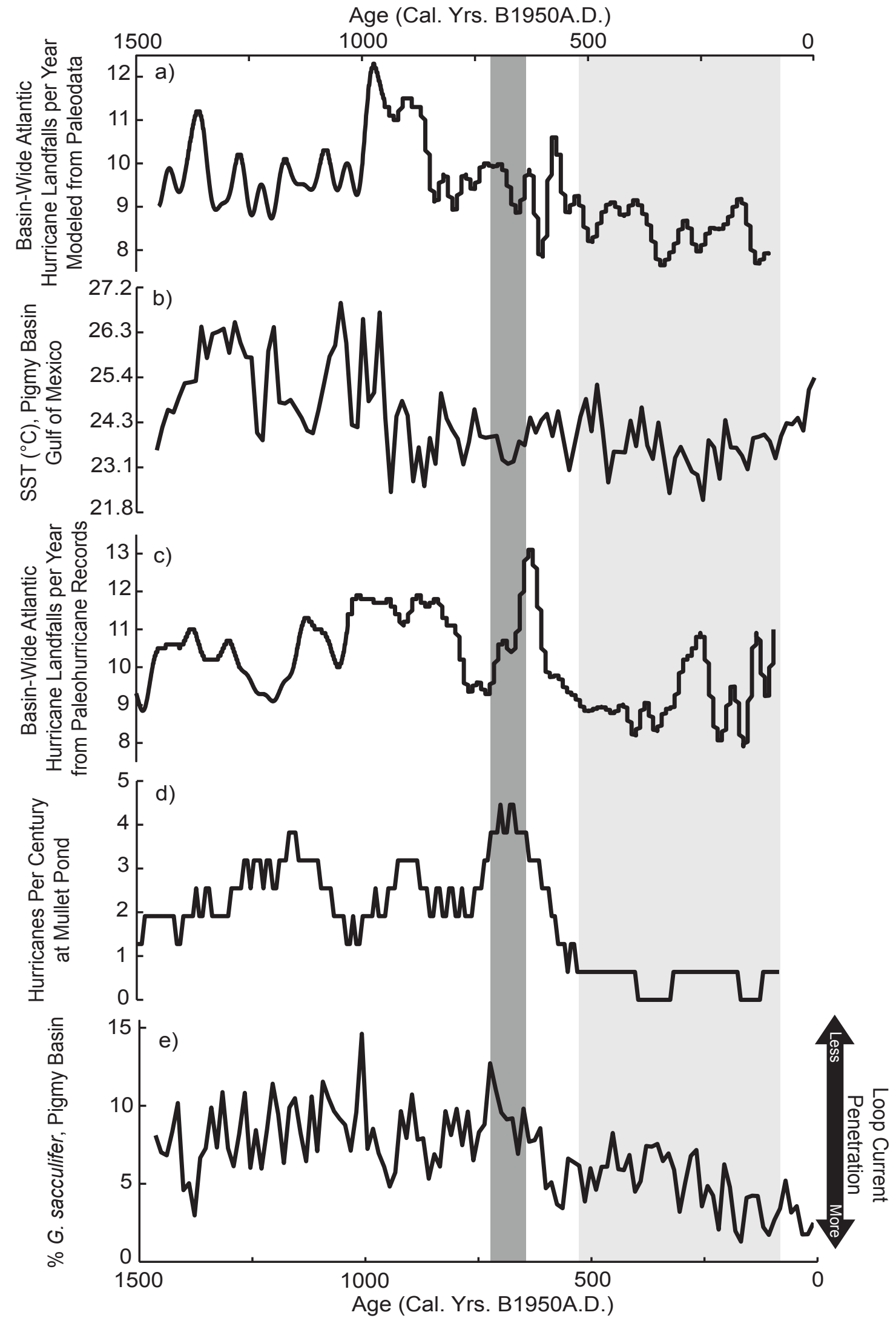


Figure 4 - Comparison of Mullet Pond storm record with paleoclimate records. Panel (a) is the time series of hurricane frequency at Mullet Pond with the darker gray shaded portion highlighting periods with storm frequency that exceeded the $90^{\text {th }}$ percentile of what would be expected by chance. The periods shaded in light gray saw fewer hurricanes with storm frequency in the bottom $10^{\text {th }}$ percentile of what would be expected by chance. Panel (b) shows both proxy records of LC penetration based on $G$. sacculifer relative abundance in marine cores taken from the Pigmy Basin (Richey et al. 2007 (gray curve), Poore, In Review (black curve)). Higher (lower) G. sacculifer abundance indicates more (less) penetration of the LC into the eastern Gulf of Mexico. The large box core from which the longer record was developed likely underwent mechanical stretching or compression during retrieval; however, the record has not been tuned here (Poore, In Press). Panel (c) is a proxy record of El Niño frequency based on lake level inferred from sand content in the crater lake El Junco in the Galapágos (Conroy et al. 2008). Panel (d) is a time series of foraminiferal $\partial^{18} \mathrm{O}$ (sea surface density) from the Bermuda Rise, inferred SST is shown on the y-axis, though a portion (estimated to be about one third) of the variability in $\partial^{18} \mathrm{O}$ is thought to be related to changes in salinity also (Keigwin 1996). Points of age control for each record are indicated with black triangles, with the exception of the Richey et al. 2007 record, which has age control points indicated with gray triangles. 


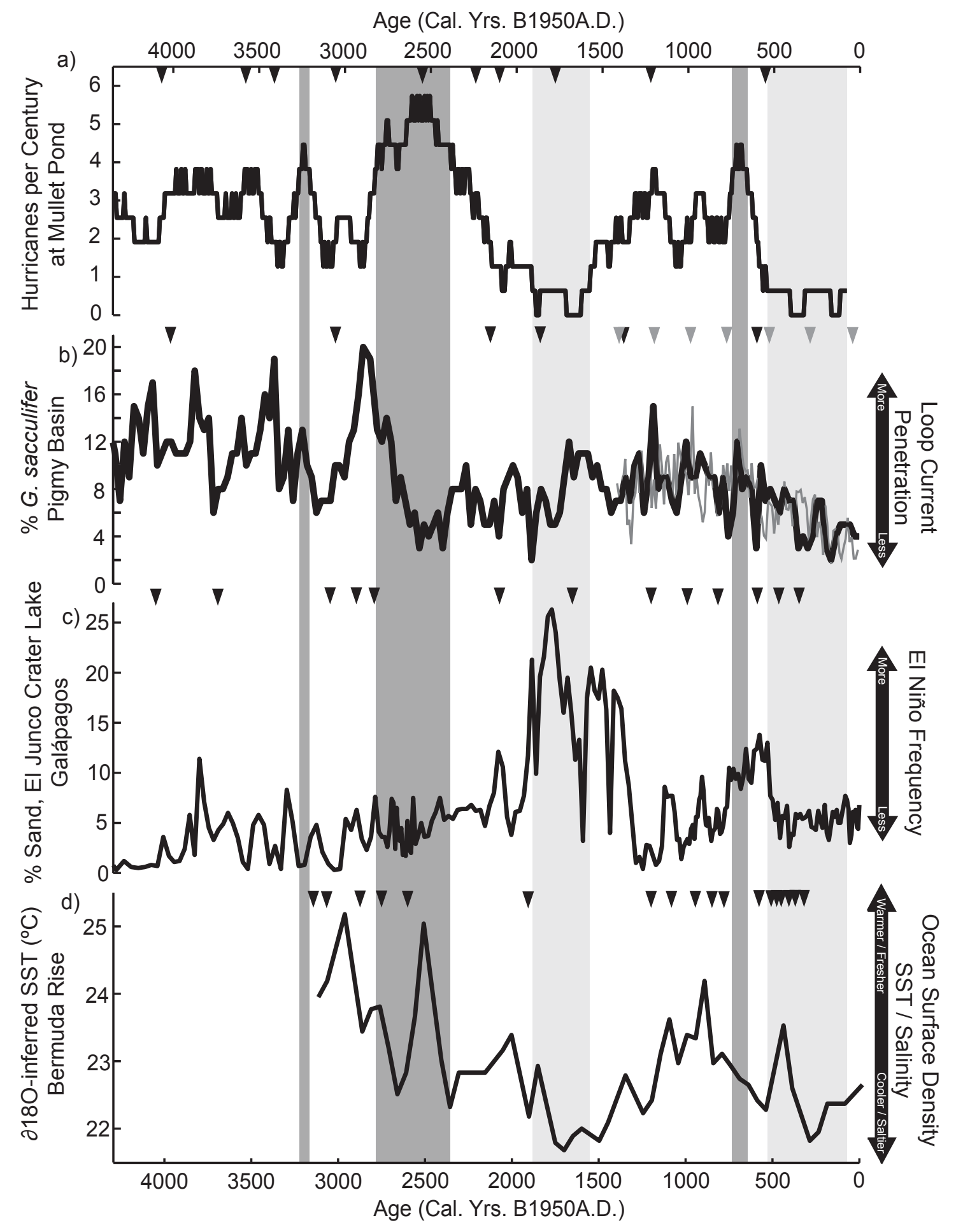




\title{
CHAPTER 3
}

\section{Modeling the storm surge climate of Apalachee Bay, Florida using synthetic hurricane records}

\begin{abstract}
A new method for estimating the frequency of tropical cyclone-induced storm surges is described and applied to the Apalachee Bay region of Florida's Gulf Coast. Large numbers of synthetic storms with characteristics conforming to climatology were generated using a statistical-deterministic hurricane wind risk model, and the surge resulting from each of these events was simulated using the SLOSH model. Using a 5175-year synthetic storm surge climatology, the 100-year event was estimated to be about 4 meters at Bald Point, Florida and approximately $5.2 \mathrm{~m}$ near the head of Apalachee Bay. The results indicate that a concentration of coastal flooding risk exists in this area; however, significant spatial variability in flooding risk is apparent over small distances with the "worst case" scenarios constraining the upper limit of surge at about $9 \mathrm{~m}$ for Bald Point and about $12 \mathrm{~m}$ for the most susceptible portions of the Bay. While the most extreme surges (500-year events) were all associated with landfalling category 4 or 5 hurricanes, large surges (100-year events) in general resulted from a broad range of storm intensities with the majority of these surges being generated by storms having moderate wind speeds (category 2 and 3 storms).
\end{abstract}




\section{Introduction}

\subsection{Motivation}

In the last half of the $20^{\text {th }}$ century, tropical cyclones overtook earthquakes as the world's deadliest and most damaging natural hazard (Murty 1984). An increase in cyclone-related fatalities and losses has been driven by rapidly growing coastal populations worldwide resulting in more people and property concentrated in areas vulnerable to storm-driven coastal flooding (Nicholls 1995). Storm surges, the abnormally high sea levels that accompanies the extreme wind and pressure anomalies of tropical cyclones, are responsible for up to 97 percent of cyclone-related deaths globally (Shah 1983, Murty 1988). As the most fatal and destructive dimension of tropical cyclones, storm surges exact as heavy a toll on society as any other geophysical phenomenon. Moreover, coastal populations and sea levels are both rising - a combination that ensures coastal communities will become increasingly vulnerable to storm surges. Mitigation of future disasters requires a quantitative analysis of risk today.

Paleohurricane research is an emerging and promising tool for the assessment of long-term hurricane risk. By identifying and dating hurricane surge deposits in coastal environments, it is possible to estimate the frequency of events at a site and determine how that frequency may have changed through time (Liu and Fearn 1993, Liu and Fearn 2000, Donnelly et al. 2001a, Donnelly et al. 2001b, Scileppi and Donnelly 2007, Donnelly and Woodruff 2007, Boldt et al. 2010, Lane et al., In Review). Such records provide unprecedented access to time and permit better estimates of the rate of occurrence of the most extreme and rare events.

In addition to providing long-term estimates of storm surge frequency, geologic proxies of hurricanes are also shedding light on how hurricane frequency and intensity have evolved over thousands of years. Paleohurricane studies of the U.S. Gulf and East coasts as well as the Caribbean, have identified relatively active 
and inactive intervals of hurricane activity (Liu and Fearn 2000, Scileppi and Donnelly 2007, Donnelly and Woodruff 2007, Lane et al., In Review). Interpretation of these findings is complicated, however, since direct comparison of modern and pre-historic activity is difficult.

Event frequencies and return times estimated from sedimentary records generally provide information about the occurrence of the largest storm surges on centennial to millennial timescales. Any very recent, possibly anthropogenic trend in hurricane activity, for example, would likely not yet be documented in the sediment record. Historic records limit analyses to multi-decadal or, at best, centennial timescales and seldom document the most extreme and potentially devastating events. A method that uses historic data to estimate storm surge frequencies and return times on the millennial timescale would facilitate more quantitative comparisons between ancient and modern levels of hurricane activity. Furthermore, better constraints on the storm characteristics capable of inundating a location would also allow investigators to determine what type of storms are represented in a particular sediment record.

\subsection{Background of coastal flooding risk analysis}

\subsubsection{The event of record}

One simple strategy that has been used to estimate the vulnerability of a location to storm surge is to assume that the largest event observed, the "event of record," can reoccur. This method was used in a U.S. Army Corp of Engineers assessment of the risk that hurricane surges pose to the New York City area. The report by Tippets et al. (1958) examines the consequences of the reoccurrence of the hurricane of 1821 A.D., a storm that caused the water level in New York Harbor to rise 4 meters in one hour's time (Ludlum 1963). Fortunately, the highest storm surge occurred at low astronomical tide during the 1821 A.D. hurricane and resulted in a 
storm tide of 3.1 to 3.4 meters above mean sea level (Tannehill 1944). The Corp of Engineers assessment explored what would happen if the same event occurred at high tide and concluded that the 4.6-meter surge (above mean sea level) would flood nearly 23 percent of the New York City area. While such a cautiously pessimistic assessment is warranted when planning for the worst, there is no guarantee that the event of record appropriately approximates the worst-case scenario. Furthermore, the largest event observed during a particular period may not be representative of the largest event likely to happen in that interval of time.

\subsubsection{Extreme value methods applied to water level observations}

Given the limitations of using the event of record as a benchmark for risk, other methods for estimating the frequency of extreme water levels at a location have been developed. These techniques generally involve fitting extreme value distributions (Gumbel 1954, Gumbel 1958, Jenkinson 1969) to water level observations to make inferences about the frequency of events ranging from the routinely measured to the unobserved extremes. The assumption underlying these techniques is that the frequency of the rarest and most extreme events can be ascertained from the frequency of more frequent, smaller surge events (Yang et al. 1970, Ackers and Ruxton 1975, Fuhrboter 1979, Pugh and Vassie 1979, Coles and Tawn 1990, Tawn 1992). While frequency estimates for events that are well represented in the record may be reasonable, assumptions about the tail of the distribution, where the least frequent and most damaging events reside, may be tenuous (Walton 2000). When using extreme value methods, the assumption that the

largest events scale with smaller events is necessary due to both the relatively short duration of accurate and continuous tide gauge records and the rarity of large surge events at any particular location. Since most reliable tide gauge records span less than a century (Zhang et al. 2000), this approach is temporally limited and produces 
estimates of frequency and return time for relatively minor events on relatively brief timescales.

\subsubsection{Joint probability methods}

The methods of estimating storm surge frequency thus far discussed rely on water level observations at specific locations. The results from these methods are therefore limited spatially as well as temporally. Due to the sensitivity of storm surge to bathymetry and coastline shape (Jelesnianski 1966, 1967, 1992), it is not possible to generalize event frequencies from point observations (e.g. high water marks or tide gauges) and apply those estimates uniformly across regions with complex coastal geometries. In an effort to circumvent the spatial and temporal limitations of earlier methods, researchers began to use hydrodynamic models to simulate the regional extent of surges associated with historic and hypothetical hurricanes (Myers 1970, Ho 1974, Ho and Tracey 1975a, Ho and Tracey 1975b, Myers 1975). These

climatological-hydrodynamic techniques, sometimes called joint probability methods, estimate the frequency of storm surges by assuming that the distributions of storm parameters contributing to surge, namely intensity, storm motion and size, are well approximated in a region of interest (Pore and Barrientos 1976). These a priori distributions are used to drive regional, hydrodynamic models of storm surges associated with hypothetical storms that have attributes selected from the provided distributions.

While such a method is similar to the synthetic method outlined in this paper, it differs in a few important ways. When using the climatological-hydrodynamic method, the modeler must know the likelihood of all storm events, even very rare storms, at a particular location. Some variables (direction of motion and intensity, for example) are treated as independent, while good physical arguments can be made that they are not (Emanuel et al. 2006). These hypothetical storms are usually modeled using discrete values of the relevant variables, which are treated as constants 
throughout the life of the storm. Additionally, these steady-state storms are usually propagated along straight, parallel lines at discrete intervals. As such, these techniques do not provide for the more exotic behaviors of real tropical cyclones that can influence the magnitude of a storm surge.

\subsubsection{The synthetic method}

In this paper, we present a new method of modeling regional and local storm surge climate, which relates the frequency of a surge event to its magnitude. The method uses a statistical-deterministic hurricane wind risk model developed by Emanuel et al. (2006) to generate large numbers $\left(10^{4}\right)$ of synthetic storm events. The storm surge associated with each of these events is then simulated by the Sea, Lake, and Overland Surges from Hurricanes (SLOSH) model (Jelesnianski et al. 1992) to produce a large sample of climatologically plausible storm surges at a location.

The method detailed in this paper employs hydrodynamic modeling of hypothetical storms; however, it does not require existing knowledge of local distributions of storm parameters. Rather, the characteristics of each hypothetical storm are modeled deterministically by treating the environmental factors that give rise to and affect the evolution of a storm as random variables having values and behaviors consistent with climatology. On the timescale for which accurate meteorological observations are available, the large-scale characteristics of the ocean surface and atmosphere that affect tropical cyclones are better constrained than are the local distributions of tropical storm characteristics. By deterministically modeling the track, intensity and structure of a very large number of storm events throughout an ocean basin in this way, we obtained a large, representative sample of surge events affecting a region or location of interest.

This method can be applied to any location where SLOSH has been configured for use, which includes the entire U.S. Eastern and Gulf coasts. The same strategy could also be generalized to any location where ample atmospheric and 
oceanic observations are available and a storm surge model has been properly configured. We apply this method, hereafter referred to as the synthetic method, to the Apalachee Bay region of Florida's Gulf Coast and examine the local, modeled storm surge climate of Bald Point, Florida.

\subsection{Study area - Apalachee Bay, Florida}

Apalachee Bay, situated in the Big Bend region of Florida's Gulf Coast, encompasses $400 \mathrm{~km}^{2}$ of the coastal shelf submerged to an average depth of 3 meters (USEPA 1999). This shallow, concave bay is highly susceptible to extreme storm surges generated by hurricanes that frequent the Gulf of Mexico. Storm tide frequency analysis by a joint probability method suggests that the expected maximum 100 -yr still water level surge in the bay is about 4.5 meters above mean sea level (Ho and Tracey 1975), and inundation modeling indicates that surges exceeding 8 meters, which would penetrate tens of kilometers inland, could occur under extreme storm conditions (Jelesnianski et al. 1992).

In addition to its concave geometry and shallow bathymetry, Apalachee Bay is particularly vulnerable to large storm surges due to enhancement from coastallytrapped Kelvin waves. These waves form when storms move northward along Florida's west coast and pile water up along the shelf as they approach the Florida Panhandle. The resulting wave propagates along the coast with the storm and can contribute significantly to the overall surge in Apalachee Bay. Hurricane Dennis in 2005 generated a coastally-trapped wave that led to a dramatic and unexpected enhancement of the coastal flooding in Apalachee Bay (Morey et al. 2006). Similarly, Hurricane Kate in 1985 generated sea height anomalies that propagated along the west Florida shelf and ultimately amplified the storm surge along Apalachee Bay (Blain et al. 1994). In each case, the trapped wave contributed an additional meter to the total storm tide in Apalachee Bay. 
While evidence indicates that Apalachee Bay may be vulnerable to extremely large and frequent hurricane-generated storm surges, tide gauge records in the region are brief and eyewitness accounts provide evidence for surges no larger than 3 to 4 meters during the historic period (Ludlum 1963, Case 1986). Analysis of the Best Track dataset reveals that the average return time for a major hurricane landfall in Apalachee Bay (about 73 years) is significantly longer than in any other portion of the U.S. Gulf Coast (NOAA 2011), which may suggest that the region is in some way sheltered from intense hurricane impacts. On the other hand, this stretch of shoreline might simply have been fortunate during the approximately 150 years for which hurricane records are available.

The power of the synthetic method presented here is the ability to generate long synthetic hurricane records that conform to climatology but are not based on the life histories of particular, observed storms. These synthetic climatologies are particularly illuminating in regions where vulnerability to surge may be extreme but observations are brief or otherwise limiting. For these reasons, Apalachee Bay is an ideal environment to demonstrate the usefulness of the synthetic method for simulating storm surge climatology. Furthermore, several paleohurricane records from the Apalachee Bay region are being developed, and an accurate assessment of the frequency of coastal floods of various sizes will aid in the interpretation and development of these storm archives.

\section{Methods}

\subsection{The SLOSH model}

The SLOSH model is an operational, numerical model used by the National Hurricane Center to simulate hurricane storm surges in a time-sensitive, forecast capacity. As such, SLOSH is a nimble but low-resolution model. When compared with higher-resolution models, SLOSH performs well at simulating the maximum 
storm surge at a location for a particular event, though sub-grid scale variations in the local surge will be averaged out in SLOSH (Ning et al. 2010).

SLOSH uses a system of polar, hyperbolic, and elliptical grids, called basins. Depending on the basin, the spacing between the model grid points ranges from 0.1 $\mathrm{km}$ near the coast to about $7 \mathrm{~km}$ in the domain farthest away from the shore. SLOSH also includes parameterizations for some sub-grid features, including barriers to flow, breaks in barriers, channel flow, variable friction due to vegetation and onedimensional flow in rivers. The topographic and bathymetric data used by the model come from the U.S. Geological Survey and sea still-water elevations are referenced to the North American Vertical Datum of 1988.

To quantify the contribution of coastally-trapped Kelvin waves to the longterm storm surge climate in Apalachee Bay, flooding events caused by Best Track storms impacting the area were modeled using two different grid domains: the spatially-limited Apalachicola (APC) basin (Figure A2.1) and the much larger but lower-resolution Gulf-wide (EGLL) basin (Figure A2.2). The APC basin neglects the effects of remotely-produced, coastally-trapped Kelvin waves, which are sometimes generated beyond the model domain and can travel into the area of interest. The EGLL basin includes the whole northern Gulf of Mexico and is capable of simulating the trapped wave phenomenon; however, this basin lacks an inundation model and treats the coastline as a fixed barrier.

SLOSH requires a time series of six meteorological variables: the (1) latitude and (2) longitude of the storm center, the (3) translation speed and (4) bearing of the storm's motion, the (5) radius of maximum wind (RMW), and (6) the difference between the barometric pressure of the ambient environment and the low barometric pressure of the storm center $(\Delta \mathrm{P})$. These values, inputted as 100-hour track files with 1-hr timesteps, are used to generate parametric wind and pressure fields and to calculate the forces that act upon the ocean's surface during a tropical cyclone. SLOSH uses these forces together with a topographic and bathymetric map of a coastal region to solve the continuity and momentum equations for a fluid on a 
rotating sphere in order to determine the water column height anomaly (storm surge) at each grid cell in the model domain (Jelesnianski 1992).

\subsection{The ADCIRC model}

The ADvanced CIRCulation (ADCIRC) model is a numerical model designed to simulate the hydrodynamics of coasts, shelves, and estuaries. As a storm surge model, ADCIRC is typically configured with a much higher resolution, finer mesh than that used by SLOSH and also requires a much smaller time step. A typical storm surge simulation in SLOSH will require no more than 20 seconds of computer time on a desktop, while simulating the same event using ADCIRC requires five to six hours on twenty-four processors. ADCIRC is computationally prohibitive when performing very large numbers of simulations, but permits detailed and complex simulations of a small number of events. In addition to simulating still-water surge levels, ADCIRC uses coupled wave (SWAN) and tide models to estimate the contributions of these factors to the total water level at a location (Leuttich et al. 1992).

ADCIRC also requires a time series of six meteorological variables: the (1) latitude and (2) longitude of the storm center, the (3) maximum sustained wind and (4) central barometric pressure of the storm (Pc), the (5) RMW, and (6) the outer radius of the storm (Ro), which is the distance from the storm center where the influence of its circulation on atmospheric flow vanishes. These values are inputted as 96-hour track files with 1-second timesteps. Similar to SLOSH, ADCIRC uses these values to generate parametric wind and pressure fields to calculate surge values, but ADCIRC also calculates wave setup, significant wave height, and astronomical tide level (Westerink et al. 1992). 


\subsection{Estimation of regional storm surge climate from historic storm record}

Observations were required to assess the appropriateness of the synthetic method for surge climate modeling; however, direct storm tide observations from the Apalachee Bay region are scarce. For this reason, we modeled the storm surges associated with historic hurricanes impacting the region. Return times for storms and surges of various magnitudes were rendered from meteorological observations and the empirical surge results with the expectation that historic and synthetic values should compare favorably for short timescales and smaller magnitude events.

\subsubsection{SLOSH modeling of Best Track (1851 - 2007 A.D.) storms affecting Apalachee Bay}

A filter capable of identifying all Best Track storms that could potentially generate any surge of consequence in Apalachee Bay was applied to the historic data.

Any storm having a maximum wind speed of at least 40 knots while within $500 \mathrm{~km}$ of a point on the west Florida shelf $\left(27.3^{\circ} \mathrm{N}, 85.58^{\circ} \mathrm{W}\right)$ was selected for modeling. The Atlantic Best-Track Dataset provided storm positions and maximum wind speed estimates at 6-hour intervals going back to 1851 A.D. (Jarvinen et al. 1984, Landsea et al. 2004, Landsea et al. 2008, NOAA 2010b). Rather than maximum wind speed, SLOSH uses the barometric pressure difference between the storm center and the ambient environment $(\Delta \mathrm{P})$ as the intensity parameter (Jelesnianski et al. 1992). This quantity was estimated from the Best-Track maximum wind using an empirical windpressure parameterization specific to the Gulf of Mexico (Landsea et al. 2004). Position vectors were spline interpolated, and all other variables were linearly interpolated to $1-\mathrm{hr}$ resolution. 


\subsubsection{ADCIRC modeling of Best Track (1851 - 2007 A.D.) storms affecting Apalachee Bay}

Due to the computational demands of the model, ADCIRC was used to simulate only those events producing significant $(>1 \mathrm{~m})$ surges according to SLOSH. Latitude, longitude (spline interpolated to 1-second resolution) and maximum wind speed (linearly interpolated to 1-second resolution) were taken from the Best Track dataset. Central pressure was calculated using the Landsea et al. (2004) parameterization and an assumed environmental pressure of $1013 \mathrm{mb}$. A parametric wind field by Emanuel (unpublished), which is somewhat different than the one encoded in SLOSH but similar to Holland (2008) in its effects on storm surge, was used. A surface to flight level wind ratio of 0.8 , the same as SLOSH uses, was specified. The tide model required a 48-hour spin-up period for each simulation, and a medium-resolution grid encompassing the entire Gulf of Mexico was used (Figure A2.3).

\subsection{Synthetic storm dataset generation}

A large number of synthetic storms $(\mathrm{N}=10,000)$ having maximum wind speeds of at least 40 knots while within $500 \mathrm{~km}$ of a point $\left(27.3^{\circ} \mathrm{N}, 85.58^{\circ} \mathrm{W}\right)$ on the west Florida shelf were generated. Note that these selection criteria are identical to the ones used to filter the Best Track data. For each storm, a genesis point was randomly selected from a distribution constructed from historical track data going back to 1970 (NOAA 2007b). This genesis distribution is a function of location and time of year in the model. Once initiated, 2-hr storm displacements were calculated using the beta and advection model (Marks 1992) where 850 and $250 \mathrm{mb}$ environmental steering flows vary randomly but in accordance with the mean, variance and covariances of the National Center of Environmental Prediction (NCEP) and National Center for Atmospheric Research (NCAR) reanalysis data for the North 
Atlantic. The steering flows at these pressure levels were also made to have kinetic energies that obey the $\omega^{-3}$ power law of geostrophic turbulence. Vertical wind shear, an important factor in the development and intensification of hurricanes, was calculated directly from the modeled steering flows at the two pressure levels. Thus, the dependence of vertical shear on storm track was incorporated into the model.

The Coupled Hurricane Intensity Prediction System (CHIPS), a deterministic numerical model, was used to simulate the maximum, vortex-relative wind speed of each storm along its simulated track (Emanuel et al. 2004). The model, which assumes axisymmetric storm structure and includes a one-dimensional ocean, employs climatological values of potential intensity and upper ocean thermal structure to model the intensity evolution of each synthetic storm. CHIPS calculates the maximum wind speed using an angular momentum coordinate scheme that maximizes model resolution where it is most crucial - in the storm eyewall. The impact of wind shear on storm intensity is dealt with parametrically in CHIPS.

Storm positions are modeled directly by the statistical-deterministic storm model; however, variables other than latitude and longitude had to be determined through other means. Storm forward speed was found first by using consecutive storm positions to solve the Haversine formula for the distance traveled along a spherical earth. This distance was then divided by the time increment ( $\Delta t=2$ hours) to solve for storm translation speed. The bearing, or compass direction in degrees, of storm motion was similarly calculated from successive latitude and longitude observations.

\subsection{Radius of maximum wind model}

\subsubsection{RMW model for historic storms}

The RMW critically affects both the magnitude and distribution of surge associated with a storm. This can be the most challenging aspect of forecasting a 
storm surge as the extent of coastal flooding can be very sensitive to the structure of the wind field, which is difficult to measure and even more difficult to forecast. In lieu of observed RMW values for most events, we modeled the evolution of this variable by assuming partial angular momentum conservation of inflowing air as it travels from a storm's outer radius (Ro) to the RMW. Again, the Ro is defined here as the radius at which the wind field becomes indistinguishable from the ambient flow. Based on an analysis of North Atlantic storm size statistics (Demuth et al. 2006, Kossin et al. 2007), Dean et al. (2009) found Ro has a mean value of $392 \mathrm{~km}$, and this was used as a constant for the historic surge simulations in this paper. The RMW evolution was then modeled according to:

$$
\left(V_{\max } \times R_{\max }\right)+\frac{f \times R_{\max }^{2}}{2}=\frac{\alpha \times f \times R_{o}^{2}}{2}
$$

where $V_{\max }$ is the maximum vortex-relative wind speed $(\mathrm{m} / \mathrm{s}), \mathrm{R}_{\max }$ is the radius of maximum wind $(\mathrm{m}), f$ is the latitude-dependent Coriolis parameter $\left(\mathrm{s}^{-1}\right)$ and $\alpha$ is the dimensionless fraction of angular momentum that is conserved. $V_{\max }$ and $f$ are either provided by the statistical-deterministic model or can be determined from its output. The fraction of angular momentum conservation, $\alpha \approx 0.43$, was treated as a constant and estimated empirically by finding the mean value of the solution to the above equation for $\mathrm{R}_{\max }$ using observations from Dean et al. (2009) and comparing the predicted $\mathrm{R}_{\max }$ to the observed RMW values (Figure 2A.4). The evolution of RMW for each historic storm was calculated at each time step.

\subsubsection{RMW Model for Synthetic Storms}

In the same way that a good estimate of RMW is critically important to forecasting storm surge during a particular event, a realistic distribution of RMW is likewise required when attempting to simulate the full range of events likely to affect a location over a long period of time. Indeed, it may be simpler to model surge 
distributions, based on reasonable RMW distributions, than it is to model the surge of a particular event where a very good estimate of the RMW is required. Based on an analysis of North Atlantic storm size statistics (Demuth et al. 2006, Kossin et al. 2007), Dean et al. (2009) found Ro follows a lognormal distribution around its geometric mean value of $392 \mathrm{~km}$. Since Ro is known to vary the least of all hurricane size metrics throughout a storm's lifetime (Frank 1977), Ro was treated as a random variable with each draw from the lognormal distribution kept as a constant for each storm. As before, partial angular momentum conservation was used to model the RMW evolution for each storm.

\section{Results}

\subsection{Best Track and synthetic storms affecting the northeastern Gulf of Mexico}

Of the 1,418 North Atlantic storms in the Best Track dataset during the period from 1851 - 2007 A.D., 274 ( 19 percent) pass through the specified $500 \mathrm{~km}$ search radius while having at least 40-knot winds (Figure 1) resulting in an annual frequency

of 1.75 storms year $^{-1}$ that meet the criteria for surge modeling. Approximately 52,000 synthetic Atlantic basin storms were generated over 5,175 years of modeled time to produce a dataset of $10^{4}$ storms meeting the previously stated filtering criteria (Figure 2), which also implies that about 19 percent of synthetic Atlantic storms affected the northeastern Gulf. In the model, an average of 1.93 storms passed through the 500 $\mathrm{km}$ search radius with at least 40-knot winds every year.

The distributions of the variables relevant to surge compare favorably between the Best Track and synthetic records (Figures A2.5, A2.6). The intensity distribution of synthetic storms entering the northeastern Gulf and approaching Bald Point is similar to that experienced by the region during the historic period; however, the regional frequency of Saffir-Simpson (SS) category 5 storms is significantly higher 
(by about 300 percent) in the synthetic dataset than what has been documented since 1851 A.D. (Tables A2.1, A2.2).

\subsection{Modeled, historic surge events at Bald Point}

Of the 274 Best Track storms meeting the criteria for surge modeling, 15 of these produced surges in excess of $1 \mathrm{~m}$ at Bald Point in SLOSH (Figure 3). Modeled surges exceeded $1 \mathrm{~m}$ in both the EGLL and APC SLOSH basins for each of these 15 events, and all but Hurricane \# 3 of 1886 A.D. also produced at least a meter of surge in ADCIRC (Table A2.3). However, after the effects of wave setup and astronomical tide were included, the total storm tide from this event was modeled at $1.1 \mathrm{~m}$ (Table A2.4). The largest of the SLOSH surges at Bald Point, $4.3 \mathrm{~m}$, was generated by SScategory 3 Hurricane Elena (1985) in the EGLL basin (Table A2.5). In ADCIRC, Hurricane \# 5 of 1852, a category 2 storm at its nearest approach to Bald Point, produced the largest simulated surge of $5.3 \mathrm{~m}$ at the site.

The average absolute value of astronomical tide adjustment to the total flooding level that ADCIRC applied was $31 \mathrm{~cm}$, with a maximum adjustment of -54 cm for Hurricane \# 4 of 1886 (Table A2.4). The effects of wave setup added, on average, $7 \mathrm{~cm}$ to the total storm tide at Bald Point, with a maximum of $16 \mathrm{~cm}$ modeled for Hurricane \# 2 of 1886 (Table A2.4). All fifteen significant, historic storms were at least category 1 hurricanes at their nearest approach to Bald Point (Table A2.5).

\subsection{Calculation of event frequency and return times from simulated surge data}

\subsubsection{Best Track surge data}

With only 5.5 percent of Best Track storms entering the northeastern Gulf of Mexico generating surges of at least a meter at Bald Point, the results indicate that 
most storm events produced little to no surge at the site and can be neglected when calculating event frequency, return times and other measures of risk. For this reason, the tails of the surge distributions (Figures A2.7, A2.9) were modeled using the Generalized Pareto Distribution, which was fit to surge exceedance values $(>1 \mathrm{~m})$ (Figures A2.8, A2.10). Maximum, simulated surges at Bald Point for the 156-year historic period were $3.2 \mathrm{~m}, 4.3 \mathrm{~m}$, and $5.3 \mathrm{~m}$ in the SLOSH APC and EGLL basins and in ADCIRC, respectively (Table A2.3, Figures A2.7, A2.9a). For the Best Track, surge only simulations in ADCIRC, an exceedance value of 0.79 was used so that the surge from Hurricane \# 3 of 1886 A.D. would be included in the fit (Figure A2.10a)

\subsubsection{Synthetic surge data}

Approximately 12 percent of modeled synthetic storms produced surges exceeding $1 \mathrm{~m}$ at Bald Point in both SLOSH APC and EGLL basins. The maximum, simulated surges at Bald Point for the modeled 5,175-year period were $8.9 \mathrm{~m}$ and 7.0

$\mathrm{m}$ in the APC and EGLL basins, respectively (Figure A2.11). The Generalized Pareto Distribution was fit to the tails of the data (values $>1 \mathrm{~m}$ ) (Figure A2.12), and the fits were used to estimate event frequency and return time.

\subsection{Frequency and return times of storm surges at Bald Point}

The fits to the Best Track SLOSH data indicate that estimates of the frequency of surges smaller than $2.5 \mathrm{~m}$ are larger and return times are slightly shorter when the APC basin is used instead of the EGLL basin (Figures 4, 5, Table A2.6). However, surges exceeding $2.5 \mathrm{~m}$ were estimated to be more common when the fit to the EGLL data was used. The 100-year event at Bald Point was estimated at 3.0 and $3.5 \mathrm{~m}$ for APC and EGLL datasets, respectively (Table A2.7). Similarly, surges of about $4.3 \mathrm{~m}$ or less were estimated to be more common when the fit to the ADCIRC storm tide data was used rather than the surge only simulations in ADCIRC, but surges 
exceeding $4.3 \mathrm{~m}$ were more common in the ADCIRC surge only case. The 100-year event at Bald Point was estimated at $4.1 \mathrm{~m}$ for both ADCIRC surge only and storm tide cases (Table A2.7). The fits derived from the synthetic surge data indicate that surges less than $5.5 \mathrm{~m}$ were slightly more common in the EGLL basin than in the APC basin but also suggest that larger surges were modeled more frequently in the APC basin. The synthetically-derived 100-year event in APC and EGLL was 3.9 and $4.0 \mathrm{~m}$, respectively (Table A2.7)

When Best Track simulated surges were used, the frequency and return times for surges of $2 \mathrm{~m}$ were similar regardless of the model or basin used. Larger surges, however, were estimated to be more frequent when the ADCIRC model was used. Estimates of the frequency of surges not exceeding 2.5 meters were substantially higher when synthetic data were used. Synthetic estimates for surges ranging from 2.5 to $4.5 \mathrm{~m}$ fall between the Best Track SLOSH and ADCIRC estimates. Surges exceeding this range were more frequent in the synthetic record when compared to the historic record (Figures 4, 5, Table A2.6)

\subsection{Regional mapping of storm surge risk in Apalachee Bay using synthetic records}

A map of the synthetically-derived 100-year event in the APC basin reveals the regional distribution of coastal flooding susceptibility and demonstrates that a maximum in flooding risk exists in Apalachee Bay (Figure 6). The 100-year event is $3.9 \mathrm{~m}$ at Bald Point and $5.3 \mathrm{~m}$ in the most susceptible areas at the head of Apalachee Bay. The geographic distribution of the "worst case" modeled surges in the APC basin during the 5,175-year synthetic record, with a maximum of $8.9 \mathrm{~m}$ at Bald Point and $12.3 \mathrm{~m}$ in the most vulnerable parts of Apalachee Bay, supports the notion that this area is extremely susceptible to very large surges capable of penetrating tens of kilometers inland (Figure 7). These results also indicate that storm surge climate can vary dramatically over relatively short distances. 
A map of the synthetically-derived 100-year event in the northeastern portion of the EGLL basin shows, again, how flooding risk is highly concentrated in Apalachee Bay. The 100-year event at Bald Point was estimated at $4.0 \mathrm{~m}$ and was 5.1 $\mathrm{m}$ near the head of Apalachee Bay (Figure 8). The data also indicate that the largest storm surges possible in the western Gulf of Mexico occur in Apalachee Bay, where the "worst-case" scenario is estimated at $10.9 \mathrm{~m}$ (Figure 9). The largest synthetic surge modeled at Bald Point in the EGLL basin was $7.0 \mathrm{~m}$.

\subsection{Synthetic storms producing ten largest surges at Bald Point}

Of the ten largest modeled surges at Bald Point in the APC basin, half were category 5 hurricanes at landfall and the other half were category 4 storms (Figure 10). All but one of these storms originated in the Main Development Region, traveled westward through the Greater Antilles and then north-northwestward along the west coast of Florida before making landfall near Apalachicola. The synthetic storms generating the ten largest flooding events in the EGLL basin exhibit somewhat greater spread in their location of genesis, angle of approach to the coastline and landfall location (Figure 11). Nine of these storms were category 4 at landfall and one was a category 5. Only two of the storms responsible for the top ten surges at Bald Point in APC also produced top ten surge events at Bald Point in the EGLL basin.

\subsection{Storm surge distributions by Saffir-Simpson category}

Though all of the top ten surge events at Bald Point were associated with category 4 and 5 storms, boxplots of simulated surges grouped according to the Saffir-Simpson category of the storms that produced them indicate that the relationship between storm surge and storm intensity may not be straightforward (Figures 12, 13). The synthetic surge data indicate that, while the uppermost fraction 
of storm surges (for example, the 500-year event) are associated with the most extreme storm intensities, moderately intense (category 2 and 3 storms) produce, on average, larger surges at any particular location. For example, a storm responsible for a surge of $4 \mathrm{~m}$ or larger, approximately the 100-year event at Bald Point, is most likely to be a category 3 storm. Moreover, according to the results from the EGLL basin (Figure 13), a surge exceeding $4 \mathrm{~m}$ at Bald Point is more likely to have resulted from a category 2 rather than a category 5 storm.

\subsection{Modeled radius of maximum wind distribution}

The modeled synthetic RMW distribution has a geometric mean of $59.7 \mathrm{~km}$, while the combined Kossin et al. (2007) and Demuth et al. (2006) RMW observations for North Atlantic tropical cyclones have a geometric mean of $57.3 \mathrm{~km}$. The synthetic RWM distribution is very similar to that of the Demuth et al. (2006) RMW estimates, which are based on a combination of satellite imagery, aircraft, ship and surface reports of North Atlantic storms occurring between 1988 and 2006 (Figure 14a). The Kossin et al. (2007) data, which are satellite-based RMW estimates of North Atlantic storms from 1983 through 2005, have a distribution that exhibits much less variability than either the Demuth et al (2006) or the modeled synthetic distribution. The modeled RMWs exhibit a lognormal distribution with values ranging from 10 to $250 \mathrm{~km}$ (Figure 14b). The observational datasets suggest that more (less) intense storms have, on average, smaller (larger) RMWs (Figure 14c). The synthetic RMW values, which were modeled by assuming partial angular momentum conservation, appear to reasonably replicate the observed relationship between storm intensity and size distributions (Figure 14d). 


\section{Discussion}

\subsection{Comparison of historic and synthetic storm datasets}

Overall, the synthetic storm model does an excellent job of replicating the historic tropical cyclone characteristics that are relevant to and required for the simulation of storm surge. While the underlying distributions of modeled and observed surge-relevant parameters appear very similar (Figures A2.5, A2.6), the synthetic method provides a sample size forty times larger than the Best Track dataset. The overall frequency of storms passing through the $500-\mathrm{km}$ radius is slightly higher (by about 0.2 storms year $^{-1}$ ) in the model than in the historic record. The frequency of category 5 storms passing through the northeastern Gulf of Mexico is three times greater in the synthetic record. This may reflect the fact that a portion of the storm model was constructed using observations from only the last few decades (Emanuel et al. 2006), which may have been unusually favorable for North Atlantic hurricane activity. The low frequency of high intensity storms may also result from an observational bias in the Best Track dataset. In the first four decades of the Best Track dataset, only one category 4 storm passed through the search radius, but in the subsequent forty years nine category 4 storms passed through the region. Additionally, no category 5 storms affected the region until 1960 A.D., after which there were an average of one per decade. This is consistent with the syntheticallyderived return time of 11 years for category 5 storms in the northeastern Gulf of Mexico (Table A2.2).

\subsection{Model comparisons for historic storm surges}

For historic storms that traveled roughly parallel to Florida's west coast, surges modeled in SLOSH tended to be somewhat larger in the EGLL basin when compared to the smaller APC basin (Table A2.3). Additional surge caused by 
coastally trapped Kelvin waves, which the Gulf-wide EGLL basin can adequately simulate, is the most likely explanation for this. The only Best Track storm with a significantly larger (about $80 \mathrm{~cm}$ ) surge modeled in the APC basin was storm \# 3 of 1886 A.D., which approached Bald Point from the southwest and, therefore, likely did not trigger a trapped wave. Modeled surges tended to increase most with the size of the model domain for storms like Hurricane Elena and Dennis, which produced remotely-generated surges that propagated into Apalachee Bay without affecting Bald Point directly with their strongest winds.

Significant differences of $50 \mathrm{~cm}$ or more in modeled surge also exist between the Best Track SLOSH EGLL and ADCIRC simulations for storm \# 5 of 1852 A.D., storms \# 2 and 3 of 1886 A.D. and Hurricane Elena (Table A2.3). The two surge models employ different parametric wind fields, bathymetric and topographic representations, frictional coefficients and other differences that may account for inconsistencies in some of the historic surge simulations. Though not included in SLOSH, ADCIRC indicates that wave setup typically contributes a few $\mathrm{cm}$ to the storm tide, which is the total "still" water level that results from the combined effects of storm surge, wave setup, and astronomical tide (Table A2.4). Astronomical tide may add or subtract up to $50 \mathrm{~cm}$ to the storm tide. ADCIRC indicates that significant wave heights during storms tend to scale with the magnitude of the surge. Wave runup is likely a significant component of flooding and inundation extent. For these reasons, surge simulations made with the SLOSH model should be considered minimum estimates of the flooding level.

The Best Track simulations indicate that Bald Point is susceptible to significant surges that can be generated by a broad range of storm intensities. Hurricanes ranging from category 1 to category 4 storms were responsible for producing at least $1 \mathrm{~m}$ of surge at the site since 1851 A.D. According to the ADCIRC model, the largest historic surge of $5.3 \mathrm{~m}$ was caused by a direct hit from a category 2 storm in 1852 A.D. 


\subsection{Surge frequency and return time estimates}

Surge frequency and return time estimates based on the Best Track simulations in SLOSH are roughly the same in both the APC and EGLL basins for surges smaller than about $2.5 \mathrm{~m}$. Larger surges were estimated to be more frequent in the EGLL basin due to the amplification of most surges by the trapped-wave phenomenon. Small surge frequencies were estimated to be slightly higher based on the APC surges, but this is likely an artifact of small sample size and the tail of the EGLL surge distribution on the shape of the frequency and return time curves.

Surges larger than $2 \mathrm{~m}$ were estimated to be more frequent when ADCIRC was used instead of SLOSH. Historic surges in ADCIRC were, on average, $20 \mathrm{~cm}$ larger than those modeled in the EGLL basin and $50 \mathrm{~cm}$ larger than those in the APC basin. One reason for this may be that ADCIRC's larger model domain may model the effects of trapped waves better than either SLOSH basin. Other previously discussed differences between SLOSH and ADCIRC may also play a role. With the

effects of astronomical tide and wave setup included, the ADCIRC estimates of surge frequency increase for surges up to $4.5 \mathrm{~m}$. Beyond $4.5 \mathrm{~m}$, the tail of the ADCIRC distribution is composed of one value, which is the modeled surge from the 1852 A.D. storm. ADCIRC applied a $30 \mathrm{~cm}$ adjustment to account for low astronomical tide during this storm, and this is why event frequency estimated from the surge only case increases for the largest surges relative to the total storm tide case. This emphasizes the difficulty of estimating the rate of occurrence of rare events by applying statistical analyses to small datasets.

Surge frequency and return time estimates using the synthetic method indicate that surges of all magnitudes are more common than the Best Track SLOSH results would suggest. This is especially true for surges smaller than $2.5 \mathrm{~m}$, which the synthetic method estimates to be significantly more frequent than the historic SLOSH and ADCIRC simulations indicate. This is likely due to an overestimation of surge in SLOSH for very large but weak storms. In the Best Track simulations, the mean 
value of $392 \mathrm{~km}$ for Ro was used, which resulted in an upper limit of about $150 \mathrm{~km}$ for RMW (Figure A2.5d). The lognormal distribution of Ro that was used in the synthetic simulations allowed for RMW to range up to $250 \mathrm{~km}$ (Figure 14b). While this provided a more realistic RMW distribution, SLOSH has difficulty producing realistic wind fields for very large storms (Jelesnianski et al. 1992). The effect on surge may be especially pronounced in Apalachee Bay, where large wind fields may enhance water levels by generating trapped coastal waves. For surges larger than 2.5 $m$ and smaller than 4.5 meters, synthetic SLOSH estimates fall between the Best Track-based estimates made with the SLOSH and ADCIRC results. Surges exceeding $4.5 \mathrm{~m}$ were estimated by the synthetic method to be more frequent than historic records would suggest.

In the synthetic case, surges $<6 \mathrm{~m}$ were estimated to be more common when the EGLL data were used instead of the APC data (Figures 3,4). Again, this likely reflects the role of trapped Kelvin waves in determining the surge climate at the site. However, for largest surges ( $>6 \mathrm{~m}$ or $\sim 700$-year event) at Bald Point were simulated in the APC basin, and this is reflected in the tail of the storm frequency and return time curves. The higher resolution of the APC basin relative to the EGLL basin together with an inundation model allows the APC basin to better simulate the most extreme surges associated with direct strikes from the most intense storms. The coarser resolution of the EGLL basin averages out the smaller scale variability in the spatial distribution of surges. The EGLL basin also treats the shoreline like a wall, whereas the APC basin permits the tilt of the water surface to extend inland allowing the greatest water levels relative to sea level to be properly simulated.

The shape of the return time curve has important implications for coastal flooding risk assessment and paleohurricane research. Regardless of which set of simulations is considered, there exists an inflection point above which return times increase dramatically (Figure 5). As sea levels rise, some coastal communities will experience disproportionate increases in flooding frequency depending upon their elevation and the local shape of this curve. Similarly, paleohurricane research sites at 
elevations that have remained in the horizontal portion of the curve likely document changes in storm climate rather than changes in flooding susceptibility due to sea level change. On the other hand, study sites located at elevations near the inflection point would document only a brief period of the most intense storm strikes if sea level had been rising. When taken with sea level reconstructions from the area which suggest about $3 \mathrm{~m}$ of sea level rise over the last four millennia (Wright et al. 2005), this finding implies that paleohurricane sites along Apalachee Bay that are now located near sea level have been subject to routine inundation for at least the last few thousand years. Significant variations in inundation frequency at such sites would likely reflect changes in storm climate rather than site elevation relative to sea level.

\subsection{Geographic distribution of coastal flooding risk}

Maps of the 100-year surge in the APC and EGLL basins (Figures 6, 8) demonstrate that, though Bald Point is susceptible to large surges, other portions of Apalachee Bay are even more prone to extreme surges. The maximum 100-year event in both the APC $(5.3 \mathrm{~m})$ and EGLL basins $(5.1 \mathrm{~m})$ is located along (EGLL) or just landward (APC) of the normal shoreline position near the head of Apalachee Bay. The 100-year surge at Bald Point is approximately $4 \mathrm{~m}$ in both basins. The maximum "worst case" surge for each location in the APC basin $(12.3 \mathrm{~m})$ is located several kilometers inland and is significantly larger than the "worst case" value of 10.9 m modeled near the head of Apalachee Bay in the EGLL basin (Figures 7,9). This underscores the importance of model resolution and inundation when attempting to simulate the rarest and largest events. Mapping surge susceptibility in this way reveals that surge climate can vary dramatically over relatively small distances. The largest plausible storm surge in the APC basin varies over $8 \mathrm{~m}$ depending upon the coastal location considered, and this variability is controlled primarily by bathymetry, coastline shape and coastal topography. 


\subsection{Storm intensity and surge magnitude}

The storms producing the ten largest surges in the APC basin at Bald Point in the synthetic record all make landfall just west of the site at category 4 or 5 intensity. In this basin, the most extreme surges result from maximum onshore winds at the site. The largest surges at Bald Point as modeled in the EGLL basin were generated by storms having a broader range of intensities, angles of approach and landfall locations. Because the contributions of trapped waves are included in the EGLL basin, the largest surges do not necessarily coincide with the strongest onshore winds.

Though the most extreme surge events in both basins were associated with either category 4 or 5 storms, this does not imply that there is a direct relationship between storm intensity and storm surge. Significant surges at a location, the 100year event for example, are more likely to result from storms of moderate intensity (category 2 and 3 storms) than from extremely intense storms. This is partly due to the overall higher frequency of category 2 and 3 storms when compared to higher category storms. The inverse relationship between a storm's intensity and the size of its wind field also plays a role (Figure 14c,d). As a storm intensifies, its wind field contracts and the fetch and time over which the wind stress acts also decrease resulting in smaller surge. The surges generated by smaller storms also impact shorter stretches of coastline. However, the same pattern can be generalized to entire model basins implying that the spatial extent of surge plays less of a role than the effect of partial angular momentum conservation (Figures A2.13, A2.14).

This finding implies that it may not be possible to infer the Saffir-Simpson category of a paleohurricane in a sediment-based record by merely constraining the magnitude of the storm surge that produced an overwash deposit. Unless recording only exceedingly rare surges ( $\sim 500$-year events), sedimentary records of coastal flooding likely represent a broad cross-section of storm intensities. Even on a stormby-storm, these findings indicate that the Saffir-Simpson scale is inadequate for classifying storms by surge. For example, though hurricanes Camille (category 5, 
1969 A.D.) and Katrina (2005 A.D., category 3) took very similar paths and impacted similar areas, Katrina produced a larger and more extensive surge due to its larger size at landfall though it was the weaker of the two storms. Given the disconnect between storm category and surge that these findings suggest and the fact that storm surge is the most damaging and fatal dimension of tropical cyclones, the SaffirSimpson scale is inadequate for communicating the risks that hurricanes pose.

\section{Conclusions}

Understanding the rate at which hurricane-generated storm surges of various magnitudes occur is a necessary step toward quantifying the risk that these events pose to coastal communities and interpreting sediment-based records of hurricane activity and variability. The novel method presented here relates the frequency of storm surges to their magnitude and provides an approximate upper limit of flooding that can occur at any location in the Apalachee Bay region. The 100-year and "worst case" events were estimated to be about $4 \mathrm{~m}$ and $8 \mathrm{~m}$, respectively, at Bald Point, and about $5.2 \mathrm{~m}$ and $12.3 \mathrm{~m}$, respectively, near the head of Apalachee Bay.

The results indicate that Apalachee Bay is more vulnerable to storm surge than any other region in the eastern Gulf of Mexico, and that significant variability in susceptibility exists over relatively small distances. On the regional scale of this study, the variability in surge risk largely results from local differences in bathymetry, coastal topography and coastline geometry rather than from spatial variability in storm climate. When taken with sea level reconstructions from the area, these finding implies that paleohurricane sites along Apalachee Bay that are now located near sea level have been subject to routine inundation for at least the last few thousand years. Significant variations in inundation frequency at such sites would likely reflect changes in storm climate rather than site elevation relative to sea level.

The simulations suggest that a large surge model domain is required to adequately simulate the effects of coastally-trapped Kelvin waves, which often form 
as storms track northward in this region and can ultimately amplify the final maximum surge in Apalachee Bay. On the other hand, higher surge model resolution and an inundation scheme are apparently required to appropriately simulate the most extreme (500-year) surge events.

While extreme surge events were generated by the uppermost storm intensities, most large surges (100-year events) resulted from a wider range (category 2 to category 5 storms) of intensities with moderately intense storms most likely to produce such events. One reason medium intensity storms shoulder a surprising proportion of surge-related risk is that they outnumber extremely intense storms. They also tend to have larger wind fields, which can produce larger and more extensive surges than the more compact wind fields of more intense storms. This finding implies that overwash-based paleohurricane intensities should be inferred with caution and also suggests that the way in which hurricane-related perils are communicated to the public could benefit from the consideration of how storm size, intensity, and surge are related. It may not be possible to infer the Saffir-Simpson category of a paleohurricane in a sediment-based record by merely constraining the magnitude of the storm surge that produced an overwash deposit. Unless recording only exceedingly rare surges ( $~ 500$-year events), sedimentary records of coastal flooding likely represent a broad cross-section of storm intensities. 


\section{Acknowledgements}

I would like to thank Kerry Emanuel and Sai Ravela at MIT for providing the synthetic storm dataset and advice on its use, Jeff Dusenberry at WHOI and Jaime Rhome, Tarah Sharon, Steven Morey and Rebecca Waddington at the National Hurricane Center for help with the SLOSH model, Daniel Chavas at MIT for making the hurricane size datesets available, and Ning Lin at MIT for her help with the ADCIRC simulations of Best Track storms.

\section{References}

Ackers, P. and T.D. Ruxton. 1975. Extreme levels arising from meteorological surges. Proceedings of the $14^{\text {th }}$ Coastal Engineering Conference. ASCE, N.Y. pp. 69-96.

American Meteorological Society (AMS). 1973. Policy statement on hurricanes by the American Meteorological Society. Bulletin of the American Meteorological Society, 54: 46-47.

Boldt, K.V., Lane, P., Woodruff, J.D., Donnelly, J.P., 2010. Calibrating a sedimentary record of overwash from southeastern New England using modeled historic hurricane surges. Marine Geology. v. 275, p.127-139.

Boose, E.R., Chamberlin, K.E., Foster, D.R., 2001. Landscape and regional impacts of hurricanes in New England. Ecological Monographs. 71(1): 27-48.

Coles, S.G. and J.A. Tawn. 1990. Statistics of coastal flood prevention. Philosophical Transactions of the Royal Society of London, A. 332. pp. 457-476.

Dean, L., K. A. Emanuel, and D. R. Chavas. 2009. On the size distribution of Atlantic tropical cyclones, Geophys. Res. Lett., 36, L14803, doi: 10.1029/2009GL039051.

Demuth, J.L., DeMaria, M. and J.A. Knaff. 2006. Improvement of advanced microwave sounding unit tropical cyclone intensity and size estimation algorithms. Journal of Applied Meteorology and Climatology. 45. pp. 1573 - 1581.

Donnelly, J.P., et al., 2001. Sedimentary evidence of intense hurricane strikes from New Jersey. Geology. 29: 615-618.

Donnelly, J.P. et al. 2001. $700 \mathrm{yr}$ sedimentary record of intense hurricane landfalls in southern New England. GSA Bulletin. 113(6): 714-727.

Elsner, J.B. and A.B. Kara, 1999. Hurricanes of the North Atlantic. Oxford Univ. Press. 488 pp. 
Emanuel, K., DesAutels, C., Holloway, C., and R. Korty. 2004. Environmental Control of Tropical Cyclone Intensity. Journal of Atmospheric Science. 61. pp. 843 858.

Emanuel, K., Ravela, S., Vivant, E. and C. Risi. 2006. A Statistical Deterministic Approach to Hurricane Risk Assessment. Bulletin of the American Meteorological Society. 87(3). pp. $299-314$.

Frank, W.M. 1977. Structure and energetics of the tropical cyclone, part 1, Storm structure. Monthly Weather Review. 105. pp. 1119 - 1135.

Fuhrboter, A. 1979. Frequencies and probabilities of extreme storm surges. Proceedings of the $16^{\text {th }}$ Coastal Engineering Conference. ASCE, N.Y. pp. 949-964.

Gumbel, E.J. 1954. Statistical theory of extreme values and some practical applications. Applied Mathematics, 33. U.S. National Bureau of Standards.

Ho, F.P. 1974. Storm tide frequency analysis for the coast of Georgia. NOAA Technical Memorandum NWS HYDRO 19. Office of Hydrology, NWS, Silver Spring, M.D.

Ho, F.P. and R.J. Tracey. 1975. Storm tide frequency analysis for the coast of North Carolina, south of Cape Lookout. NOAA Technical Memorandum NWS HYDRO 21. Office of Hydrology, NWS, Silver Spring, M.D.

Ho, F. P. and R. J. Tracey, 1975: Storm tide frequency analysis for the Gulf coast of Florida, from Cape San Blas to St. Petersburg Beach. NOAA Technical Memorandum NWS HYDRO 20, Office of Hydrology, NWS, Silver Spring, MD.

Hsu, S.A. and Yan, Z. 1998. A note on the radius of maximum wind for hurricanes. Journal of Coastal Research. 14(2). pp. 667-668.

Holland, G.J. 1980. An analytic model of the wind and pressure profiles in hurricanes. Monthly Weather Review. 108. pp. 1212-1218.

Holland, G. 2008. A revised hurricane pressure-wind model. Monthly Weather Review. 136. pp. 3432-3445.

Houston, S.H., Shaffer, W.A., Powell, M.D., and J. Chen. 1999. Comparisons of HRD and SLOSH surface wind fields in hurricanes: implications for storm surge modeling. Weather and Forecasting. 14. pp. 671-686. 
Howes, B.L. and D.D. Geohringer, 1996. Ecology of Buzzards Bay: An Estuarine Profile. Biological Report 31. 146 pp.

Jarvinen, B. 2006. A Look at the Storm Tides in Twelve Tropical Cyclones Including Four Intense New England Hurricanes. NOAA/Tropical Prediction Center/National Hurricane Center. pp. 99.

Jelesnianski, C.P. 1966. Numerical computations of storm surges without bottom stress. Monthly Weather Review. 94(6). pp. 379-394.

Jelesnianski, C.P. 1967. Numerical computations of storm surges with bottom stress. Monthly Weather Review. 95(11). pp. 740-756.

Jelesnianski, C.P., Chen, J. and W.A. Shaffer. 1992. SLOSH: Sea, Lake, and Overland Surges from Hurricanes. NOAA Technical Report NWS 48, April 1992, Silver Spring, Maryland.

Jenkinson, A.F. 1969. Estimation of maximum floods. World Meteorological Office Technical Note 98, Chapter 5.

Kabir, M.M., Saha B.C., Hye, J.M.A. 2007. Cyclonic Storm Surge Modeling for the Design of Coastal Polder. Institute of Water Modeling.

Knabb, R.D., Rhome, J.R., Brown, D.P. 2006. Tropical Cyclone Report: Hurricane Katrina: 23-30 August 2005. National Hurricane Center.

Kossin, J.P., Knaff, J.A., Berger, H.I., Herndon, D.C., Cram, T.A., Velden, C.S., Murnane, R.J., and J.D. Hawkins. 2007. Estimating hurricane wind structure in the absence of aircraft reconnaissance. Weather and Forecasting. 22. 89-101.

Ludlum, D.M. 1963. Early American Hurricanes: 1492-1870. American Meteorological Society. 198 pp.

Luettich, R.A., Westerink, J.J. and N.W. Scheffner. 1992. ADCIRC: An advanced three-dimensional circulation model for shelves, coasts, and estuaries. Report 1: Theory and methodology of ADCIRC-2DDI and ADCIRC-3DL, Dredging Research Program Technical Report. DRP-92-6, Coastal Engineering Research Center Vicksburg, Mississippi.

Marks, D.G. 1992. The beta and advection model for hurricane track forecasting. NOAA Technical Memorandum. NWS NMC 70. 89 pp.

Murty, T.S. 1984. Storm surges: meteorological ocean tides. J. Fisheries Aquatic Sciences Bull. No. 212. Ottawa, Canada. 
Murty, T.S. 1988. List of major natural disasters, 1960-1987. Natural Hazzards. 1. pp. 303-304.

Myers, V.A. 1970. Joint probability method of tide frequency analysis applied to Atlantic City and Long Beach Island, N.J. ESSA Technical Memorandum. WBTM HYDRO 11. Silver Spring, M.D.

Myers, V.A. 1975. Storm tide frequency on the South Carolina coast. NOAA Technical Rep. NWS 16. Silver Spring, M.D.

National Geophysical Data Center (NGDC). 2007. Coastline Extractor. World Data Bank II (designed for 1:2,000,000). < http://rimmer.ngdc.noaa.gov/coast/>

Nicholls, R.J. 1995. Coastal megacities and climate change. GeoJournal, 37.3. pp. 369-379.

NOAA. 2007. The Deadliest Atlantic Tropical Cyclones: 1492 -1996.

$<$ http://www.nhc.noaa.gov/pastdeadlyapp1.shtml $>$

NOAA. 2007. Hurricane Research Division. HURDAT Re-analysis Project. $<$ http://www.aoml.noaa.gov/hrd/hurdat/Data_Storm.html $>$

NOAA. 2007. Tides and Currents. $<$ http://tidesandcurrents.noaa.gov/data_menu.shtml?stn= 8447930\%20Woods\%20Hole,\%20MA\& \&ype=Historic\%20Tide\%20Data $>$.

Pore, N.A. and C.S. Barrientos. 1976. Storm Surge. MESA New York Bight Atlas Monograph 6. New York Sea Grant Institute. Albany, N.Y. 43 pp.

Pugh, P.T. and J.M. Vassie. 1979. Extreme sea levels from tide and surge probabilities. Proceedings of the $16^{\text {th }}$ Coastal Engineering Conference. ASCE, N.Y. pp. 911-930.

Scileppi, E. and J. P. Donnelly, 2007. Sedimentary evidence of hurricane strikes in western Long Island, New York. Geochemistry Geophysics Geosystems. 8: Q06011, doi:10.1029/2006GC001463.

Shah, B.V. 1983. Is the environment becoming more hazardous? - a global survey 1947-1980. Disasters, 7. pp. 202-209.

Reich, B.J. and M. Fuentes. 2007. A multivariate semiparametric Bayesian spatial modeling framework for hurricane surface wind fields. The Annals of Applied Statistics. 1. No. 1 pp 249-264. 
Tannehill, I.R. 1944. Hurricanes. $5^{\text {th }}$ Edition. Princeton University Press, Princeton, N.J.

Tawn, J.A. 1992. Estimating probabilities of extreme sea-levels. Journal of the Royal Statistical Society, Series C, Applied Statistics. 41. No. 1. pp. 77-93.

Tippets, Abbett, McCarthy and Stratton. 1958. Hurricane tide inundation damage survey-New York Harbor, including New York metropolitan area, New York, and New Jersey. Revised Rep. for Corps of Engineers, N.Y. District.

Walton, T.L. Jr. 2000. Distributions for storm surge extremes. Ocean Engineering. 27. 1279-1293.

Westerink, J.J., Leuttich, R.A., Blain, C.A. and N.W. Scheffner. 1992. ADCIRC: An advanced three-dimensional circulation model for shelves, coasts, and estuaries. Report 2: User's Manual for ADCIRC-2DDI, Dredging Research Program Technical Report. DRP-92-6, Coastal Engineering Research Center Vicksburg, Mississippi.

Wright, E.E., Hine, A.C., Goodbred, S.L., Locker, S.D., 2005. The Effect of Sea-Level and Climate Change on the Development of a Mixed Siliciclastic-Carbonate, Deltaic Coastline: Suwannee River, Florida, USA. Journal of Sedimentary Research. 75(4), 621-635.

Yang, C.Y., Parisi, A.M. and W.S. Gaither. 1970. Statistical prediction of hurricane storm surge. Proceedings of the $12^{\text {th }}$ Coastal Engineering Conference. ASCE, N.Y. pp. 2011-2030.

Zhang, K., Douglas, B.C. and S.P. Leatherman, 2000. Twentieth-Century Storm Activity Along the U.S. East Coast. Journal of Climate. 13: 1748 - 1761. 


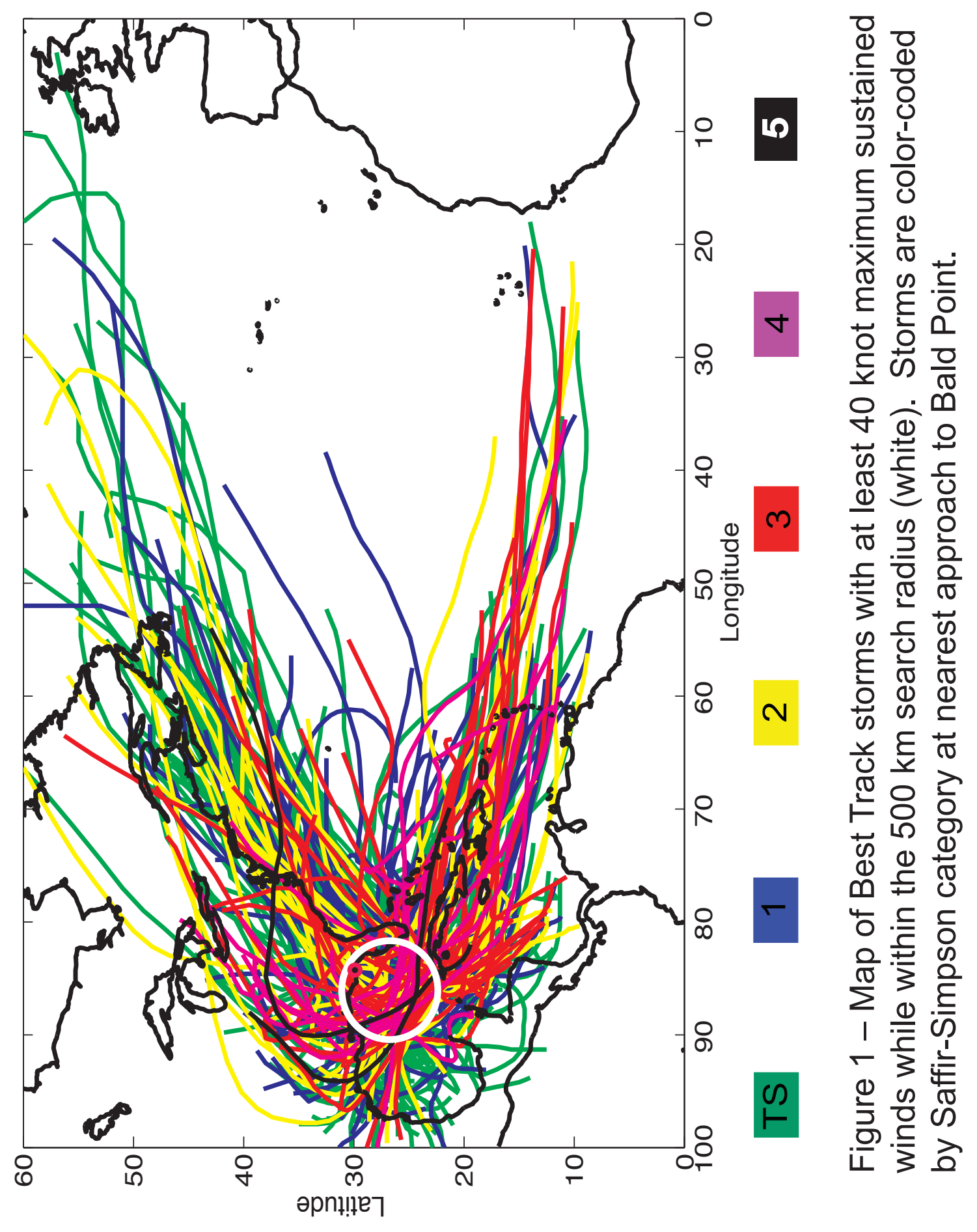




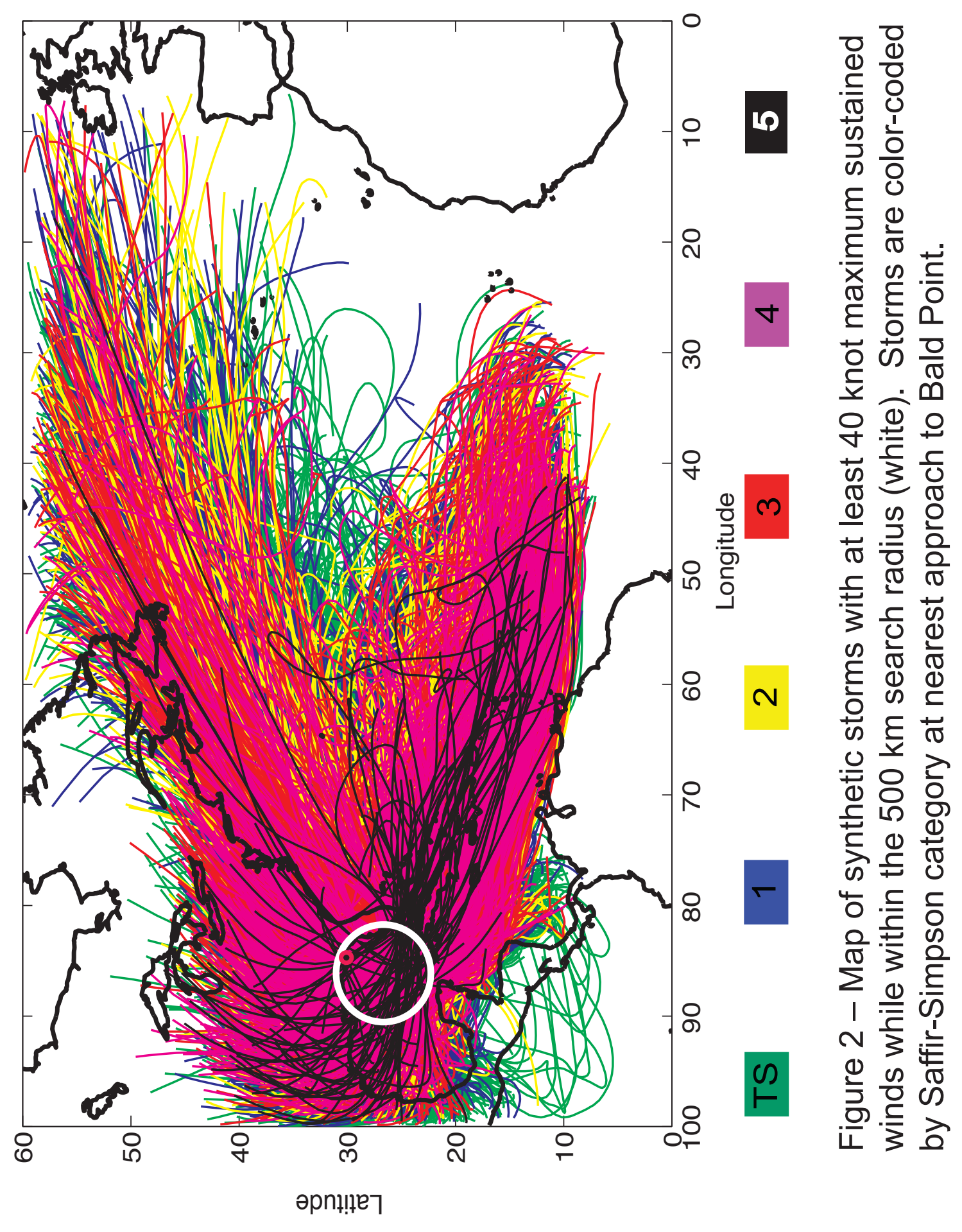




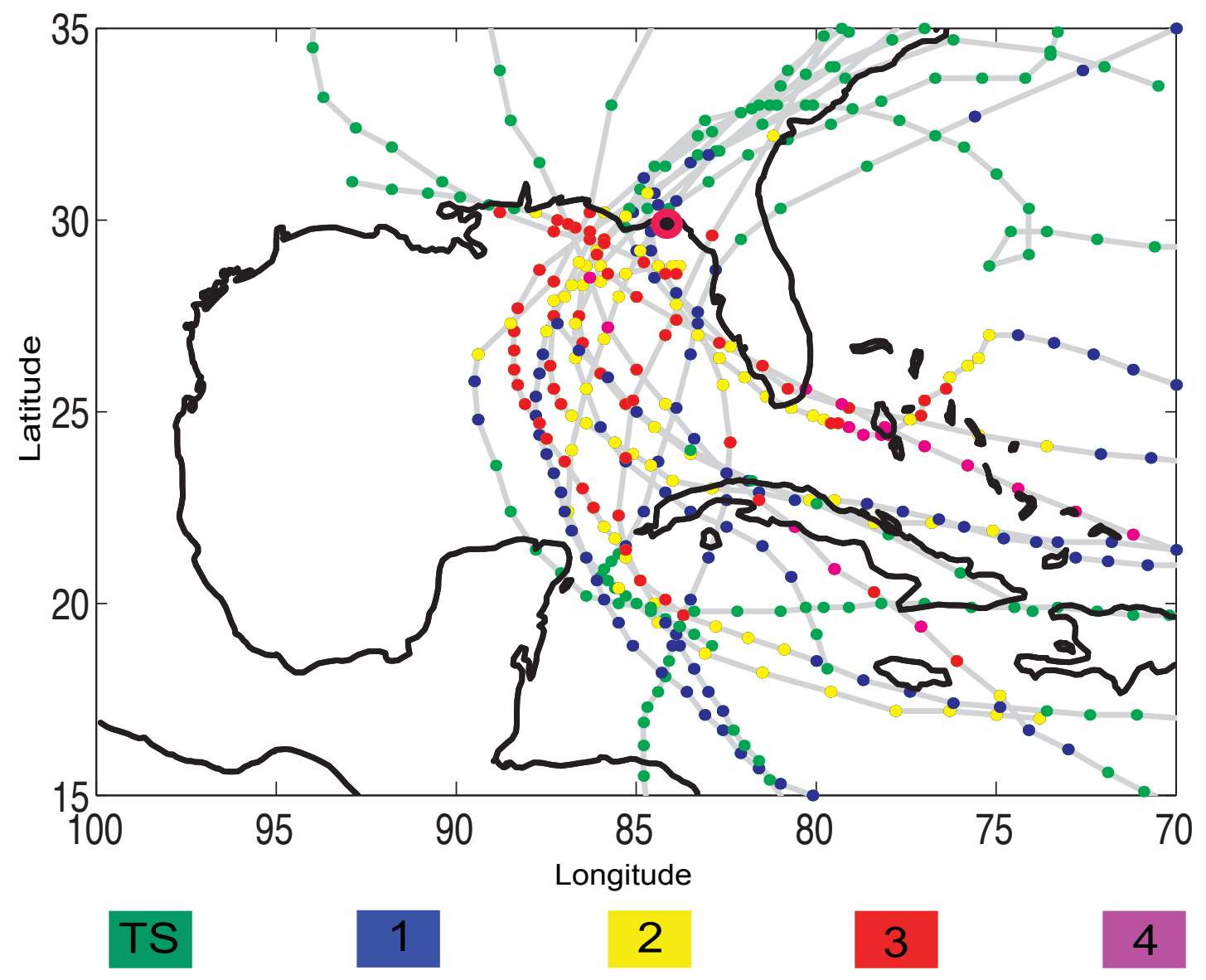

Figure 3 - Map of Best Track storms producing at least $1 \mathrm{~m}$ of surge at Bald Point. Storms are color-coded by their intensity evolution according to the Saffir-Simpson scale. The location of Bald Point is indicted by the bullseye. 


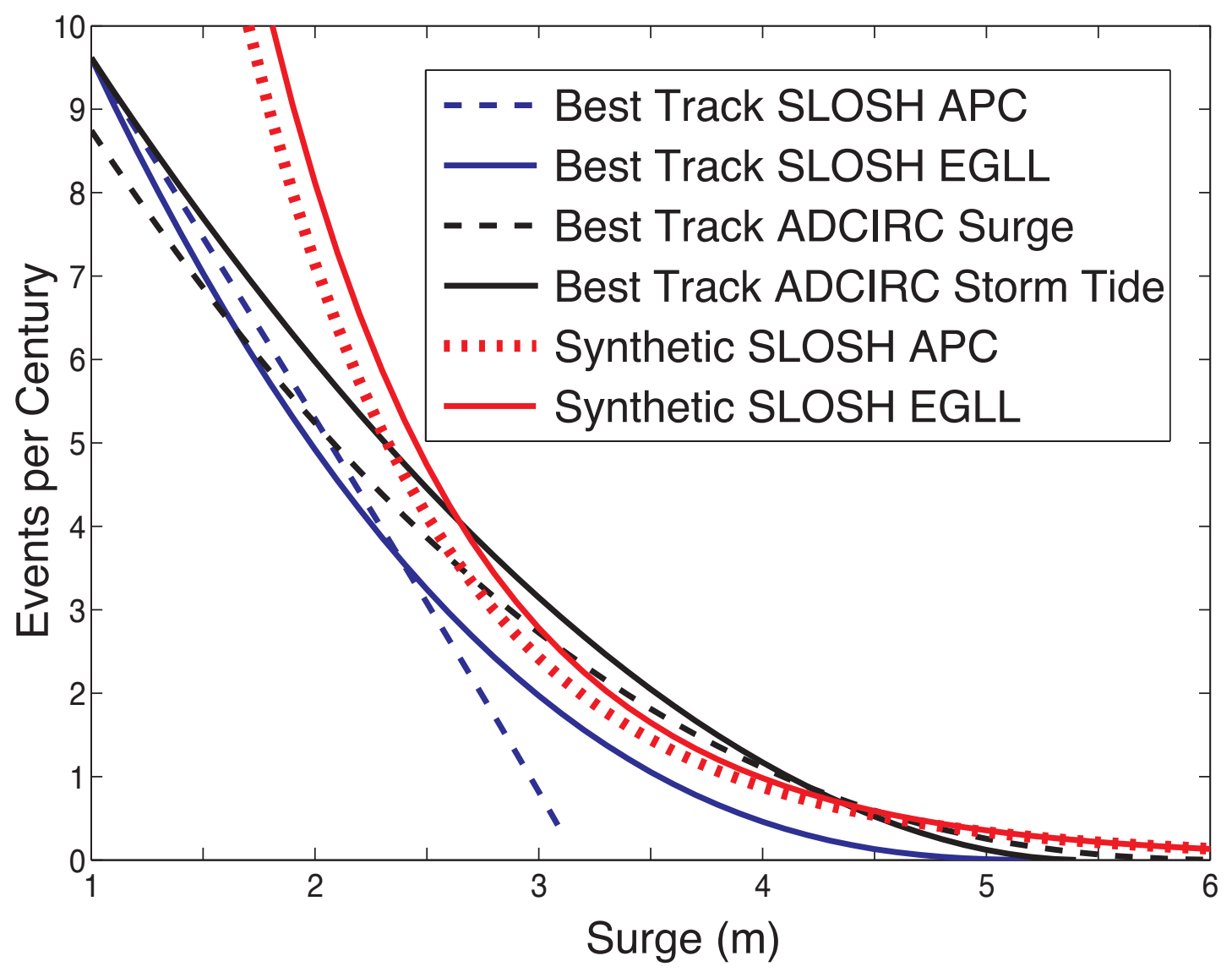

Figure 4 - Surge frequency versus magnitude based on Generalized Pareto Distribution fits to Best Track modeled and synthetic surges at Bald Point in SLOSH APC and EGLL basins and in ADCIRC for surge only and total storm tide values. 


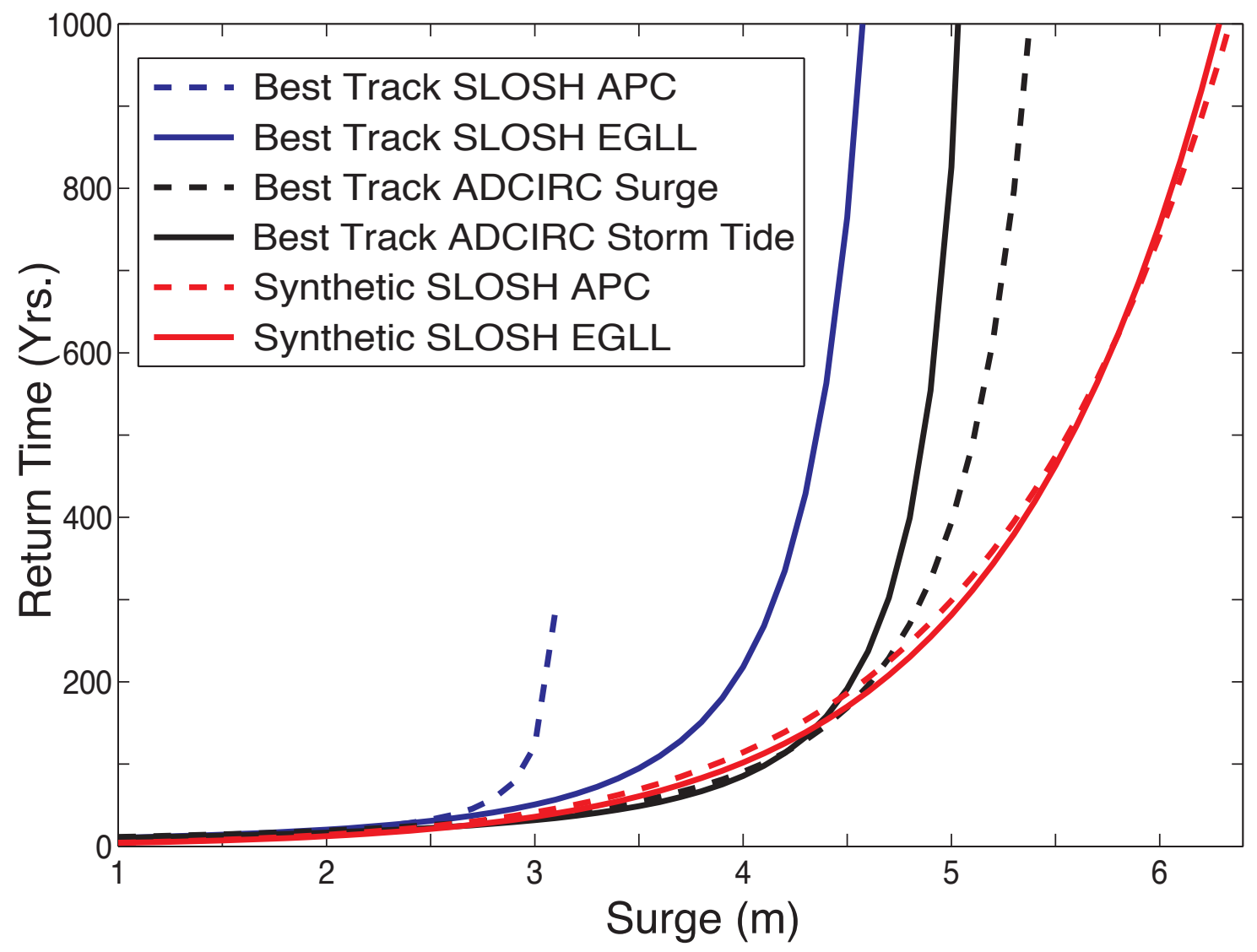

Figure 5 - Return time versus surge magnitude based on Generalized Pareto Distribution fits to Best Track modeled and synthetic surges at Bald Point in SLOSH APC and EGLL basins and in ADCIRC for surge only and total storm tide values. 


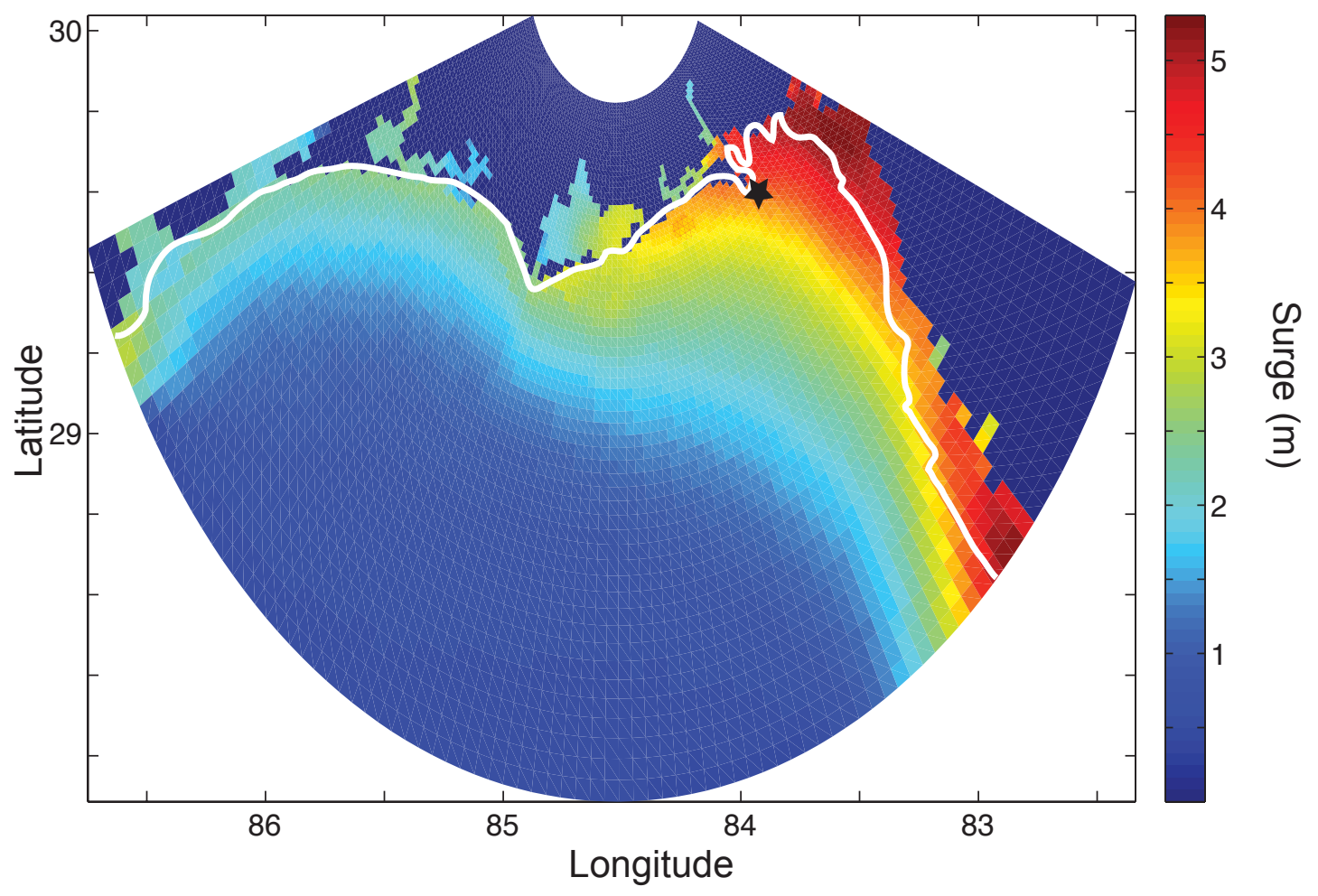

Figure 6 - Map of 100-year event in each grid cell of the SLOSH APC basin. Values derived directly from the 5175-year synthetic record without GPD fit. White line approximates normal position of shoreline. Location of Bald Point is indicated with a black star. 


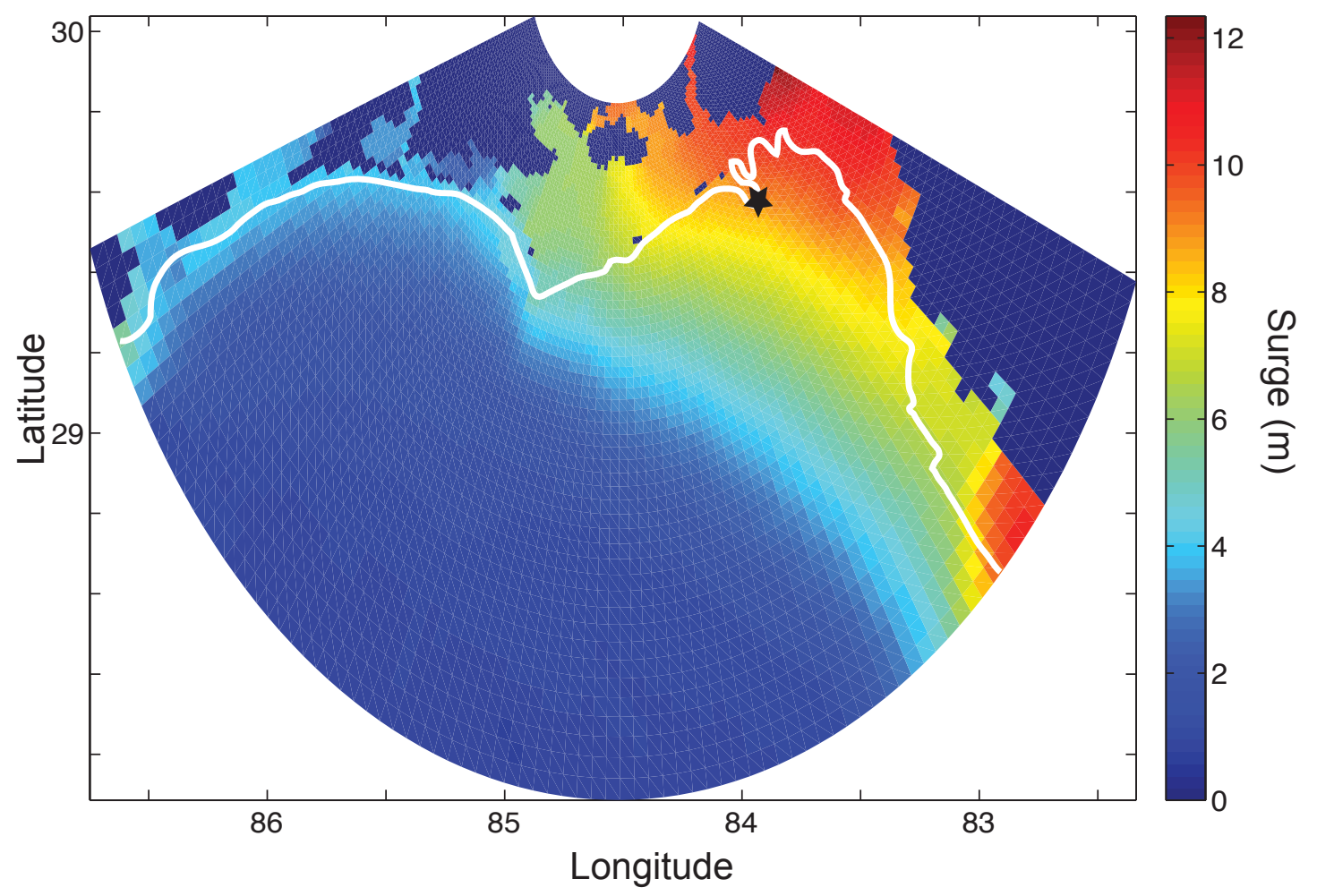

Figure 7 - Map of "worst-case" scenarios for each location in the SLOSH APC basin. For each grid cell, maximum modeled values during the 5175-year synthetic record are shown. White line approximates normal position of shoreline. Location of Bald Point is indicated with a black star. 


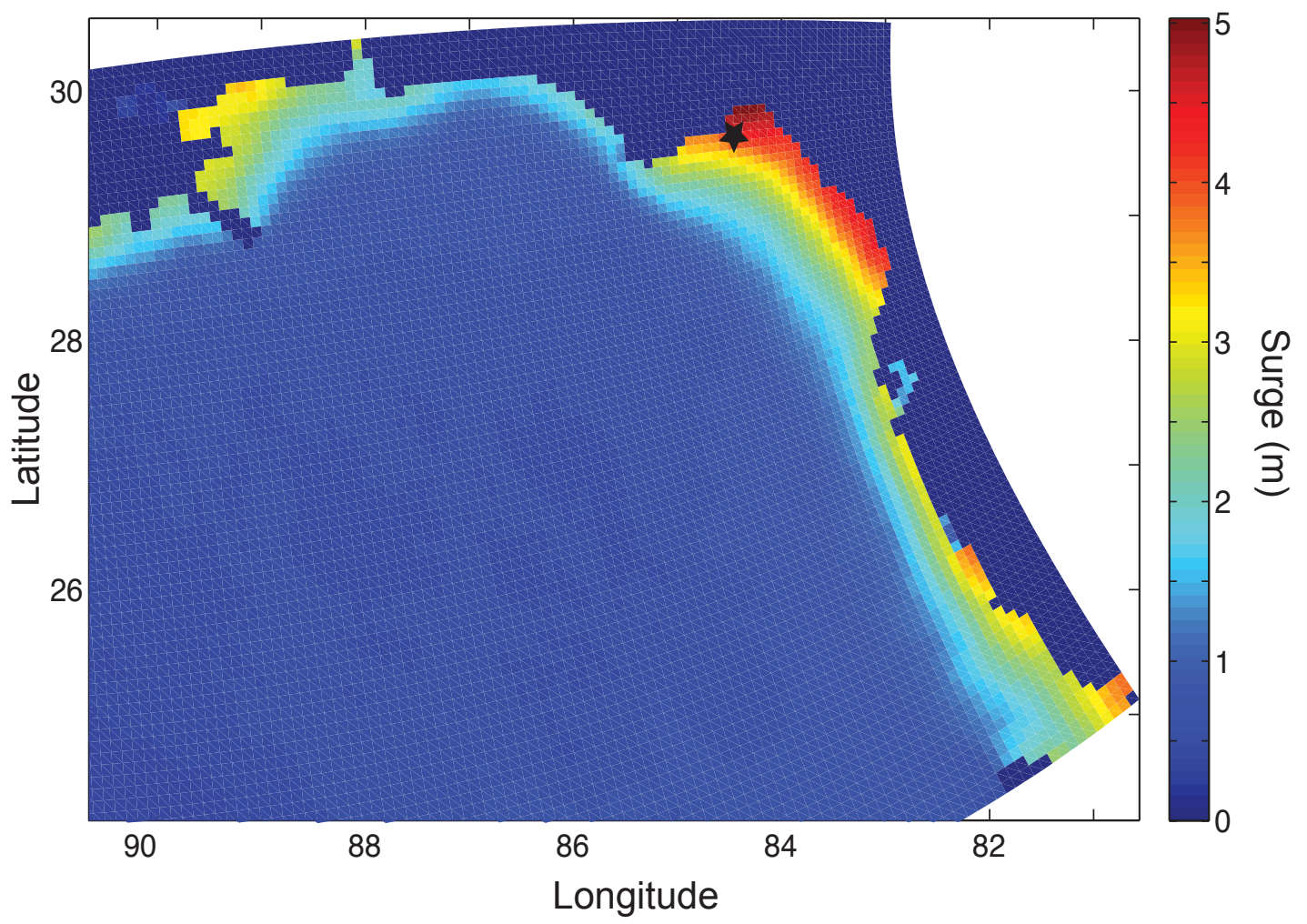

Figure 8 - Map of 100-year event in each grid cell of the northeastern portion of the SLOSH EGLL basin. Values derived directly from the 5175-year synthetic record without GPD fit. Location of Bald Point is indicated with a black star. 


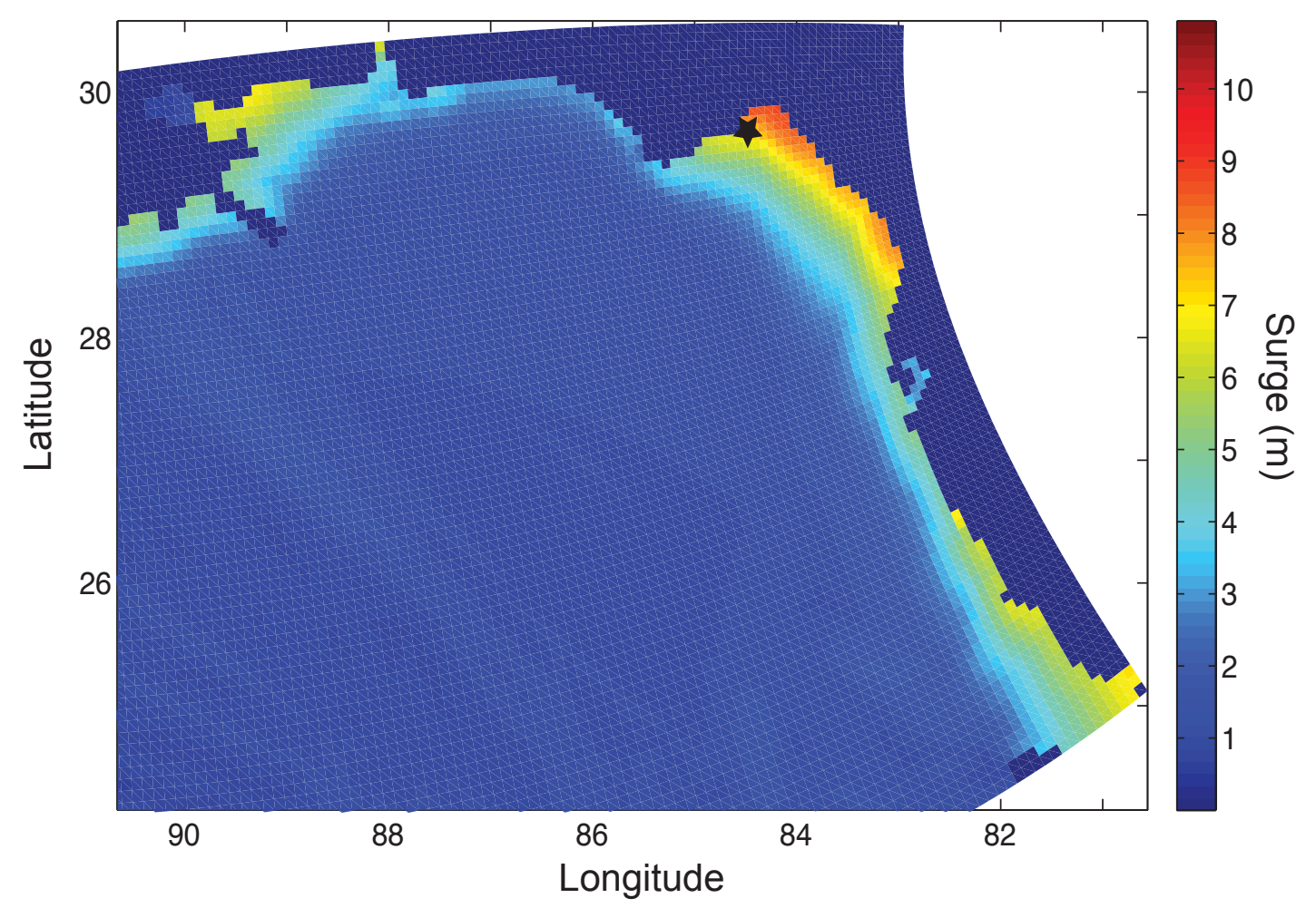

Figure 9 - Map of "worst-case" scenarios for each location in the northeastern portion of the SLOSH EGLL basin. For each grid cell, maximum modeled values during the 5175-year synthetic record are shown. Location of Bald Point is indicated with a black star. 


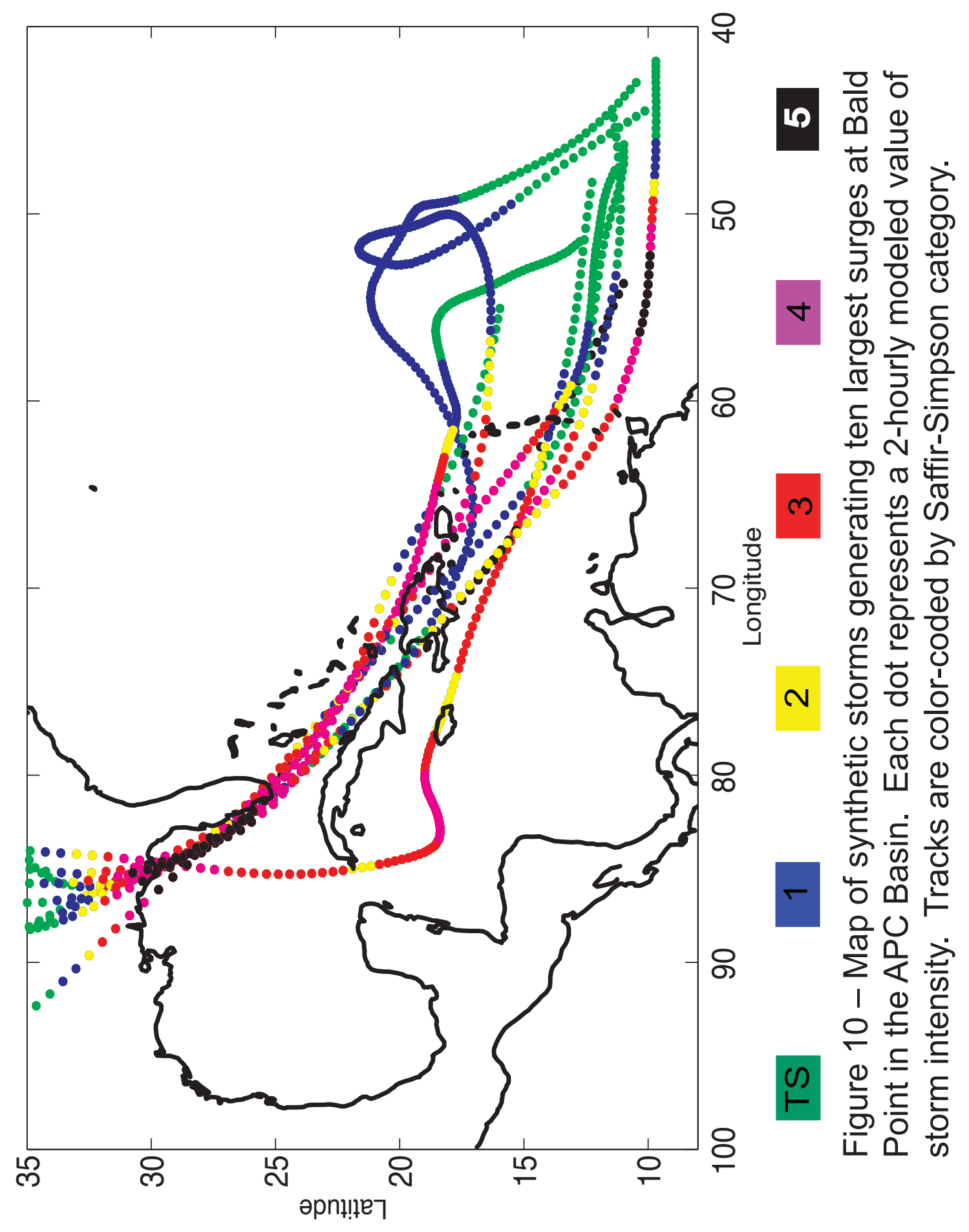




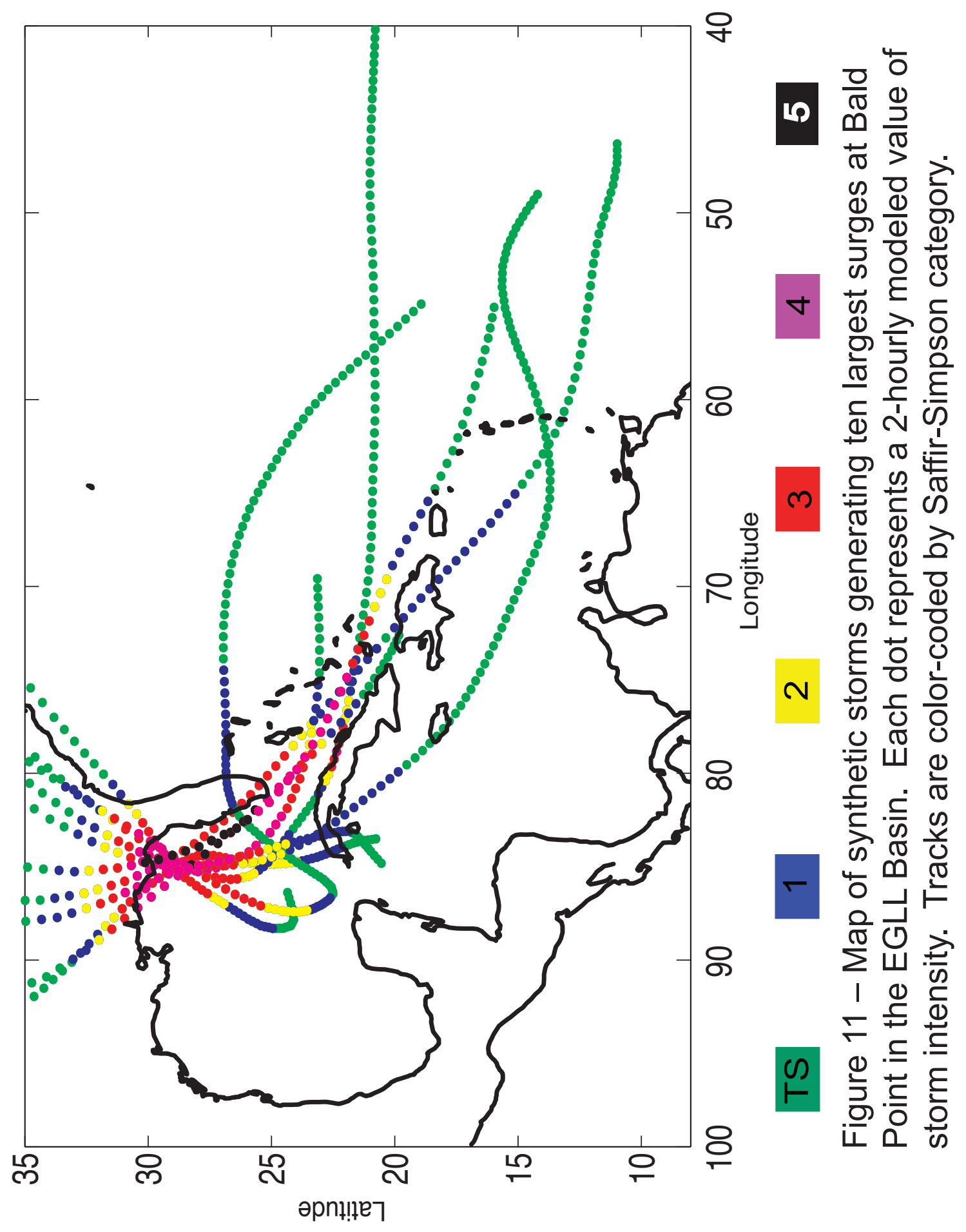




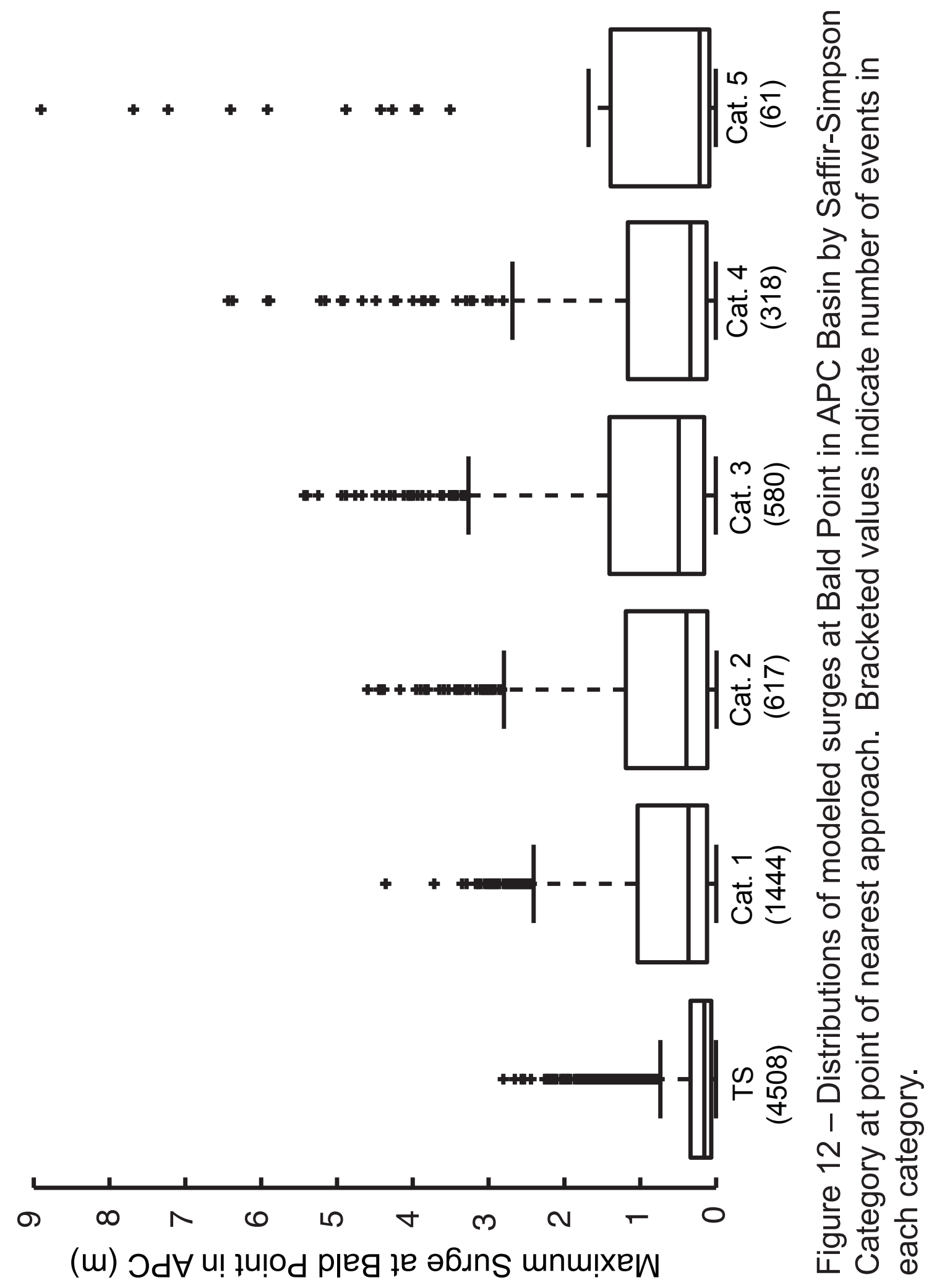




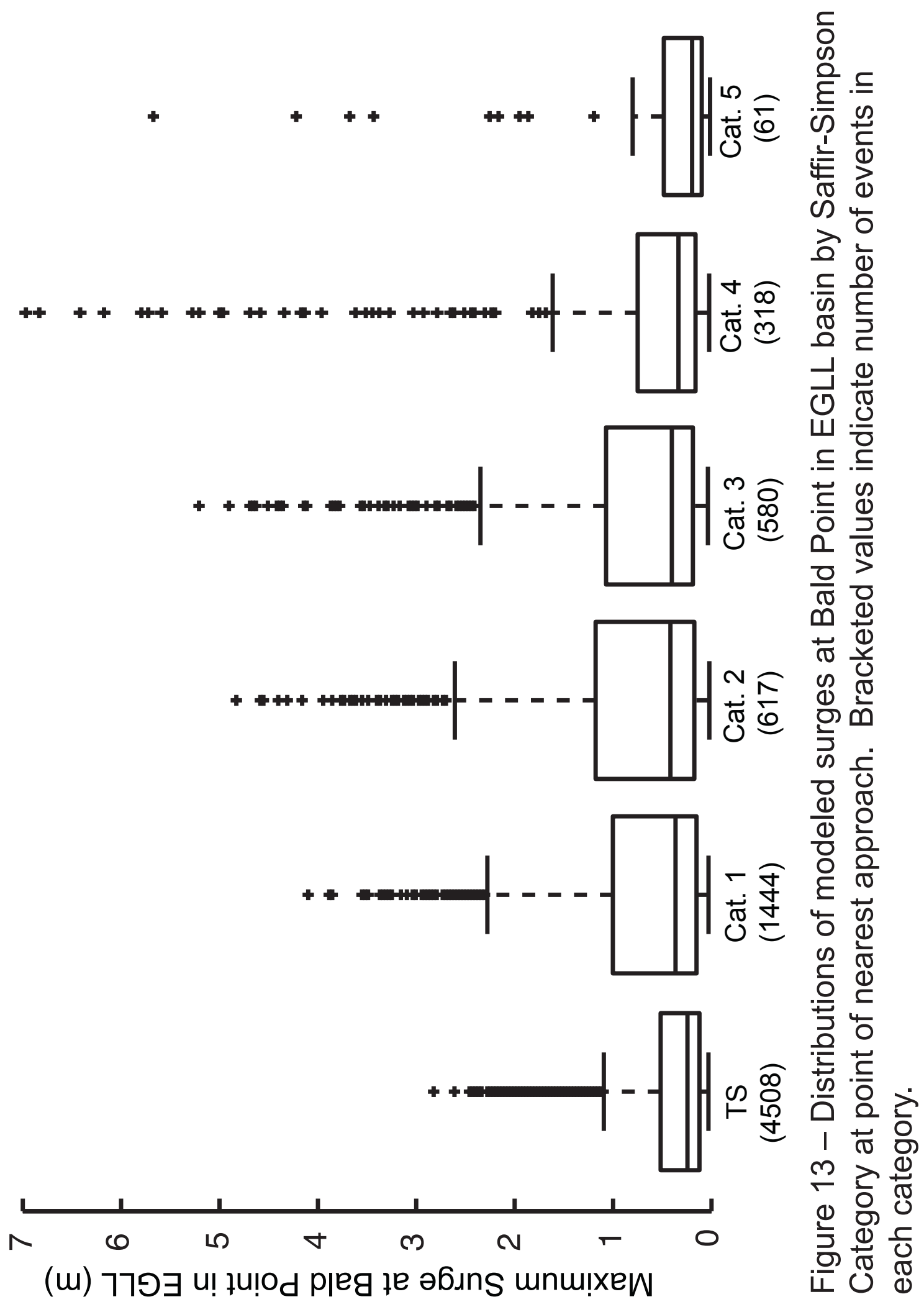



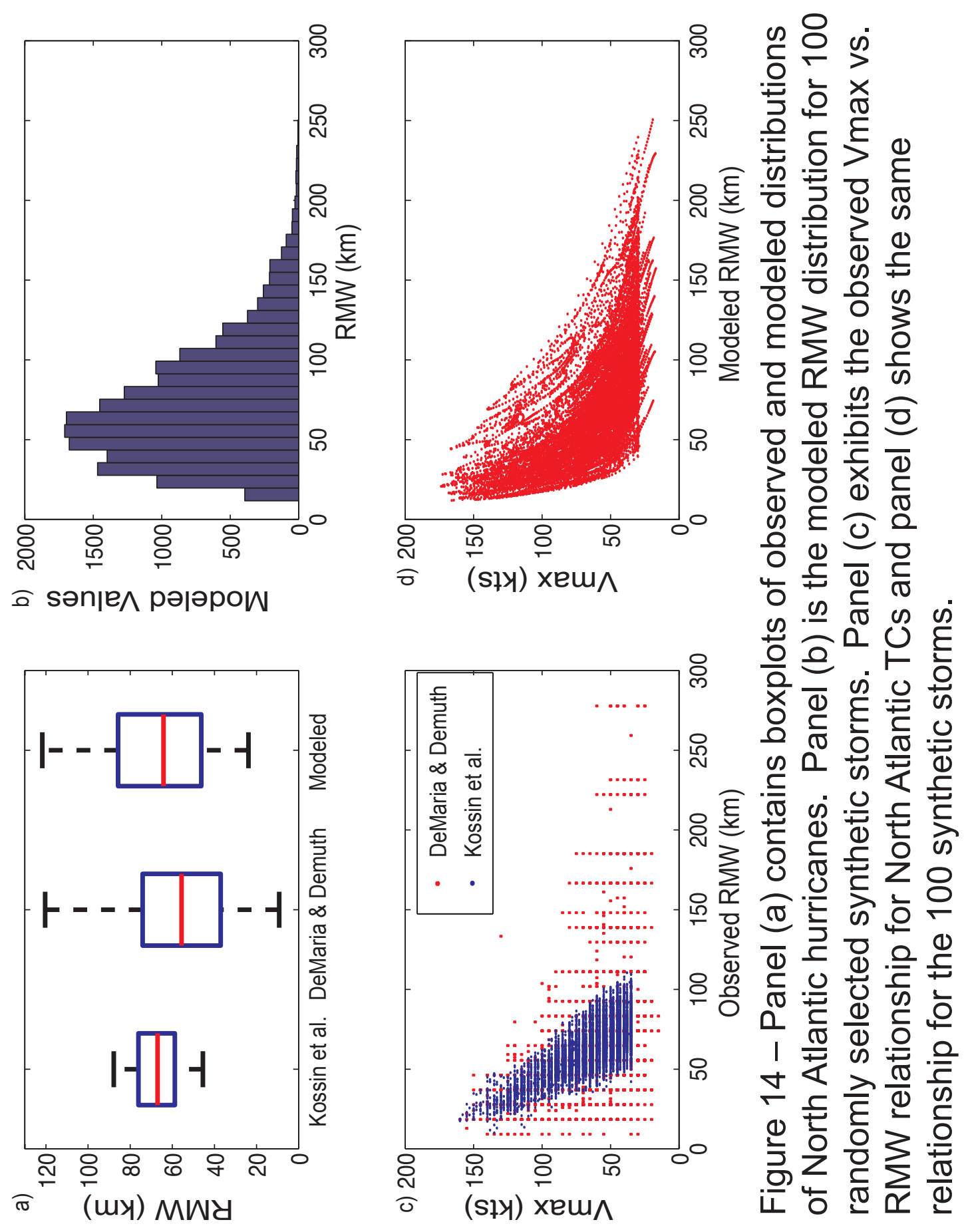


\title{
CHAPTER 4
}

\section{Assessing the role of temporal resolution and geographic boundary conditions on paleohurricane records from Bald Point, Florida}

\begin{abstract}
The most recent $1.65 \mathrm{ka}$ of the Mullet Pond record is reproduced from another sinkhole pond on the Bald Point peninsula. This second site, located approximately 2 $\mathrm{km}$ inland and not adjacent to a sediment-supplying barrier, has geographic boundary conditions similar to what Mullet Pond may have had thousands of years ago. LiDAR data is used to develop a detailed elevation and inundation model of Bald Point, which indicate that both sites currently have very similar flooding thresholds. Together with the historic portion of the records that were used to calibrate these reconstructions, these results suggest that both sites are susceptible to and record similar magnitude surge events. Microfossil evidence from the second site along with the inundation model results suggest that even the interior portions of Bald Point are routinely inundated by surge waters carrying suspended sediments. These findings minimize the role of geographic boundary conditions on paleohurricane reconstructions in this setting and suggest that changing storm climate and flooding thresholds are more significant than evolving site-to-sea distances and other local details of the terrain. Temporal resolution was found to have a complicating effect on the records, with reconstructed storm frequency increasing significantly with accumulation rates at the second site.
\end{abstract}




\section{Introduction}

\subsection{Background}

Sedimentary storm archives from the Caribbean, the Gulf of Mexico, and the Northeastern U.S. have been developed from overwash deposits preserved in back barrier lagoons (Donnelly 2005, Donnelly and Woodruff 2007, Woodruff et al. 2008a, Woodruff et al. 2008b, Wallace and Anderson 2010), coastal lakes (Liu and Fearn 1993, Liu and Fearn 2000, Liu and Fearn 2002, Lambert et al. 2003, Lambert et al. 2008), and marshes (Donnelly et al. 2001a, Donnelly et al. 2001b, Donnelly et al. 2004, Scileppi and Donnelly 2007, Boldt et al. 2010). In these settings, storm deposits are produced when the surge and wave action of hurricanes breach coastal barriers and advect coarse sediment from the barrier and possibly from offshore into typically low-energy depositional basins. This process is usually characterized by landward thinning of storm layers and fining of grain sizes within the depositional basin (Woodruff et al. 2008b).

Novel depositional basins, which include kettle ponds in the Northeastern U.S. and sinkholes in Florida, are being explored for paleohurricane research. Typically smaller in spatial extent and sometimes located considerably landward of a barrier, such environments may still document storm activity but do so in a way that differs from the barrier breach model described for other types of basins.

In Chapter 1, a paleohurricane reconstruction was developed from the sediments of Mullet Pond, a sinkhole currently located $200 \mathrm{~m}$ behind the dune ridge that separates it from Apalachee Bay. Given the shallow bathymetry of the bay and the approximate $3 \mathrm{~m}$ of sea level rise in the region over the course of the 4500 -year record, maximum site-to-sea distances could have been as large as $4 \mathrm{~km}$ in the earliest portions of the record. While microfossils and storm surge modeling provide evidence for repeated marine inundations throughout the record, it is important to 
assess the impact of changing geographic boundary conditions on the paleohurricane record.

Also of interest is the role of sediment accumulation rates, which determine the temporal resolution of paleohurricane reconstructions. Storm undercounting tends to decrease as the sedimentation rate increases, thereby permitting multiple overwash layers deposited during a short interval of time to be distinguished as multiple events (Woodruff et al. 2008a). Some coastal sediment records suggest an increase in storm deposition and this may, in part, reflect increasing sedimentation rates at the sites studied (Scileppi and Donnelly 2007, Donnelly and Woodruff 2007, Boldt et al. 2010). This effect is important for records developed from the sediments of marshes and coastal lagoons, where accumulation rates are tied to sea levels that have been rising at an accelerating pace.

In this paper, the most recent 1650-year portion of the Mullet Pond (hereafter MLT) record is reproduced from a nearby sinkhole that has a nearly identical flooding threshold and is subject to the same storm surge climate. However, this second site, Shotgun Pond (hereafter SHG), is currently located a minimum distance of $2 \mathrm{~km}$ inland and is not adjacent to an overwash sediment-supplying barrier. These findings suggest that in this setting and for this type of depositional basin inundation frequency is largely controlled by storm climate and flooding threshold rather than

site-to-sea distances, local sediment sources, and other details of the terrain that may have evolved through time. Moreover, the variable sedimentation rate of the SHG record, which is at times lower and at times higher than the MLT record, effectively demonstrates the complicating effect that variable temporal resolution can have on a paleohurricane record.

\subsection{Study Area}

Both MLT and SHG sinkhole sites are located on the eastern portion of Bald Point, a small peninsula that protrudes into the westernmost waters of Apalachee Bay 
in the Big Bend region of Florida's Gulf Coast (Figure 1). SHG (29 ${ }^{\circ} 55.896^{\prime} \mathrm{N}$, $84^{\circ} 21.300^{\prime} \mathrm{W}$ ) is approximately $70 \mathrm{~m}$ in diameter (about one-third the size of MLT) and is located in the interior of the Bald Point peninsula about $2 \mathrm{~km}$ from Apalachee Bay to the east and $2 \mathrm{~km}$ from Ochlokonee Bay to the north. SHG lacks a tidal connection and has a surface salinity of $0 \mathrm{psu}$, though it is a mere $80 \mathrm{~m}$ from a large tidal marsh and creek system that runs from Ochlokonee Bay and through the center of Bald Point.

\section{Methods}

\subsection{Field work}

A portable Edgetech $31004-24 \mathrm{kHz}$ sonar was used to map the bathymetry and image the sub-bottom stratigraphy of $\mathrm{SHG}$, and the resulting data guided the selection of coring locations. Sediment cores SHG1 and SHG2 were retrieved from near the deepest (about $5.1 \mathrm{~m}$ and $5.0 \mathrm{~m}$, respectively), central portions of SHG where sub-bottom stratigraphy indicated the greatest reservoirs of sediment. A piston corer was used to capture surface drives in 3" polycarbonate barrels, while deeper drives were collected in 3" aluminum vibracores. A handheld GPS unit provided the coordinates of coring and surface sample locations, and salinities were measured with an optical diffraction salinity meter.

\subsection{Age control}

To develop an age model, five plant fragments and one bulk sediment sample were collected and sent to the National Ocean Sciences AMS facility at Woods Hole Oceanographic Institution for radiocarbon dating. Plant and wood materials were cleaned and dried beforehand. Calendar ages (in years before present, where present is 1950 A.D. by convention) and corresponding uncertainties were calculated from 
${ }^{14} \mathrm{C}$ ages and associated analytical errors using the IntCal09 calibration curves in the Calib6 program (Reimer et al. 2009). An age model was constructed using multiple, linear fits to the calibrated ages with the aim of minimizing changes in sedimentation rate while validating the 1-sigma age ranges. Recent sedimentation rates were estimated using ${ }^{137} \mathrm{Cs}$ (Pennington et al. 1973) horizons as measured by a Canberra GL2020RS low-energy Germanium gamma well detector.

\subsection{Sedimentary analysis}

Loss on ignition analysis was performed on the uppermost $366 \mathrm{~cm}$ of SHG1 at continuous, $1-\mathrm{cm}$ resolution. Samples were dried at $105^{\circ} \mathrm{C}$ for 24 hours and then combusted at $550^{\circ} \mathrm{C}$ for 2 hours. Before and after each process, samples were weighed to determine the relative contributions of water, organics and inorganics to the mass of the sediment (Dean 1974). The remaining inorganic ash was sieved and the sand size particles $(>63 \mu \mathrm{m})$ were retained, dried and weighed to determine the percent coarse by dry weight in each sample.

As with MLT, a limited sampling strategy for microfossil content was adopted to determine if the most visually obvious sand layers had a marine origin. A $35 \mathrm{~cm}$ interval (267 - $302 \mathrm{~cm}$ depth) containing prominent sand layers was sampled using standard methods for foraminiferal sample preparation and analysis (Scott and Medioli 1980, de Rijk 1995, de Rijk and Troelstra 1997, Scott et al. 2001, Horton and Edwards 2006). Foraminifera were concentrated from $3-\mathrm{cm}^{3}$ bulk sediment samples by washing the material over $500 \mu \mathrm{m}$ and $32 \mu \mathrm{m}$ sieves and retaining the particles in this size range. When foraminiferal abundance was sufficient, up to 150 specimens were tallied from the remaining $32 \mu \mathrm{m}$ to $500 \mu \mathrm{m}$ fraction. 


\subsection{Identifying storm deposits in the record}

As in the MLT record, the raw coarse fraction time series was high-pass filtered to remove variability on frequencies lower than $30^{-1} \mathrm{yrs}^{-1}$. Sea, Lake, and Overland Surges from Hurricanes (SLOSH) model results for historic, Best Track storms were used to establish thresholds for event detection (Jelesnianski et al. 1992). These thresholds were applied to the time series of coarse fraction anomalies to arrive at low threshold (LT) and high threshold (HT) event chronologies.

\subsection{High-resolution digital elevation and inundation model}

High-resolution Light Detection and Ranging (LiDAR) elevation data for the eastern portion of Bald Point was obtained through a seed proposal grant from the National Center for Airborne Laser Mapping (Figure 1). The data were collected in September 2010 by Airborne Laser Swath Mapping (ALSM) of a roughly $36 \mathrm{~km}^{2}$ area. Elevations are referenced to NAVD88 and have 1-sigma errors ranging from 5 to $30 \mathrm{~cm}$. The bare-earth digital elevation model supplied by NCALM was then used to create a detailed surge inundation model for the area. The spatial extent of flooding on the peninsula was mapped at $10 \mathrm{~cm}$ intervals for surges ranging from 0 to $7 \mathrm{~m}$. Together with SLOSH surge simulations for historic storms, the results were used to constrain flooding thresholds for both MLT and SHG ponds.

\section{Results}

\subsection{Description of SHG sediment cores}

SHG1 and SHG2 had total lengths of 502 and $471 \mathrm{~cm}$, respectively. The upper $370 \mathrm{~cm}$ of SHG1 was comprised of organic-rich, fine-grained sediment, which was underlain by approximately a meter of coarser sands followed by $30 \mathrm{~cm}$ of 
limestone debris. SHG2 was similarly composed of fine organics down to about 400 $\mathrm{cm}$ with coarse sand below. Given the presence of limestone at the base of SHG1, this core contained the longer of the two records and was therefore selected as the basis for the SHG record.

\subsection{Age control}

The six radiocarbon dates providing age control for SHG1 were all chronostratigraphically consistent (Table 1). The multiple, linear fit to the calibrated ages indicated an accelerating sedimentation rate through time, with an average of 0.9 $\mathrm{mm} \mathrm{yr}^{-1}$ between 366 and $305 \mathrm{~cm}$ (1650 to $980 \mathrm{cal}$. yrs. B.P.), $2.5 \mathrm{~mm} \mathrm{yr}^{-1}$ between 305 and $140 \mathrm{~cm}$ (980 to $320 \mathrm{cal}$. yrs. B.P.), and $4.4 \mathrm{~mm} \mathrm{yr}^{-1}$ above $140 \mathrm{~cm}$ (320 to -58 cal. yrs. B.P.) (Figure 2). These sedimentation rates range from 60 to over 300 percent of the sedimentation rate for MLT1, which was a nearly constant $1.4 \mathrm{~mm} \mathrm{yr}^{-1}$ throughout the 4500 -year record. ${ }^{137} \mathrm{Cs}$ horizons associated with the onset $(\sim 1954$ A.D.) and moratorium on ( 1963 A.D.) atmospheric nuclear weapons testing were identified at 23 and $19 \mathrm{~cm}$, respectively, suggesting recent accumulation rates very similar to the $4.4 \mathrm{~mm} \mathrm{yr}^{-1}$ estimate based on the uppermost radiocarbon samples (Figure 3).

\subsection{Microfossil content}

Both sand content and microfossil analyses of the interval from $267-302 \mathrm{~cm}$ (approximately 825 - 965 cal. yrs. B.P.) in SHG1 suggested that at least two large storm events occurred during this period (Figure 4). The storm deposits, centered near 920 and 880 cal. yrs. B.P., were associated with temporarily elevated sand and inorganic content in the core along with increases in both marsh-indicative foraminifera (Arenoparella mexicana) and shallow marine (open coast) foraminifera (Ammobaculites dilatus and Ammobaculites exiguus). 


\subsection{Recent sand deposits in SHG and historic hurricanes}

A comparison of the youngest sand layers in SHG1 (as represented by coarse fraction anomalies) with the SLOSH-simulated surges associated with historic Best Track storms affecting the area suggests that as many as six known modern hurricanes may be present in the record (Figure 5). Though dated approximately a decade younger than expected, the uppermost event is likely Hurricane Elena (1985 A.D.). Field notes indicate that the sediment-water interface for this core may not have been retrieved, suggesting that each layer may in fact be slightly older and that a layer from Hurricane Dennis (2005 A.D.) may not have been recovered. Other historic storms that may be present are Hurricane Alma (1966 A.D.), and the Hurricanes of 1941, 1926, and 1929 A.D. It is difficult to assign any particular late $19^{\text {th }}$ century storm to either of the coarse deposits dating to that time. The oldest coarse fraction anomaly in Figure 5 may have been produced by the very large surge modeled in association with the Hurricane of 1852 A.D.

The number and magnitude of modern coarse fraction anomalies is similar to that detected in the upper portion of MLT1, though the placement differs somewhat. Again, some of the difference can be accounted for if each deposit in SHG1 is five to ten years older than what is shown (Figure 6). Using the same strategy employed in Chapter 1, LT (1.08) and HT (3.25) values were set based on the modern portion of the SHG1 record.

\subsection{Comparison of MLT and SHG storm chronologies}

Raw coarse fraction and coarse fraction anomalies in SHG1 for the period from 1650 cal yrs. B.P. through present reveal relatively high concentrations of HT storm activity between 1200 and 700 cal. yrs. B.P. with smaller clusters of HT events

around 500 cal. yrs. B.P. and in the $19^{\text {th }}$ century (Figure 7a,c). Two significant lulls in activity occurred between 700 and 500 cal. yrs. B.P. and between 500 and 200 cal. 
yrs. B.P. The SHG record also suggests that the $20^{\text {th }}$ Century was relatively inactive. In comparison, the MLT1 record shows a broad peak in activity between 1400 and 600 cal. yrs. B.P., with a considerable (and sustained) decline thereafter (Figure 7b,d).

\subsection{LiDAR elevation and inundation model}

LiDAR data for roughly the eastern half of Bald Point (Figure 1) reveals that most of the area is extremely flat, with elevations below $2 \mathrm{~m}$. Topographic highs of 3 to $4 \mathrm{~m}$ were found along the dune ridge just east of Mullet Pond. Elevations of nearly 15 meters were found in the western portion of the peninsula, possibly in association with relic dune features. The inundation model suggests that SHG pond has an initial flooding threshold near $1.1 \mathrm{~m}$ (Figure 8), while MLT pond begins to flood when surges reach $1.2 \mathrm{~m}$ (Figure 9). Thus, both sites have nearly identical flooding thresholds. The 100-year surge, approximately $4 \mathrm{~m}$ at Bald Point (Chapter 3), inundates nearly the entire peninsula and submerges MLT and SHG beneath approximately $3 \mathrm{~m}$ of floodwaters (Figure 10).

\section{Discussion}

\subsection{Vulnerability of sites to storm surge}

The presence of open coast microfossil taxa in SHG, which is located at least $2 \mathrm{~km}$ from the source of these foraminifera, supports the assertion made in Chapter 1 that storm surges can transport suspended sediments a considerable distance landward in this setting (Figure 4). Moreover, these foram-rich layers were found to be nearly a 1000 years old suggesting that periodic inundation is a persistent feature of this landscape. The inundation model provides further support for this claim by demonstrating that the 100-year event is capable of flooding nearly the entire peninsula. The high frequency and extreme extent of floods in the region may 
explain why geographic boundary conditions appear to play little role in the reconstruction of paleohurricane frequency from sites on Bald Point.

\subsection{Paleohurricanes and storm surge climate}

According to the LiDAR-based inundation model, initial flooding begins at both MLT and SHG when surges exceed $1 \mathrm{~m}$. Surge return time estimates for events of this magnitude are $10 \mathrm{yrs}$. and $4.5 \mathrm{yrs}$. based on Best Track and synthetic methodologies, respectively (Chapter 3, Table A2.6). However, the number of LT events in the modern portion of the MLT and SHG sediment records indicates return times of 26 and 22 years, respectively. These return times are consistent with surges in the $2.5 \mathrm{~m}$ range using both Best Track and synthetic methods (Table A2.6). A minimum water depth is likely needed for sediment transport, and these results may indicate that approximately 1 to $1.5 \mathrm{~m}$ of surge is required at these sites to begin mobilizing sediment. The dune ridge to the east of MLT is not completely submerged even during the 100-yr event (Figure 10) and this would suggest that waves breaking on the barrier would likely play a role in sediment transport in this location. However, ADCIRC surge modeling of historic events suggest that the magnitude of significant waves heights just off of Bald Point scales with the magnitude of the surge. This may help minimize the role of geographic boundary conditions and explain why both sites can record similar events and similar event frequencies in spite of their different settings (Chapter 3, Table A2.3). The return time for HT storms, which is by definition the length of the Best Track dataset, is consistent with a surge of $4.3 \mathrm{~m}$ (Table A2.6). The largest modeled surge in the Best Track dataset ranges from $4.3 \mathrm{~m}$ during Hurricane Elena in SLOSH (EGLL) up to 5.3 $\mathrm{m}$ for the Hurricane of 1852 in ADCIRC (Table A2.3). 


\subsection{Storm frequency and record resolution}

Similar mean storm frequencies were derived from both MLT1 and SHG2 records. The average frequency of low threshold events was 3.7 and 4.4 storms century $^{-1}$ in MLT1 and SHG1, respectively. When only high threshold events were counted, these values were 1.8 and 2.3 storms century $^{-1}$. However, temporal resolution appears to significantly affect the apparent rate of storms recorded in SHG1 through time. The rate of occurrence of LT storms in MLT1 has been quite steady since 1650 cal. yrs. B.P., as demonstrated by the nearly constant slope of the cumulative plot for these events (Figure 11a). While the temporal resolution of MLT1 is a nearly constant 7.4 years, the resolution of SHG1 increases from 11 yrs., to 4 yrs., and finally to 2.3 yrs. Since both sites are subject to and record similar events, the increase in LT event frequency in SHG likely results solely from increasing record resolution. The record of cumulative HT events in MLT1 indicates that changes in storm climate have probably occurred during this period; however, changes in the cumulative frequency of HT events in SHG1 are probably related both to changes in storm climate and the temporal resolution of the record (Figure 11b). The effect of resolution on apparent storm frequency is likely two-fold. As resolution increases, undercounting of storms occurring in quick succession decreases. The other effect may merely be an artifact of applying a high-pass filter to the raw data. As sedimentation rates increase, storm deposits appear as more distinct and punctuated events in the time series of sand content, and filtering accentuates this (Figure $7 \mathrm{a}, \mathrm{c})$.

\subsection{Hurricane activity since $1.65 \mathrm{ka}$}

In spite of complications associated with its variable sedimentation rate, SHG still represents an important new storm archive for the region. It reproduces the general patterns detected in MLT, with storm activity increasing between 1650 and 
600 cal. yrs. B.P. followed by an abrupt decline. Brief rebounds in activity occur in the SHG record around 500 and between 200 and 100 cal. yrs. B.P., and each of these periods are represented by lone HT events in the MLT record. The SHG record suggests that the $19^{\text {th }}$ Century was particularly active in the region and, while some of this apparent activity may be an artifact of temporal resolution and data filtering, historic records do provide support for several significant hurricanes in Apalachee Bay during the early to mid-1800s, including storms in 1837, 1842, 1844 and 1850 A.D. (Ludlum 1963).

\section{Conclusions}

Geographic boundary conditions, such as site-to-sea distances, appear to play little role in determining reconstructed paleohurricane frequencies from sites on Bald Point. Record resolution, however, can complicate these reconstructions by causing the apparent frequency of storm events to increase significantly with sedimentation rate. This effect results, in part, from reduced undercounting as accumulation rates increase. It may also be an artifact of how the sedimentary data are processed and used to detect storm events. The presence of open coast microfossils within the SHG record and the inundation model results provide further evidence that sedimentcarrying floodwaters can penetrate kilometers inland in this setting and have for thousands of years. The SHG record advocates for the same general pattern of storm activity originally suggested by the MLT record, which indicated that storm frequency increased between 1600 and $600 \mathrm{cal}$. yrs. B.P. before declining significantly thereafter. More recent intervals in activity detected in the SHG record likely resulted, at least in part, from increases in the temporal resolution of the record. 


\section{Acknowledgments}

P. Donnelly and J. Woodruff provided assistance with fieldwork and M. Gomes, S. Moret and S. Zipper assisted with laboratory analysis. The Florida State University Marine Laboratory provided lodging during fieldwork. I would also like to thank NCALM for providing the LiDAR data and R. Sullivan for his considerable expertise in its use.

\section{References}

Boldt, K.V., Lane, P., Woodruff, J.D., Donnelly, J.P., 2010. Calibrating a sedimentary record of overwash from Southeastern New England using modeled historic hurricane surges. Marine Geology. 275. pp. 127-139.

Dean, W.E., 1974. Determination of carbonate and organic matter in calcareous sediments and sedimentary rocks by loss on ignition: comparison with other methods. Journal of Sedimentary Petrology. 44, 242-248.

de Rijk, S., 1995. Salinity control on the distribution of salt-marsh foraminifera (Great-Marshes, Massachusetts). Journal of Foraminiferal Research. 25, 156-166.

de Rijk, S., Troelstra, S.R., 1997. Salt marsh foraminifera from the Great Marshes, Massachusetts: environmental controls. Palaeogeography, Palaeoclimatology, Palaeoecology. 130, 81-112.

Donnelly, J.P., S.S. Bryant, J. Butler, J. Dowling, L. Fan, N. Hausmann, P. Newby, B. Shuman, J. Stern, K. Westover, Webb III., T., 2001. A 700-year sedimentary record of intense hurricane landfalls in southern New England. Geological Society of America Bulletin. 113, 714-727.

Donnelly, J.P., S. Roll, M. Wengren, J. Butler, R. Lederer, Webb III, T., 2001. Sedimentary evidence of intense hurricane strikes from New Jersey. Geology. 29, 615-618.

Donnelly, J.P., J. Butler, S. Roll, Micah Wengren, Webb III, T., 2004. A backbarrier overwash record of intense storms from Brigantine, New Jersey. Marine Geology. 210, 107-121.

Donnelly, J.P., 2005. Evidence of Past Intense Tropical Cyclones from Backbarrier Salt Pond Sediments: A Case Study from Isla de Culebrita, Puerto Rico, USA. Journal of Coastal Research. SI42, 201-210.

Donnelly, J.P., Woodruff, J.D., 2007. Intense hurricane activity over the past 5,000 years controlled by El Niño and the West African monsoon. Nature. 447, 465-468. 
Horton, B.P., Edwards, R.J., 2006. Quantifying Holocene sea-level change using intertidal foraminifera: lessons for the British Isles. Cushman Foundation for Foraminiferal Research, Special Publication, 40, 97 pp.

Jelesnianski, C.P., Chen, J., Shaffer W.A., 1992. SLOSH: Sea, Lake, and Overland Surges from Hurricanes. NOAA Technical Report NWS 48, April 1992, Silver Spring, Maryland.

Lambert, W. J., Aharon, P., Rodriguez, A.B., 2003. An Assessment of the Late Holocene Record of Severe Storm Impacts from Lake Shelby, Alabama. TransactionsGulf Coast Association of Geological Societies. 53. pp. 443.

Lambert, W.J., Aharon, P., Rodriguez, A.B., 2008. Catastrophic hurricane history revealed by organic geochemical proxies in coastal lake sediments: a case study of Lake Shelby, AL (USA). Journal of Paleolimnology. 39, 117-131.

Liu, K.B., Fearn, M.L., 1993. Lake-sediment record of late Holocene hurricane activities from coastal Alabama. Geology 21, 793-796.

Liu, K.B., Fearn, M.L., 2000. Reconstruction of prehistoric landfall frequencies of catastrophic hurricanes in northwestern Florida from lake sediment records. Quaternary Research 54, 238-245.

Liu, K. B., Fearn, M.L., 2002. Lake sediment evidence of coastal geologic evolution and hurricane history from Western Lake, Florida: Reply to Otvos. Quaternary Research. 57, 429-431.

Ludlum, D. M., 1963. Early American Hurricanes. American Meteorological Society, Boston

Pennington, W., Cambray, R.S., Fisher, E.M., 1973. Observations on Lake Sediments Using Fallout Cs-137 as a Tracer. Nature. 242, 324-326.

Scileppi, E.M., Donnelly, J.P., 2007. Sedimentary evidence of hurricane strikes in western Long Island, New York. Geochemistry, Geophysics, Geosystems. 8(6), Q06011.

Scott, D.B., Medioli, F.S., 1980. Quantitative studies of marsh foraminiferal distributions in Nova Scotia: Implications for sea level studies. Cushman Foundation for Foraminiferal Research Special Publication 17, 58 p.

Scott, D.B., Medioli, F.S., Schafer, C.T., 2001. Monitoring in coastal environments using foraminifera and thecamoebian indicators. Cambridge University Press, London. 175 p. 
Reimer, P.J., Baillie, M.G.L., Bard, E., Bayliss, A., Beck, J.W., Blackwell, P.G., Bronk-Ramsey, C., Buck, C.E., Burr, G.S., Edwards, R.L., Friedrich, M., Grootes, P.M., Guilderson, T.P., Hajdas, I., Heaton, T.J., Hogg, A.G., Hughen, K.A., Kaiser, K.F., Kromer, B., McCormac, F.G., Manning, S.W., Reimer, R.W., Richards, D.A., Southon, J.R., Talamo, S., Turney, C.S.M., van der Plicht, J., Weyhenmeyer, C.E., 2009. IntCal09 and Marine09 radiocarbon age calibration curves, 0-50,000 years cal BP. Radiocarbon. 51(4), 1111-1150.

Wallace, D.J., Anderson, J.B., 2010. Evidence of similar probability of intense hurricane strikes for the Gulf of Mexico over the late Holocene. Geology. 38(6). pp. 511-514.

Woodruff, J.D., Donnelly, J.P., Emanuel, K.A., Lane, P., 2008. Assessing sedimentary records of paleohurricane activity using modeled hurricane climatology. Geochemistry, Geophysics, Geosystems. 9(9). Q09V10.

Woodruff, J.D., Donnelly, J.P., Mohrig, D., Geyer, W.R., 2008. Reconstructing relative flooding intensities responsible for hurricane-induced deposits from Laguna Playa Grande, Vieques, Puerto Rico. Geology. 36(5), 391-394. 


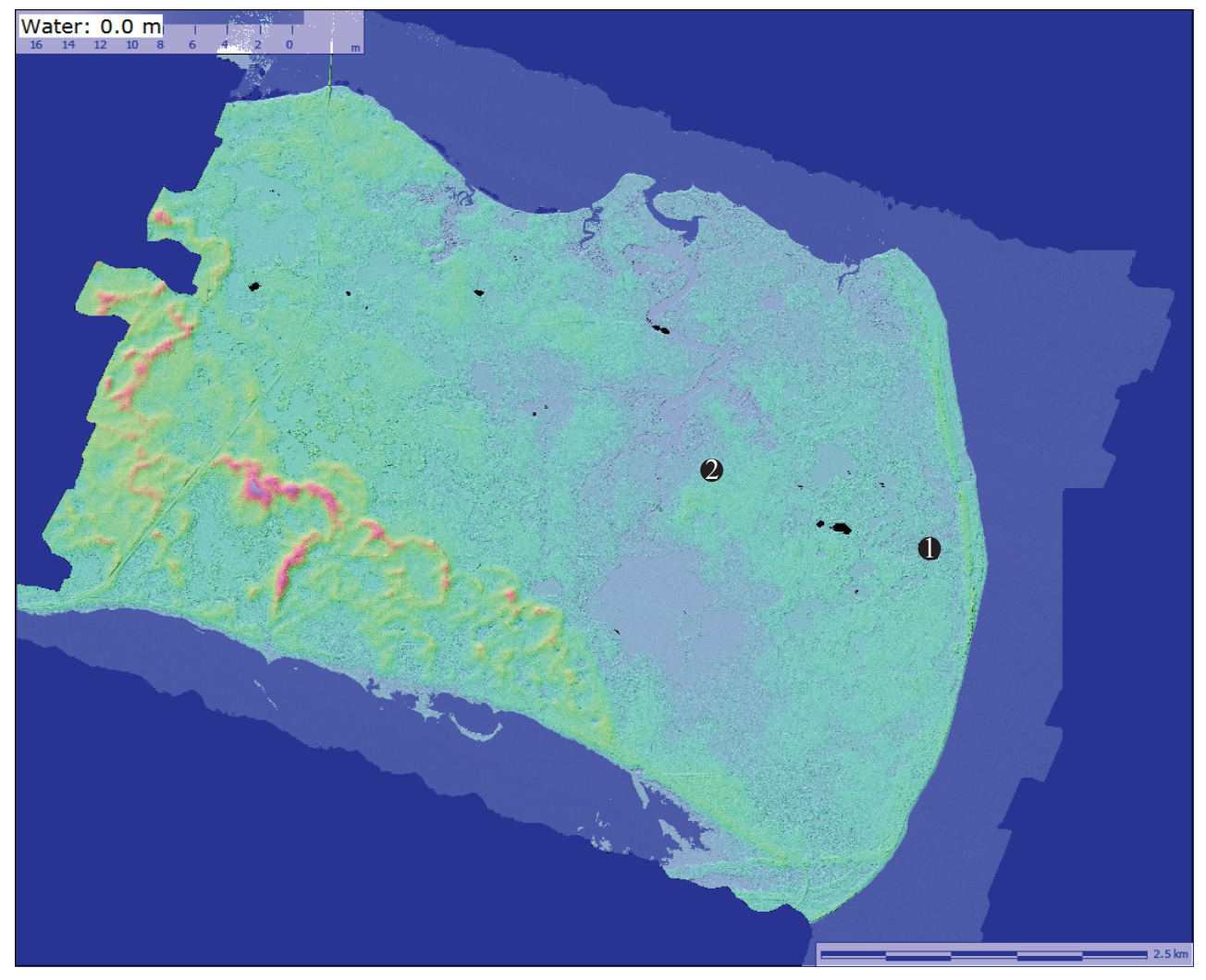

Figure 1 - LiDAR elevations for eastern half of Bald Point. Locations of MLT and SHG sites are indicated by numbered black circles (1) and (2), respectively. 


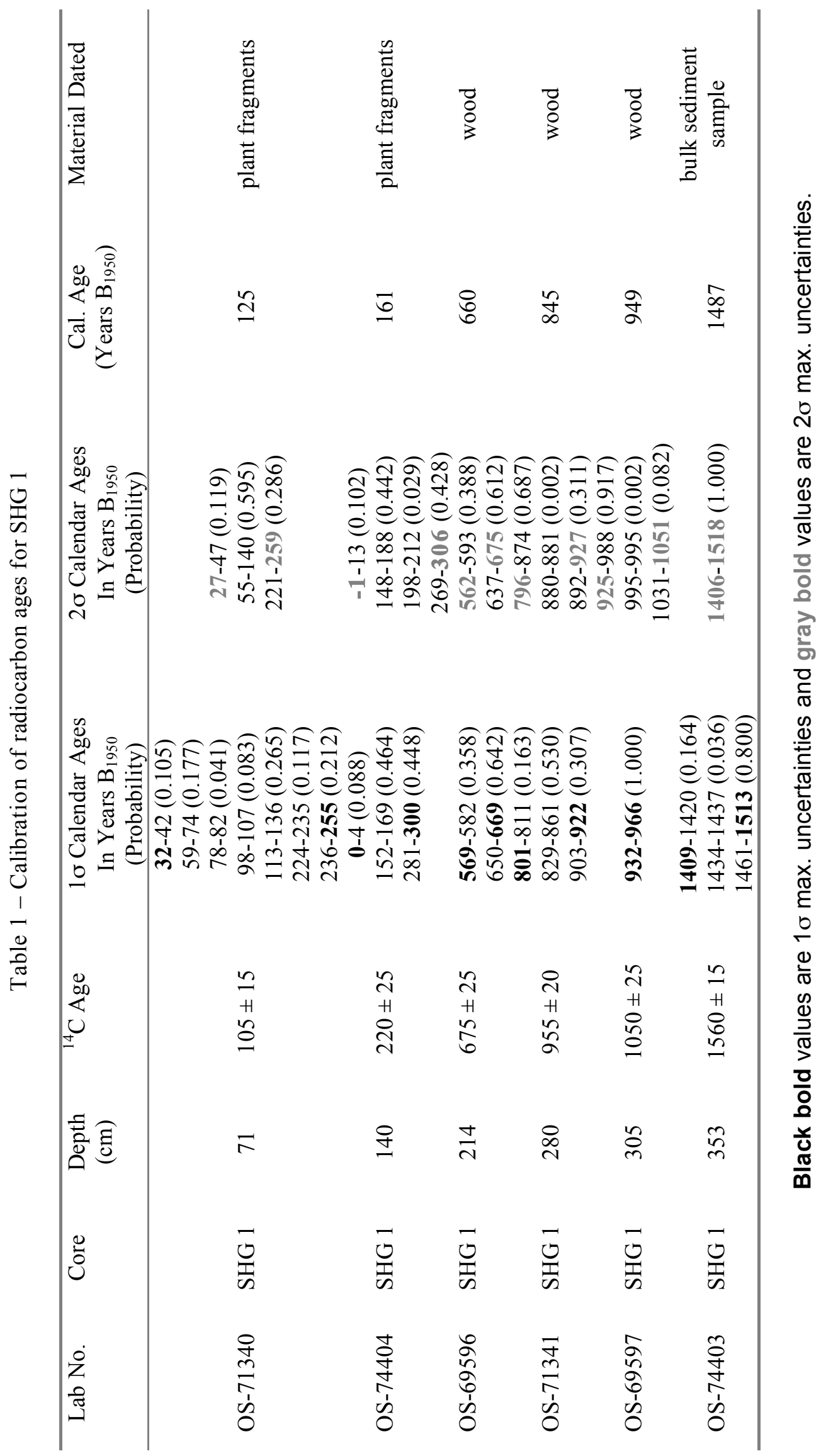




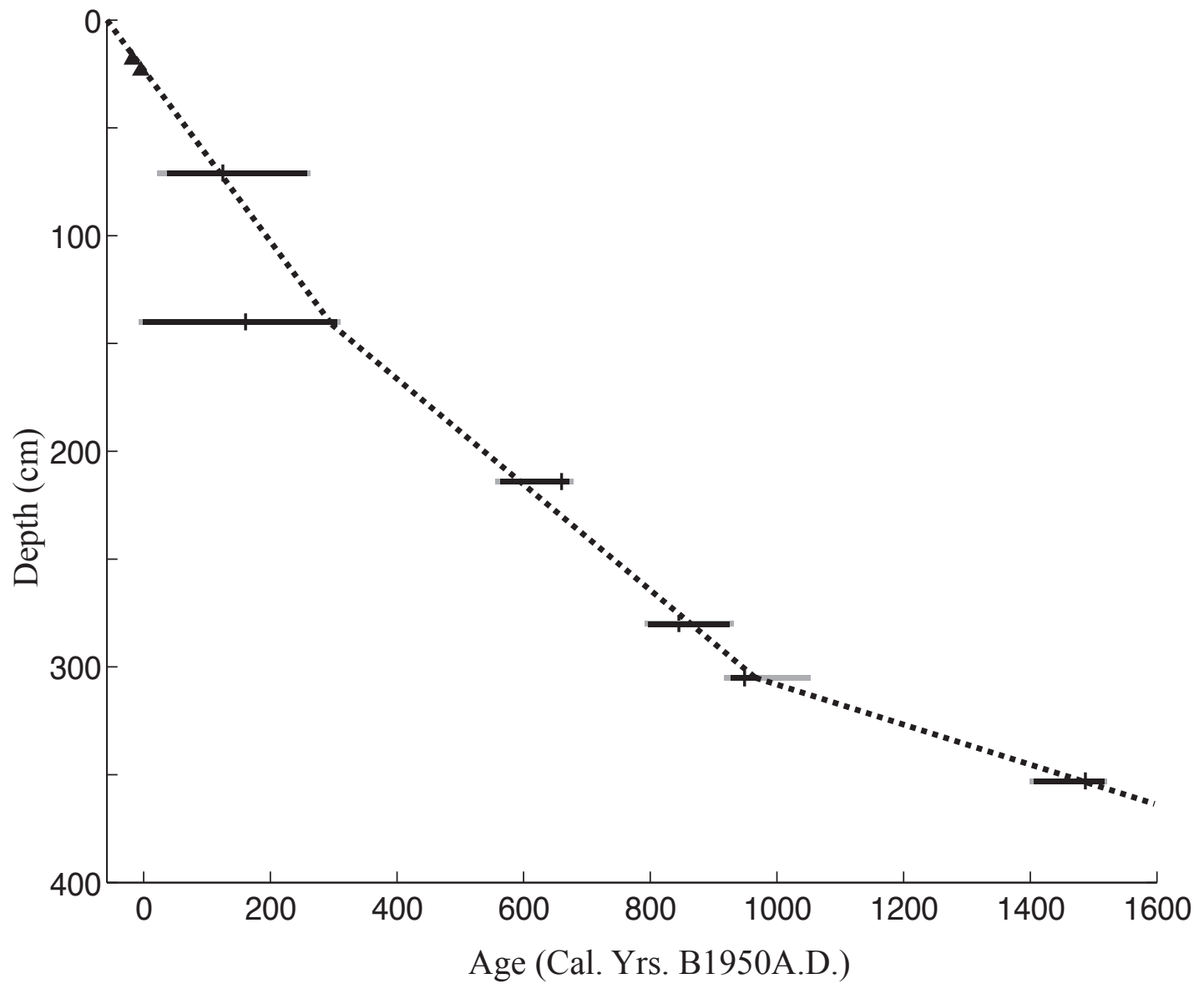

Figure 2 - Age model for SHG1 based on Cs-137 ages (black triangles) and calibrated radiocarbon ages. Gray bars are the maximum 2-sigma age ranges, black bars are the maximum 1-sigma age ranges, and vertical lines are the mean of the highest probability 1-sigma ages. Dashed line is the interpolated age model. 


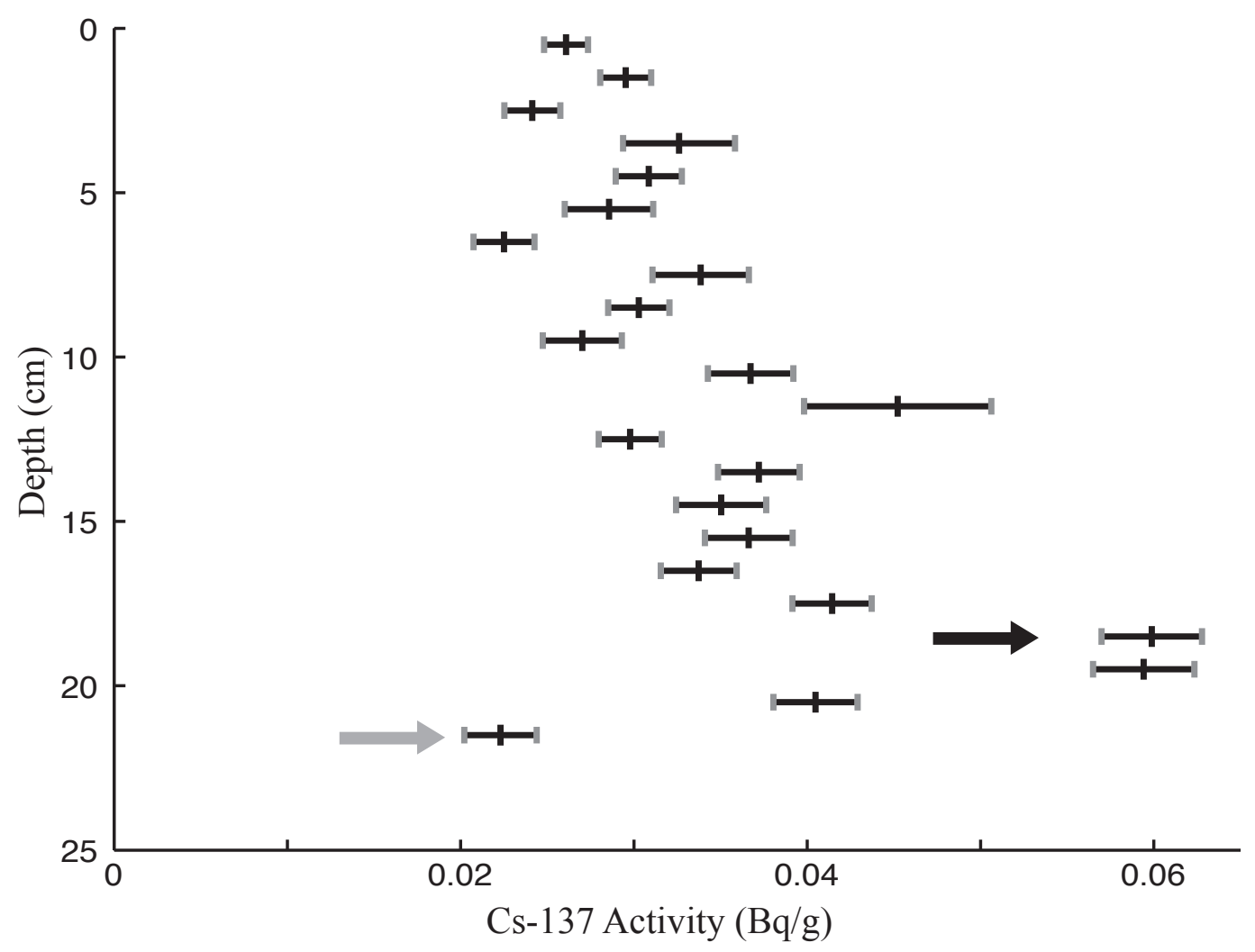

Figure 3 - Vertical profile of Cs-137 activity in the uppermost $25 \mathrm{~cm}$ of SHG1. Initial detection ( 1954 A.D.) and subsequent peak ( 1963 A.D.) in Cs-137 are noted at $23 \mathrm{~cm}$ and $19 \mathrm{~cm}$ depth by gray and black arrows, respectively. 

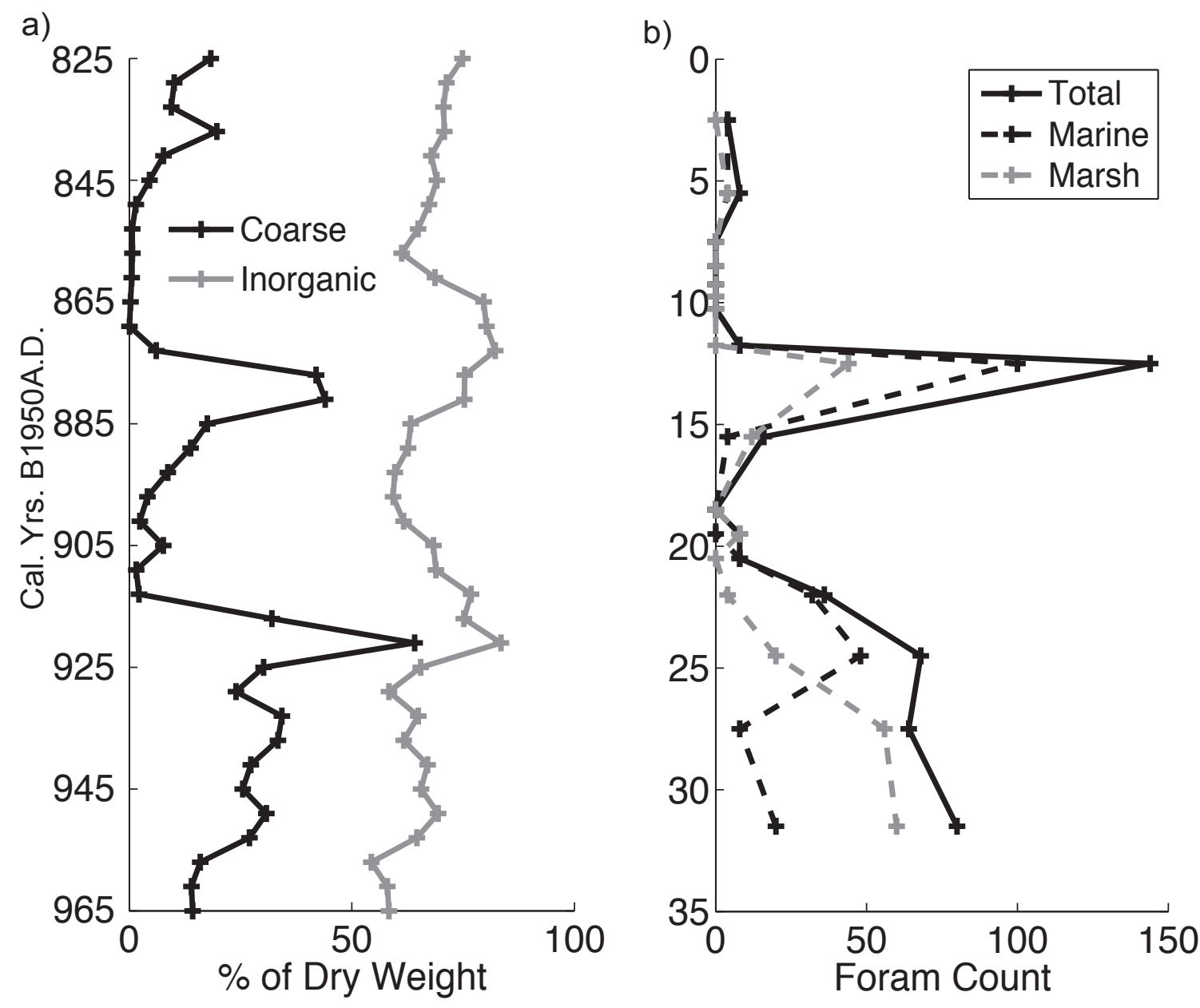

Figure 4 - Loss on ignition (coarse and inorganic fraction) (a) and microfossil data (b) for two prominent storm layers in the interval dating from 825 to 965 cal. yrs. B.P. Storm deposits are associated with increased sand, inorganic and foram content. Marsh-indicative taxa include A. mexicana and marine-indicate taxa include

$A$. dilatus and $A$. exiguus. 


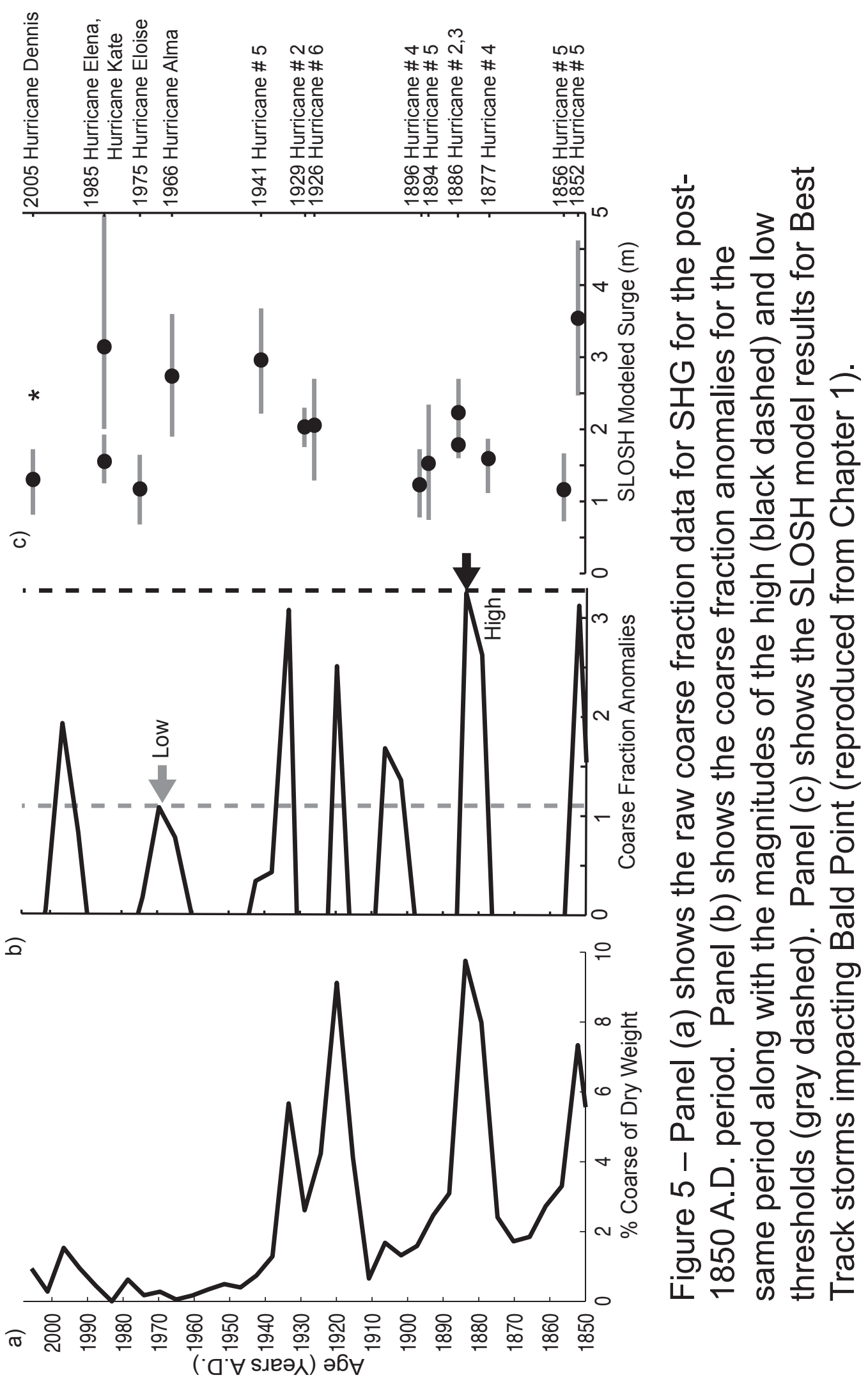




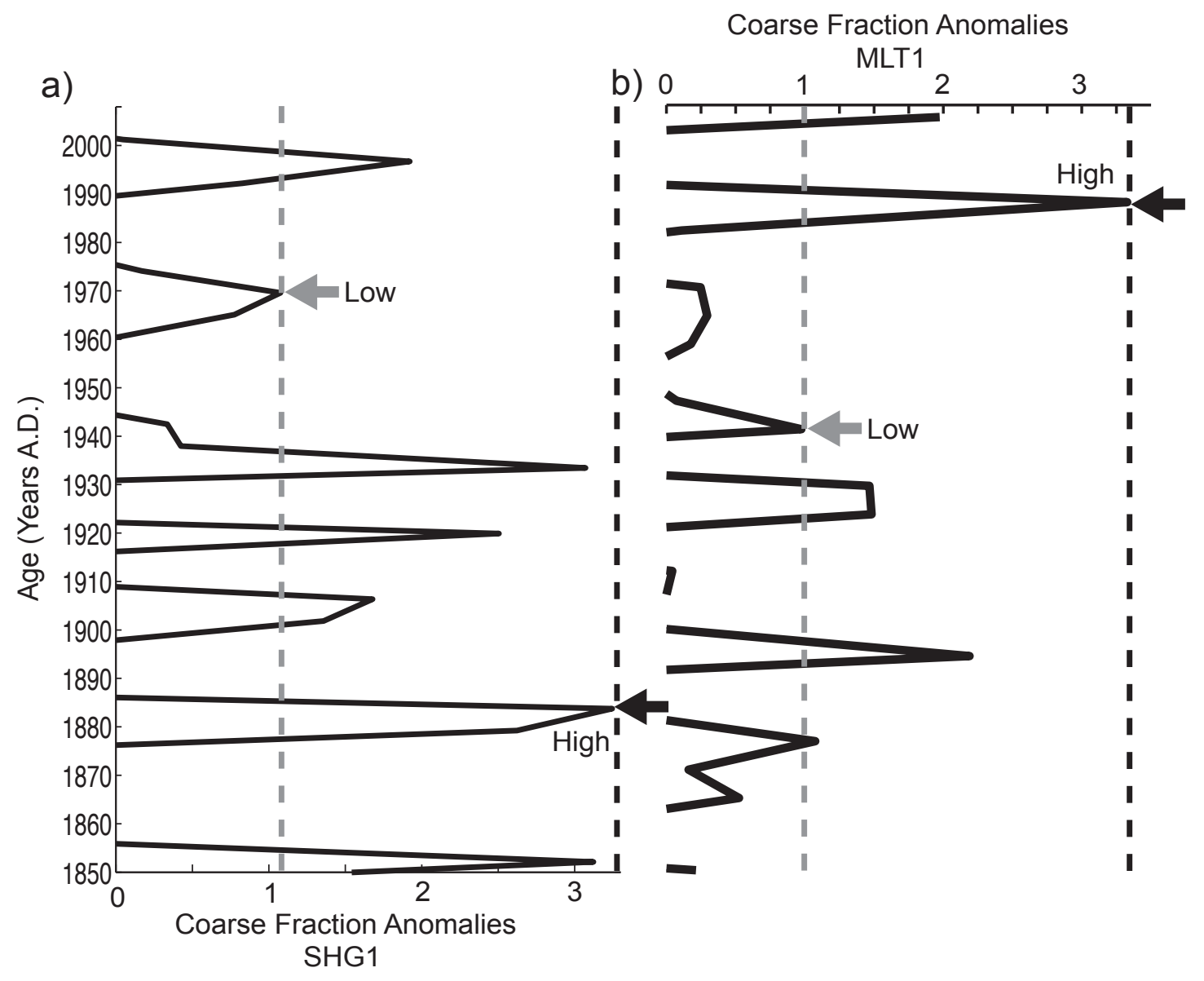

Figure 6 - Comparison of modern (post-1850 A.D.) coarse fraction anomalies in SHG1 (Panel a) MLT1 (Panel b) with low and high thresholds indicated by gray and black dashed lines, respectively. 
Figure 7 - Coarse fraction data for SHG1 (Panel a) and MLT1 (Panel b) and coarse fraction anomalies for SHG1 (Panel c) and MLT1 (Panel d) for the period from 1650 cal. yrs. B.P. through present. The low and high thresholds used in each case are shown as horizontal gray and black lines in Panels $\mathrm{c}$ and $\mathrm{d}$. 
Cal. Yrs. B.1950A.D.
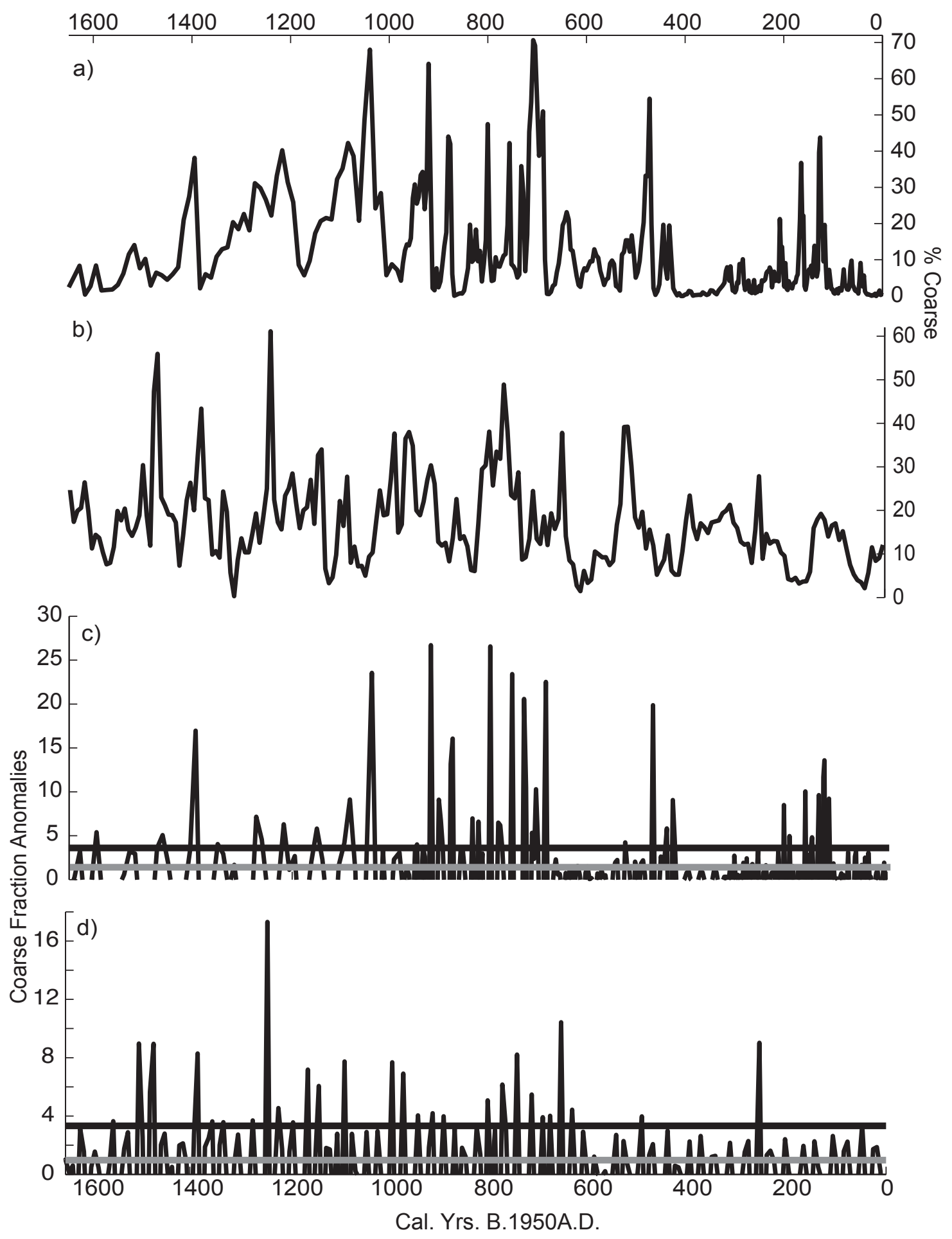


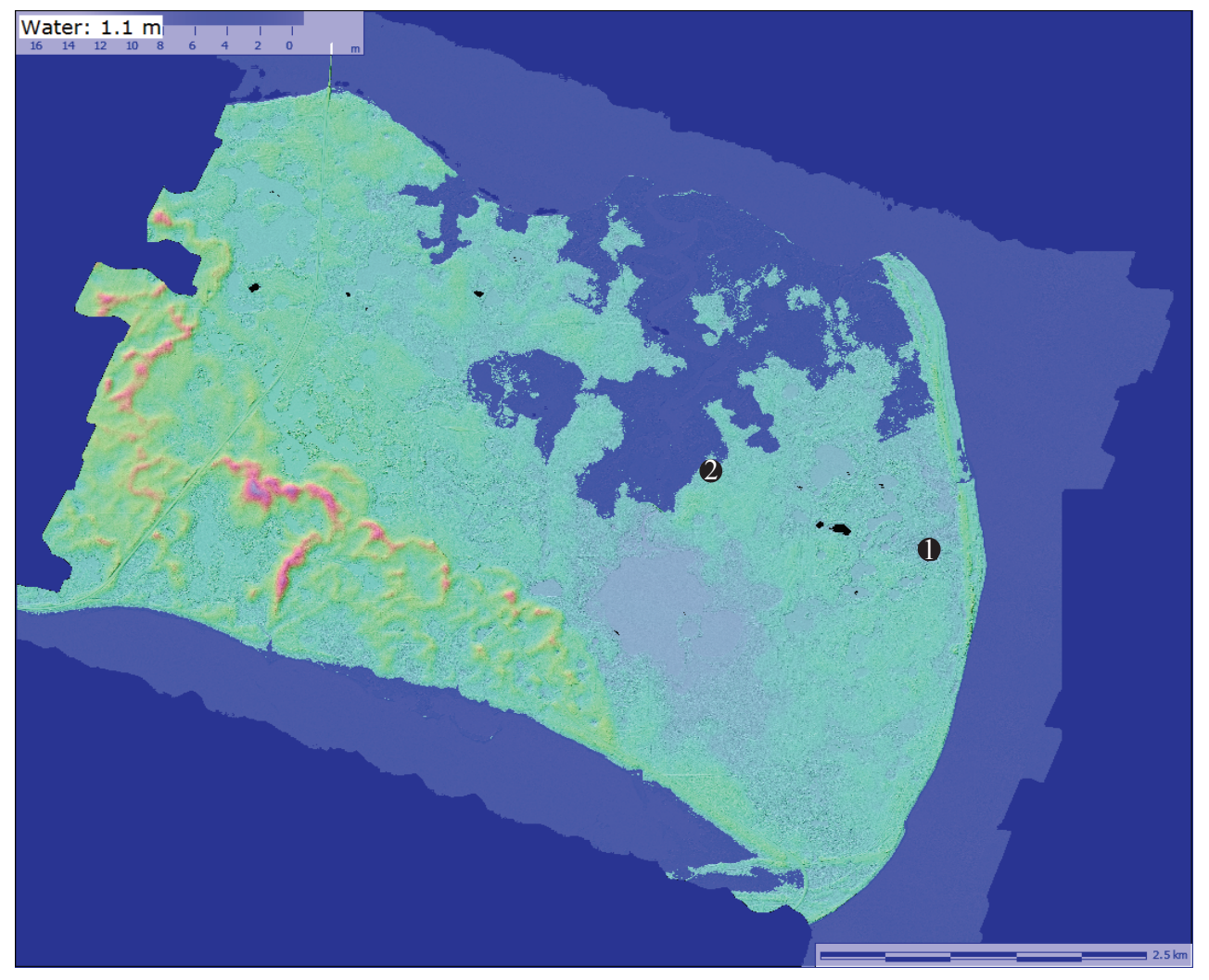

Figure 8 - LiDAR elevations for Bald Point for $1.1 \mathrm{~m}$ inundation, the surge level at which SHG pond begins to be flooded. Locations of Mullet and SHG ponds are indicated by numbered black circles (1) and (2), respectively. 


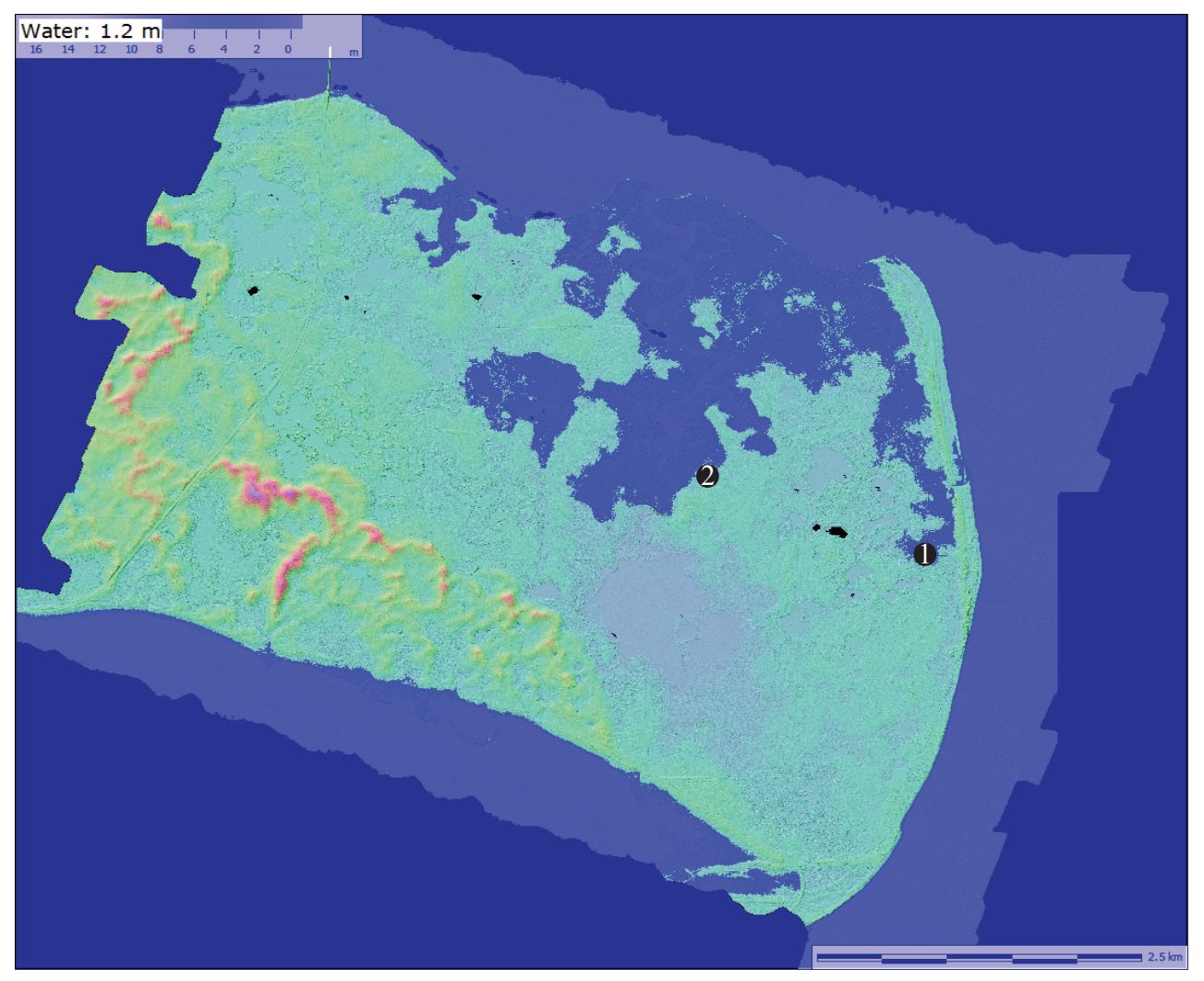

Figure 9 - LiDAR elevations for Bald Point for $1.2 \mathrm{~m}$ inundation, the surge level at which Mullet Pond begins to be flooded. Locations of Mullet and SHG ponds are indicated by numbered black circles (1) and (2), respectively. 


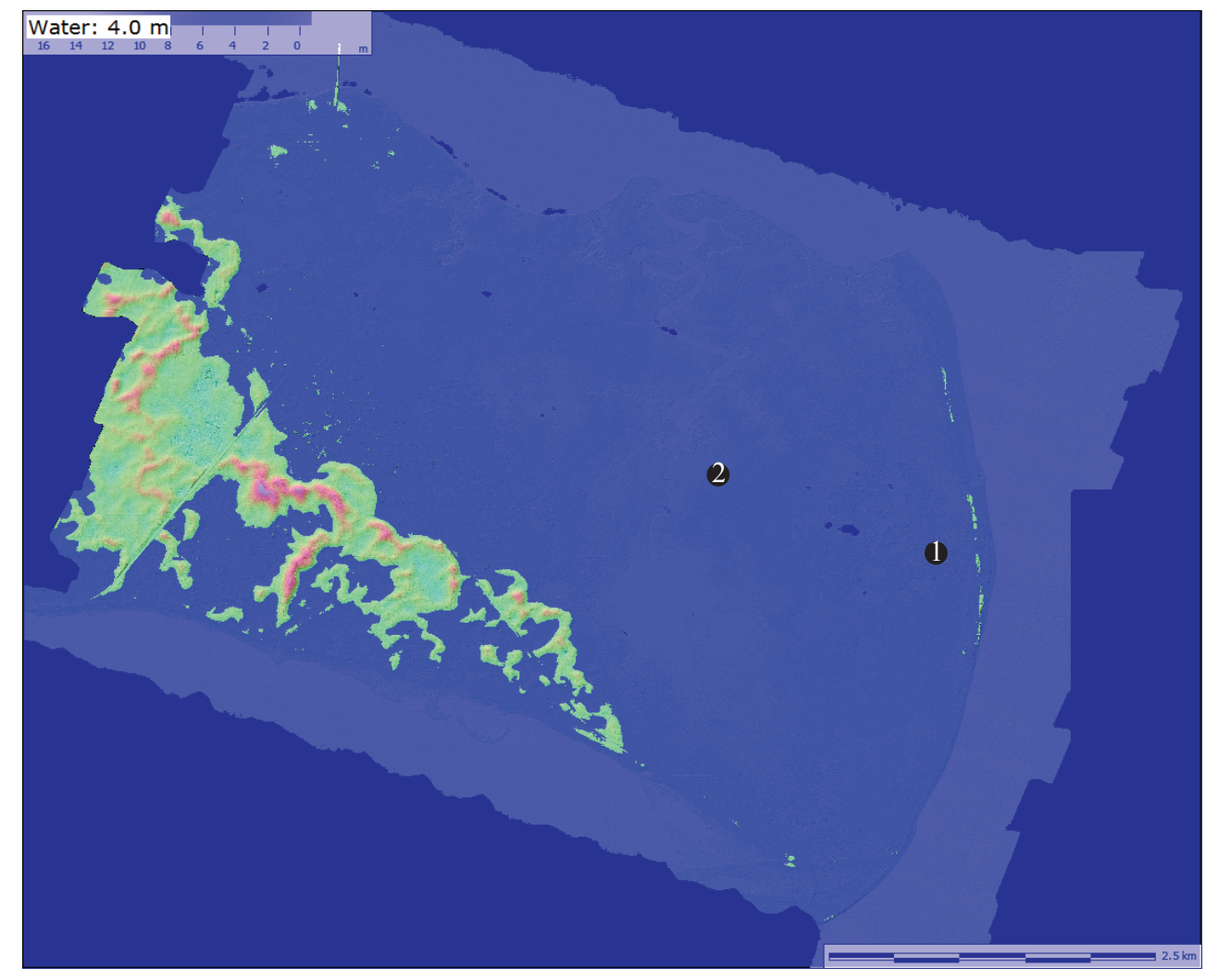

Figure 10 - Inundation of Bald Point for a 100-year surge event $(\sim 4 \mathrm{~m})$. Locations of MLT and SHG sites are indicated by numbered black circles (1) and (2), respectively. 


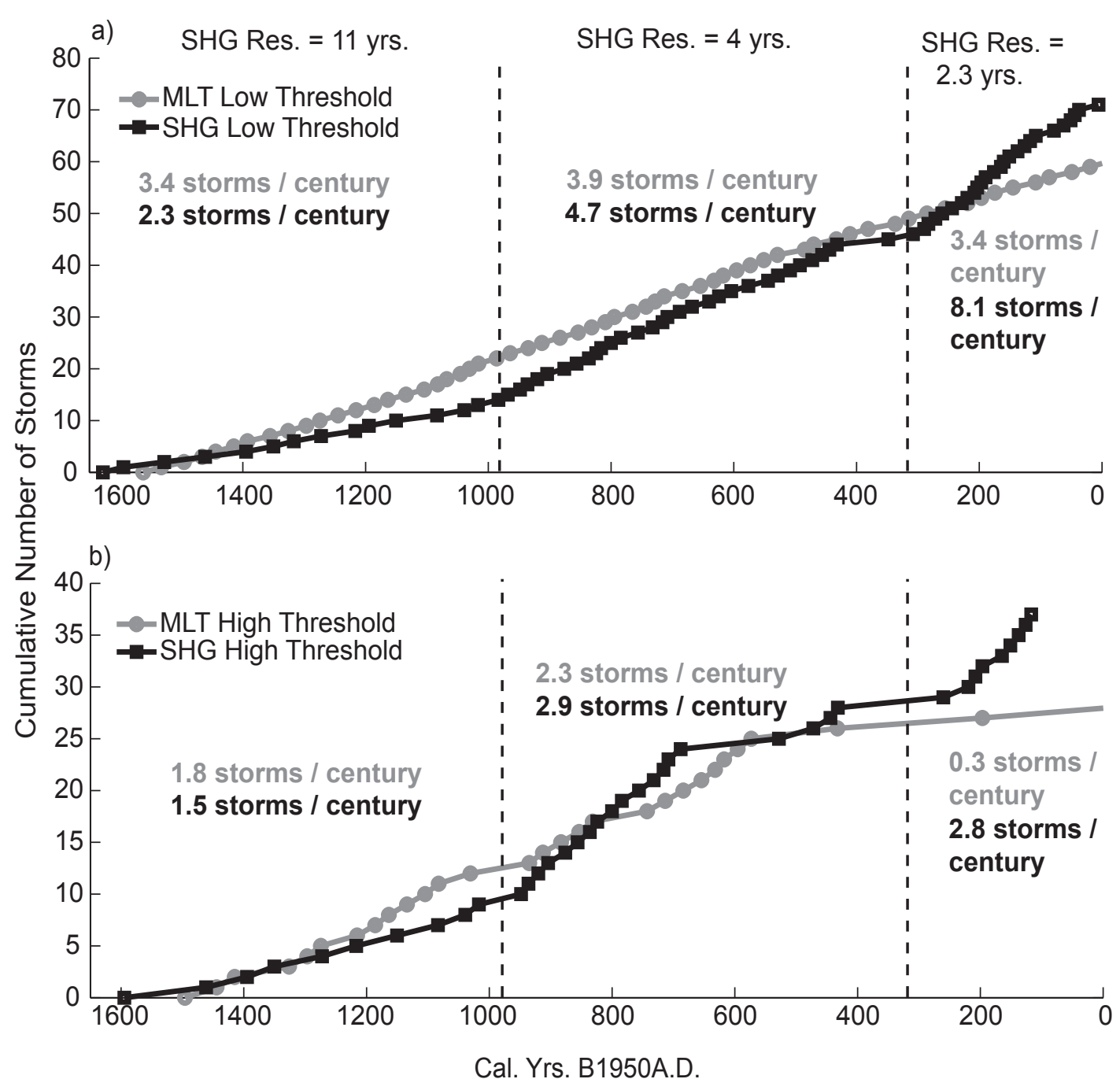

Figure 11 - Cumulative plots of storm events in MLT1 (gray circles) and SHG1 (black squares) for the interval 1650 cal. yrs. B.P through present. The temporal resolution of MLT1 is $\sim 7.4 \mathrm{yrs}$. and the data are sectioned by temporal resolution in SHG1, which increases through time. Panel (a) contains the cumulative number of LT events and panel (b) shows the same for HT events. Average storm frequencies are shown for each section with gray text indicating values for MLT1 and black text for SHG1. 
Appendix A1: Supplementary Material for Chapter 1 
Supplementary Figure 1 - MLT1 and MLT2 radiocarbon-based age models. Ten radiocarbon-based calendar age ranges for terrestrial plant fragments taken from MLT1 and five from MLT2 are plotted versus the depths from which they were collected in each core. Calendar ages and ranges in years before 1950 A.D. were found from ${ }^{14} \mathrm{C}$ ages and uncertainties using the IntCal09 calibration dataset in the Calib6 program (Reimer et al. 2009). See Table 1 and 2 for details. A single linear model (solid black line) was fit to the MLT1 ages and three different linear models (dashed black lines) were fit to the MLT2 ages. 
Cal. Yrs. B.P.

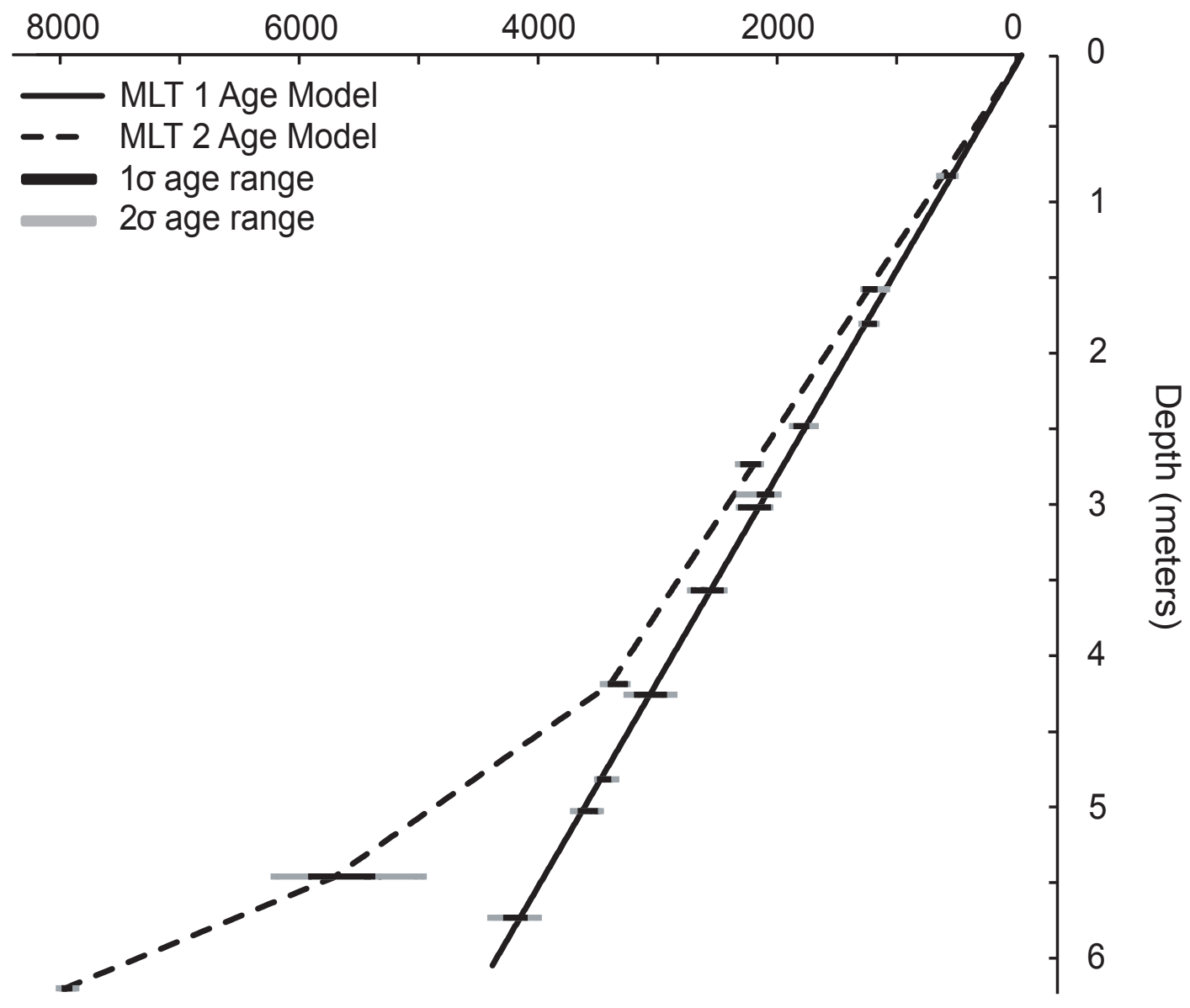


Supplementary Figure 2 - MLT1 ${ }^{210} \mathrm{~Pb}$ and ${ }^{137} \mathrm{Cs}$ data. Panel (a) is the vertical profile of ${ }^{210} \mathrm{~Pb}$ activity in the uppermost $40 \mathrm{~cm}$ of MLT1. Below about $20 \mathrm{~cm}$ depth, all ${ }^{210} \mathrm{~Pb}$ activity appeared to be supported by the sediment itself at a level of approximately $0.035 \mathrm{~Bq} / \mathrm{g}$ (gray dashed line). Panel (b) is the vertical profile of ${ }^{137} \mathrm{Cs}$ activity in the uppermost $40 \mathrm{~cm}$ of MLT1. The initial detection and subsequent peak of ${ }^{137} \mathrm{Cs}$ associated with the advent of ( 1954 A.D. $)$ and moratorium on $(\sim 1963$ A.D.) atmospheric nuclear weapons were detected at 9.5 and $6.5 \mathrm{~cm}$ depth respectively. In both panel (a) and (b), the black squares represent the measured values, and the gray bars are the analytical uncertainty in those measurements. 

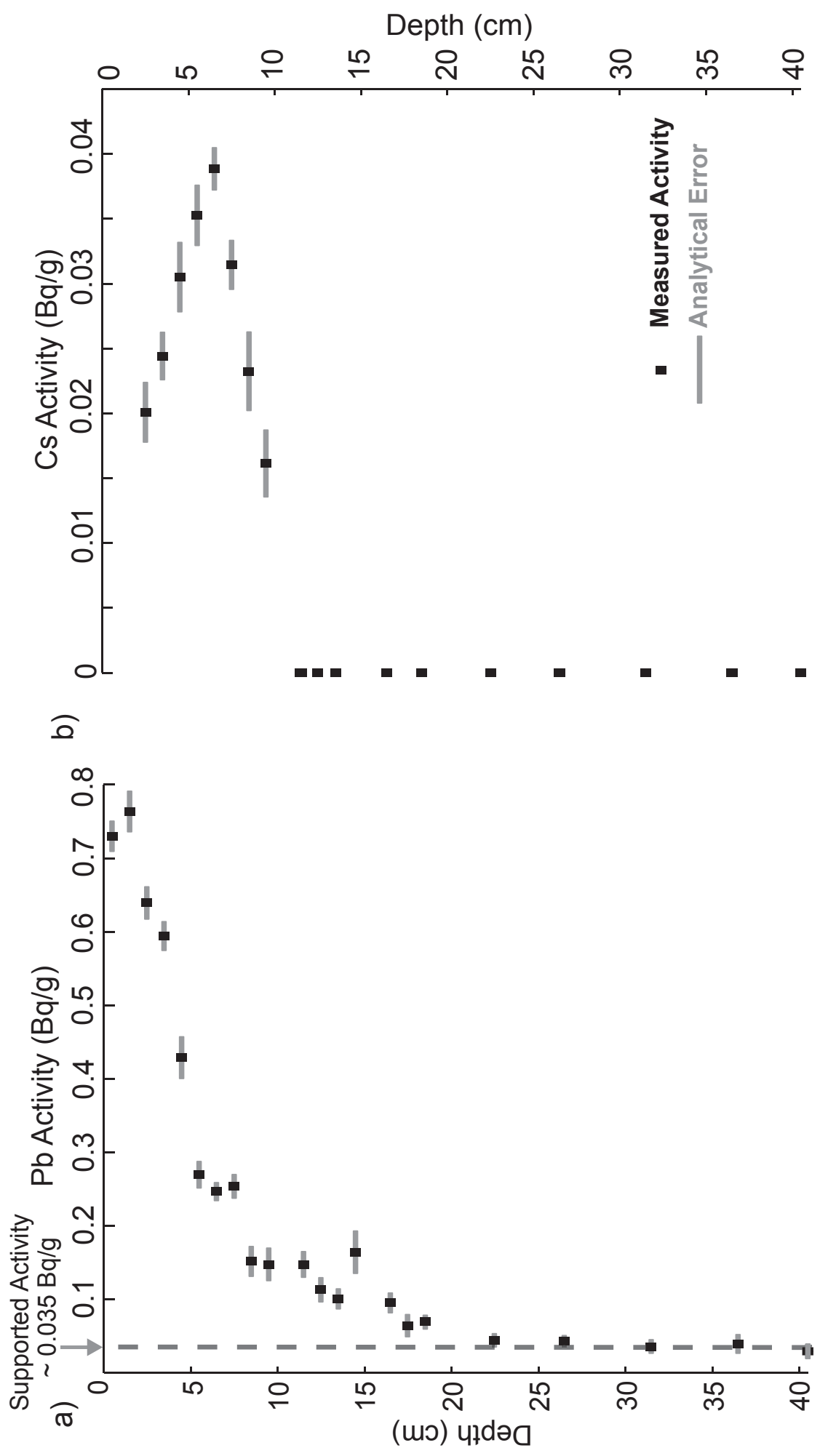


\section{Supplementary Figure 3 - Power spectra of MLT2 inorganics and coarse}

fraction time series. Panel (a) shows the power spectrum of the MLT2 time series of percent inorganics. The solid, black curve is the power calculated for each frequency bin and the gray shading is the 95 percent confidence interval of that power calculation. The dashed and dotted curves are the 95 and 99 percent confidence intervals for a comparable red noise power spectrum. Periods (in years)

corresponding to frequencies with calculated power exceeding the 95 and 99 percent red noise confidence intervals are labeled in regular and bold fonts respectively.

Panel (b) shows the same analysis for the MLT2 time series of percent coarse $(>63$ $\mu \mathrm{m})$. 


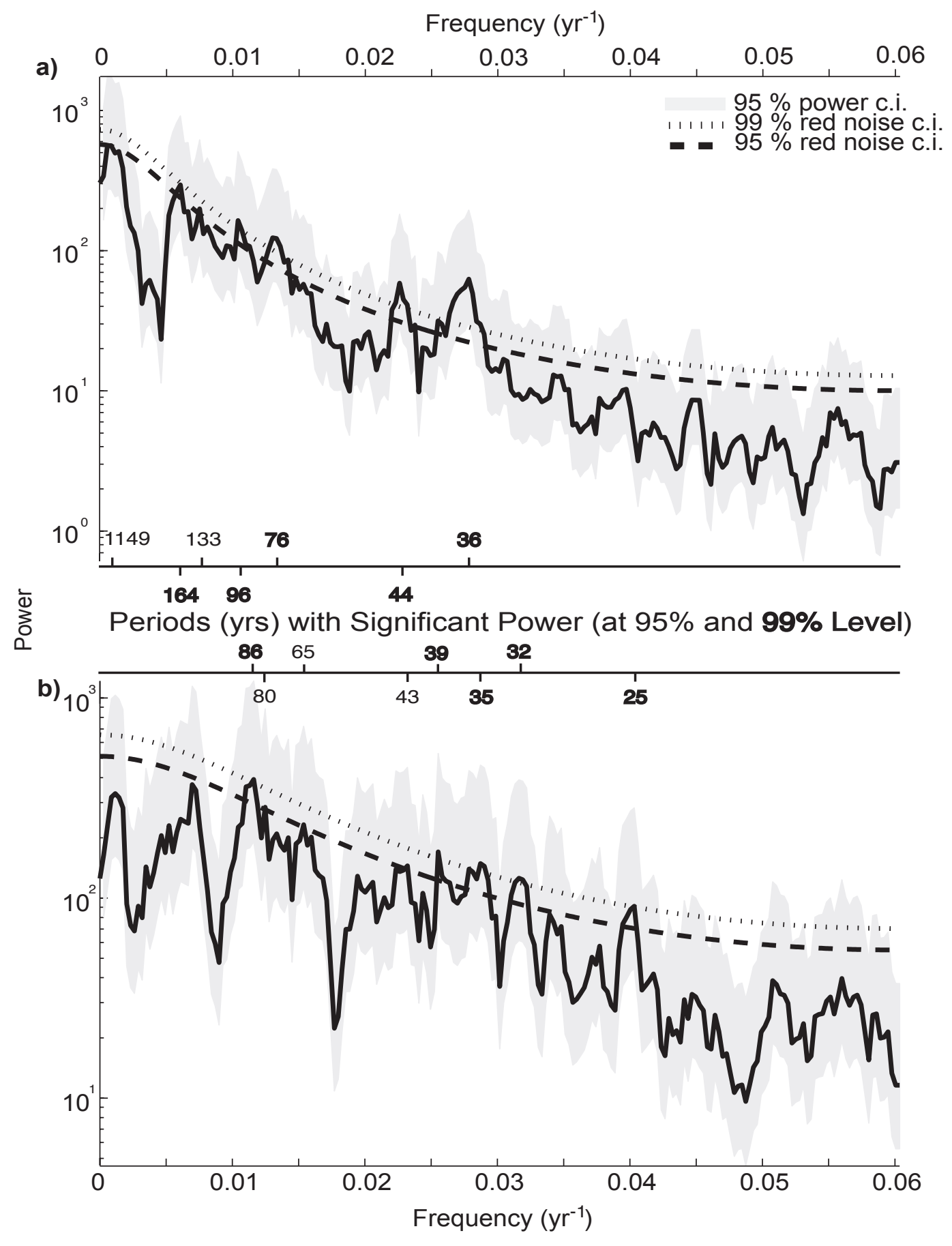




\section{Supplementary Figure 4 - Modern event deposits MLT1 and MLT2 comparison.}

Panel (a) and (b) show the positive coarse fraction anomalies that resulted from the subtraction of the low-frequency background from the raw MLT1 and MLT2 data respectively. These coarse fraction anomalies represent the high-frequency $(<30$ years) variability in the modern coarse fraction time series. In both MLT1 and MLT2, the coarse fraction anomalies that form the basis for the low (LT, gray dashed line) and high thresholds (HT, black dashed line) used for storm detection were related to hurricanes in 1941 A.D. (gray arrow) and 1985 A.D. (Elena, 1985) respectively. Storms with simulated surges possibly exceeding $2 \mathrm{~m}$ above NAVD are shown to the right of the coarse fraction anomalies they likely produced. 


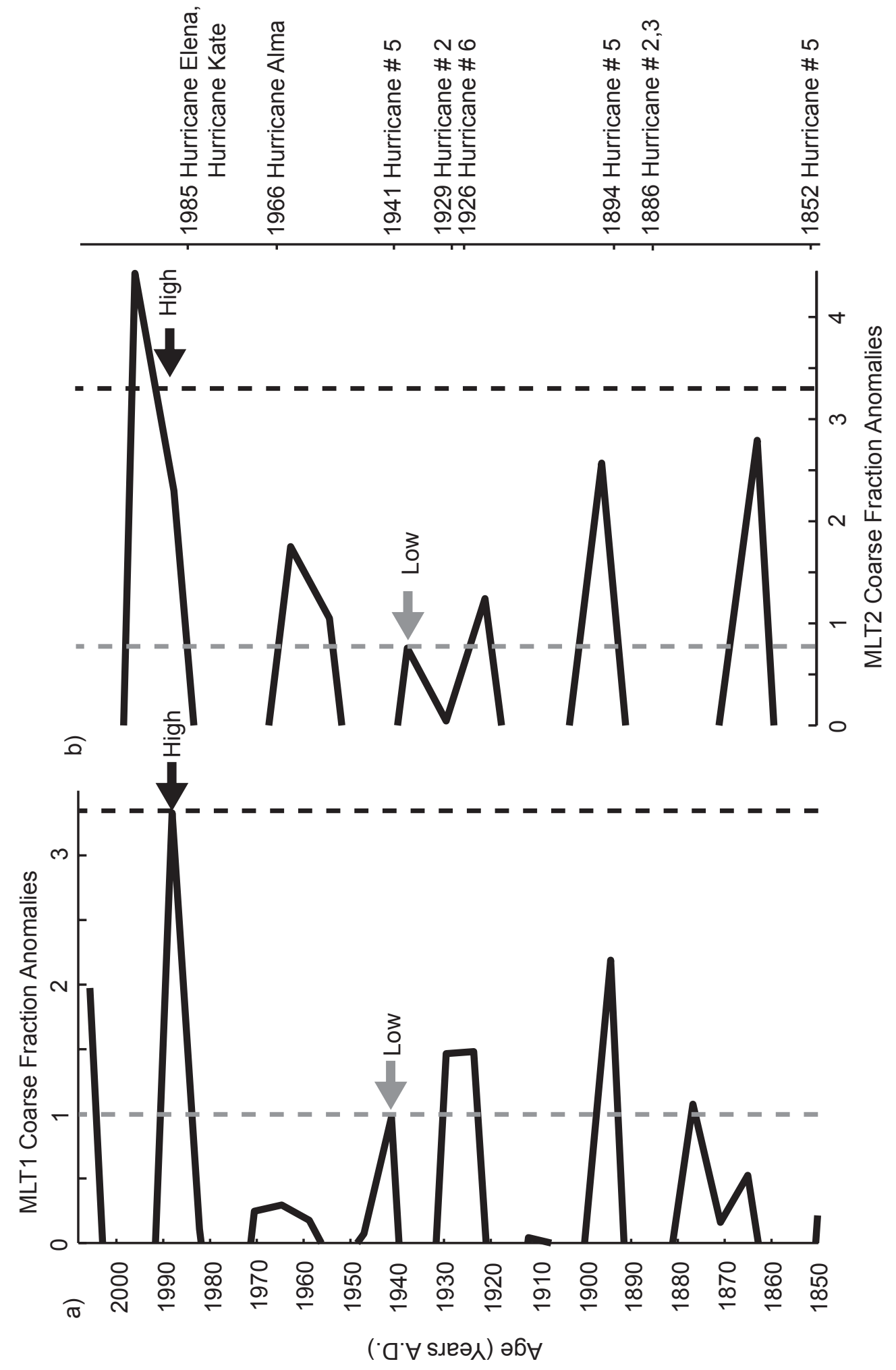




\section{Supplementary Figure 5 - MLT1 and MLT2 storm frequency time series comparison. Panel (a) is the MLT1 time series of hurricane frequency normalized to events per century as described in Figure 7. Panel (b) is the time series of hurricane frequency attained by applying the same process and HT value to the MLT2 record. Darker gray shaded portions of both panels highlight periods with storm frequency that exceeded the $90^{\text {th }}$ percentile of what would be expected by chance. The lighter gray periods were less active times in the record when storm frequency was in the bottom $10^{\text {th }}$ percentile of what would be expected by chance.}




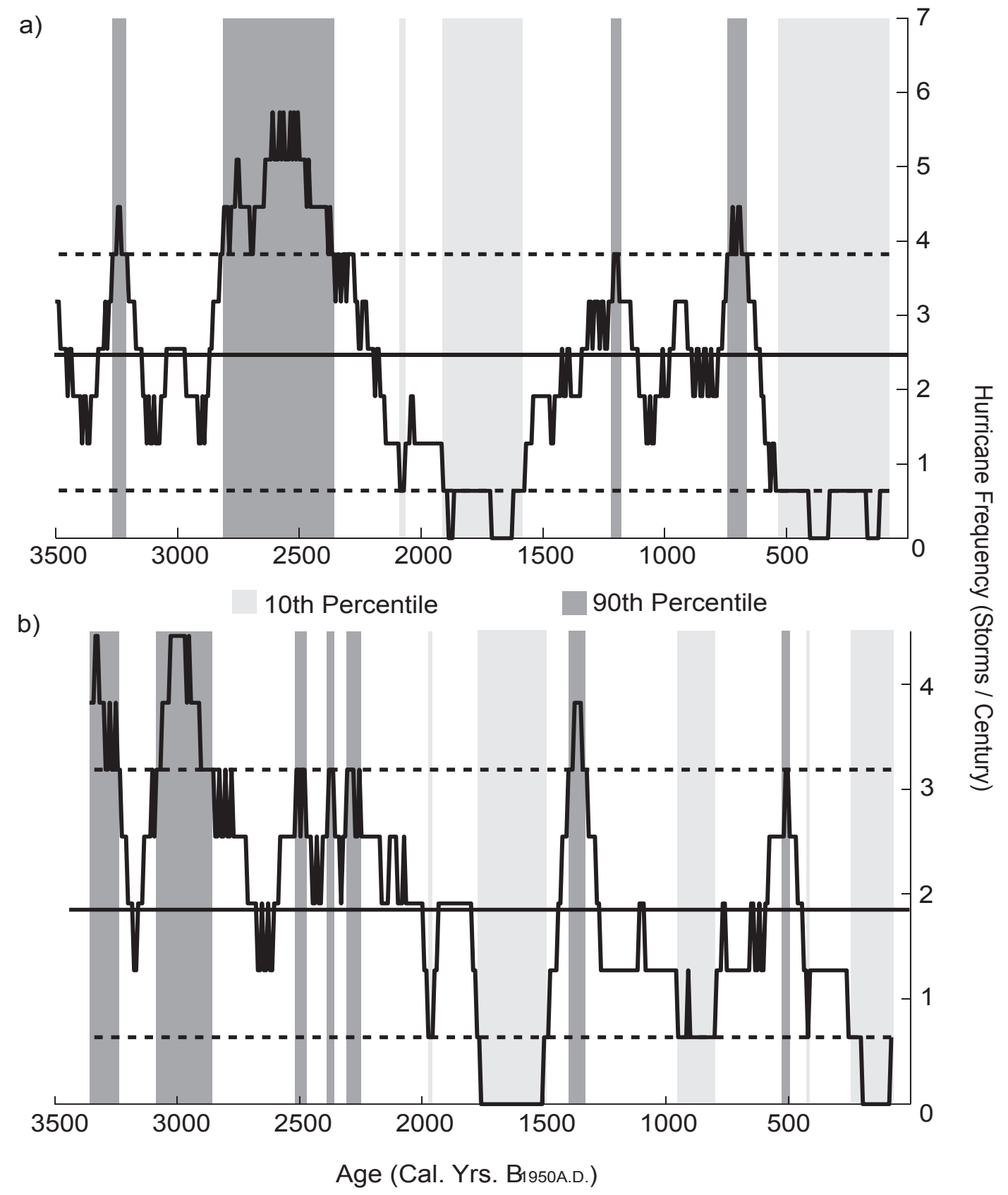


Appendix A2: Supplementary Material for Chapter 3 


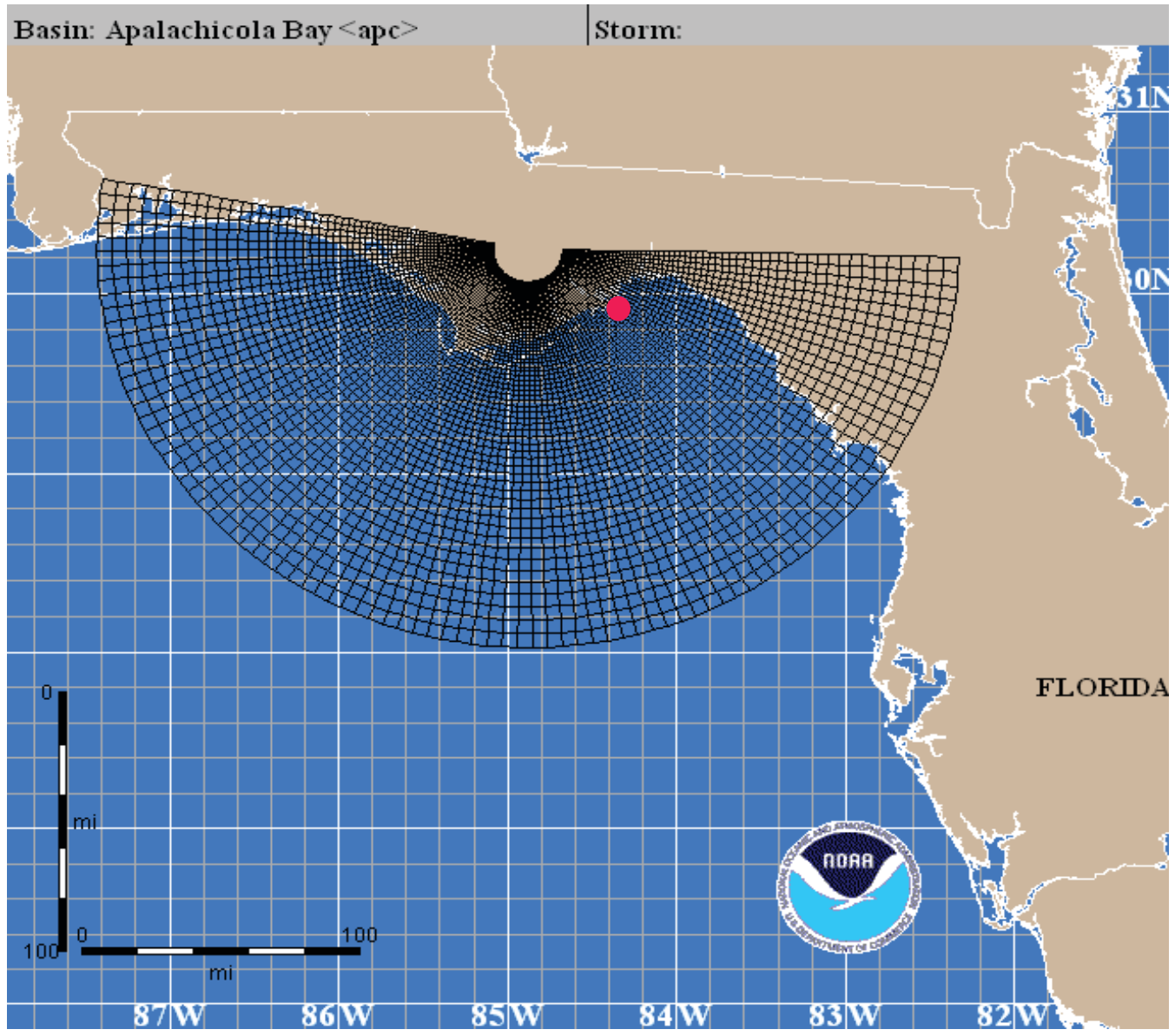

Figure A2.1 - SLOSH Apalachicola (APC) basin and location of Bald Point, Florida (red dot). 


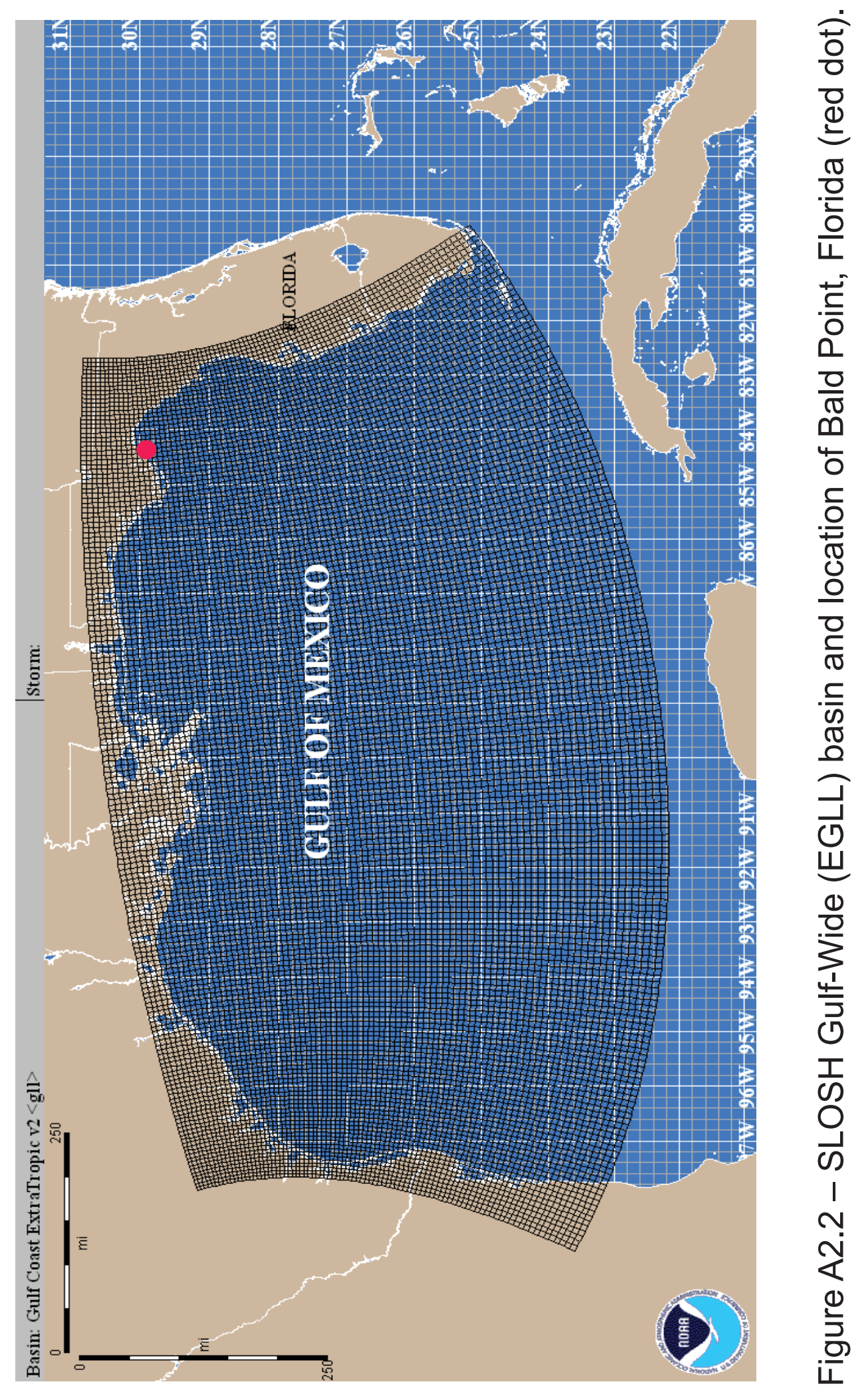




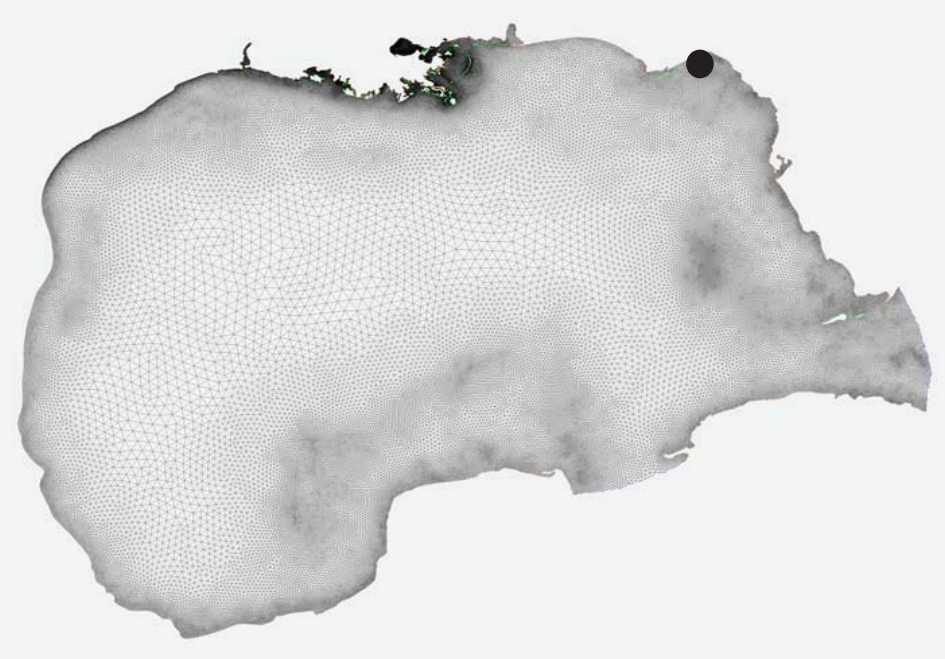

Figure A2.3 - ADCIRC Gulf-wide mesh used in surge modeling of Best Track storms. Location of Bald Point is shown (black dot). 
a)
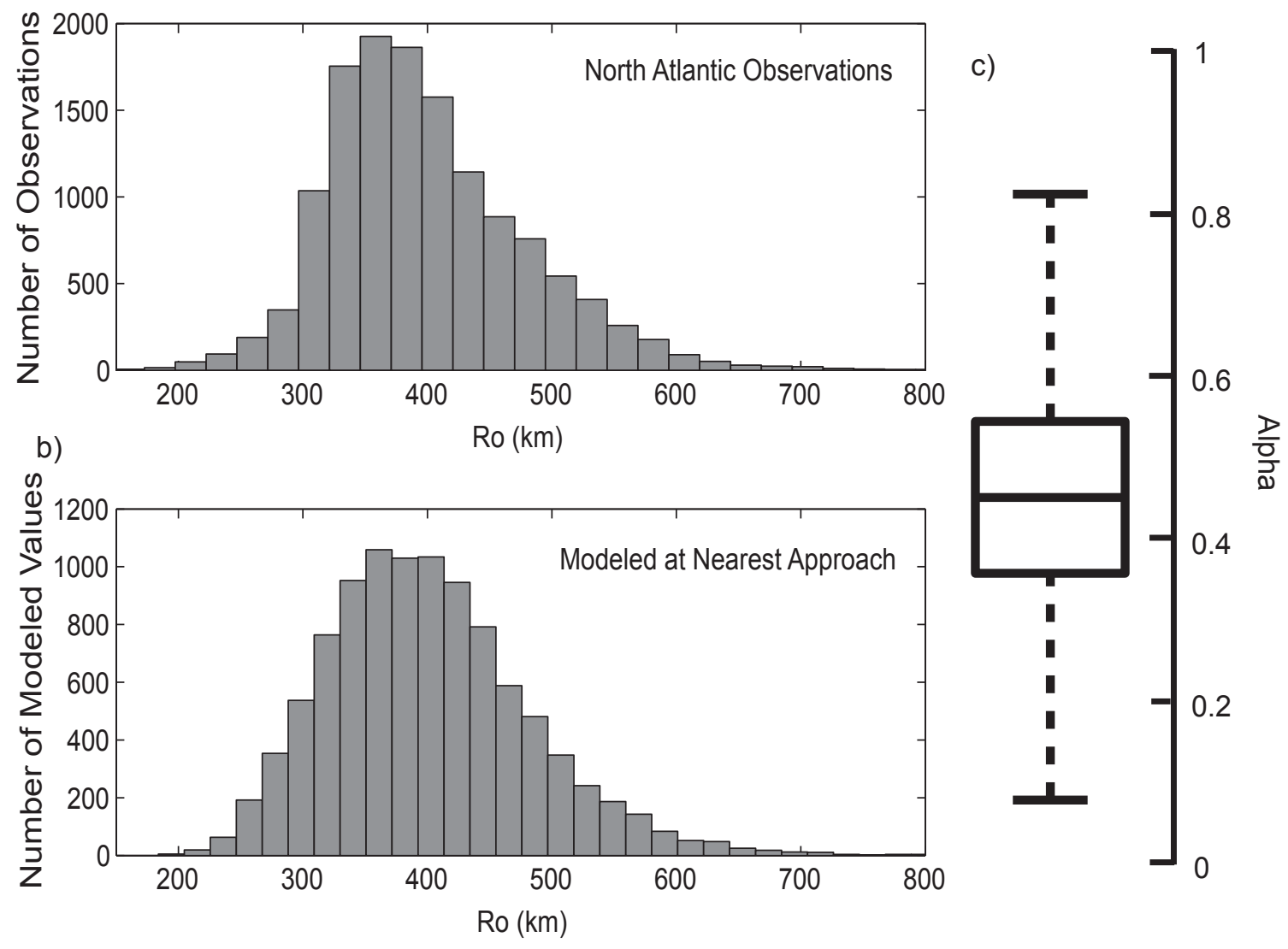

Figure A2.4 - Panel (a) is a histogram of observations $(\mathrm{N}=13,270)$ of North Atlantic TC outer radius (Ro) from Dean et al. (2009). Panel (b) is the histogram of modeled Ro at nearest approach to Bald Point, FL for the 10,000 synthetic events based on the lognormal distribution. Panel (c) is a boxplot of values of the fraction of angular momentum conservation (alpha) calculated from Equation 1 and observed values of North Atlantic TC latitude, Vmax, Ro and RMW. 


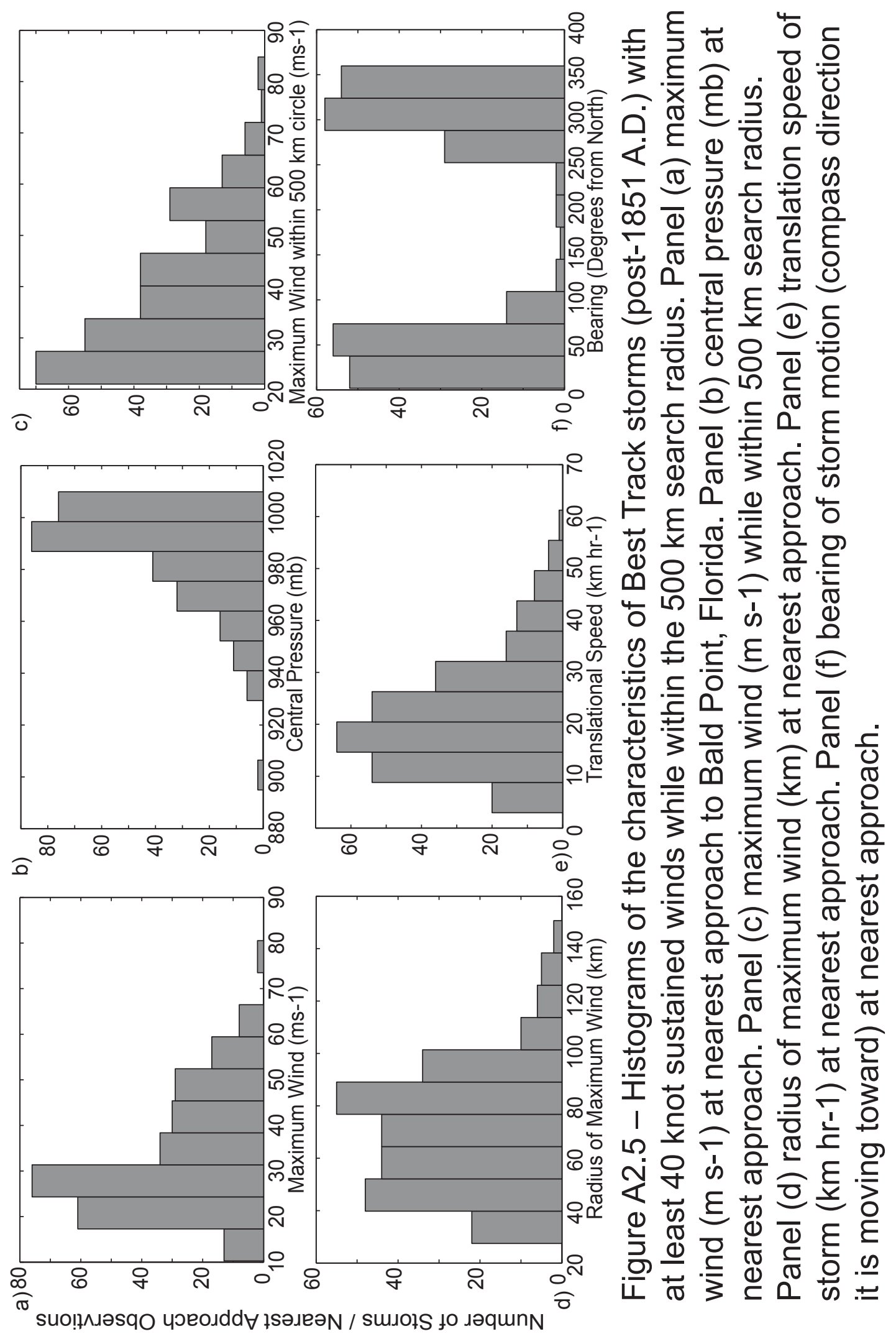



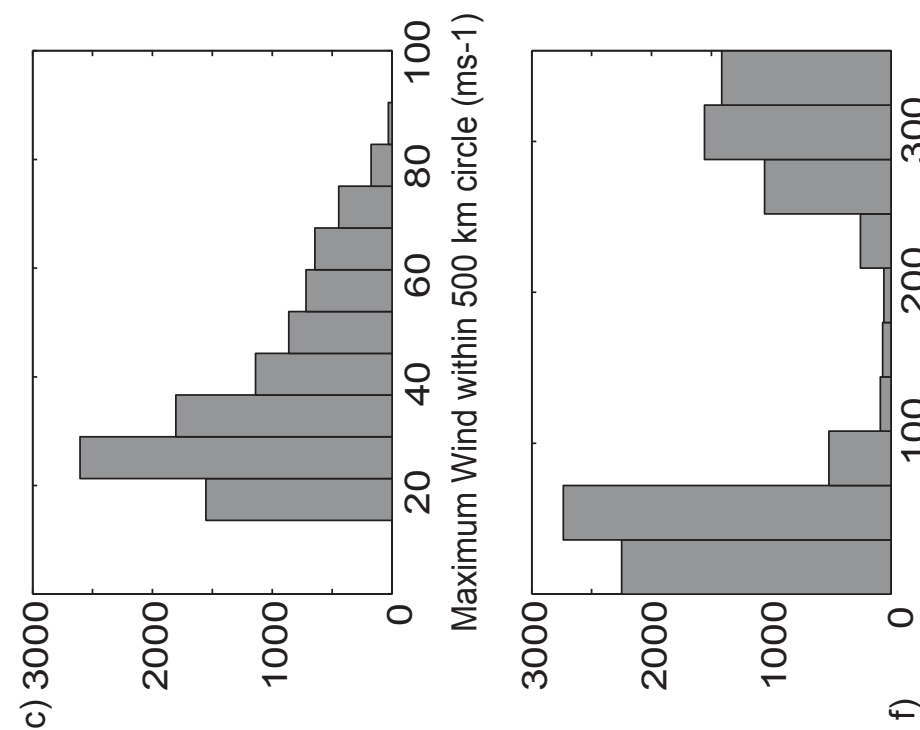

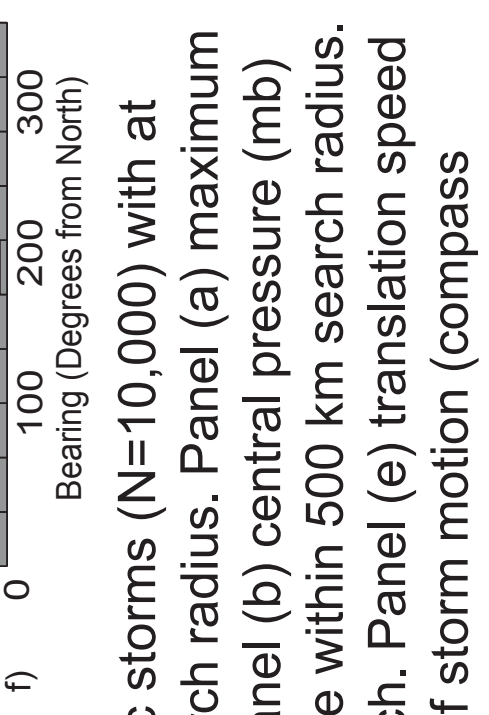
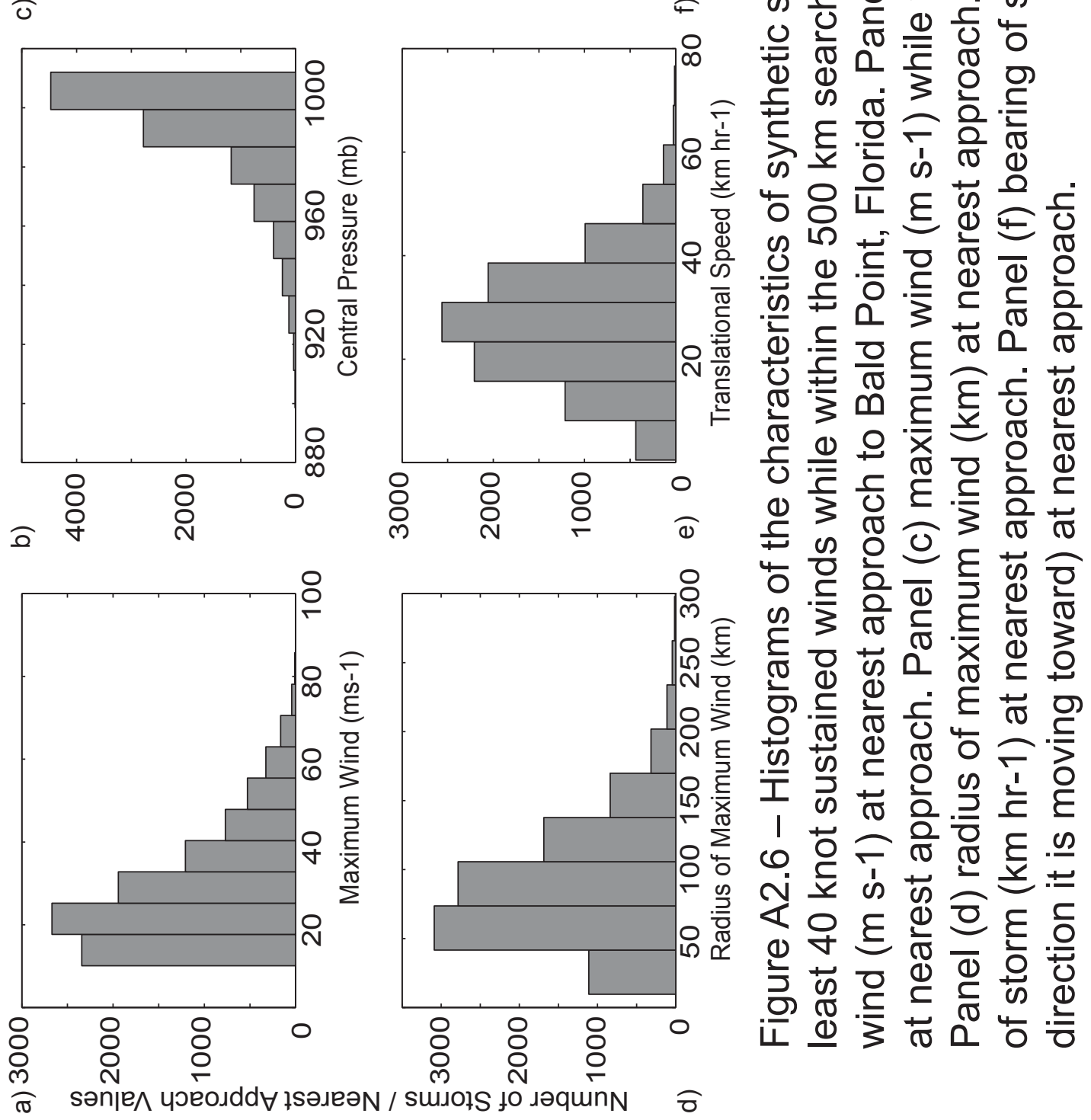


\begin{tabular}{|c|c|c|c|c|}
\hline Non-Cumulative & & & & \\
\hline Return Time (yrs.) & Best Track & & Synthetic & \\
\hline $\begin{array}{l}\text { Saffir-Simpson } \\
\text { Category }\end{array}$ & $\begin{array}{c}\text { Nearest } \\
\text { Approach } \\
\text { (Bald Point, } \\
\text { FL) }\end{array}$ & $\begin{array}{c}\text { Within } 500 \\
\text { km } \\
\text { Search } \\
\text { Radius }\end{array}$ & $\begin{array}{c}\text { Nearest } \\
\text { Approach } \\
\text { (Bald Point, } \\
\text { FL) }\end{array}$ & $\begin{array}{c}\text { Within } 500 \\
\text { km } \\
\text { Search } \\
\text { Radius }\end{array}$ \\
\hline Tropical Storm & $1.1 \mathrm{yrs}$. & $1.3 \mathrm{yrs}$. & $1.2 \mathrm{yrs}$. & $1.1 \mathrm{yrs}$. \\
\hline Category 1 & 3.1 yrs. & 2.7 yrs. & 3.6 yrs. & 3.1 yrs. \\
\hline Category 2 & 5.0 yrs. & 4.6 yrs. & 8.4 yrs. & 6.1 yrs. \\
\hline Category 3 & 6.8 yrs. & 4.5 yrs. & 8.9 yrs. & 5.8 yrs. \\
\hline Category 4 & 15.6 yrs. & 7.1 yrs. & 16.3 yrs. & 5.6 yrs. \\
\hline Category 5 & 78.0 yrs. & 39.0 yrs. & 84.8 yrs. & 11.1 yrs. \\
\hline
\end{tabular}

Table A2.1 - Storm return times by Saffir-Simpson category in the northeastern Gulf of Mexico based on Best Track (post-1851 A.D.) and synthetic storm datasets $(\mathrm{N}=$ $10^{4}, \sim 5175$ yrs. long). Estimates are made from non-cumulative numbers of events and represent the average amount of time elapsed before observing a storm of equal Saffir-Simpson category. Return times are calculated from nearest approach (to Bald Point, Florida) storm intensity statistics as well as from maximum storm intensities while within the specified $500 \mathrm{~km}$ search radius. 


\begin{tabular}{|l|c|c|c|c|}
\hline Cumulative & & & & \\
\hline Return Time (yrs.) & Best Track & Synthetic & \\
\hline Saffir-Simpson & $\begin{array}{c}\text { Nearest } \\
\text { Category }\end{array}$ & $\begin{array}{c}\text { Within } 500 \\
\text { km } \\
\text { (Bald Point, } \\
\text { FL) }\end{array}$ & $\begin{array}{c}\text { Search } \\
\text { Radius } \\
\text { Approach } \\
\text { (Bald Point, } \\
\text { FL) }\end{array}$ & $\begin{array}{c}\text { Within } 500 \\
\text { km } \\
\text { Search } \\
\text { Radius }\end{array}$ \\
\hline Tropical Storm & 0.6 yrs. & 0.6 yrs. & 0.7 yrs. & 0.6 yrs. \\
\hline Category 1 & 1.3 yrs. & 1.0 yrs. & 1.7 yrs. & 1.1 yrs. \\
\hline Category 2 & 2.4 yrs. & 1.6 yrs. & 3.3 yrs. & 1.7 yrs. \\
\hline Category 3 & 4.5 yrs. & 2.6 yrs. & 5.4 yrs. & 2.3 yrs. \\
\hline Category 4 & 13.0 yrs. & 6.0 yrs. & 13.7 yrs. & 3.7 yrs. \\
\hline Category 5 & 78.0 yrs. & 39.0 yrs. & 84.8 yrs. & 11.1 yrs. \\
\hline
\end{tabular}

Table A2.2 - Storm return times by Saffir-Simpson category in the northeastern Gulf of Mexico based on Best Track (post-1851 A.D.) and synthetic storm datasets $(\mathrm{N}=$ $10^{4}, \sim 5175$ yrs. long). Estimates are made from cumulative numbers of events and represent the average amount of time elapsed before observing a storm of equal or greater Saffir-Simpson category. Return times are calculated from nearest approach (to Bald Point, Florida) storm intensity statistics as well as from maximum storm intensities while within the specified $500 \mathrm{~km}$ search radius. 


\begin{tabular}{|c|c|c|c|c|c|c|}
\hline $\begin{array}{c}\text { Storm } \\
\text { No. }\end{array}$ & Name & $\begin{array}{c}\text { Year } \\
\text { (A.D.) }\end{array}$ & $\begin{array}{c}\text { Season } \\
\text { No. }\end{array}$ & $\begin{array}{c}\text { SLOSH APC } \\
\text { Surge (m) }\end{array}$ & $\begin{array}{c}\text { SLOSH } \\
\text { EGLL } \\
\text { Surge (m) }\end{array}$ & $\begin{array}{c}\text { ADCIRC } \\
\text { Surge (m) }\end{array}$ \\
\hline 1 & None & 1852 & 5 & 3.2 & 4.1 & 5.3 \\
\hline 2 & None & 1856 & 5 & 1.1 & 1.3 & 1.3 \\
\hline 3 & None & 1877 & 4 & 1.7 & 1.5 & 1.7 \\
\hline 4 & None & 1886 & 2 & 1.5 & 2.2 & 3.7 \\
\hline 5 & None & 1886 & 3 & 2.5 & 1.7 & 0.8 \\
\hline 6 & None & 1894 & 5 & 1.7 & 1.2 & 1.7 \\
\hline 7 & None & 1896 & 4 & 1.1 & 1.7 & 2.2 \\
\hline 8 & None & 1926 & 6 & 1.7 & 2.6 & 2.1 \\
\hline 9 & None & 1929 & 2 & 1.8 & 2.4 & 2.3 \\
\hline 10 & None & 1941 & 5 & 3.0 & 2.9 & 3.0 \\
\hline 11 & Alma & 1966 & 1 & 2.8 & 2.5 & 2.8 \\
\hline 12 & Eloise & 1975 & 5 & 1.2 & 1.1 & 1.6 \\
\hline 13 & Elena & 1985 & 5 & 2.6 & 4.3 & 3.4 \\
\hline 14 & Kate & 1985 & 11 & 1.7 & 1.7 & 1.9 \\
\hline 15 & Dennis & 2005 & 4 & 1.1 & 1.8 & 2.0 \\
\hline
\end{tabular}

Table A2.3 - Best Track storms producing at least $1 \mathrm{~m}$ of surge at Bald Point, Florida. 


\begin{tabular}{|c|c|c|c|c|c|c|}
\hline $\begin{array}{c}\text { Storm } \\
\text { No. }\end{array}$ & Name & $\begin{array}{c}\text { Year } \\
\text { (A.D.) }\end{array}$ & $\begin{array}{c}\text { Season } \\
\text { No. }\end{array}$ & $\begin{array}{c}\text { ADCIRC } \\
\text { Surge }+ \\
\text { Wave Setup } \\
(\mathrm{m})\end{array}$ & $\begin{array}{c}\text { ADCIRC } \\
\text { Surge + Setup } \\
+ \text { Tide } \\
(\mathrm{m})\end{array}$ & $\begin{array}{c}\text { ADCIRC } \\
\text { Sig. Wave } \\
\text { Height } \\
(\mathrm{m})\end{array}$ \\
\hline 1 & None & 1852 & 5 & 5.4 & 5.0 & 3.5 \\
\hline 2 & None & 1856 & 5 & 1.4 & 1.8 & 1.8 \\
\hline 3 & None & 1877 & 4 & 1.8 & 2.2 & 2.0 \\
\hline 4 & None & 1886 & 2 & 3.9 & 3.4 & 2.7 \\
\hline 5 & None & 1886 & 3 & 0.8 & 1.1 & 1.0 \\
\hline 6 & None & 1894 & 5 & 1.8 & 2.3 & 1.9 \\
\hline 7 & None & 1896 & 4 & 2.2 & 2.2 & 1.9 \\
\hline 8 & None & 1926 & 6 & 2.2 & 2.4 & 2.1 \\
\hline 9 & None & 1929 & 2 & 2.4 & 2.6 & 2.4 \\
\hline 10 & None & 1941 & 5 & 3.1 & 3.4 & 2.7 \\
\hline 11 & Alma & 1966 & 1 & 2.8 & 3.1 & 2.6 \\
\hline 12 & Eloise & 1975 & 5 & 1.8 & 1.4 & 1.9 \\
\hline 13 & Elena & 1985 & 5 & 3.5 & 3.5 & 2.8 \\
\hline 14 & Kate & 1985 & 11 & 1.9 & 1.7 & 2.1 \\
\hline 15 & Dennis & 2005 & 4 & 2.2 & 2.4 & 2.1 \\
\hline
\end{tabular}

Table A2.4 - ADCIRC results for Best Track storms with at least 1 meter of surge modeled at Bald Point, Florida. Still-water surge levels, which include wave setup and astronomical tide, are shown along with the near-shore significant wave height (approximately one-third of the maximum wave height). 


\begin{tabular}{|c|c|c|c|c|c|c|c|c|c|c|c|c|c|c|c|}
\hline 尝 & $\stackrel{\overbrace{}}{\mathrm{N}}$ & $\stackrel{\infty}{\sim}$ & $n$ & $\infty$ & $\infty$ & 只 & ণิ & $\underset{ల}{\Omega}$ & $\frac{a}{m}$ & N & $\stackrel{m}{n}$ & $\stackrel{\wp}{\checkmark}$ & ñ & $\frac{7}{c}$ & $\stackrel{\vec{c}}{\mathrm{c}}$ \\
\hline 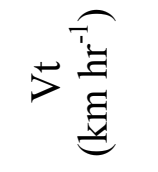 & N & $\stackrel{\infty}{\sim}$ & 工 & $\stackrel{\sim}{\sim}$ & ñ & 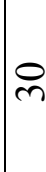 & 요 & 工 & 0 & $\stackrel{m}{\sim}$ & N & $\pi$ & 士 & 1 & 10 \\
\hline 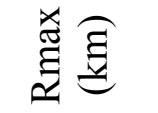 & $\hat{n}$ & $\hat{m}$ & $\hat{m}$ & $m$ & m & $m$ & m & $m$ & 워 & \& & 웅 & $m$ & $m$ & ल & $\stackrel{\circ}{\circ}$ \\
\hline 욭 & જે & ชู & فे & $\stackrel{m}{a}$ & $\frac{m}{a}$ & ñ & ค̊ & n & $\frac{\infty}{a}$ & $\frac{\infty}{a}$ & $\vec{\infty}$ & $\begin{array}{l}n \\
\curvearrowleft\end{array}$ & $\begin{array}{l}\infty \\
n \\
\sigma\end{array}$ & $\underset{\sigma}{\infty}$ & 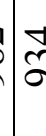 \\
\hline 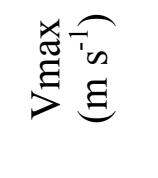 & $\begin{array}{l}0 \\
\text { f }\end{array}$ & 은 & † & ষ & ষ & 只 & in & น & 워 & 寸 & $\infty$ & $\stackrel{\sim}{\sim}$ & in & $\underset{c}{\infty}$ & 8 \\
\hline 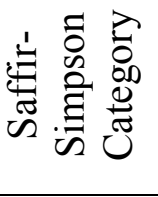 & $N$ & $m$ & $\sim$ & $\sim$ & $N$ & $m$ & $m$ & $m$ & - & 一 & - & $m$ & $m$ & - & $\mid \nabla$ \\
\hline 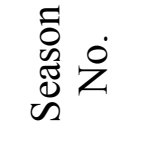 & $n$ & $n$ & $\checkmark$ & $\sim$ & $m$ & in & $\nabla$ & 6 & $N$ & in & - & $n$ & $n$ & $=$ & $\nabla$ \\
\hline 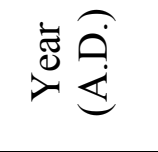 & $\begin{array}{l}N \\
\infty \\
\infty\end{array}$ & $\begin{array}{l}0 \\
\infty \\
\infty\end{array}$ & $\infty$ & $\begin{array}{l}\infty \\
\infty \\
\infty\end{array}$ & $\begin{array}{l}\infty \\
\infty \\
\infty\end{array}$ & ஓ & ○े & ป & ๙ิ & すั & b & $\frac{n}{a}$ & $\begin{array}{l}n \\
\infty \\
0\end{array}$ & $\stackrel{r}{a}$ & $\stackrel{r}{\varrho}$ \\
\hline $\begin{array}{l}\text { E } \\
\text { Z }\end{array}$ & $\begin{array}{l}\stackrel{o}{0} \\
\text { Z }\end{array}$ & 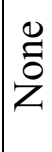 & 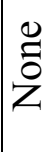 & $\begin{array}{l}\mathscr{0} \\
\tilde{0} \\
z\end{array}$ & $\begin{array}{l}\mathscr{O} \\
\tilde{0} \\
Z \\
Z\end{array}$ & $\begin{array}{l}\mathscr{0} \\
\tilde{0} \\
\text { Z }\end{array}$ & $\begin{array}{l}\mathscr{0} \\
\tilde{0} \\
\mathbf{Z}\end{array}$ & $\begin{array}{l}\mathscr{\Xi} \\
\tilde{0} \\
\text { Z }\end{array}$ & 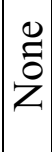 & $\begin{array}{l}0 \\
0 \\
z\end{array}$ & $\frac{⿱ 乛}{\Xi}$ & $\frac{0}{\frac{D}{0}}$ & $\frac{\widetilde{\sigma}}{\tilde{O}}$ & $\frac{5}{\sigma}$ & $\frac{u}{\frac{U}{2}}$ \\
\hline 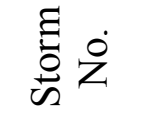 & -1 & $\sim$ & $m$ & $\nabla$ & in & 6 & 1 & $\infty$ & $a$ & 으 & 二 & $\simeq$ & $\cong$ & 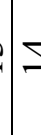 & $n$ \\
\hline
\end{tabular}




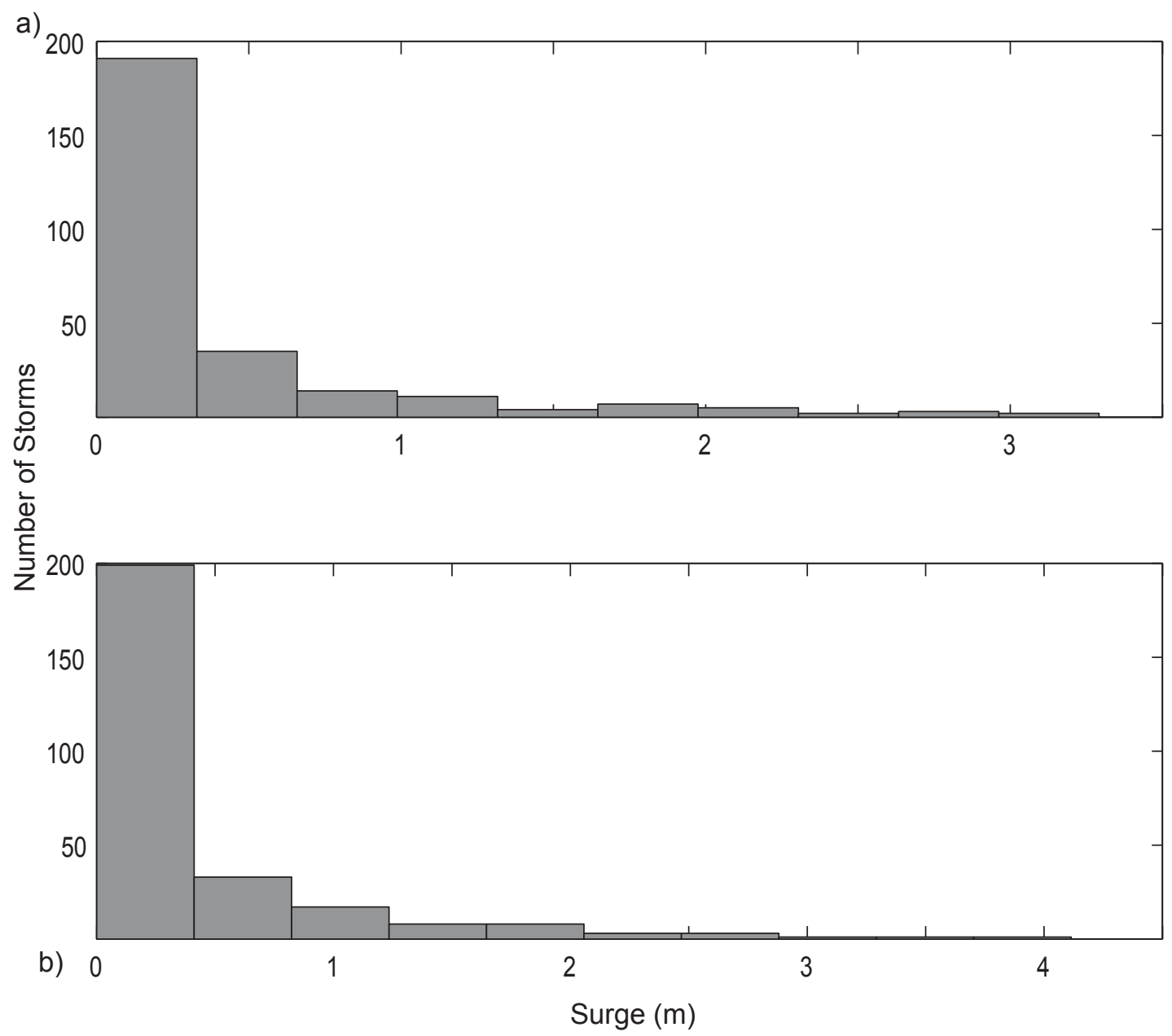

Figure A2.7 - Histograms of modeled surges from Best Track storms in SLOSH. Panel (a) contains the maximum surges at Bald Point in the APC basin and panel (b) shows the maximum surges at Bald Point in the EGLL basin. $\mathrm{N}=274$ storms meeting the selection criteria for modeling and $\mathrm{T}=156 \mathrm{yrs}$., which gives an annual frequency of 1.76 storms yr-1. 


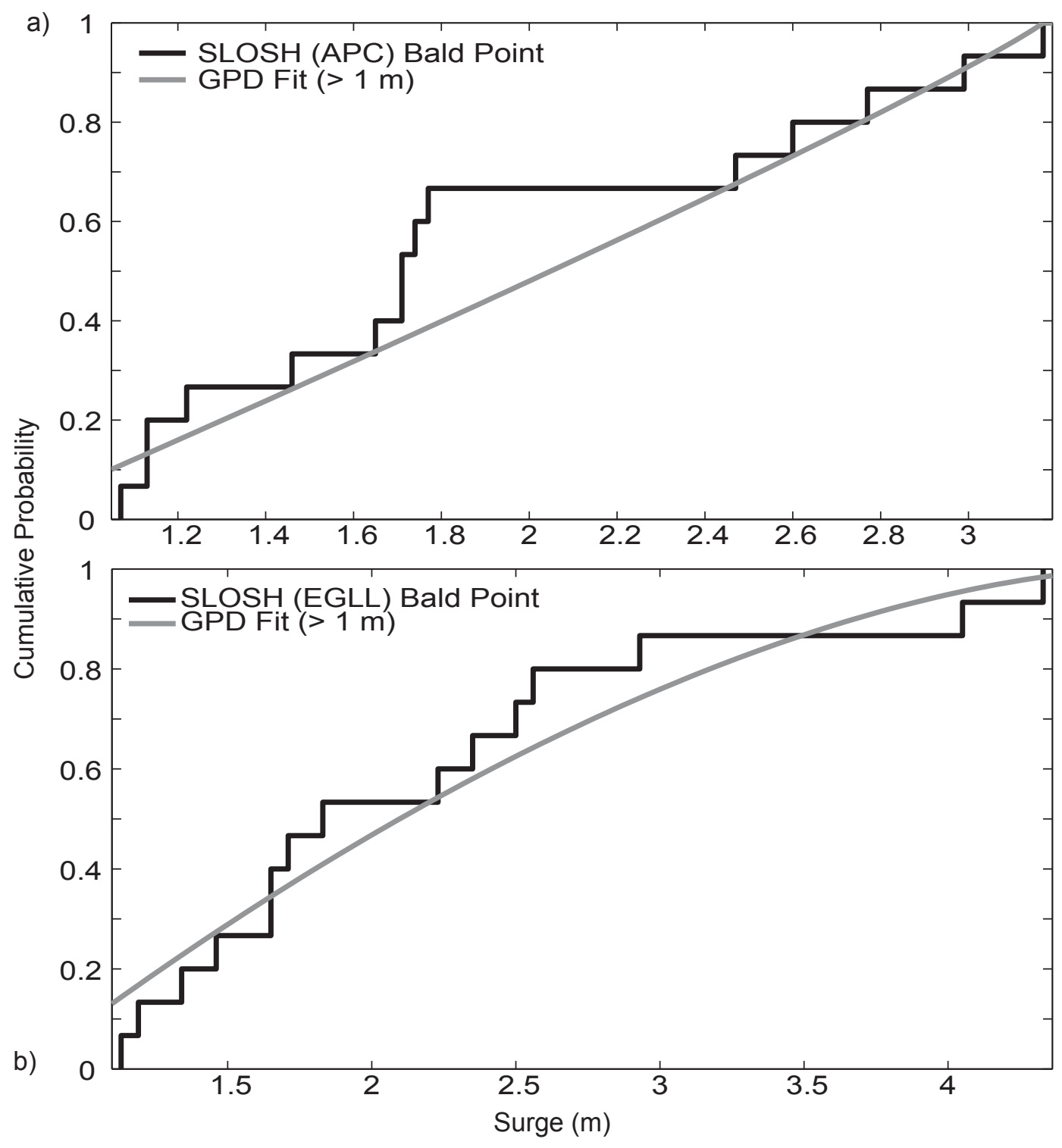

Figure A2.8 - Cumulative probability plots and Generalized Pareto Distribution fits to Best Track maximum modeled surges exceeding $1 \mathrm{~m}$ at Bald Point. Panel (a) shows modeled values and fits for the APC basin, and panel (b) shows modeled values and fits for the EGLL basin. 


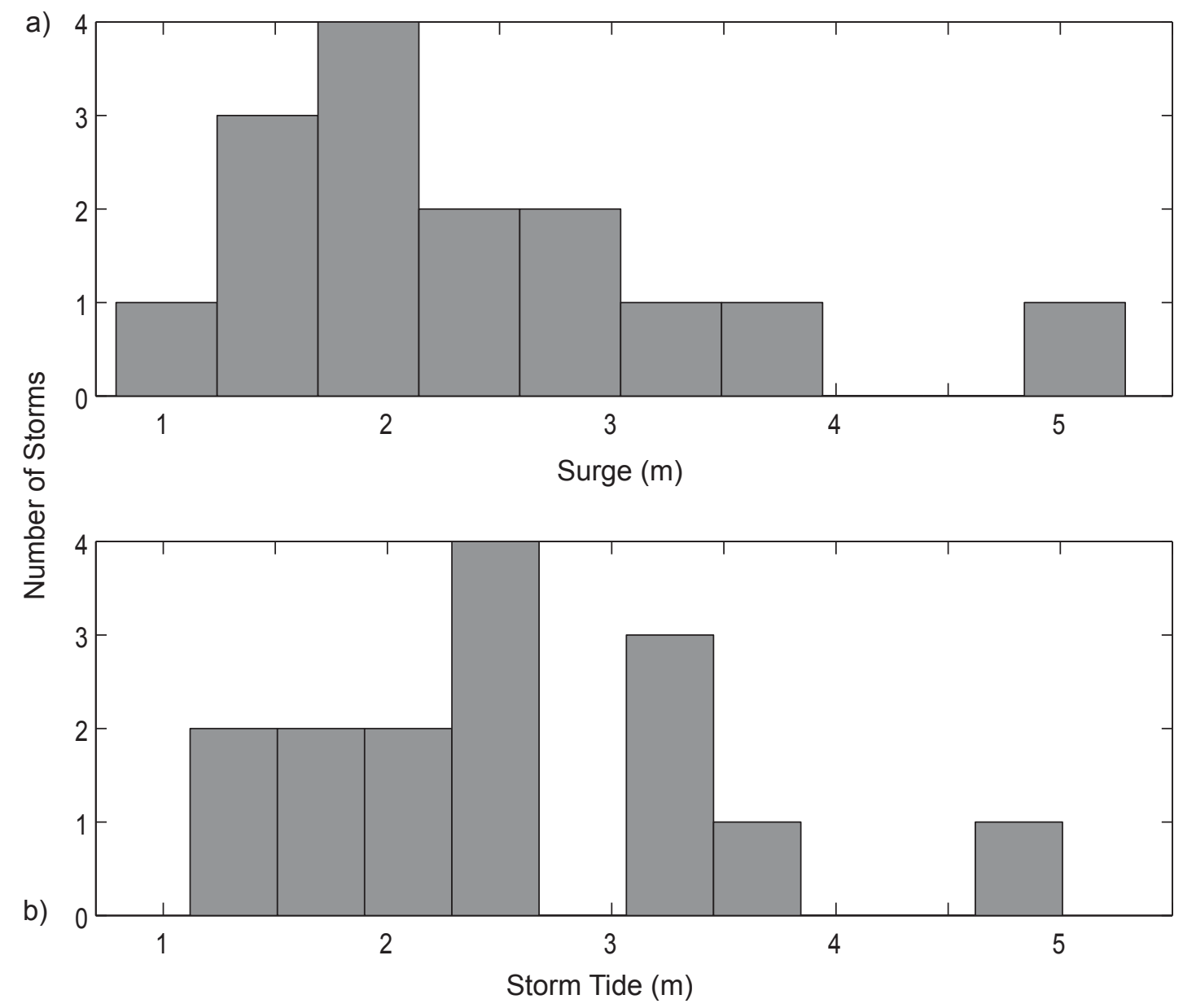

Figure A2.9 - Histograms of modeled surges and total storm tides (surge + wave setup + astronomical tide) from Best Track storms in ADCIRC. Panel (a) contains the maximum surge at Bald Point and panel (b) shows the maximum storm tide at Bald Point in the EGLL basin. $N=274$ storms meeting the selection criteria for modeling and $\mathrm{T}=156 \mathrm{yrs}$., which gives an annual frequency of 1.76 storms yr-1. 


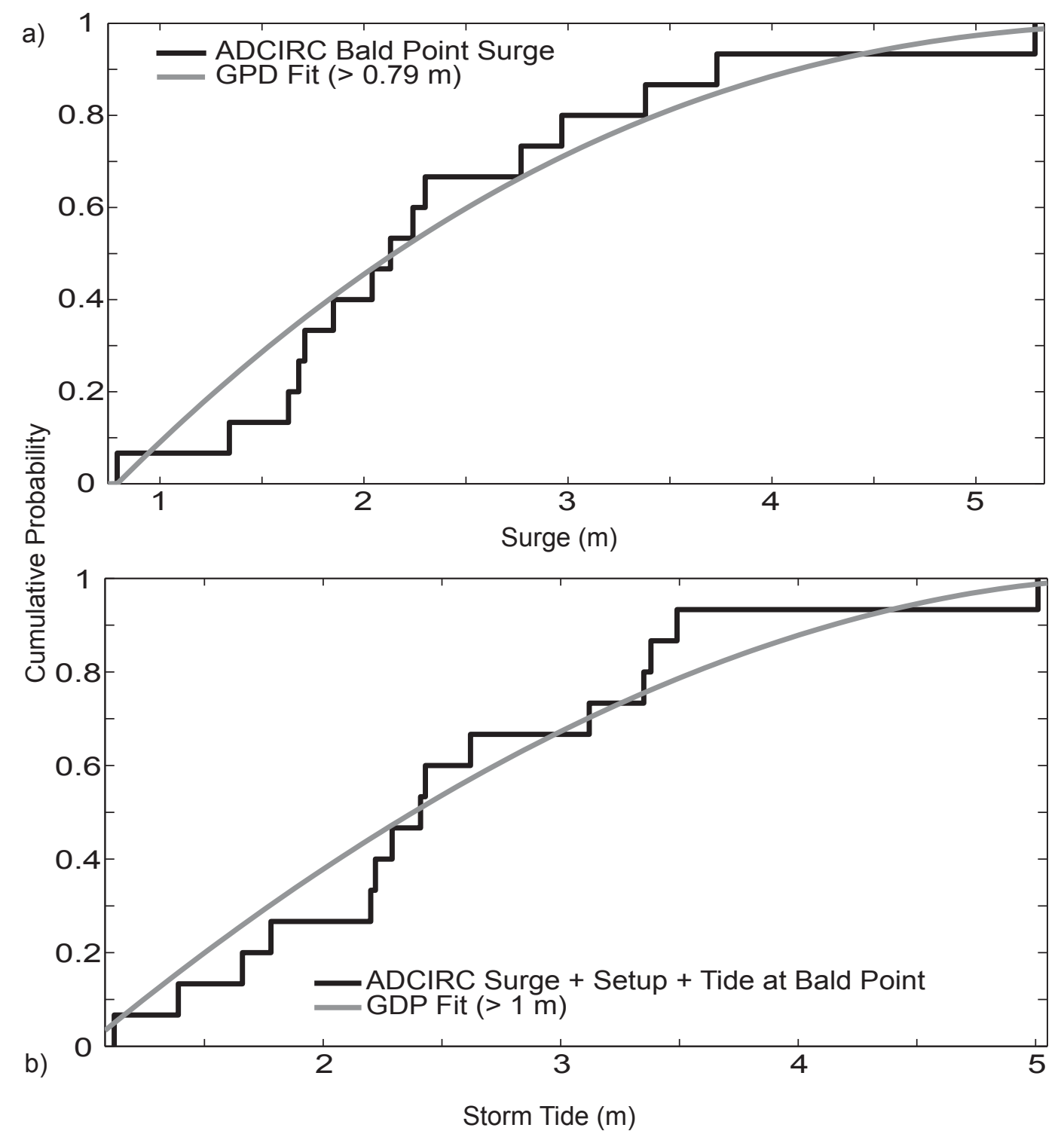

Figure A2.10 - Cumulative probability plots and Generalized Pareto Distribution fits to Best Track maximum modeled surges and storm tides exceeding $1 \mathrm{~m}$ at Bald Point. Panel (a) shows modeled values and fits for surge values modeled in ADCIRC, and panel (b) shows modeled values and fits to storm tide values (surge + wave setup + astronomical tide) in ADCIRC. 


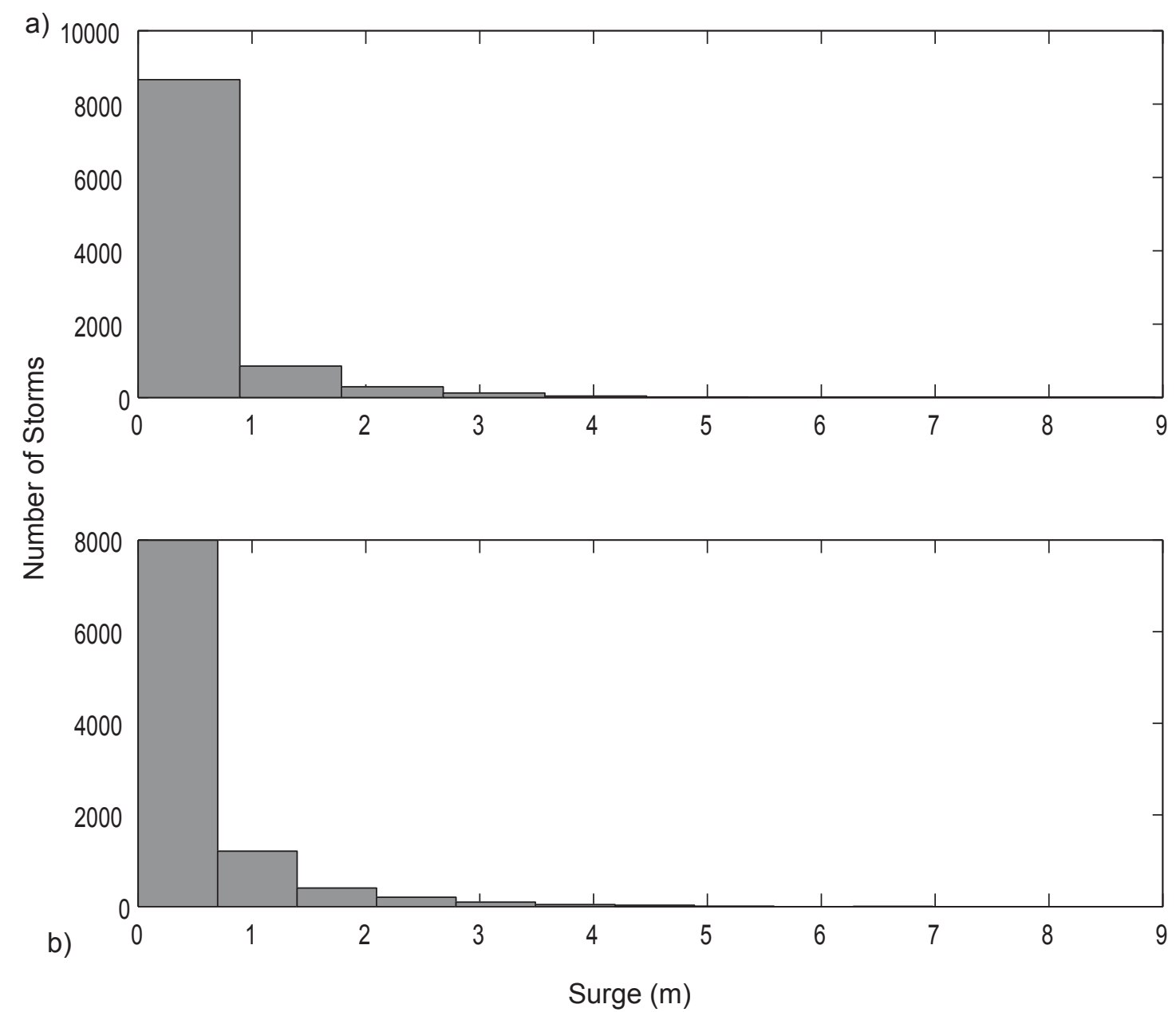

Figure A2.11 - Histograms of modeled surges from synthetic storms in SLOSH. Panel (a) contains the maximum surges at Bald Point in the APC basin and panel (b) shows the maximum surges at Bald Point in the EGLL basin. $\mathrm{N}=10,000$ storms meeting the selection criteria for modeling and $T=5175$ yrs., which gives an annual frequency of 1.93 storms $\mathrm{yr}-1$. 


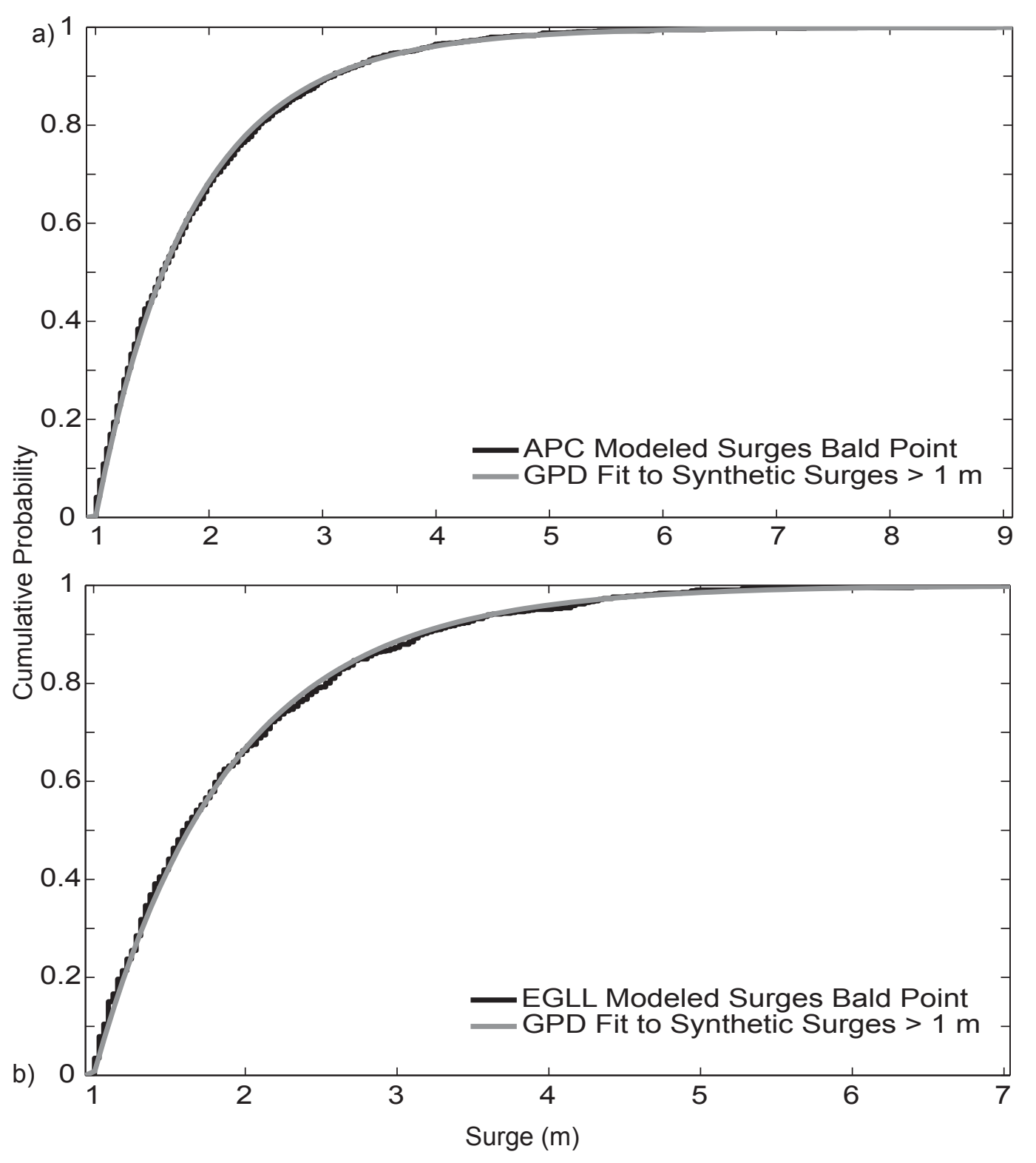

Figure A2.12 - Cumulative probability plots and Generalized Pareto Distribution fits to synthetic maximum modeled surges exceeding $1 \mathrm{~m}$ at Bald Point. Panel (a) shows modeled values and fits for the APC basin, and panel (b) shows modeled values and fits for the EGLL basin. 


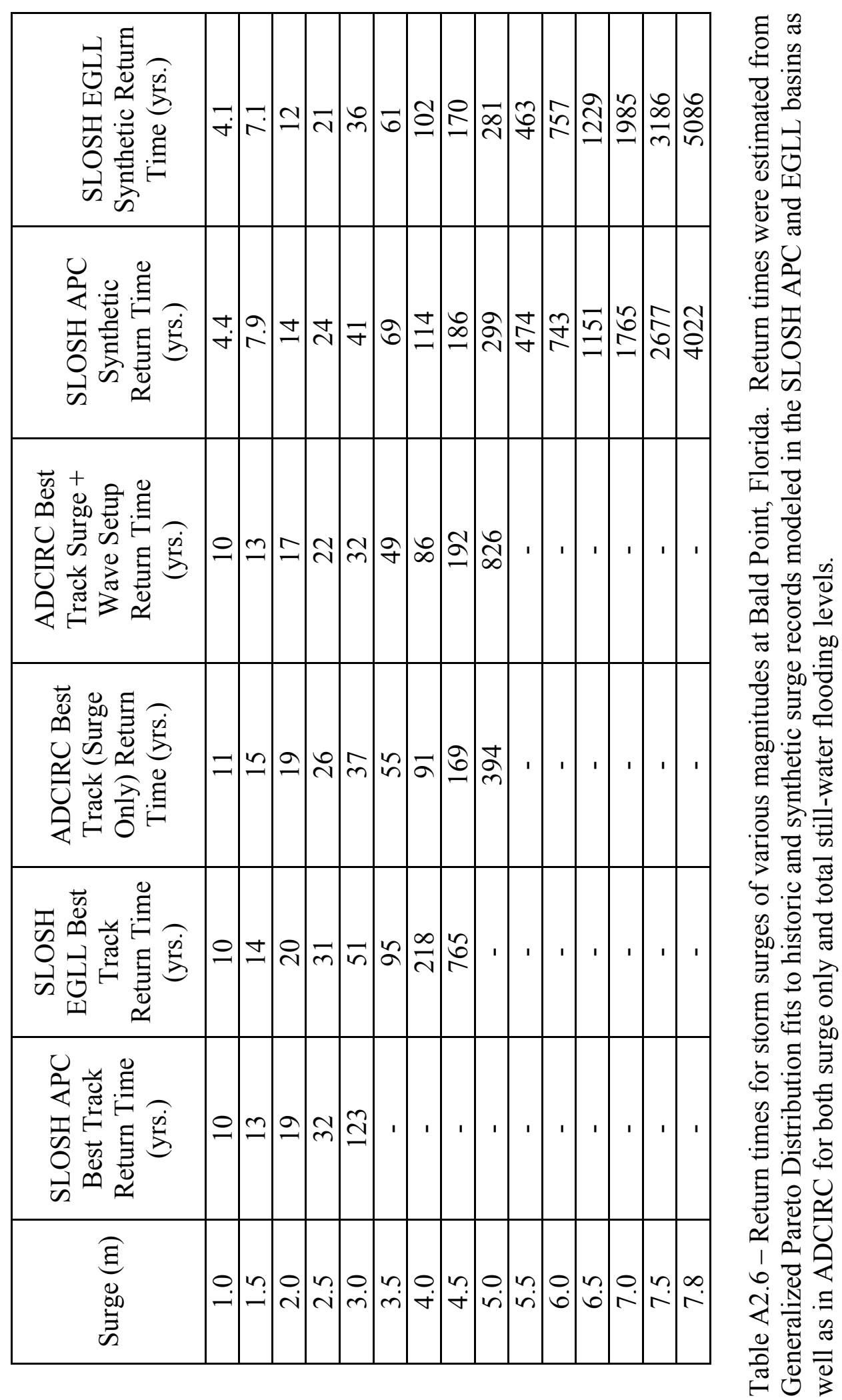




\begin{tabular}{|c|c|c|c|c|c|c|c|c|c|}
\hline 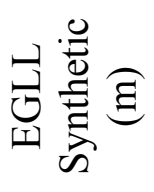 & $\stackrel{\infty}{-}$ & $\overrightarrow{\mathrm{i}}$ & $m$ & $\begin{array}{l}0 \\
\dot{\nabla}\end{array}$ & $\begin{array}{l}9 \\
\dot{\gamma}\end{array}$ & $\begin{array}{l}0 \\
i \\
i\end{array}$ & ?ִ. & rי & $\begin{array}{c}0 \\
\infty \\
\infty\end{array}$ \\
\hline 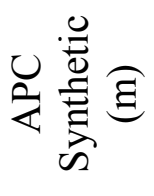 & $\Xi$ & $\begin{array}{l}0 \\
\dot{i} \\
\end{array}$ & $\stackrel{c}{m}$ & $\hat{\sigma}$ & $\begin{array}{l}\infty \\
\dot{\nabla}\end{array}$ & $\begin{array}{l}0 \\
i \\
i\end{array}$ & ?ִ & $\stackrel{\Delta}{\sim}$ & $?$ \\
\hline 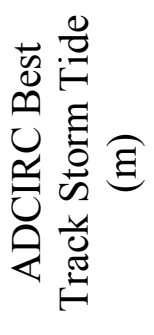 & $\vec{v}$ & $\vec{i}$ & $\begin{array}{l}n \\
m\end{array}$ & 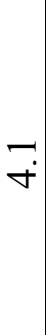 & $\left|\begin{array}{l}0 \\
\dot{\nabla}\end{array}\right|$ & $\begin{array}{l}q \\
\dot{\nabla}\end{array}$ & $\begin{array}{l}0 \\
i n\end{array}$ & 斻 & ? \\
\hline 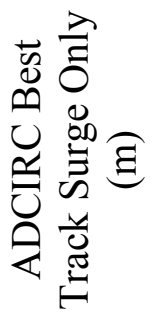 & $\vec{v}$ & $\begin{array}{l}\nabla^{\prime} \\
\end{array}$ & $\begin{array}{l}\nabla \\
\dot{r}\end{array}$ & $\vec{\nabla}$ & $\dot{\nabla}$ & $\vec{n}$ & $\begin{array}{l}\vec{i} \\
\dot{v}\end{array}$ & \begin{tabular}{|l}
0 \\
$i$ \\
$i$
\end{tabular} \mid & $\begin{array}{l}\infty \\
\dot{r}\end{array}$ \\
\hline 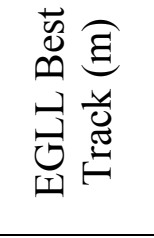 & $\vec{v}$ & $\stackrel{n}{\sim}$ & $\begin{array}{c}0 \\
\dot{m}\end{array}$ & $\begin{array}{l}n \\
m\end{array}$ & 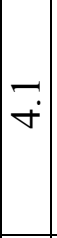 & $\begin{array}{l}\dot{\nabla} \\
\dot{v}\end{array}$ & $\begin{array}{l}0 \\
\dot{\nabla}\end{array}$ & $\begin{array}{l}\infty \\
\dot{\nabla}\end{array}$ & $\stackrel{\vartheta}{\dot{\tau}}$ \\
\hline 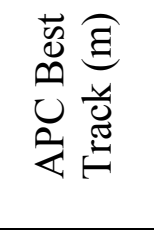 & $\overrightarrow{\mathrm{v}}$ & $\stackrel{m}{\sim}$ & $\stackrel{i}{i}$ & $\begin{array}{c}0 \\
\dot{n}\end{array}$ & $\vec{r}$ & ' & ' & I & 1 \\
\hline 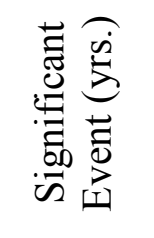 & $\stackrel{0}{ }$ & $\approx$ & in & 8 & 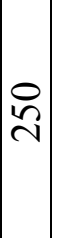 & ○ & 옹 & $\mid \begin{array}{c}\circ \\
\circ \\
\\
\text { ㄱ. }\end{array}$ & \begin{tabular}{l}
8 \\
8 \\
$\circ$ \\
\hdashline
\end{tabular} \\
\hline
\end{tabular}




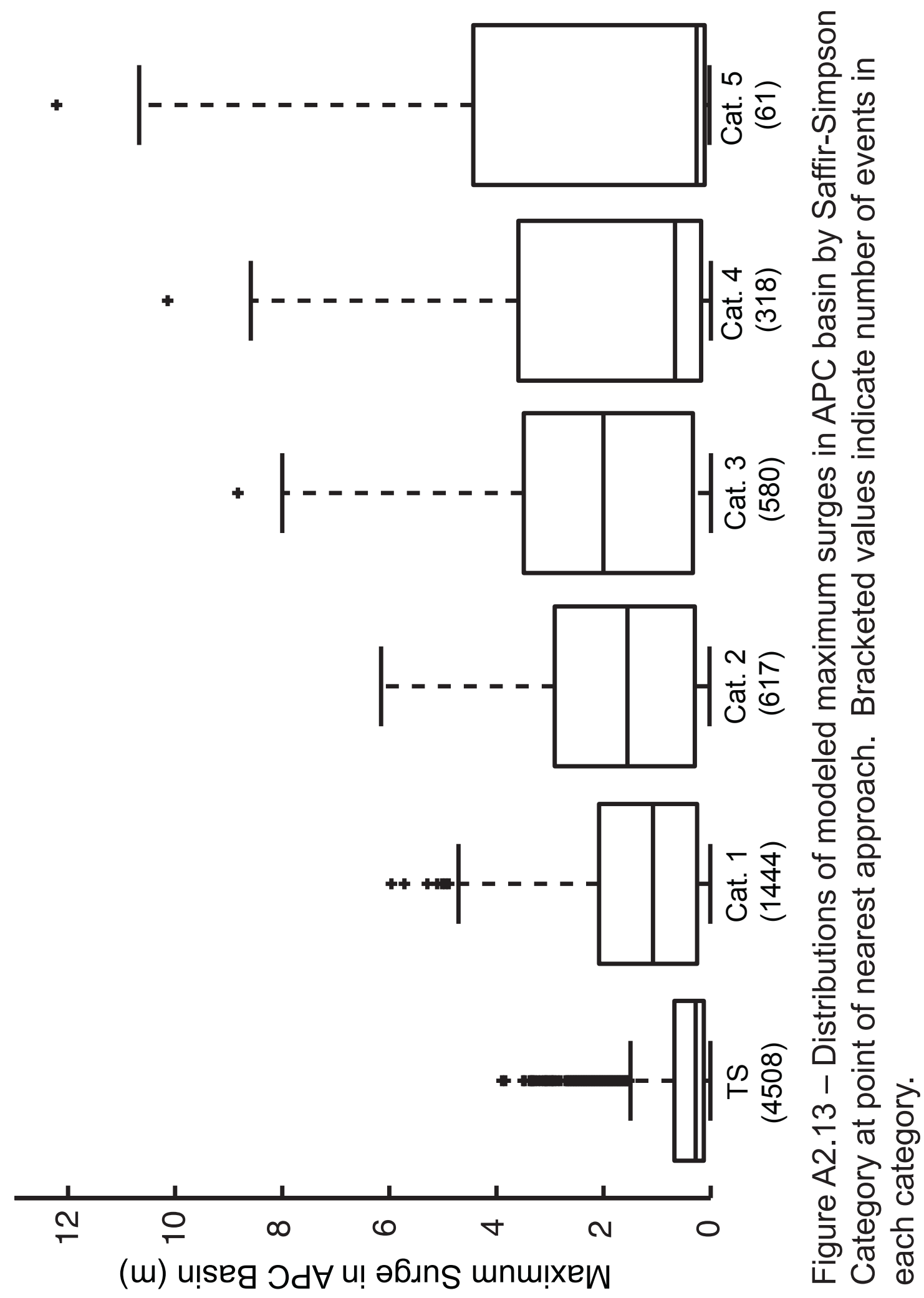




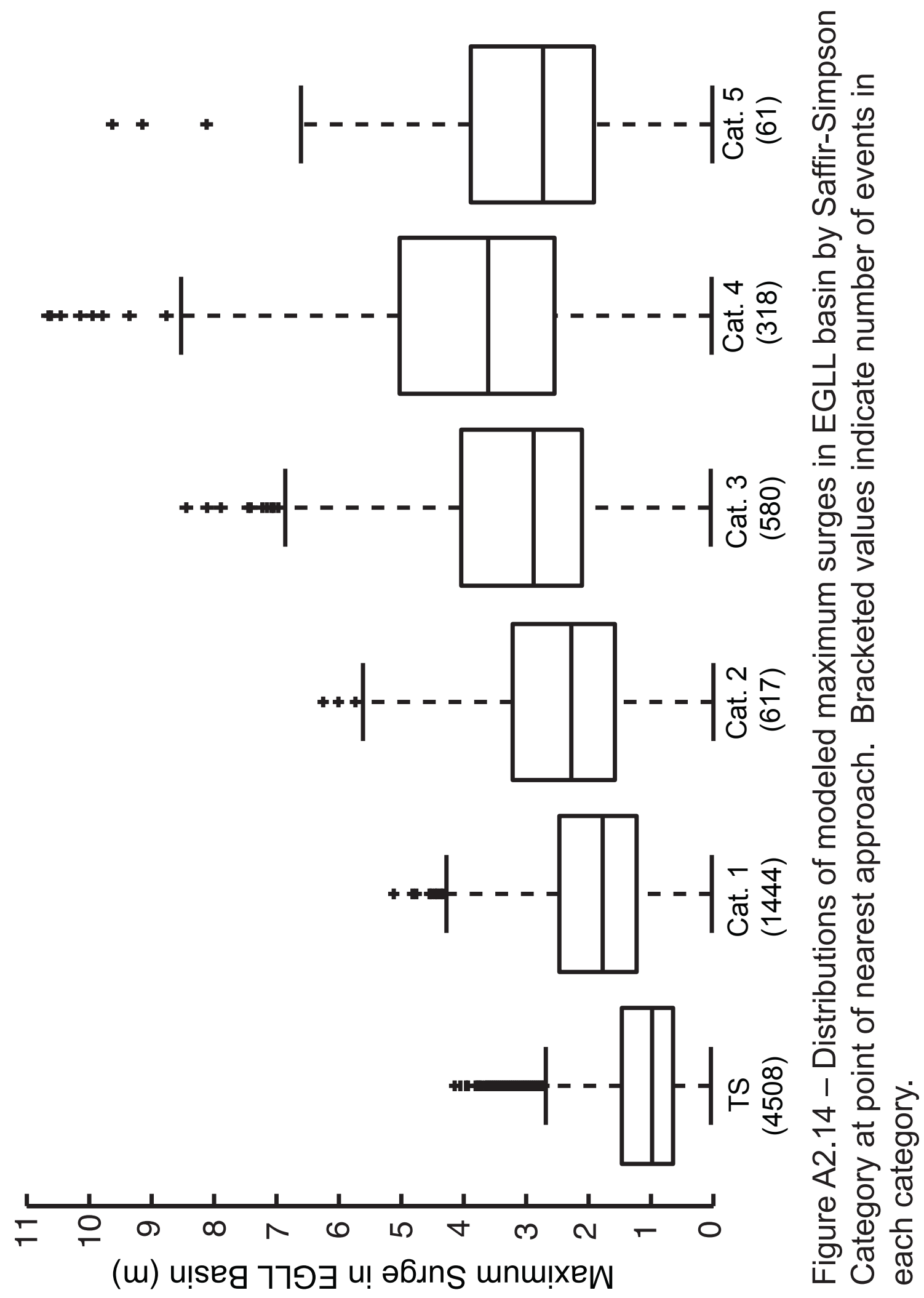

